Aus der Klinik für Neurologie

(Prof. Dr. M. Bähr)

im Zentrum Neurologische Medizin

der Medizinischen Fakultät der Universität Göttingen

\title{
Liquormarker in der Diagnostik bei Patienten mit \\ Morbus Parkinson, Parkinson-Demenz-Komplex und \\ Morbus Alzheimer
}

INAUGURAL - DISSERTATION

zur Erlangung des Doktorgrades

der Medizinischen Fakultät der

Georg-August-Universität zu Göttingen

vorgelegt von

Henning Lemke

aus

Oldenburg

Hamburg 2015 
Dekan:

I. Berichterstatterin:

II. Berichterstatter/in:

III. Berichterstatter/in:
Prof. Dr. rer. nat. H.K. Kroemer

\author{
Prof. Dr. I. Zerr \\ Prof. Dr. M. Sommer \\ Prof. Dr. C. Stadelmann-Nessler
}

Tag der mündlichen Prüfung: $\quad$ 13.10.2015 


\section{INHALTSVERZEICHNIS}

1 EINLEITUNG ............................................................................................. 1

1.1 Geschichte und Entwicklung der Demenzerkrankungen.................................. 1

1.1.1 Lewy-Körperchen-Erkrankungen (PD, PDD, DLB) …................................ 1

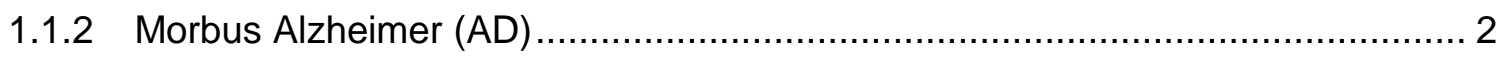

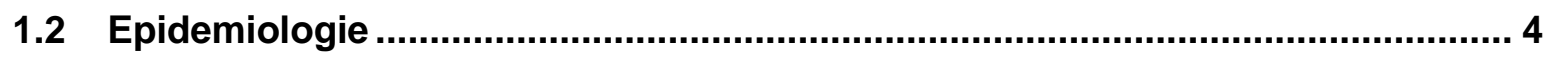

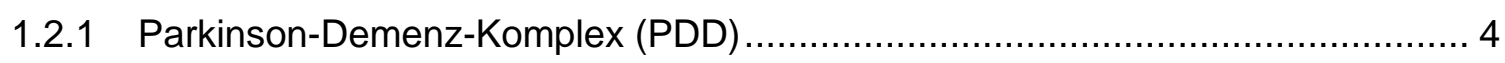

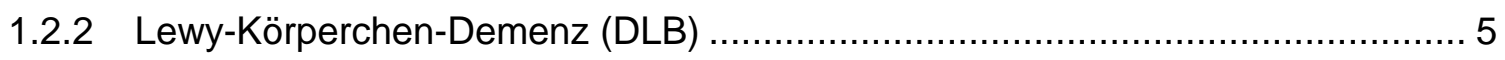

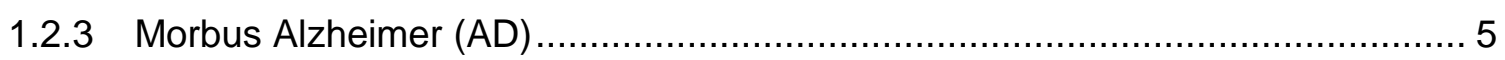

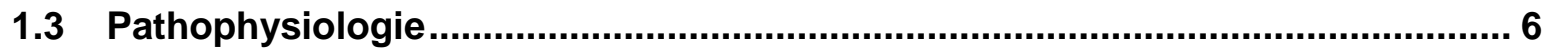

1.3.1 Lewy-Körperchen-Demenzen (PDD, DLB) …............................................. 6

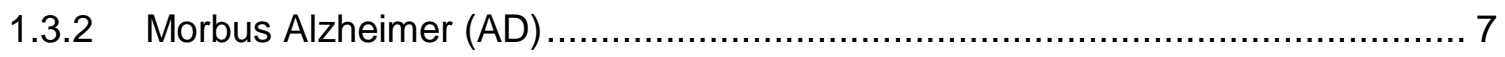

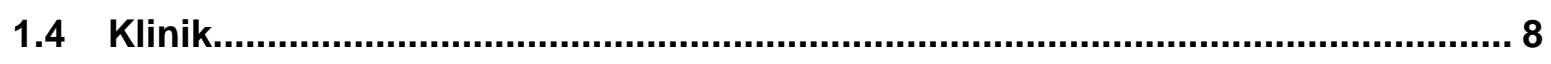

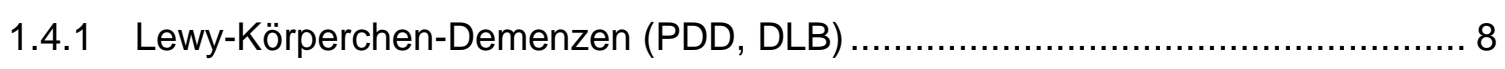

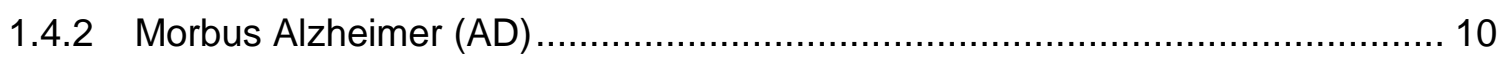

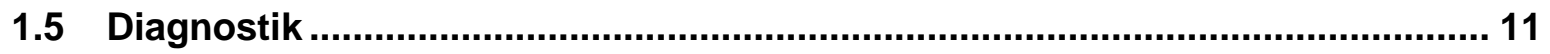

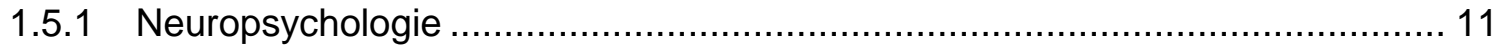

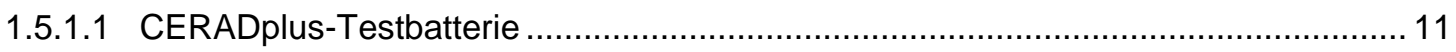

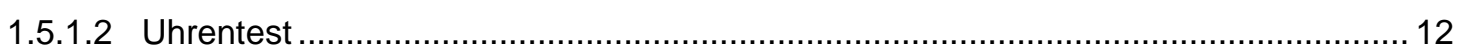

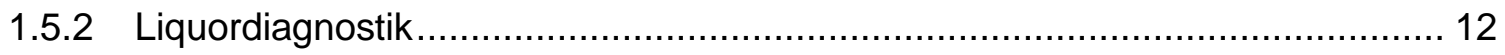

1.5.2.1 Tau-Protein und hyperphosphorylisiertes Tau .................................................... 12

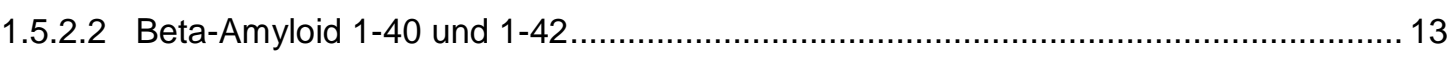

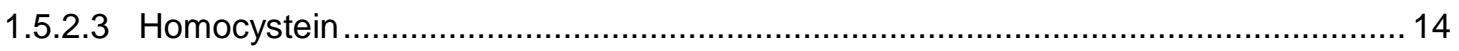

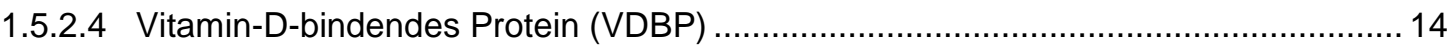

1.5.2.5 Apolipoprotein $\mathrm{E}$ (Apo $\mathrm{E}$ ) quantitativ in Liquor und qualitativ als genetischer

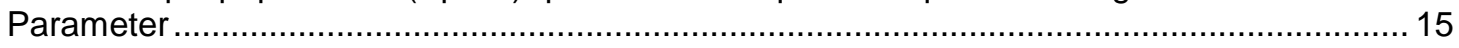

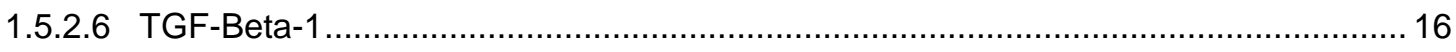

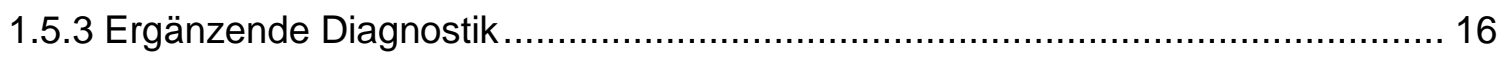

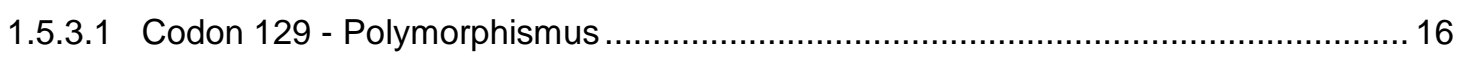

1.5.3.3 Unified Parkinson's Disease Rating Scale (UPDRS) ......................................... 17

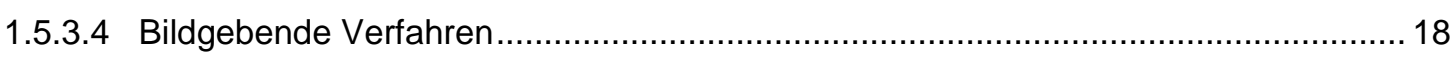

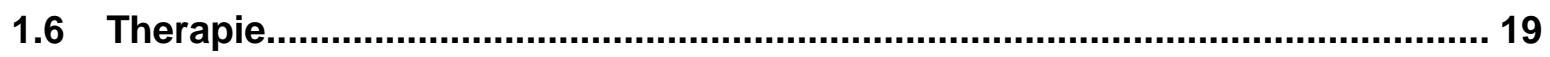

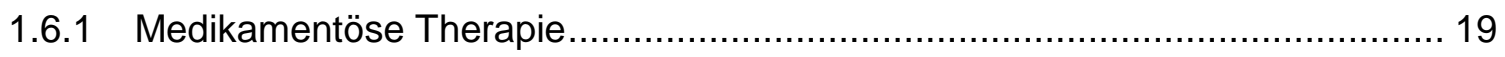

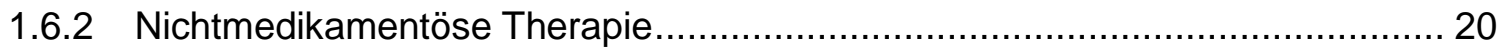

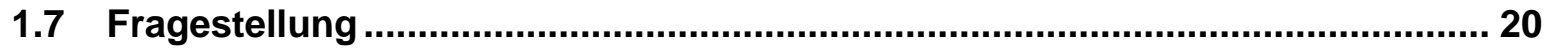

2 MATERIAL UND METHODEN ...................................................................... 21

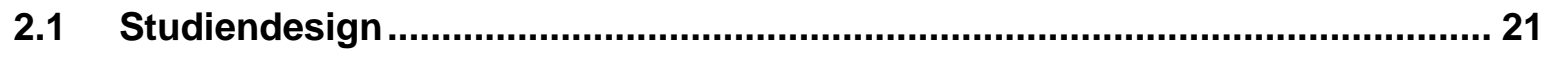

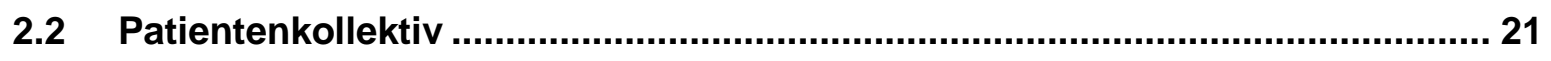

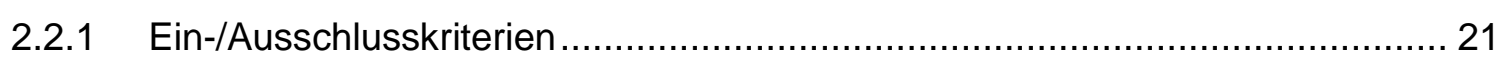




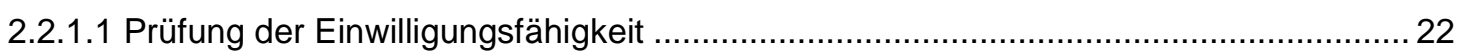

2.2.1.2 Klassifikation der Diagnose Morbus Parkinson und Demenz bei Parkinson ............... 22

2.2.1.3 Klassifikation der Diagnose Demenz mit Lewy-Körperchen .................................. 23

2.2.1.4 Klassifikation der Diagnose Morbus Alzheimer ................................................ 23

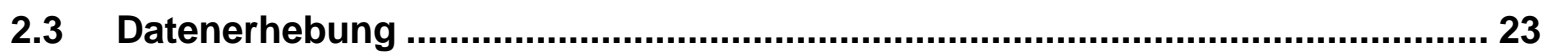

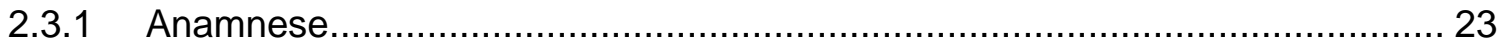

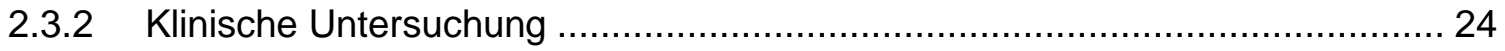

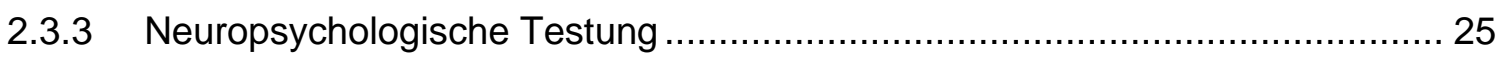

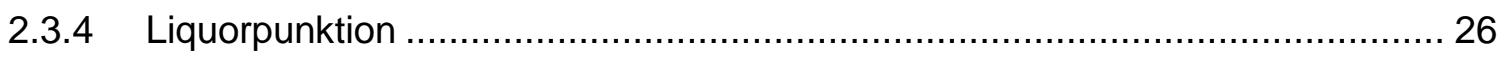

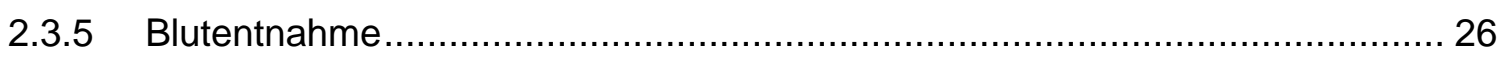

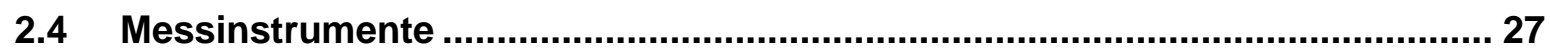

2.4.1 ELISA-Verfahren und Bestimmung der Biomarker aus dem Liquor ................. 28

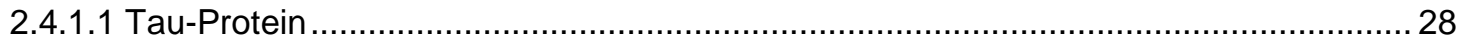

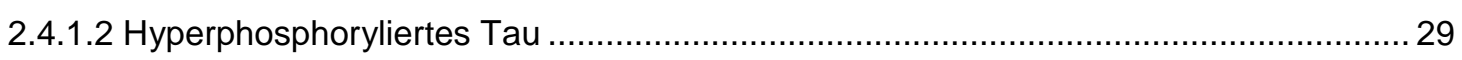

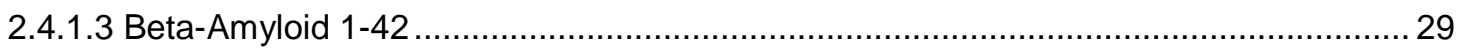

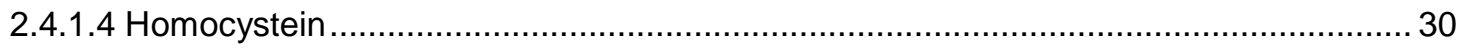

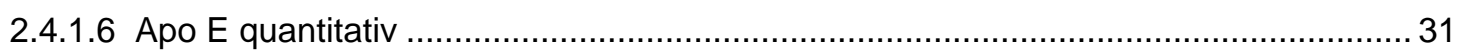

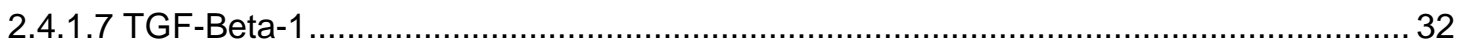

2.4.2 Qualitative Bestimmung genetischer Marker aus Blutprodukten...................... 33

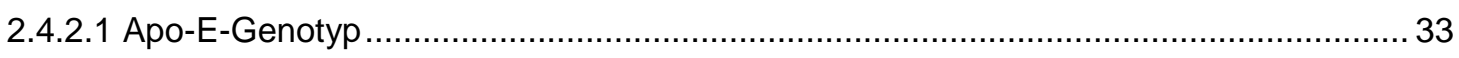

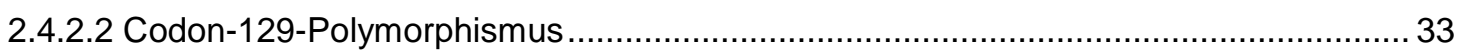

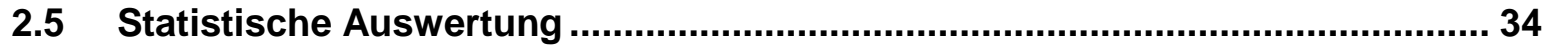

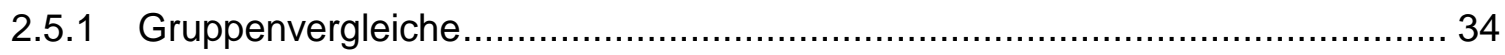

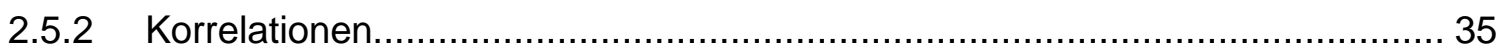

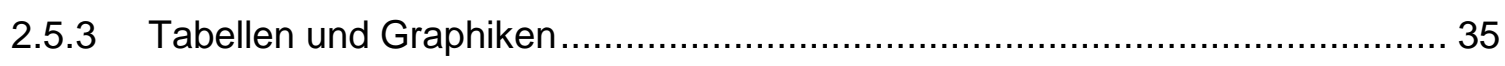

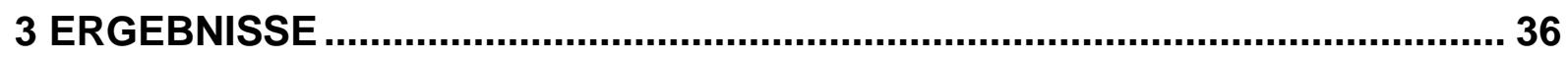

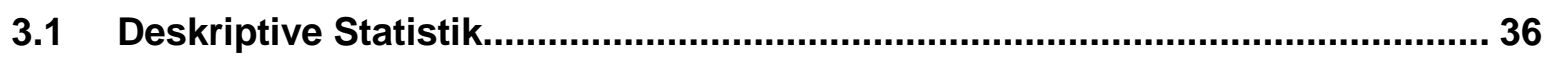

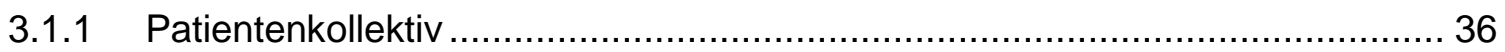

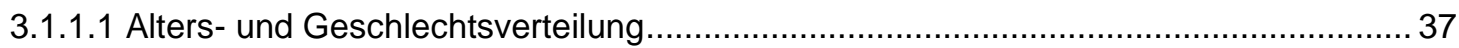

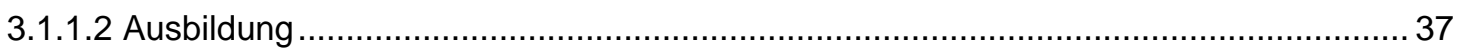

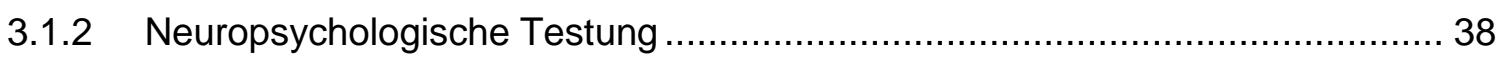

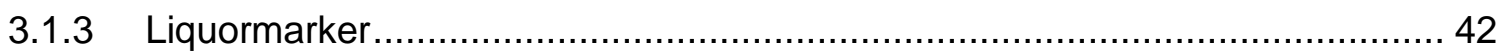

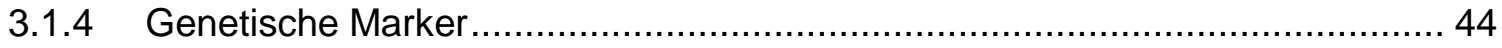

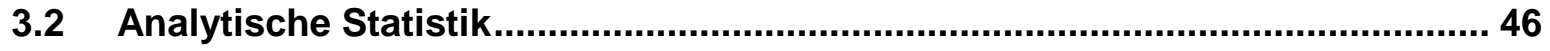

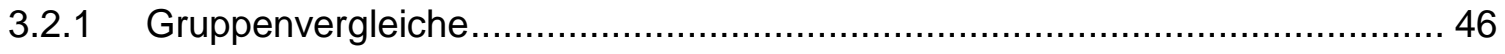

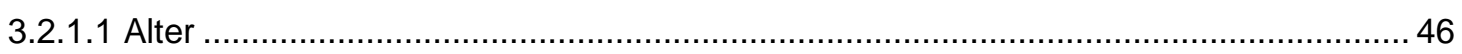

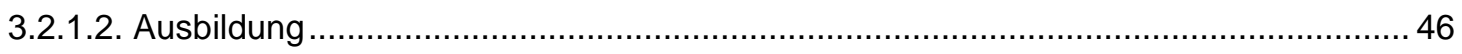

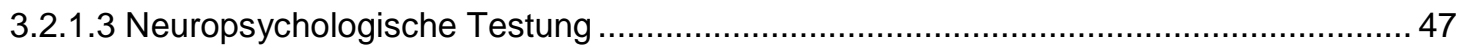

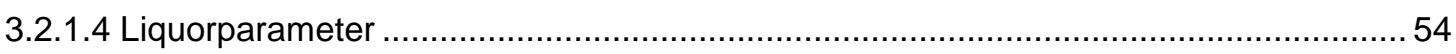

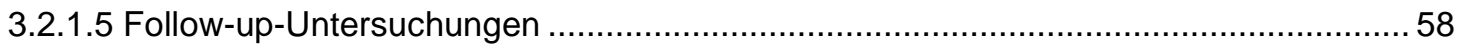




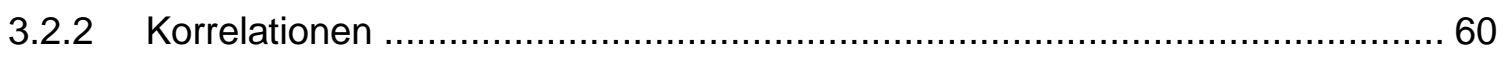

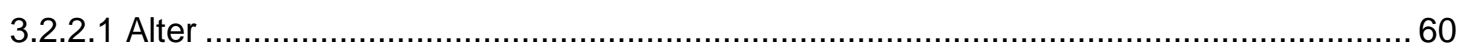

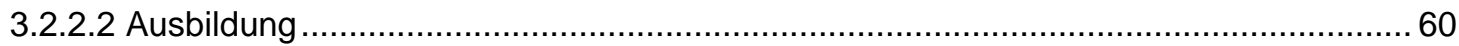

3.2.2.3 Liquormarker und Neuropsychologische Testbatterie............................................ 61

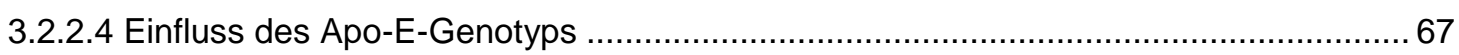

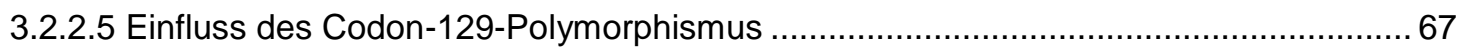

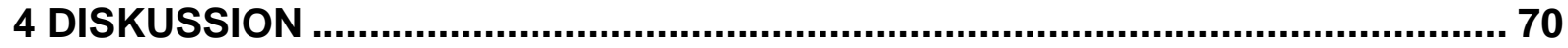

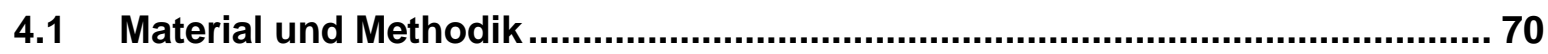

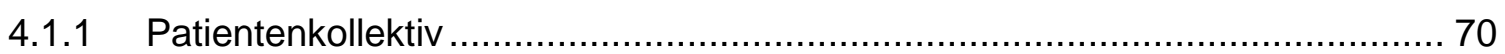

4.1.2 Neuropsychologische Testung ............................................................. 70

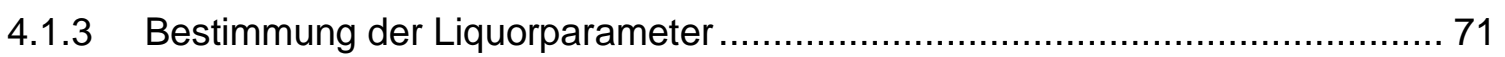

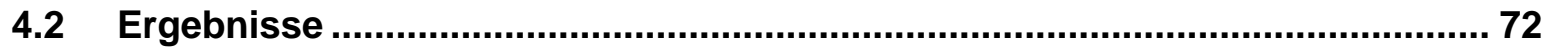

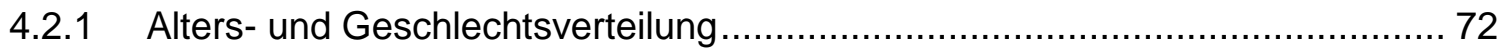

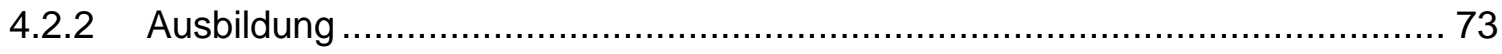

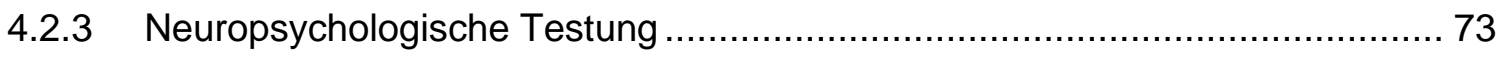

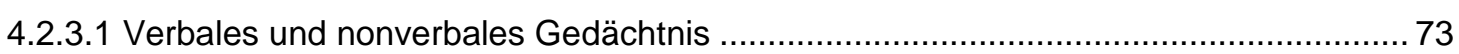

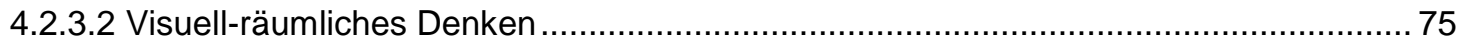

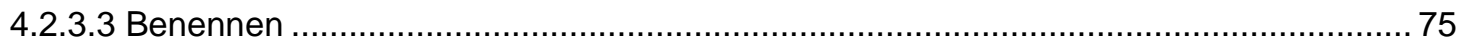

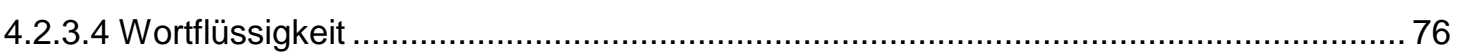

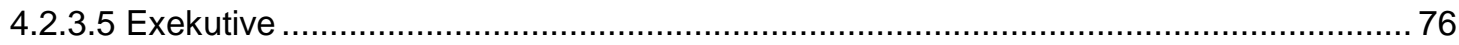

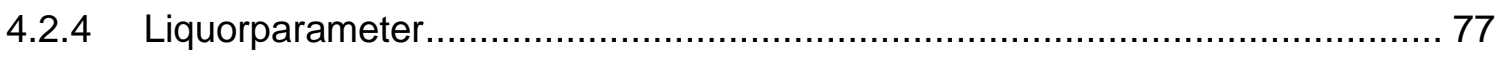

4.2.4.1 Die etablierten Liquormarker Tau-Protein, Phospho-Tau und Abeta 1-42................... 77

4.2.4.2 Experimentelle Liquormarker: ApoE, Homocystein, TGFß-1, VDBP ............................ 80

4.2.4.3 Genetische Parameter: ApoE-Genotyp, Codon 129-Polymorphismus ........................ 82

4.2.4.4 Eignung von Liquormarkern als Prädiktor für die Demenzentwicklung....................... 83

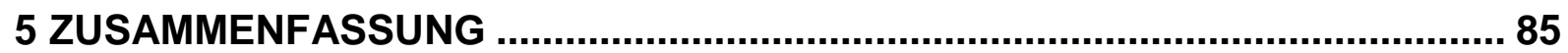

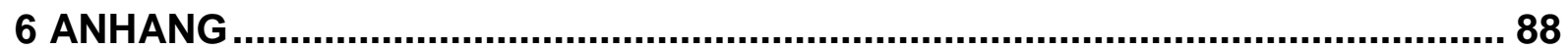

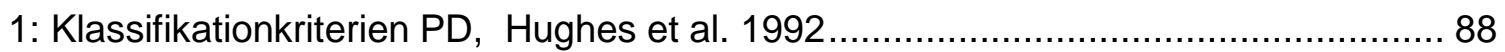

2: Klassifikationskriterien DLB, McKeith et al. 1996/1999........................................ 89

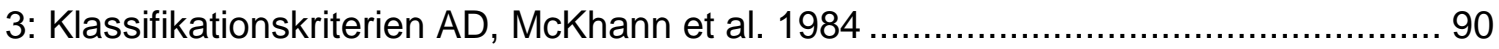

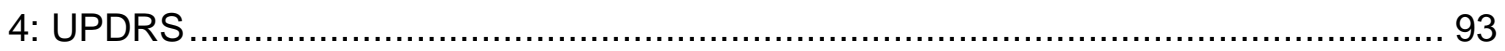

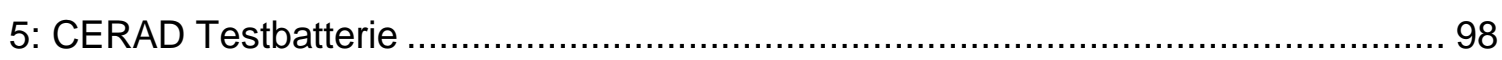

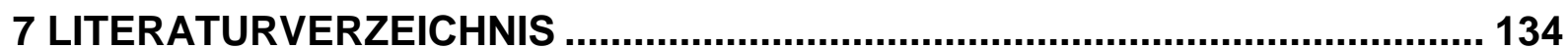




\section{EINLEITUNG}

\subsection{Geschichte und Entwicklung der Demenzerkrankungen}

Gemäß der internationalen Klassifikation der Krankheiten (ICD-10) der WHO ist eine Demenz definiert als erworbene, auf organischen Hirnschädigungen beruhende Gedächtnisstörung, die mit einem Abbau des Denkvermögens, Veränderungen der Persönlichkeit und in der Folge mit einer deutlichen Beeinträchtigung der Selbstständigkeit einhergeht. Für eine sichere Diagnose wird eine Dauer der Symptomatik von mindestens sechs Monaten gefordert.

\subsubsection{Lewy-Körperchen-Erkrankungen (PD, PDD, DLB)}

Bereits über einhundert Jahre vor Definition der Lewy-Körperchen-Erkrankungen veröffentlichte James Parkinson im Jahre 1917 das berühmt gewordene Buch „An Essay on the Shaking Palsy" und beschrieb darin erstmals die "Schüttellähmung" als eigenständiges Krankheitsbild. Aufgrund der zur damaligen Zeit geringen Lebenserwartung von Patienten mit Morbus Parkinson kam es in der Regel gar nicht erst zur Entwicklung von dementiellen Symptomen. Falls doch, wurden diese jedenfalls nicht in Zusammenhang mit der erst neu beschriebenen Parkinsonerkrankung gesehen.

Im Rahmen einer wesentlichen Verstärkung und Internationalisierung der Erforschung des M. Parkinson nach dem zweiten Weltkrieg kam es zum einen zu einem besseren Verständnis von Pathophysiologie und Pathogenese der Erkrankung, zum anderen zur Entwicklung der chemischen Substanz L-Dopa. Neben einer deutlichen Verringerung der Kardinalsymptome Rigor und Akinese sorgte die weltweite Etablierung von L-Dopa als Haupttherapeutikum für eine stetig steigende Lebenserwartung von Parkinsonpatienten (Hoehn und Yahr 1967). Durch die Einführung weiterer Medikamente wie Decarboxylasehemmer und Dopaminagonisten konnte schrittweise eine weitere Verbesserung der Lebensqualität erreicht werden, sodass bis heute eine in der Neurologie selten positive Bilanz bezüglich der Errungenschaften von Diagnostik und Therapie des Morbus Parkinson gestellt wird (Gerlach et al. 2003). 
Der möglichen Verbindung zwischen der Erkrankung Morbus Parkinson und der Entwicklung einer Demenz wurde erst innerhalb der letzten beiden Jahrzehnte gröBere Bedeutung beigemessen. Zwar beschrieb der Berliner Neurologe und Neuropathologe Jacob Heinrich Lewy bereits im Jahre 1912 die Lewy-Körperchen im Hirn von Parkinsonpatienten, brachte diese jedoch nicht in Bezug zu einer möglichen Demenzentwicklung (Lewy 1913). Erst 1990, unter anderem durch die zunehmende Lebenserwartung und somit stärkeren Präsenz von Demenz in der Bevölkerung, gelang es mehreren unabhängigen Forschungsgruppen einen Zusammenhang zwischen Demenz und Vorhandensein von Lewy-Körperchen festzustellen (Kosaka 1990, Perry et al. 1990, Hansen et al. 1990). Mit der Entdeckung des Proteins Alpha-Synuclein als deren Hauptbestandteil im Jahre 1997 konnten weitere offene Fragen in der Pathogenese von Lewy-Körperchen beantwortet werden. Im gleichen Jahr wurde erstmals der Terminus Lewy-Körperchen-Demenz (DLB) genutzt, wobei dessen Berechtigung aufgrund einer ähnlichen Pathologie bei Patienten mit Parkinson und Demenz (PDD) lange bezweifelt wurde (Polymeropoulus et al. 1997).

Erst 2007 fand man eine bis heute gültige Terminologie. So spricht man seither von der Gruppe der Lewy-Körperchen-Erkrankungen, zu denen Morbus Parkinson, Demenz bei Morbus Parkinson sowie die Lewy-Körperchen-Demenz gehört. Letztere werden unter dem Begriff Lewy-Körperchen-Demenzen subsumiert und unter Annahme einer weitgehend gleichen Pathologie lediglich anhand ihres zeitlichen klinischen Verlaufes unterschieden (Lippa et al. 2007, McKeith et al. 2005).

\subsubsection{Morbus Alzheimer (AD)}

Im Jahre 1907 veröffentlichte der deutsche Psychiater Alois Alzheimer seinen Artikel „Über eine eigenartige Erkrankung der Hirnrinde“, nachdem er über fünf Jahre eine damals 50-jährige Patientin mit beeindruckenden Symptomen einer Demenz bis zu deren Tod begleitet hatte (Alzheimer 1907). Nach ihrem Tod stellte er fest, dass sich in ihrem Gehirn Ablagerungen befanden, die auch heute noch die Grundlage des Verständnisses der Pathogenese des Morbus Alzheimer sind.

Leider fand seine aus heutiger Sicht sicherlich bahnbrechende Studie zunächst wenig Beachtung und wurde erst Jahre später durch Alzheimers ehemaligen Lehrer 
Emil Kraepelin gewürdigt. Dieser prägte schließlich auch den Begriff der AlzheimerDemenz, wobei er eine Aufspaltung in eine präsenile $(<65 a)$ und senile (>65a) Form vorsah (Kraepelin 1910). Nach nur lückenhafter und schlecht dokumentierter Forschung während der Weltkriege konnten pathologische Untersuchungen an Hirnen in den sechziger Jahren jedoch keinen ultrastrukturellen Unterschied zwischen der präsenilen und senilen Form nachweisen (Terry et al. 1964). Dies führte nach einigen Jahren der Diskussion zur bis heute gültigen Definition des Morbus Alzheimer als einer Entität.

Im Jahre 1984 erfolgte die Veröffentlichung einer ersten standardisierten klinischen Skala zur Diagnose des Morbus Alzheimer in „möglich, wahrscheinlich und sicher", die bis heute in modifizierter Form angewendet wird (McKhann et al. 1984).

Ein weiterer Meilenstein in der Erforschung des Morbus Alzheimer war 1985/86 die Entdeckung des B-Amyloids als Hauptbestandteil der bereits von Alois Alzheimer beschriebenen Plaques sowie dessen Vorläuferprotein "Amyloid Precursor Protein“ (Hardy und Higgins 1992). In den achtziger Jahren stellte sich die bis heute bedeutsame Erkenntnis ein, dass die ebenfalls im Hirn von Alzheimerpatienten nachweisbaren Neurofibrillenbündel aus verändertem Tau-Protein hervorgehen. Im Verlauf der weiteren Erforschung konnten schließlich zusätzlich genetische Veränderungen an Chromosom 21, 19 und 14 mit dem zeitlich unterschiedlichen Auftreten von Demenz in Verbindung gebracht werden (Hardy und Allsop 1991, Goate et al. 1991, Saunders et al. 1993). Auch zeigte sich in den 90er Jahren, dass das vermehrte Vorhandensein des ApoE-4-Allels als Risikofaktor der AD gesehen werden kann (Corder et al. 1993).

Bedeutsam für die Therapie der kognitiven Defizite war ein aufsehenserregender Bericht des US-Forschers William Summer, der über die erfolgreiche Therapie eines Alzheimer-Patienten mit Tacrin, einem Acetylcholinmodulator, referierte. Dieser wurde schließlich 1993 als erster Wirkstoff zur Behandlung des Morbus Alzheimer zugelassen, erreichte wegen seiner ausgeprägten Nebenwirkungen allerdings keine groBe Verbreitung. Nach Zulassung des nebenwirkungsärmeren Cholinesterasehemmstoffs Donepezil 1996, der sich schnell zum Marktführer entwickelte, kam im Jahr 2002 mit Memantin ein weiter Wirkstoff zur Behandlung besonders schwerer Krankheitsverläufe auf den Markt. 


\subsection{Epidemiologie}

In Deutschland leben gegenwärtig etwa 1,2 Millionen Demenzkranke, wobei die Zahl der jährlich hinzukommenden Neuerkrankungen von aktuell ca. 300.000 aufgrund der alternden Gesellschaft weiter zunehmen wird. Ohne Durchbruch in Prävention und Therapie wird sich die Krankenzahl Berechnungen zufolge bis zum Jahr 2050 auf etwa 2,6 Millionen Menschen erhöhen (Bickel 2005).

Bedeutend ist, dass Demenzen zu den häufigsten Ursachen für Behinderungen im Alter zählen, da diese sich unverhältnismäßig stark auf die Fähigkeit der Eigenversorgung auswirken. Entsprechend leben bis zu 50 \% der Menschen mit Demenz in einer Pflegeinstitution (Macdonald und Cooper 2007).

\subsubsection{Parkinson-Demenz-Komplex (PDD)}

Zwar ist die Entwicklung einer Demenz bei vorliegendem Morbus Parkinson und auch Parkinsonsyndromen im Allgemeinen mittlerweile Inhalt gegenwärtiger Forschung, einheitliche Daten zur Häufigkeit und Wahrscheinlichkeit des Auftretens fehlen allerdings. Eine im Jahr 2005 veröffentliche Studie, die sich mit der Schwierigkeit der Epidemiologie der Demenz bei Morbus Parkinson aufgrund der oftmals nur in Form einer Punktprävalenz angegebenen Häufigkeit der PDD beschäftigt, gibt als Schätzungsvermittler aus den solidesten Studien einen Mittelwert von 32\% Demenz unter Parkinsonpatienten an (Aarsland et al. 2005 b). Dabei schwanken die Angaben der Einzelstudien allerdings zwischen 22 und 48 Prozent (Athey et al. 2005; De Lau et al 2005; Hobson et al. 2005).

In weiteren Studien wurde neben der Punktprävalenz die Entwicklung von Demenz bei Langzeitbeobachtung von neu diagnostizierten Parkinsonpatienten untersucht. Auch diese unterscheidet sich innerhalb verschiedener Studien enorm. So berichten Reid et al. über eine Konversionsrate von PD zu PDD in 26\% der Fälle über einen Zeitraum von 3-5 Jahren, im Gegensatz dazu allerdings Aarsland et al. über eine solche in Höhe von $80 \%$ in einem Zeitraum von 8 Jahren (Reid et al. 1996, Aarsland et al. 2003 a).

Nicht zu vernachlässigen ist der offensichtliche Bezug zwischen Entwicklung einer 
Demenz und dem wichtigen Cofaktor Alter. So variiert die Inzidenz von Demenz bei Morbus Parkinson zwischen $3 \%$ bei Patienten unter 60 Jahren und mehr als $15 \%$ bei Patienten über 80 Jahren (Biggins et al. 1992, Marder et al 1995; Mayeux et al. 1990).

\subsubsection{Lewy-Körperchen-Demenz (DLB)}

Die Lewy-Körperchen-Demenz, nach den klinischen Kriterien von McKeith et al. (1996/1999) definiert als Entwicklung einer Demenz innerhalb eines Jahres vor oder nach Entwicklung eines Parkinsonsyndromes, hat bezüglich der Epidemiologie eine deutlich dünnere Datenlage. Es existieren 6 zuverlässige Studien, in denen die Prävalenz der DLB zwischen 0 und $5 \%$ in der allgemeinen Population und zwischen 0 und 31\% innerhalb aller Demenzen angegeben ist (Zaccai et al. 2005). Die Inzidenz soll anhand einer Studie aus dem Jahr 2002 3\% im Bereich der Demenzen und 0,1\% in der Allgemeinbevölkerung betragen (Miech et al. 2002).

\subsubsection{Morbus Alzheimer (AD)}

Morbus Alzheimer ist mit $50-70 \%$ die häufigste aller Demenzen, wobei die Inzidenz und Prävalenz durch zunehmende Fortschritte in der Erforschung anderer Demenzformen in den vergangenen Jahrzehnten eher abgenommen hat (Buhl und BojsenMøller 1988). Dennoch liegt gerade für die Epidemiologie der Alzheimerdemenz die breiteste Studienlage vor.

Auch hier zeigt sich eine rasche Zunahme der Prävalenz des Morbus Alzheimer in Bezug auf das Lebensalter. So verdoppelt sich die Krankenziffer im Abstand von jeweils 5 Altersjahren und nimmt von knapp über ein Prozent in der Gruppe der 65- bis 69-jährigen auf mehr als 30 Prozent unter den über 90-jährigen zu (Bickel 2000, 2005). In 5-10\% der Erkrankungsfälle zeigt sich eine familiäre Häufung und ein besonders frühes Auftreten der Demenz durch Mutationen in Präsenilin- oder APPGenen.

Gemäß des Welt-Alzheimer-Berichtes liegt die gemischte weltweite Prävalenzrate 
zwischen 5 und 7\%, wobei besondere Unterschiede zwischen Westafrika (2,07\%) und Lateinamerika $(8,5 \%)$ bestehen. Für die Zukunft wird erwartet, dass die Anzahl der Menschen mit Alzheimer in den nächsten 20 Jahren um $40 \%$ in Europa, $63 \%$ in Nordamerika und bis zu $146 \%$ in Lateinamerika ansteigen wird (World Alzheimer Report 2009). Als Ursache hierfür ist vor allem die zunehmende Bevölkerungszahl sowie das demographische Altern zu sehen.

\subsection{Pathophysiologie}

\subsubsection{Lewy-Körperchen-Demenzen (PDD, DLB)}

Pathognomische Grundlage für die PDD und DLB ist nach heutigem Stand der Wissenschaft die Ansammlung sogenannter Lewy-Körperchen. Dies sind eosinophile Einschlusskörper, die fehlaggregiertes Alpha-Synuclein enthalten, sich in Neuronen der Großhirnrinde und des Hirnstammes ablagern und dort zu deren Zelltod führen (McKeith et al. 1996). Eine Ursache für die Bildung von Lewy-Körperchen ist möglicherweise ein veränderter neurofilamentärer Stoffwechsel durch endogene oder exogene Faktoren, der zu einer Konformationsänderung des Alpha-Synucleins von einer alpha- in eine beta-Faltblattstruktur führt. Folge könnte schließlich eine vermehrte Aggregationsneigung zu zellulären Einschlusskörperchen sein, die im Verlauf an Größe zunehmen, den physiologischen axonalen Transport verhindern und schließlich zum Nervenzelluntergang führen (Giasson et al. 2004).

Je nach Lage der Lewy-Körperchen kommt es zu unterschiedlicher Symptomatik. Bei vorwiegender subkortikaler Ablagerung im Hirnstamm überwiegt durch den Untergang dopaminerger Neurone die Parkinsonsymptomatik im Sinne von Rigor, Tremor und Akinese. Bei zusätzlicher oder auch vorangegangener Ablagerung im Bereich des Neokortex und limbischen Systems kommt es zu kognitiven Einschränkungen. Des Weiteren entwickelt sich durch neuronale Zellverluste im Bereich des Nucleus basalis Meynert meist ein begleitendes cholinerges Defizit (Duda 2004).

Festgelegte Kriterien zur post mortem-Unterscheidung zwischen PDD und DLB anhand des beschriebenen Verteilungsmusters von Lewy-Körperchen existieren bisher allerdings nicht, da bei beiden Erkrankungen oft ein diffuses Verteilungsmuster beobachtet wird. Auch eine Abgrenzung zu Morbus Parkinson ohne Demenz ist nicht 
etabliert, da hier ebenfalls Lewy-Körperchen nachgewiesen werden können.

Nebenbefundlich finden sich sowohl bei PDD als auch bei DLB oftmals neuritische Plaques und Tangles, die die Annahme einer gewissen Überschneidung mit Morbus Alzheimer nahelegen (McKeith et al. 2004). Umgekehrt treten Lewy-Körperchen auch bei Patienten mit fortgeschrittener Alzheimerkrankheit auf (Hamilton 2000).

\subsubsection{Morbus Alzheimer (AD)}

Der Nervenzelluntergang bei Patienten mit Morbus Alzheimer basiert auf der extrazellulären Ablagerung seniler Plaques sowie dem Vorkommen intrazellulärer Neurofibrillenbündel, die gemeinsam zum Nervenzelluntergang führen.

Die senilen Plaques bestehen hauptsächlich aus fehlaggregiertem Protein BetaAmyloid 1-42, welches durch proteolytische Spaltung aus seinem Vorläuferprotein APP (=Amyloid-Precursor-Protein) entsteht. Die Spaltung des ubiquitär im Hirn vorkommenden APP erfolgt durch eine beta- und gamma-Sekretase, wodurch BetaAmyloid in einer Länge von 39 bis 43 Aminosäuren entsteht. Je nach Länge des entstehenden Amyloids besteht eine hohe (Abeta 1-42) oder sehr niedrige (Abeta 1-40) Aggregationsneigung (Shimokawa et al. 1993). Als Risikofaktor für die vermehrte Entstehung von Beta-Amyloid 1-42 gilt unter anderem das Vorhandensein des ApoE4-Alleles (Bu 2009).

Zusätzlich zum amyloidogenen Abbauweg existiert auch ein sogenannter nichtamyloidogener Weg, in dem das APP innerhalb der Amyloid-beta-Sequenz gespalten wird und somit keine Gefahr der Entstehung neurotoxischer seniler Plaques besteht (Sisodia et al. 1990).

Es wird angenommen, dass alle drei beschriebenen Prozessierungswege des APP in jedem Individuum existieren, es jedoch aufgrund genetischer oder exogener Faktoren zu einem Überwiegen der proteolytischen Spaltung über die gamma-Sekretase kommen kann.

Die zusätzlich intrazellulär auftretenden Neurofibrillenbündel entstehen durch Hyperphosphorylierung von Tau-Protein, welches dadurch seine eigentliche Funktion als Stabilisator der Mikrotubuli verliert. Die direkten Auswirkungen der Neurofibrillenbündel auf den Hirnstoffwechsel sind noch nicht ausreichend verstanden, man geht aber ebenfalls von einer Neurotoxizität aus (Lee et al. 2005). 
Aufgrund des Untergangs cholinerger Kerne von Nervenzellen kommt es außerdem zu einem Mangel am Botenstoff Acetylcholin, der neben dem generellen Verlust von Neuronen zur Ausbildung kognitver Defizite beiträgt (Procter et al. 1988).

\subsection{Klinik}

Mit besserem Verständnis von Entstehung sowie Entwicklung unterschiedlicher Demenzformen hat auch eine Unterscheidung der verschiedenen Demenzen anhand ihres klinischen Ausprägungsmusters eine Berechtigung gefunden. So erfolgt heute nach Ausschluss akut behandlungsbedürftiger Ursachen einer vorliegenden Gedächtnisstörung meist zunächst eine neuropsychologische Testung. Die vorherrschende Klinik sowie das typische Ausfallmuster lässt schließlich oftmals die Unterscheidung in eine eher kortikale oder subkortikal dominierte Demenz zu, woraufhin bereits eine erste Verdachtsdiagnose gestellt bzw. weitere Untersuchungen angestellt werden können.

Eine Demenz mit kortikalem Ausfallprofil besticht in der neuropsychologischen Testung durch eine primäre Speicherschwäche, das heißt erlernte Inhalte, zum Beispiel im Sinne einer Wortliste, können weder gespeichert noch abgerufen werden. Typisches Beispiel eines solchen kognitiven Defizits ist der Morbus Alzheimer.

Bei einer Demenz mit subkortikalem Ausfallprofil besteht hingegen lediglich ein sogenanntes Abrufdefizit, das heißt, Lerninhalte werden zwar gespeichert, können allerdings nicht aktiv vom Patienten abgerufen werden. Zum passiven Wiedererkennen erlernter Wörter aus einer Wortliste ist ein Patient mit subkortikaler Störung hingegen in der Lage. Ein typisches Beispiel einer subkortikalen Demenz ist die Demenz bei Morbus Parkinson und auch die Lewy-Körperchen-Demenz.

\subsubsection{Lewy-Körperchen-Demenzen (PDD, DLB)}

Eine klinische Unterscheidung zwischen Demenz bei Morbus Parkinson und LewyKörperchen-Demenz fällt aufgrund der großen Übereinstimmung in Bezug auf die kognitiven Ausfallprofile sowie der ähnlichen Pathogenese schwer. Nicht umsonst 
gibt es bis heute die Frage nach dem pathophysiologischen Unterschied und somit nach der Berechtigung beider Krankheitsentitäten. Auch heute gibt es Autoren, die beide Erkrankungen lediglich als unterschiedliche Ausprägungsmuster einer gemeinsamen Erkrankung sehen (Aarsland et al. 2004).

Letztlich hat sich durchgesetzt, beide Erkrankungen unter dem Dach der Alpha-1Synuclein-Pathologien zu sehen und sie vor allem anhand ihres zeitlichen Ausprägungsmusters zu unterscheiden. So stellt sich die Frage nach Vorhandensein einer Lewy-Körperchen-Demenz gemäß der sogenannten „Ein-Jahres-Regel“ der klinischen Diagnosekriterien nach McKeith et al. immer dann, wenn kognitive Störungen und Parkinsonsyndrom innerhalb eines Jahres auftreten. Lag vor Eintreten der kognitiven Defizite bereits länger als ein Jahr ein Parkinsonsyndrom vor, ist hingegen die Diagnose Demenz bei Parkinson zu stellen.

Vom kognitiven Ausfallprofil her steht bei beiden Krankheiten im Gegensatz zum Morbus Alzheimer oftmals nicht primär das reine Gedächtnisdefizit, sondern im Sinne einer gemischt kortikal-subkortikalen Störung vor allem eine generelle Verlangsamung im Vordergrund. Begleitend treten visuell-räumliche Defizite im Sinne von wiederkehrenden Halluzinationen und Wahnvorstellungen auf, die bei der LewyKörperchen-Demenz allerdings oftmals als ausgeprägter und in frühen Erkrankungsstadien auftretend beschrieben werden (McKeith et al. 2004). Außerdem kann die Anamnese nicht selten eine Orthosthasesymptomatik und Kontinenzstörungen beinhalten. Eine Unterscheidung anhand der bei beiden Erkrankungen beobachteten REM-Schlaf-Abnormalitäten sowie der Neuroleptikasensitivität kann ebenfalls nicht zuverlässig getroffen werden (Boeve et al. 1998, Aarsland et al. 2005 a).

Einige Studien beschreiben nach Auswertung neuropsychologischer Testungen, dass Patienten mit Lewy-Körperchen-Demenz größere Defizite im Bereich von Aufmerksamkeit und Verständnis aufweisen (Aarsland et al. 2001/2003 b). Des Weiteren werden Unterschiede in Bezug auf den auftretenden Parkinsonismus berichtet, wobei dieser bei Patienten mit PDD häufiger asymmetrisch und generell stärker ausgeprägt sei, bei DLB hingegen am ehesten vom generalisiert verlangsamten, postural instabilen, nicht-tremordominanten Typ sei (Burn et al. 2003).

Aufgrund der ersichtlichen Schwierigkeiten in der qualitativen klinischen Differenzierung gibt es bis heute keine festgelegten Diagnosekriterien für die Diagnose PDD. Die Einordnung in die jeweilige Erkrankungsgruppe erfolgt daher weiter quantitativ anhand der "Ein-Jahres-Regel" sowie des typischen zeitlichen Verlaufs. So tritt eine Demenz mit Lewy-Körperchen nicht selten subakut mit relativ raschem Verlauf auf 
(Ballard et al. 2004) und zeigt in 50-75\% eine deutliche Fluktuation in Bezug auf die kognitive Funktion, die sich mitunter innerhalb von Minuten bis Stunden ändern kann (McKeith et al. 2004).

\subsubsection{Morbus Alzheimer (AD)}

Beim Morbus Alzheimer stehen als Repräsentant einer typischen kortikalen Demenz vor allem eine deutliche Gedächtnisstörung im Vordergrund. Aufgrund einer nicht oder nur geringfügig auftretenden Denkverlangsamung wirken entsprechende Patienten im Gespräch oder bei der Verrichtung erlernter routinierter Alltagsaktivitäten zunächst unauffällig, fallen bei Durchführung neuropsychologischer Testungen allerdings schnell durch eine primäre kortikale Speicherschwäche auf. Allerdings gibt es auch bei dieser meist eher langsam progredienten verlaufenden Erkrankung im Verlauf Aphasien, Apraxien und Störungen des visuell-räumlichen Denkens, welche sich in Schwierigkeiten beim Rechnen, Umgang mit Geld und beispielsweise der Bearbeitung von Formularen zeigen (Schmidtke und Hüll 2007). In späteren Krankheitsstadien kommt es neben weiterem kognitiven Abbau oftmals auch zu fokalneurologischen Defiziten wie Rigor und extrapyramidalen Symptomen (Heinemann et al. 2007). Nebenbefundlich zeigen sich besonders zu Beginn der Erkrankung depressive Episoden. Eine Störung von Bewusstsein oder stark fluktuierenden Aufmerksamkeit ist im Gegensatz zur DLB allerdings eher untypisch (McKhann et al. 1984).

Von Besonderheit ist die Möglichkeit der Entwicklung einer sogenannten präsenilen $A D$, die häufig eine positive Familienanamnese aufweist und auf Mutationen im Präsenilin-1/-2 oder APP-Gen beruhen. Diese in ca. 10-15\% auftretende Unterform hat im Gegensatz zur beschriebenen sporadischen senilen AD einen oftmals raschen und besonders schweren Verlauf. 


\subsection{Diagnostik}

Die Diagnostik der Demenzerkrankungen befindet sich wie kaum eine anderes Gebiet der Medizin in rascher Weiterentwicklung. Nachdem vor Jahrzehnten nur postmortem eine sichere Diagnose gestellt werden konnte, erlauben heute vor allem hochauflösende bildgebende Verfahren sowie Erfolge in der Liquordiagnostik eine stets sicherer werdende Diagnostik.

\subsubsection{Neuropsychologie}

Eine neuropsychologische Untersuchung sollte bei Verdacht auf eine Demenz stets vor apparativen Untersuchungen erfolgen. Sie ermöglicht neben der Bestimmung der objektiven Schwere der kognitiven Störungen die Zuordnung zu einem Demenzsyndrom vom kortikalen oder subkortikalen Typ. Die alleinige Anwendung des in der klinischen Praxis angewendeten Mini - Mental -Status - Tests (MMSE) reicht hierfür nicht aus. Eine vertiefte und ausführliche Testung zur Diagnostik von Teilleistungsstörungen in den Bereichen verbales Gedächtnis, visuell-räumliches Denken, Benennen, Praxis und exekutive Leistungen ist notwendig (Schmidtke und Hüll 2007).

\subsubsection{CERADplus-Testbatterie}

Die Testbatterie wurde 1986 vom National Institute on Aging in den Vereinigten Staaten entwickelt, um ein standardisiertes Instrument zur Erfassung kognitiver Defizite bei Morbus Alzheimer zu etablieren.

Dabei wurde zur Differenzierung von Teilleistungsstörungen zunächst eine Aufteilung in acht Einzeltests vorgenommen, heute hat sich nach Übersetzung in verschiedenste Sprachen und Normierung für entsprechende Bevölkerungsgruppen die Anwendung von zwei weiteren Subtests etabliert. So umfasst die CERADplus-Testbatterie aktuell die Subtests Verbale Flüssigkeit, Modifizierter Boston Naming Test, Mini Mental Status Examination, Wortliste Gedächtnis, Konstruktive Praxis, Wortliste Abrufen, Wortliste Wiedererkennen, Konstruktive Praxis Abrufen, Trail Making Test und Phonematische Flüssigkeit. 
Für den deutschsprachigen Raum konnte im Rahmen einer multizentrischen Studie an der Universitätsklinik Basel nachgewiesen werden, dass die CERAD-Testbatterie zuverlässig zwischen gesunden und dementen Personen unterscheiden kann (Aebi 2002).

Im Anschluss des circa 60 Minuten dauernden Tests erfolgt unter Berücksichtigung von Alter, Geschlecht und Bildung eine PC-gestützte Konversion von Rohwerten in sogenannte Z-Werte, die schließlich einen Vergleich mit der alters- und bildungsgleichen Normstichprobe ohne Anzeichen einer Demenz zulässt (Satzger et al. 2001).

\subsubsection{Uhrentest}

Der etablierte und schnell durchzuführende Uhrentest dient als Ergänzung zur CERAD-Testbatterie, da er sehr sensibel räumlich-visuelle Denkstörungen aufzeigt. Hierbei erhält der Patient einen vorgezeichneten Kreis und wird gebeten die Ziffern sowie eine vorgegebe Uhrzeit gemäß eines gewöhnlichen Ziffernblattes einzuzeichnen.

Die anschließende Auswertung erfolgt nach den Kriterien Vollständigkeit sowie Platzierung von Ziffern und Zeigern (Shulman 2000).

\subsubsection{Liquordiagnostik}

Besonders im Bereich des Morbus Alzheimer sind durch die im Liquor nachweisbaren Demenzmarker B-Amyloid und Tau-Protein bahnbrechende Erfolge in der Diagnostik gelungen. Daher erscheint die Evaluation von weiteren Demenzmarkern zur Früherkennung und Differenzierung von PDD und DLB sinnvoll.

\subsubsection{Tau-Protein und hyperphosphorylisiertes Tau}

Das Tau-Protein ist ein aus sechs Isoformen bestehendes Protein, welches in neuronalen Axonen lokalisiert ist und dort für die Stabilität der Mikrotubuli sorgt (Buée et al. 2000). Bei pathologischen Veränderungen des Tau-Proteins, so zum Beispiel einer Hyperphosphorylisierung im Rahmen des Morbus Alzheimer geht die beschriebene Bindungsfähigkeit an Mikrotubuli verloren. Das verbliebene hyperphosphorylisierte 
Tau-Protein bildet schließlich die Hauptkomponente der sogenannten gepaarten helikalen Filamente (PHF), die wiederum die in der Pathogenese der AD bedeutsamen Neurofibrillen und senilen Plaques ausmachen (Grundke-lqbal et al.1986).

In der Diagnostik erfolgt darüber hinaus stets die Bestimmung des Gesamt-Tau (Total-Tau), das bei Patienten mit AD im Schnitt 3,2-fach höher ist als bei gesunden Kontrollen. Dabei korreliert die Erhöhung mit der Stärke neuronaler Schädigung bzw. Degeneration (Blennow et al. 2001). Bedeutsam ist allerdings, dass auch ein akuter Untergang von Neuronen, beispielsweise im Rahmen eines Schlaganfalles, eine Erhöhung des Total-Tau bewirken kann. Es sollte daher stets Phospho-Tau mit herangezogen werden, da dieses Protein beim akuten Nervenzelluntergang nicht ansteigt und daher als demenzspezifisch angesehen werden kann (Hesse et al. 2001). Neuere Studien zeigen außerdem, dass geringfügig erhöhte Phospho-Tau-Werte als Prädiktor für die Entwicklung von Morbus Alzheimer bei bestehendem Mild Cognitive Impairment gesehen werden können (Ewers et al. 2007).

Für Patienten mit DLB konnte ebenfalls eine signifikant erhöhte Konzentration von Total-Tau im CSF nachgewiesen werden, wobei dieser allerdings weniger stark als derjenige bei AD erhöht zu sein scheint (Mollenhauer et al.2005, Parnetti et al. 2008).

Bezüglich des Morbus Parkinson (PD) konnte bereits 1997 gezeigt werden, dass eine normale Konzentration von Tau-Protein im Vergleich zu gesunden Vergleichspersonen vorliegt (Molina et al. 1997). Bei PDD ist die Datenlage widersprüchlich, wobei einerseits von unveränderten Tau-Konzentration gegenüber gesunden Kontrollgruppen berichtet wird (Jansen et al. 1998, Parnetti et al. 2008), andererseits aber auch von signifikant erhöhter Tau-Konzentration bei PDD im Vergleich zu einer gesunden Kontrollgruppe (Mollenhauer et al. 2006).

Je nach Studienlage könnte also eine Unterscheidung von DLB und PDD anhand ihrer Total-Tau-Konzentration im Liquor möglich sein.

\subsubsection{Beta-Amyloid 1-40 und 1-42}

Beta-Amyloid bzw. die Isoformen Amyloid-beta 1-40 und 1-42 entstehen durch proteolytische Spaltung des Amyloid Precursor Proteins (APP) mit Hilfe der beta- und gamma-Sekretasen und konnten als Hauptproteine der neurotoxischen senilen Plaques bei Morbus Alzheimer identifiziert werden (Masters et al. 1985). Dabei wurde herausgefunden, dass vor allem Abeta-42 besonders rasch aggregiert und im 
Nachhinein in um 40-50\% erniedrigter Konzentration im Liquor nachweisbar ist (Blennow et al. 2001). Da Abeta 1-40 hingegen meist nicht erniedrigt ist, kann eine Abeta42/Abeta-40-Ratio kleiner eins als Hinweis auf das Vorhandensein neuritischer Plaques gesehen werden (Lewczuk et al. 2004). Auch für DLB konnte in der Vergangenheit bereits ein erniedrigter Spiegel von Abeta-42 im CSF nachgewiesen werden, wobei dieser proportional zur Dauer der Erkrankung und der kognitiven Ausfälle war (Mollenhauer et al 2006, Parnetti et al. 2008). Für Patienten mit PDD wird allenfalls eine leichte Erniedrigung von Abeta-42 berichtet, eine Korrelation zu Krankheitsdauer und-schwere scheint allerdings nicht zu bestehen (Parnetti et al. 2008).

\subsubsection{Homocystein}

Eine Erhöhung der Aminosäure Homocystein im Blut konnte bereits in einer Vielzahl von Studien als unabhängiger Risikofaktor für Arteriosklerose und dessen Folgeerkrankungen identifiziert werden.

Epidemiologische Studien konnten allerdings auch eine signifikante Korrelation von Hyperhomocysteinämie im Plasma und dem Auftreten von neurodegenerativen Erkrankungen, so unter anderem Morbus Alzheimer, nachweisen (Wald et al. 2011).

Bezüglich der naheliegenden Bestimmung von Homocystein im Liquor gibt es widersprüchliche Studienergebnisse. Sicher scheint eine Korrelation von Alter der Patienten und Höhe des Homocysteinspiegels im Liquor zu sein (Serot et al. 2005). In einer weiteren Studie konnte weiterhin eine signifikante Erhöhung des totalen Homocysteinspiegels bei Patienten mit Morbus Alzheimer und Morbus Parkinson nachgewiesen werden (Isobe et al 2005). In einer Folgestudie an Alzheimerpatienten konnte diese allerdings nicht bestätigt werden (Smach et al. 2011).

Eine weitere Verifikation der Bedeutung von Homocystein für die Entwicklung einer Demenz scheint angesichts der leichten Beeinflussbarkeit des Homocysteinspiegels durch Gabe von Vitamin B6 , B12 und Folsäure sinnvoll.

\subsubsection{Vitamin-D-bindendes Protein (VDBP)}

Das Vitamin-D-bindende Protein ist ein Glykoprotein aus der Familie der Albumine und das wichtigste Trägerprotein für Vitamin D3 im menschlichen Körper. Es ist im Plasma und in deutlich geringerer Konzentration auch im Liquor cerebrospinalis des Menschen nachzuweisen.

Abgesehen von seiner Bedeutung für den Transport von Vitamin D scheint es eine 
Rolle bei der Entfernung von Aktin zu spielen, das bei nekrotischen Prozessen im menschlichen Körper frei wird. Des Weiteren konnte es als Aktivator von Makrophagen im Rahmen der Chemotaxis identifiziert werden (Meier et al. 2006).

In einer 2008 erschienenen Studie wurde der CSF-Spiegel des VDBP bei den neurodegenerativen Erkrankungen Morbus Alzheimer und Morbus Parkinson untersucht. Hier konnte im Vergleich zu einer gesunden Kontrollgruppe eine Erhöhung des CSFSpiegels für beide neurodegenerativen Erkrankungen nachgewiesen werden (Zhang et al. 2008). Eine weitere Evaluation dieses Markers mit Ausarbeitung von möglicherweise unterschiedlichen Liquorspiegeln bei gesunden und kognitiv eingeschränkten Personen scheint daher interessant.

\subsubsection{Apolipoprotein E (Apo E) quantitativ in Liquor und qualitativ als genetischer Parameter}

Apo $E$ ist ein Eiweiß, welches ein Transportprotein für Cholesterol und andere Lipide im Plasma und zentralen Nervensystem des Menschen darstellt. Die höchste Konzentration kann in der Leber sowie dem Hirn nachgewiesen werden, wo dessen Produktion hauptsächlich durch Astrozyten erfolgt (Pitas et al. 1987).

Es existieren drei Isoformen von Apo E (E2, E3, E4) mit unterschiedlichen Eigenschaften in Bezug auf Lipidbindung und Affinität zu ApoE-Rezeptoren, wobei die phänotypische Ausbildung der Isoformen durch unterschiedliche Allelkombinationen erzeugt wird. Es können sechs verschiedene Genotypen (E2/E2, E2/E3, E2/E4, E3/3, E3/E4, E4/E4) entstehen, wobei E3 mit 77\% das häufigste und E2 mit 8\% das seltenste Allel ist.

Die Isoform ApoE4 besitzt im Gegensatz zu ApoE2 und ApoE3 eine Präferenz zur Bindung größerer Lipoproteinpartikel und stellt somit einen Risikofaktor für die Entwicklung von Hyperlipoproteinämie dar (Hatters et al. 2006). Bei der quantitativen Bestimmung von ApoE im Liquor konnte für Morbus Alzheimer und Morbus Parkinson eine erniedrigte Konzentration von ApoE nachgewiesen werden, wobei jene bei Morbus Parkinson stärker erniedrigt sein soll (Zhang et al. 2008).

Des Weiteren konnte gezeigt werden, dass Individuen mit nur einem E4-Allel dreibis viermal häufiger Morbus Alzheimer entwickeln als solche ohne E4-Allel (Corder et al. 1993, Bertram und Tanzi 2008). Entsprechend beträgt die Häufigkeit der beschriebenen Allelsequenz in der Normalpopulation etwa 15\%, unter Patienten mit 
Morbus Alzheimer allerdings ca. 40\% (Bu 2009). Dabei besteht die deutlichste Risiko-Wirkungs-Beziehung bei einem Patientenalter zwischen 60 und 70 Jahren (Blacker et al. 1997). In weiteren Studien verdichteten sich Hinweise auf einen bedeutenden Einfluss von ApoE4 bei neuronalen Signalkaskaden und der Produktion von Abeta-42. So zeigte sich für ApoE4 eine erhöhte Neurotoxizität und für ApoE3 ein besserer Schutz gegenüber Apoptose (Qiu et al. 2003). Des Weiteren konnte für ApoE4-Träger eine erniedrigte Konzentration von Abeta1-42 im Liquor cerebrospinalis nachgewiesen werden (Varges et al. 2011). Auch für Morbus Parkinson und DLB zeigte sich in genetischen Analysen eine Überrepräsentation des ApoE4-Allels (Martinez et al. 2005, Josephs et al. 2004).

Die quantitative Messung von erniedrigtem ApoE im Liquor sowie die qualitative genetische Bestimmung der vorliegenden ApoE-Allele könnte zur Diagnose bzw. Risikobestimmung für die Entwicklung von neurodegenerativen Erkrankungen eine Berechtigung finden.

\subsubsection{TGF-Beta-1}

Sowohl für Lewy-Körperchen-Erkrankungen als auch Morbus Alzheimer gibt es die Hypothese, dass die Neurodegeneration bei beiden Erkrankungen auf einem inflammatorischen Prozess bzw. erhöhten Zytokinspiegeln beruht.

Für TGF-beta-1 als ein solches Zytokin konnte eine erhöhte Konzentration im Liquor von Patienten mit Morbus Alzheimer festgestellt werden (Rota et al. 2006). In einer anderen Studie zeigte sich auch für Morbus Parkinson ein signifikant erhöhter TGFbeta-1-Liquorspiegel (Nagatsu et al. 2000).

Zuverlässige Daten für Demenz bei Morbus Parkinson sowie Lewy-KörperchenDemenz liegen noch nicht vor.

\subsubsection{Ergänzende Diagnostik}

\subsubsection{Codon 129 - Polymorphismus}

Das sogenannte Codon 129 bezeichnet einen Abschnitt auf dem Prion-Protein-Gen (PRNP), dessen Polymorphismus Bedeutung für die Ausprägung neurodegenerativer 


\section{Erkrankungen zu haben scheint.}

Durch Genanalyse ließ sich für das Codon 129 feststellen, dass in der Normalbevölkerung etwa $37 \%$ homozygot für die Aminosäure Methionin (MM), $12 \%$ homozygot für Valin (VV) und 51\% heterozygot für Methionin und Valin (MV) sind.

Für die Creutzfeldt-Jakob-Erkrankung konnte bereits zweifelsfrei nachgewiesen werden, dass vor allem eine Methionin-Homozygotie auf dem Codon 129 des PrionProtein-Gens (PRNP) einen Risikofaktor für die Ausbildung der Erkrankung und den anschließenden klinischen Verlauf darstellt. So weisen $70 \%$ der Patienten mit einer sporadischen Creutzfeldt-Jakob-Krankheit eine Homozygotie für Methionin, 16\% eine Homozygotie für Valin und 14\% eine Heterozygotie auf (Alperovitch et al. 1999).

Auch für Morbus Alzheimer zeigten sich Hinweise für eine Korrelation zwischen Methionin-Homozygotie und Risiko für die Entwicklung der Demenz (Gacia et al. 2006).

Für Morbus Parkinson konnte im Vergleich zu gesunden Vergleichspersonen bisher kein signifikanter Unterschied im PRNP-Polymorphismus evaluiert werden. Das signifikant häufigere Auftreten einer Methionin-Homozygotie bei Patienten mit hypokinetisch-rigidem Parkinsonsyndrom im Vergleich zum tremordominanten Typ lässt allerdings die Annahme eines Zusammenhangs zu (Gossrau et al. 2006, Shibao et al. 2006).

\subsubsection{Unified Parkinson's Disease Rating Scale (UPDRS)}

Die UPDRS ist ein etabliertes, zur Verlaufsbeurteilung von Morbus Parkinson bzw. Parkinsonsyndromen entwickeltes Untersuchungsverfahren. Sie ist in vier Abschnitte unterteilt, die sich mit Kognition bzw. Stimmung, Aktivitäten des alltäglichen Lebens, den motorischen Parkinsonsymptomen sowie den jüngsten Therapiekomplikationen befassen.

Im motorischen Teil der UPDRS werden die Art und Schwere der extrapyramidalen Zeichen (Rigor, Tremor, Hypokinesie) und einfache Bewegungsabläufe (Fingergeschicklichkeit, Beweglichkeit der Beine, Gang- und Haltungsstabilität) erfasst und anhand einer Ordinalskala von 0 (=normal) bis 4 (=deutlich beeinträchtigt) beurteilt (Goetz et al. 2003). 


\subsubsection{Bildgebende Verfahren}

Bildgebende Verfahren in der Diagnostik von Demenzen haben vor allem durch den großzügigeren Einsatz hochauflösender kranialer MRT-Untersuchungen sowie dem Einzug von Spezialuntersuchungen ihre Berechtigung gefunden.

Zwar lassen sich auch in der kranialen Computertomographie veränderte Größenverhältnisse des Hirns darstellen, jedoch ist zu jenen Zeitpunkt der Nervenzelluntergang in der Regel bereits so groß, dass eine Demenz auch anhand von pathologischen neuropsychologischen Testergebnissen einigermaßen sicher diagnostiziert werden kann. Die initiale CT-Bildgebung wird daher vor allem zum Ausschluss von Differentialdiagnosen wie Hirninfarkte oder Tumorleiden verwendet.

Eine MRT-Untersuchung bietet neben fehlender Strahlenbelastung eine bessere Auflösung und kann neurodegenerative Prozesse des Hirns daher früher darstellen. Für Morbus Alzheimer ist diesbezüglich vor allem eine Atrophie im Bereich des Hippocampus und dem Temporallappen typisch. Bei Morbus Parkinson ermöglichen neue MR-Techniken sogar die Darstellung einer Degeneration der Substantia nigra, sind zum jetzigen Zeitpunkt allerdings noch nicht ausreichend sensitiv (Hutchinson und Raff 1999). Demenzen bei Morbus Parkinson und der Lewy-Körperchen-Erkrankung zeigen im MRT oftmals Mischbilder aus okzipitalen und frontotemporalen Atrophien, die anhand der Standardbildgebung keine sichere Zuordnung zu einer Demenzform zulassen.

Bevor der fortschreitende Nervenzelluntergang zu einer sichtbaren Schrumpfung des Hirns führt, lassen sich heute bereits in frühen Phasen der Demenz veränderte Stoffwechselaktivitäten im PET-CT oder PET-MRT darstellen. Hier zeigt sich nach intravenöser Zufuhr von radioaktiv markiertem Zucker eine Abnahme der Durchblutung in den bevorzugt betroffenen Abschnitten des Hirns, das heißt für Morbus Alzheimer vor allem im Temporallappen (Grimmer et al. 2005).

Die zur Diagnostik von Morbus Parkinson etablierten nuklearmedizinischen Untersuchungen SPECT und DATscan, welche typische Störungen im Dopaminstoffwechsel aufzeigen, zeigen sowohl bei PDD als auch bei DLB gleichartige Reduktionen der striatalen Bindung und ermöglichen somit keine Differenzierung der Demenzformen (Asenbaum-Hanke et al. 2005). Von Bedeutung ist allerdings, dass bei Patienten mit Morbus Alzheimer meist keine relevante dopaminerge Degeneration und daher eine normale dopamintransporter-Aufnahme im DATscan vorliegt. Eine Unterscheidung von PDD und DLB gegenüber AD ist also möglich, allerdings nicht von PDD und DLB 
(Pirker und Brücke 2004).

\subsection{Therapie}

Für alle drei in dieser Studie betrachteten neurodegenerativen Erkrankungen gibt es bis heute symptomatische Therapieansätze, die auftretende kognitive Defizite bessern können.

\subsubsection{Medikamentöse Therapie}

Sowohl für Morbus Alzheimer als auch PDD und DLB konnte unabhängig von den unterschiedlichen Pathologien (Plaques und Tangles bei AD, Lewy-Körperchen bei PDD und DLB) ein Mangel am Botenstoff Acetylcholin im zentralen Nervensystem nachgewiesen werden.

Entsprechend zeigt sich für alle drei Krankheitsgruppen eine signifikante Besserung der kognitiven Funktion unter Gabe von Cholinesteraseinhibitoren, die den Abbau des Acetylcholins hemmen und somit indirekt dessen Angebot als ZNS-Botenstoff erhöhen (Farlow et al. 2010, Ballard et al. 2011).

Des Weiteren konnte gezeigt werden, dass bei Demenzen ein relatives Überangebot an Glutamat, einem bedeutenden exzitatorischen Neurotransmitter des ZNS, vorliegt. Die anhaltende Erhöhung des eigentlich die Lernvorgänge fördernden Botenstoffes sorgt durch die stattfindende Dauererregung zu fehlerhafter Informationsweiterleitung und sogar Absterben von Nervenzellen, was somit Lernvorgänge und kognitive Leistung verschlechtert. Durch Gabe des NMDA-Rezeptor-Antagonisten Memantine, der die schädliche Wirkung des Glutamat am NMDA-Rezeptor verringert, konnte ebenfalls für alle drei betrachteten Demenzformen eine verbesserte kognitive Leistung nachgewiesen werden (Aarsland et al. 2005 b). Außerdem scheint die gleichzeitige Gabe von Acetylcholinesterasehemmern und NMDA-Antagonisten einen synergistischen Effekt auf den Therapieerfolg zu haben (Riordan et al. 2011). Sämtliche Medikamente sind größtenteils für Morbus Alzheimer evaluiert und auch primär für diese Erkrankung zugelassen. Mittlerweile hat Rivastigmin als Acetylcholinesterasehem- 
mer auch eine Zulassung für PDD erhalten. Diese steht für DLB trotz in Studien nachgewiesener Wirksamkeit noch aus (Ballard et al. 2011).

\subsubsection{Nichtmedikamentöse Therapie}

Nichtmedikamentöse Therapieverfahren bei Demenzpatienten bestehen vor allem in Ergo- und Physiotherapie, deren Ziel es ist, die bestehende kognitive Funktion sowie Selbstständigkeit im Alltag zu erhalten oder zu verbessern. Leider gibt es nur wenige Studien, die Auswirkung dieser Therapien auf das Ausmaß und das Fortschreiten der Demenz untersucht haben, ein positiver Einfluss auf den Erhalt von Alltagsfähigkeiten der Patienten ist allerdings anzunehmen.

\subsection{Fragestellung}

Ziel dieser Studie soll die Betrachtung bekannter und neuer Liquorparameter sein, die in Zusammenhang mit der Demenzentwicklung bei Patienten mit Morbus Parkinson stehen könnten.

Anhand des Vergleichs der Konzentrationen der Liquormarker soll eine mögliche Unterscheidung zwischen den betrachteten Erkrankungen PD, PDD, DLB und AD untersucht werden. Des Weiteren sollen mittels Korrelation der Liquormarker mit den Ergebnissen einer neuropsychologischen Testung (CERADplus-Testbatterie) mögliche Marker definiert werden, die im Zusammenhang mit dem Schweregrad einer Demenz stehen.

Unser Hauptziel ist daher die Erhebung von Liquorparametern, die eine Diagnosefindung bei PDD und eine Abgrenzung dieser Erkrankung zu DLB und AD ermöglichen. Aufgrund der breiteren Studienlage in der Liquordiagnostik für Morbus Alzheimer und der Annahme von sich teilweise überlappenden Pathologien erscheint ein Vergleich und somit Einbezug von AD und DLB zur besseren Beurteilbarkeit der Ergebnisse für das Krankheitsbild Demenz bei Morbus Parkinson sinnvoll. 


\section{MATERIAL UND METHODEN}

\subsection{Studiendesign}

Es handelt sich um eine prospektive Querschnittsstudie.

\subsection{Patientenkollektiv}

Untersucht wurden insgesamt 102 Patienten, wovon sich für 43 im Rahmen der seit 1993 laufenden epidemiologischen Studie zur Creutzfeldt-Jakob-Erkrankung („Untersuchung zur Epidemiologie, Frühdiagnose und molekularen Pathologie humaner spongiformer Enzephalopathien“ (Antragsnummer 11/11/93, Votum der Ethikkommission vom 04.11.1993, 18.09.1996, 12.09.2002)) die Differentialdiagnose PD, PDD, AD oder DLB ergab. Die Meldung der Patienten erfolgte durch Ärzte der neurologischen Universitätsklinik Göttingen, die zuvor über Ein- und Ausschlusskriterien des an der Studie teilnehmenden Patientenkollektivs informiert wurden. Bei weiteren 19 Patienten mit PD $(n=10)$ und PDD $(n=9)$ lagen Liquorproben sowie Ergebnisse des Mini-Mental-Status-Tests vor.

Zur Ermöglichung einer größeren Patientenzahl und somit besseren Aussagekraft der Studienergebnisse wurden nach Abschluss der Datenerhebung zusätzlich 40 Patienten aus der laufenden Studie „Charakterisierung von Prädiktoren (Klinik, Bildgebung, Liquor- und Serumparameter) rapid progressiver Verläufe des Morbus Alzheimer als Differentialdiagnose zur Creutzfeldt-Jakob-Krankheit" (Antragsnummer: 9/6/08) mit der Diagnose Morbus Alzheimer einbezogen, bei denen im Vorhinein ebenfalls eine CERAD-Testung sowie die Akquirierung von Liquorproben stattgefunden hatte.

\subsubsection{Ein-/Ausschlusskriterien}

- Bereitschaft des Patienten oder gerichtlich bestellten Betreuers zur Teilnahme

- Einwilligungsfähigkeit und schriftliche Einwilligung des Patienten oder Betreuers auf dem Einwilligungsbogen 
- Zutreffen der Klassifikationskriterien des Morbus Parkinson nach Hughes et al. 1992, des Morbus Alzheimer nach McKhann et al. 1984 oder der LewyKörperchen-Demenz nach McKeith et al., 1996

\subsubsection{Prüfung der Einwilligungsfähigkeit}

Zur Feststellung der Einwilligungsfähigkeit wurde durch den Studienarzt vor Ort geprüft, ob die teilnehmende Person zum Zeitpunkt der Untersuchung trotz möglicherweise vorliegender kognitiver Defizite zum tiefgreifenden Verständnis der geplanten Untersuchung in der Lage war. Dabei wurde insbesondere darauf geachtet, dass die Risiken und Alternativen der Studie erkannt und in angemessener Weise verarbeitet wurden.

Waren diese Fähigkeiten bei der Person nicht festzustellen, musste von fehlender Einwilligungsfähigkeit ausgegangen werden.

Bei gerichtlich geregelter Betreuungssituation wurde gemäß aktueller Rechtssprechung die betreuende Person zur Einwilligung in die Studie herangezogen. Hierfür standen gesonderte Aufklärungs- und Einwilligungsbögen zur Verfügung.

\subsubsection{Klassifikation der Diagnose Morbus Parkinson und Demenz bei Parkinson}

Die Einordnung von Patienten in die Untergruppe Morbus Parkinson (oder Demenz bei Morbus Parkinson bei kognitiven Defiziten und seit über einem Jahr bestehendem Parkinsonsyndrom) erfolgte anhand der etablierten Klassifikationskriterien nach Hughes et al. von 1992 (Anhang 1). Dabei kann beim Nachweis von Bradykinese (verlangsamte Bewegungsabläufe und verminderte Spontanbewegungen, z.B. Verlust der mimischen Expression, vermindertes Mitschwingen der Arme beim Gehen) und einem weiteren Kardinalsymptom wie Rigor, Ruhetremor oder posturale Instabilität (mangelnde Stabilität der aufrechten Körperhaltung) klinisch zuverlässig die Diagnose eines Parkinsonismus gestellt werden. Als zusätzliche Hinweise gelten einseitiger Beginn der Symptomatik sowie deutliche Besserung der Symptomatik nach Gabe von Levodopa. Bei Vorliegen der Kombination Morbus Parkinson plus Demenz, die mindestens ein Jahr nach Diagnose des Parkinson aufgetreten ist, wurde die Diagnose PDD gestellt. 


\subsubsection{Klassifikation der Diagnose Demenz mit Lewy-Körperchen}

Zur Einordnung der teilnehmenden Patienten in das Kollektiv Demenz mit LewyKörperchen waren die 1996 von McKeith et al. erarbeiteten und 1999 modifizierten Klassifikationskriterien maßgeblich (Anhang 2). Dabei war neben dem zentralen Symptom der kognitiven Einschränkung der Nachweis eines Parkinsonsyndroms notwendig, welches für die Dauer von maximal einem Jahr singulär, das heißt ohne Demenz, bestand. Typische weitere unterstützende Kriterien für die Diagnose einer wahrscheinlichen DLB waren Fluktuationen der Symptomatik sowie das Auftreten von visuellen Halluzinationen.

\subsubsection{Klassifikation der Diagnose Morbus Alzheimer}

Sowohl für die im Rahmen der Studie vom Prüfarzt eigens untersuchten Patienten als auch für die hinzugenommenen Patienten aus anderen Projekten der Forschungsgruppe waren für die Diagnose des Morbus Alzheimer die Diagnosekriterien der NINCDS-ADRDA Work Group (National Institute of Neurological and Communicative Disorders and Stroke and The Alzheimer's and Related Disorders Association) nach McKhann et al. maßgeblich (Anhang 3). Zusätzlich zu den auch in den Klassifikationskriterien angegebenen typischen Befunden in der Bildgebung des Kopfes (Atrophien im Bereich des Temporallappens/Hippokampus im cCT/cMRT) wurden allerdings auch vorliegende Liquorbefunde (erhöhtes Tau, erniedrigtes Abeta-42) in die Beurteilung zur Zuordnung in die Patientengruppe einbezogen.

\subsection{Datenerhebung}

\subsubsection{Anamnese}

Bei den Patienten erfolgte nach durchgeführter Aufklärung und Einwilligung initial eine ausführliche Anamnese. Diese beinhaltete neben Evaluation von vorliegenden Begleiterkrankungen die ausführliche Erhebung des zeitlichen Ablaufs der kognitiven Defizite. Dabei wurden nach Zustimmung des Patienten, sofern notwendig, auch Angehörige oder der behandelnde Hausarzt befragt. Besonderer Wert wurde außerdem auf das Erkennen von Begleiterkrankungen gelegt, die eine Zuordnung des Patienten in eine der genannten Diagnosegruppen gemäß der geltenden Klassifikationskrite- 
rien ausschließen.

\subsubsection{Klinische Untersuchung}

Eine vor Beginn der neuropsychologischen Testung durchgeführte neurologische und orientierend-internistische Untersuchung galt dem Erkennen zuvor nicht beobachteter neurologischer Defizite sowie der Einschätzung des aktuellen Gesundheitsstandes. Darüber hinaus wurde bei allen im Rahmen dieser Studie untersuchten Patienten der motorische Teil des UPDRS angewendet, um einen bestehenden Parkinsonismus zu reevaluieren bzw. einen zuvor unbekannten Parkinsonismus festzustellen (Anhang 4).

Folgende Untersuchungen wurden durchgeführt:

- Kopfbeweglichkeit/HWS-Beweglichkeit (Meningismus, Rigor, LhermitteZeichen, HWS-Blockade)

- Psychischer Status (Wachheit, Vigilanz, Bewusstsein, Orientierung, Wahrnehmungsstörungen, Stimmungslage, Motivation)

- Hirnwerkzeugfunktionen (Aphasie, Spontansprache, Apraxie, Agnosie)

- Hirnnervenstatus (Untersuchung der Funktion der Hirnnerven I-XII)

- Motorik/Motilität (Grobe Kraft- und motorische Schnelltestung, Atrophien, Hypertrophien, Faszikulationen, Kloni, Muskeltonus, Pareseprüfung, Armhalteversuch, Beinhalteversuch)

- Reflexe (Muskeleigenreexe, Fremdreflexe, pathologische Reflexe)

- Sensibilität (Oberflächen- und Tiefensensibilität)

- Koordination (Hyper- und Hypokinesien, Diadochokinese, Zeigeversuch, Gangbild, Romberg-Stehversuch, Unterberger-Tretversuch, Knie-Hacke-Versuch)

- UPDRS, motorischer Teil

- Untersuchung des Thorax und des Herzens (Auskultation, Perkussion) 


\subsubsection{Neuropsychologische Testung}

Die neuropsychologische Testung fand bei ausreichender Mobilität der Patienten in einem speziell ausgewiesenen, reizarmen Testraum auf einer neurologischen Station der UMG statt. Die Dauer der Untersuchung betrug je nach Zustand des Patienten zwischen 40 und 80 Minuten, wobei die Durchführung der angewendeten CERADplus-Testbatterie nach den in die deutsche Sprache übersetzten Richtlinien der Memory Clinic des Universitätsspital Basel erfolgte. Der vollständige Test befindet sich im Anhang dieser Arbeit (Anhang 5).

Bei vorzeitiger Erschöpfung oder mangelnder Compliance der Patienten wurde die Testung abgebrochen und nur bei Absolvierung von mindestens 50 Prozent der Tests in die weitere Auswertung übernommen.

Im Anschluss an die Datenerhebung erfolgte noch am selben Tag die Übertragung der Testergebnisse in das ebenfalls von der Memory Clinic Basel zur Verfügung gestellte Auswertungsprogramm CERAD 1.0, welches eine rasche Konversion der Testleistungen in alters- und bildungskorrigierte Z-Werte und somit Beurteilung der kognitiven Einschränkungen ermöglichte.

Am Folgetag wurden die Auswertungsbögen an die jeweiligen behandelnden Stationsärzte und je nach individuellem Wunsch in einem persönlichen Gespräch auch an die teilnehmenden Patienten übermittelt.

Nach neun Monaten schloss sich eine erneute Testung der Patienten an. Hierzu wurden diese telefonisch und/oder postalisch kontaktiert. Bei Rückmeldung und bleibendem Einverständnis der Patienten oder deren gesetzlichen Betreuer wurde die Testung entweder im beschriebenen Testraum der UMG oder bei Immobilität der Patienten im häuslichen Umfeld durchgeführt. 


\subsubsection{Liquorpunktion}

Die Liquorpunktion wurde nicht eigens für diese Studie, sondern im Rahmen der vorliegenden Verdachtsdiagnose PD, PDD, DLB oder AD vom behandelnden Stationsarzt gemäß geltender Richtlinien und nach ausführlicher Aufklärung des Patienten durchgeführt. Nach Bestimmung der für die Klärung der Verdachtsdiagnose notwendigen Parameter im hauseigenen Liquorlabor erfolgte die Akquirierung des überstehenden Liquores, der sonst verworfen worden wäre, durch den Studienarzt. Der auf diese Weise gesammelte Liquor wurde anschließend bis zum Abschluss der Datenerhebung an den teilnehmenden Patienten bei minus $80^{\circ}$ Celsius sicher in den Laboratorien der Prionenforschungsgruppe aufbewahrt.

\subsubsection{Blutentnahme}

Vor der Blutentnahme erfolgte zunächst eine ausführliche Aufklärung und schriftliche Einwilligung des Patienten zu möglichen Risiken der Blutentnahme sowie über die aus den Blutproben zu bestimmenden genetischen Marker Apo E und Codon 129. Die Blutentnahme erfolgte im Anschluss an die neuropsychologische Testung durch den Studienarzt, wobei nach hygienischer Desinfektion der Punktionsstelle und Punktion einer sicher zugänglichen Vene (in der Regel Vena mediana cubiti) zwei Blutröhrchen à 8ml entnommen wurden.

Direkt nach der Blutentnahme wurden die gewonnenen Blutprodukte im Prionenlabor durch Zentrifugation in Serum und Plasma getrennt und ebenfalls bei minus $80^{\circ} \mathrm{Cel}-$ sius sicher aufbewahrt. 


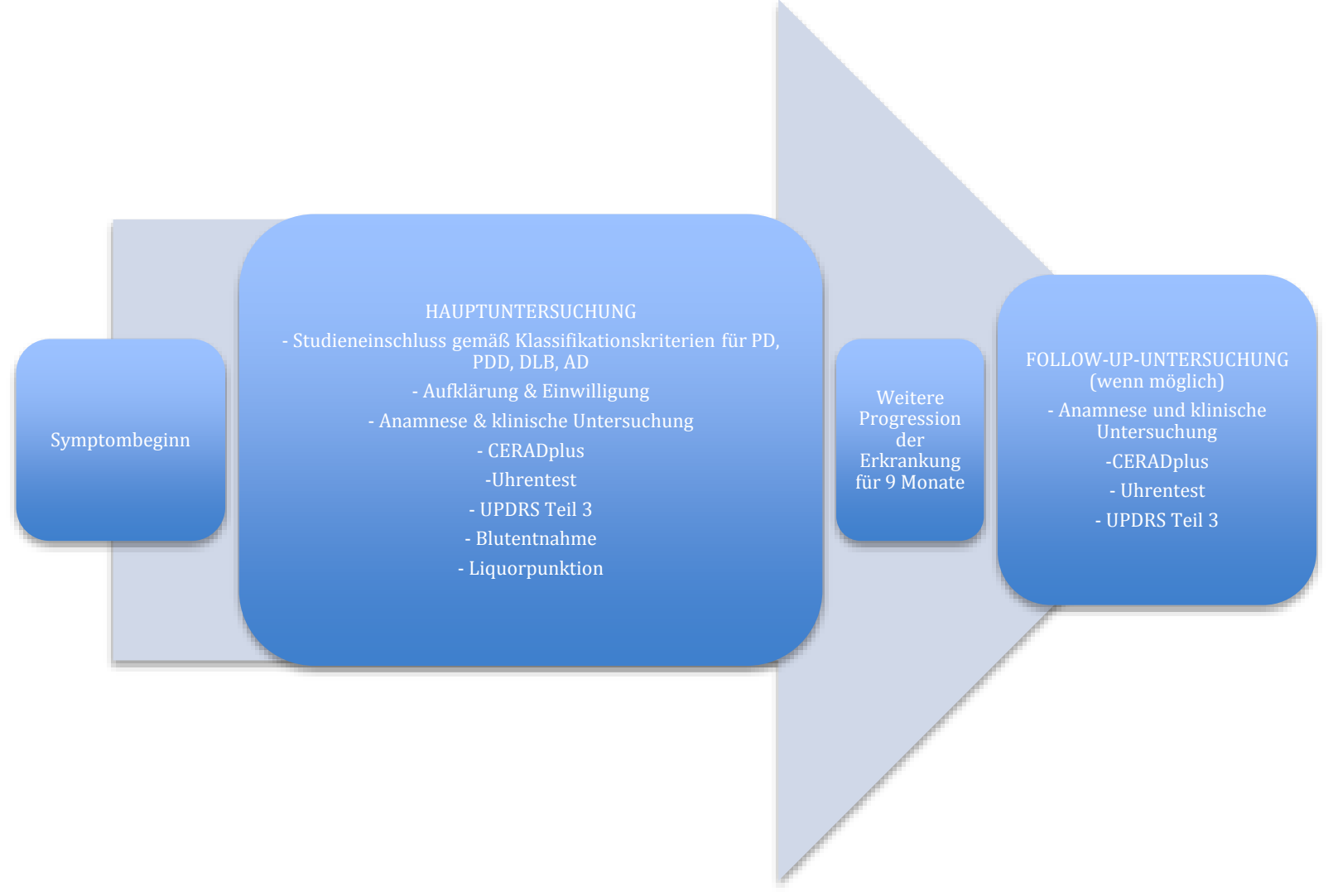

\subsection{Messinstrumente}

Nach Abschluss der klinischen Datenerhebung am Patienten erfolgte die Bestimmung potentieller Demenzmarker aus den akquirierten tiefgefrorenen Liquor- und Blutproben im Labor der Prionforschungsgruppe der UMG. Sofern auf dem Markt erhältlich, wurden zur Bestimmung der oben beschriebenen Biomarker langjährig erprobte und für die Liquordiagnostik validierte ELISA-Testkits verwendet. Für einige der zu bestimmenden Marker lagen zum Zeitpunkt der Bestimmung trotz Hinweisen für eine Anwendbarkeit mit Liquor aus verschiedenen Studien nur ELISA-Testkits zur Anwendung in anderen Körperflüssigkeiten wie Serum oder Urin vor. In einem solchen Fall erfolgten stets die Konsultation des entsprechenden Herstellers und die gemeinsame Erarbeitung der Bestimmung der Marker im Liquor.

Die genetischen Marker Apo E und Codon 129 wurden gesondert in Kooperation mit der Abteilung der Klinischen Chemie der Universitätsklinik Göttingen unter der Leitung von Professor Ahsen bestimmt. Hierzu wurde die Technik der direkten DNASequenzierung angewendet. 


\subsubsection{ELISA-Verfahren und Bestimmung der Biomarker aus dem Liquor}

Die in dieser Studie zur Bestimmung der Biomarker verwendeten Enzyme-Linked Immunosorbent Assays (ELISAs) sind immunologische Nachweisverfahren (Assays) für eine Zielsubstanz. Hierbei werden monoklonale Antikörper genutzt, die an das nachzuweisende Antigen binden. Diese enzymatisch markierten sogenannten Detektionsantikörper ermöglichen durch eine enzymkatalysierte Reaktion den Nachweis des Antigens. Das Substrat des Enzyms wird umgesetzt, und das daraus entstehende Reaktionsprodukt kann durch Farbumschlag, Fluoreszenz oder Chemolumineszenz nachgewiesen werden. Dabei ist die Signalstärke (im Fall dieser Studie die optische Dichte (OD)) eine Sigmafunktion der Antigenkonzentration, so dass ELISAs, sofern für die Zielsubstanz eine Eichreihe erstellt werden kann, für quantitative Nachweise verwendbar sind.

\subsubsection{Tau-Protein}

Der in dieser Studie genutzte ELISA „INNOTEST ${ }^{\circledR}$ hTAU Ag“ der Firma Innogenetics (Nachweisgrenze 59,3 pg/ml) ist allein für die quantitative Bestimmung von TauProtein im Liquor cerebrospinalis des Menschen validiert und zugelassen.

Dabei erfolgt nach Hinzugabe des Liquors zunächst die Bindung des enthaltenen Tau-Proteins an die Mikrotiterplatte durch den monoklonalen Antikörper AT 120. Im Anschluss binden die biotinkonjugierten tau-spezifischen monoklonalen Antikörper (HT7 und BT3). Deren Nachweis ist wiederum durch an das Biotin bindende, mit einer Rettichperoxidase (Horseradisch Peroxidase $=$ HRP) konjugierte, Streptavidin möglich. Der nächste Schritt beinhaltet das Auftragen einer Tetramethylbenzidin (TMB)-Substratlösung, um im Falle der Bindung der Detektionsantikörper HT7 und BT3 an das Tau-Protein einen Farbumschlag hervorzurufen. Das TMB dient als chromogenes Substrat für den Nachweis der Rettichperoxidase. Nur jene Kavitäten, die das Tau-Protein, die mit Biotin konjugierten Antikörper und das mit dem Enzym konjugierte Streptavidin enthalten, können einen Farbumschlag zeigen. Zuletzt wird die Enzym-Substrat-Reaktion wird durch die Zugabe von Schwefelsäure gestoppt und die Farbänderung photometrisch bei einer Wellenlänge von $450 \mathrm{~nm} \mathrm{(+/-} 2 \mathrm{~nm})$ gemessen. Die Konzentrationsbestimmung von Tau-Protein in den Patientenproben erfolgt, indem die optische Dichte (OD) der Proben mit der Standardkurve verglichen wird. 


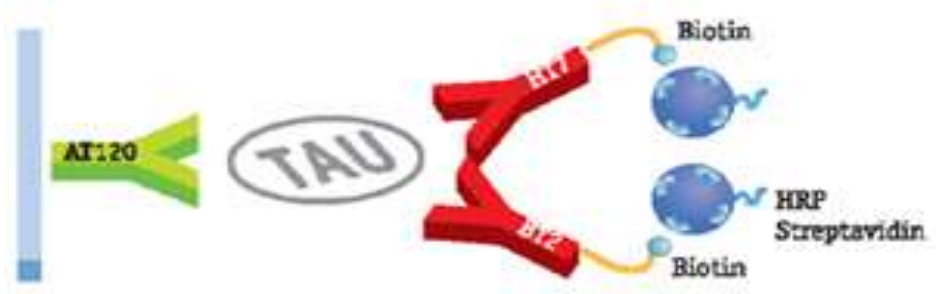

Mit freundlicher Genehmigung des Autors (@www.fujirebio-europe.com)

\subsubsection{Hyperphosphoryliertes Tau}

Der in dieser Studie genutzte ELISA „INNOTEST PHOSPHO-TAU (181P)“ der Firma Innogenetics (Nachweisgrenze 15,6 pg/ml) ist allein für die quantitative Bestimmung von hyperphosphorylisiertem Tau-Protein im Liquor cerebrospinalis des Menschen validiert und zugelassen.

Das Prinzip des Nachweises von Phospho-Tau entspricht im Sinne eines sogenannten Sandwich-ELISAs weitgehend der beschriebenen Enzym-Substrat-Reaktion beim Nachweis von Tau-Protein. Es unterscheiden sich lediglich die jeweils spezifischen Antikörper. So wird in diesem Fall die Bindung an die Mikrotiterplatte durch den monoklonalen Antikörper HT7 erreicht. Als Detektionsantikörper fungiert der biotinkonjugierte Antikörper AT270bio.

Zuletzt wird, in Übereinstimmung mit der Bestimmung von Tau-Protein, die EnzymSubstrat-Reaktion durch die Zugabe von Schwefelsäure gestoppt und die Farbänderung photometrisch bei einer Wellenlänge von $450 \mathrm{~nm}(+/-2 \mathrm{~nm})$ gemessen.

\section{Abbildung 3: Graphische Darstellung des Nachweises von Phospho-Tau}

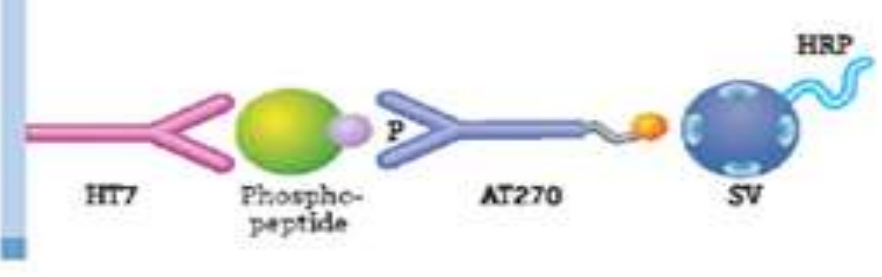

Mit freundlicher Genehmigung des Autors (@www.fujirebio-europe.com)

\subsubsection{Beta-Amyloid 1-42}

Der in dieser Studie genutzte ELISA „INNOTEST ß-Amyloid (1-42)“ der Firma Inno- 
genetics (Nachweisgrenze $50 \mathrm{pg} / \mathrm{ml}$ ) ist allein für die quantitative Bestimmung von Beta-Amyloid 1-42 im Liquor cerebrospinalis des Menschen validiert und zugelassen.

Das Testprinzip ist ebenfalls ein Sandwich-Elisa, dessen Fangantikörper (Antikörper zur Bindung von B-Amyloid an die Mikrotiterplatte) der monoklonale Antikörper $21 \mathrm{~F} 12$ ist. Der Detektionsantikörper, an den wiederum das peroxidase-konjugierte Strepatividin bindet, ist der biotinisierte Antikörper 3D6.

Das Stoppen der Reaktion sowie die anschließende photometrische Konzentrationsbestimmung entsprechen derjenigen in Kapitel 2.4.1.1.

Abbildung 4: Graphische Darstellung des Nachweises von B-Amyloid 1-42

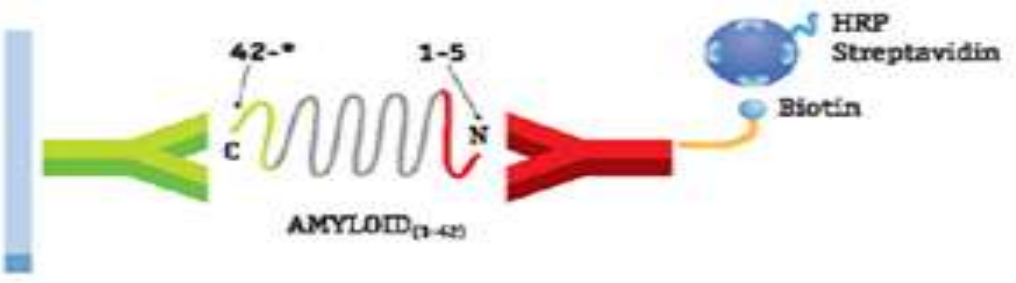

Mit freundlicher Genehmigung des Autors (@www.fujirebio-europe.com)

\subsubsection{Homocystein}

Die Konzentration von Homocystein im Liquor cerebrospinalis der Patienten wurde mit Hilfe des EIA-Testkits „Homocysteine by EIA“ der Firma BIO RAD bestimmt. Dieser ist für die Bestimmung von Homocystein in Serum und Plasma zugelassen, ein sicherer Nachweis der deutlich niedrigeren Konzentrationen im Liquor des Menschen ist aufgrund des verwendeten hochspezifischen Antikörpers Anti-SAH allerdings wahrscheinlich.

Das Testprinzip dieses enzymgekoppelten Immunadsorptionstests ist eine Detektion von Homocystein durch ein markiertes Kompetitorantigen, welches mit Homocystein um eine Bindung an der Antikörperbeschichteten Platte konkurriert. Die Stärke des letztlichen Farbumschlags ist hierbei umgekehrt proportional zur Menge der Homocysteinkonzentration.

\subsubsection{Vitamin-D-bindendes Protein (VDBP)}

Zur Bestimmung des VDBP wurde das hochsensitive Quantikine „Human Vitamin D Binding Protein Immunoassay" der Firma R\&D-Systems (Nachweisgrenze 0,65 
$\mathrm{ng} / \mathrm{ml}$ ) verwendet, welches für den quantitativen Nachweis von VDBP in Zellkulturüberständen, Serum, Plasma, Speichel, Urin und Muttermilch vorgesehen ist. Eine zuverlässige Bestimmung des Proteins im Liquor ist allerdings sehr wahrscheinlich, da in anderen bereits veröffentlichten Studien die Konzentrationsmessung an Patienten mit Morbus Parkinson und Morbus Alzheimer erfolgreich durchgeführt wurde (Zhang et al. 2008). In Erwartung der in anderen Studien nachgewiesenen Konzentrationen von VDBP im Liquor des Menschen erfolgte vor dem Auftragen auf die Mikrotiterplatte eine Liquorverdünnung in einem Verhältnis von 1:20. Alle anderen Abläufe (Waschvorgang, Inkubationsdauer etc.) wurden gemäß der in der Anleitung gegebenen Empfehlung durchgeführt.

Das Prinzip der Bestimmung beruht in diesem Fall ebenfalls auf einem SandwichELISA, wobei die verwendete ELISA-Platte mit einem für VDBP spezifischen Fangantikörper vorbeschichtet ist. Nach Bindung des VDBP erfolgt die Detektion mittels eines enzymgekoppelten (horseradish peroxidase) Antikörpers. Sowohl bei Fang- als auch bei Detektionsanitkörper handelt es sich um monoklonale Maus-Antikörper. Bei anschließender Zugabe der Substratlösung ergibt sich ein Farbumschlag, der proportional zur Menge des gebundenen VDBP ist. Die optische Dichte wird im Nachhinein bei einer Wellenlänge von $450 \mathrm{~nm}$ massenspektrometrisch bestimmt.

\subsubsection{Apo E quantitativ}

Zur Bestimmung des quantitativen Apolipoprotein E wurde der „ELISA for Human Apolipoprotein E“ der Firma Mabtech (Nachweisgrenze 0,1 ng/ml) verwendet. Dieser ist primär für die Bestimmung der ApoE-Isoformen ApoE2, E3 und E4 in menschlichem Serum und Plasma sowie Zellkulturüberständen validiert. Aufgrund der hohen Sensitivität des Testkits für die Bestimmung von ApoE in Serum, Plasma und Zellkulturüberständen, bei der stets eine sehr hohe Verdünnung notwendig ist, erscheint eine Bestimmung von ApoE im Liquor unter experimentellen Gesichtspunkten als validert.

Nach Rücksprache mit der Firma Mabtech sowie Analyse bisheriger Veröffentlichungen bezüglich der Analyse von ApoE im Liquor, bei denen eine Liquorkonzentration zwischen 0,7 und 11,3 Mikrogramm angegeben wurde (Zhang et al. 2008), erfolgte unter Berücksichtigung der Standardkurve eine Verdünnung des Liquors mit einem bereitgestellten Puffer im Verhältnis von 1:500.

Zur Herstellung des ELISAs werden an Tag 1 der Messungen zunächst die ELISA- 
Platten mit dem monoklonalen Antikörper mAb E276 beschichtet und über Nacht inkubiert. An Tag 2 erfolgt das Auftragen der verdünnten Liquorproben sowie des Standards. Als anschließender Detektionsantikörper dient der ApoE-spezifische monoklonale biotinisierte Antikörper E887-biotin, an den bei Vorliegen von ApoE eine Streptavidin-HRP (=horseradisch peroxidase) bindet und nach Zugabe der Substratlösung einen Farbumschlag hervorruft. Zuletzt erfolgt die photometrische Bestimmung der Farbänderung bei einer Wellenlänge von 450 nm und somit Bestimmung der Konzentration von ApoE im Liquor.

\subsubsection{TGF-Beta-1}

Zur Bestimmung des TGF-ß1 wurde das hochsensitive Quantikine „Human TGF-ß1 Immunoassay“ der Firma R\&D-Systems (Nachweisgrenze 4,61pg/ml) verwendet, welches für den quantitativen Nachweis von TGF-ß1 in Zellkulturüberständen, Serum, Plasma und Urin vorgesehen ist. Nagatsu et al. sowie Rota et al. konnten in der Vergangenheit in experimentellen Studien durch Verwendung von Sandwich-Elisas allerdings bereits erhöhte Werte für TGF-ß1 im Liquor cerebrospinalis von Parkinsonerkrankungen nachweisen (Nagatsu et al. 2000, Rota et al. 2006). Um den Nachweis von TGF-ß1 im Rahmen der Standardkurve zu erreichen, wurden sämtliche Liquorproben im Verhältnis 1:2,125 verdünnt. Alle anderen Abläufe (Waschvorgang, Inkubationsdauer etc.) wurden gemäß der in der Anleitung gegebenen Empfehlung durchgeführt.

Das Prinzip der Bestimmung beruht in diesem Fall, wie in Kapitel 2.4.1.5 bereits ausführlich beschrieben, ebenfalls auf einem anwendungsbereiten Sandwich-ELISA mit vorbeschichteter Mikrotiterplatte (monoklonaler TGF-B1-AK) und Nachweis des gebundenen TGF-ß1 über einen enzymgekoppelten Antikörper (polyklonaler TGF-ß1AK), der nach Umsetzen eines zugegebenen Substrates einen Farbumschlag hervorruft. Auch hier wird die optische Dichte bei einer Wellenlänge von $450 \mathrm{~nm}$ massenspektrometrisch bestimmt. 


\subsubsection{Qualitative Bestimmung genetischer Marker aus Blutprodukten}

\subsubsection{Apo-E-Genotyp}

Die Bestimmung des Apo-E-Genotyps wurde in Zusammenarbeit mit der Abteilung der Klinischen Chemie der Universitätsklinik Göttingen unter der Leitung von Professor Ahsen durchgeführt.

Hierzu erfolgte zunächst die DNA-Extraktion aus zuvor bei -20 Grad Celsius asserviertem Vollblut unter Verwendung des "Qiamp DNA Blood Mini Kit" der Qiagen $\mathrm{GmbH}$. Nach Herstellerprotokoll umfasste die DNA-Extraktion vier Schritte, in denen $200 \mu \mathrm{l}$ Vollblut zunächst mit einer Protease und einem Puffer lysiert wurden, um später eine optimale Bindung der DNA an die "Qiamp-membran" zu ermöglichen. Schließlich erfolgte eine Überführung der Lösung in spezielle Säulen (QIAampSpinColumn), in denen die DNA nach einer Minute Zentrifugation bei $8000 \mathrm{rpm}$ an die enthaltene Membran gebunden wurde. Durch zweimaliges Waschen mit den Puffern AW1 und AW2 wurde die Entfernung residueller Bestandteile von der Membran erreicht. Die letztliche Eluierung der DNA von der Membran gelang durch Hinzugabe von $200 \mu$ l eines weiteren Puffers und die anschließende Zentrifugation für 1 Minute.

Die gewonnene DNA war zur sofortigen Weiterverwendung in der PCR geeignet, konnte aber auch bei -20 Grad Celcius gelagert werden.

Im Anschluss wurde die Apo-E-Genotypisierung anhand einer real-time Polymerasekettenreaktion (PCR) durchgeführt. Hierzu wurde das Instrument Lightcycler ${ }^{\circledR}$ der Firma Roche verwendet. Nach Amplifizierung des polymorphen Bereichs des Apo-EGens wurde das generierte DNA-Fragment aufgereinigt und mit einer spezifischen Restriktionsendonuklease gemischt. Die entstehenden Spaltprodukte konnten schließlich mittlels Gelelektrophorese getrennt und dokumentiert werden. Durch Sichten der typischen Bandenmuster war schließlich die gewünschte Zuordnung zum entsprechenden Genotyp möglich.

\subsubsection{Codon-129-Polymorphismus}

Auch die Aufschlüsselung des Codon 129-Polymorphismus erfolgte in der Abteilung Klinische Chemie der Universitätsmedizin Göttingen (UMG). Die genomische DNA wurde auch hier unter Verwendung des "Qiamp DNA Blood Mini Kit" aus Vollblut extrahiert, weshalb der Ablauf jenem in Kapitel 2.4.2.1 entspricht. Anschließend erfolgte 
mit Hilfe des Lightcycler ${ }^{\circledR}$ die Amplifikation des gesamten proteinkodierenden Teil des PrP-Gens mit Hilfe der Polymerasekettenreaktion (PCR), sodass eine direkte Sequenzierung der entstehenden DNA möglich war.

\subsection{Statistische Auswertung}

Zunächst erfolgte die deskriptive Evaluation und tabellarische oder graphische Aufarbeitung der gewonnenen Daten mit Hilfe eines unterstützenden Biometrikers der Abteilung Medizinische Statistik. Im Anschluss wurde ein statistischer Analyseplan erstellt, wobei zunächst die Leistungen der beobachteten Patientengruppen in der neuropsychologischen Testung sowie die Konzentrationen der beobachteten Liquormarker im Gruppen- und Paarvergleich auf Signifikanz geprüft wurden. Schlussendlich wurde versucht, anhand der Korrelation von Ergebnissen der neuropsychologischen Testung mit den bestimmten Liquormarkern eine Vorhersage zu deren Aussagekraft bezüglich der Entwicklung einer Demenz zu erlauben.

\subsubsection{Gruppenvergleiche}

Im Rahmen der Gruppenvergleiche erfolgte aufgrund der drei zu analysierenden Patientengruppen zunächst eine Varianzanalyse (ANOVA) als Globaltest auf statistisch signifikante Unterschiede zwischen AD, PD und PDD im Allgemeinen. Bei Nachweis eines signifikanten Unterschieds $(p<0,05)$ in der ANOVA-Testung wurden daraufhin Paarvergleiche anhand eines t-Tests durchgeführt. Um eine Kumulation des AlphaFehlers zu verhindern, wurde das Signifikanzniveau im Paarvergleich gemäß der Bonferroni-Methode angepasst, das heißt die annehmbare Irrtumswahrscheinlichkeit $\mathrm{P}(=5 \%)$ durch die Anzahl der betrachteten Gruppen bzw. durchgeführten t-Tests dividiert. Entsprechend ergab sich im Paarvergleich ein korrigiertes Signifikanzniveau von $p<0,016$. Hierzu wurden die Programme Statistica der Firma Statsoft ${ }^{\circledR}$ sowie SPSS-Statistics der Firma IBM ${ }^{\circledR}$ verwendet. 


\subsubsection{Korrelationen}

Mögliche Korrelationen wurden anhand von Scatterplots unter Berechnung des Pearson-Korrelationkoeffizienten ( $r$ ), der Signifikanz $(p)$ und des Bestimmtheitsmaß $\left(r^{2}\right)$ dargestellt. Hierfür wurde das Programm Statistika® verwendet.

\subsubsection{Tabellen und Graphiken}

Sämtliche weitere Tabellen und Graphiken, die nicht im Rahmen der Paarvergleiche und Korrelationen anhand des Programmes Statistika ${ }^{\circledR}$ entstanden sind, wurden mit Hilfe der Programme Microsoft ${ }^{\circledR}$ WORD und EXCEL erstellt. 


\section{ERGEBNISSE}

\subsection{Deskriptive Statistik}

\subsubsection{Patientenkollektiv}

In die Auswertung wurden nur jene Patienten übernommen, von denen nach sicherer Zuordnung zu einer der geforderten Diagnosen (PD, PDD, AD, DLB) die Ergebnisse aus der neuropsychologischen Testung und/oder gemessene Liquorwerte vorlagen. So zeigte sich ein in die Auswertung eingehendes Gesamtkollektiv von 89 Patienten, welches sich in die Diagnosen Morbus Parkinson $(n=15)$, Parkinson-DemenzKomplex ( $n=23)$, Morbus Alzheimer $(n=47)$ und Lewy-Körperchen-Demenz $(n=4)$ aufteilen ließ. Zusätzlich untersuchte 13 Patienten mit unklarem dementiellen Syndrom, die sich im Anschluss an die bereits erfolgte neuropsychologische Testung anhand geltender Diagnosekriterien keiner der untersuchten Krankheiten zuordnen ließen, wurden nicht weiter berücksichtigt. Auch die Ergebisse der Patienten mit der Diagnose Lewy-Körperchen-Demenz werden aufgrund der geringen Fallzahl nur in besonderen Fällen deskriptiv betrachtet und gehen nicht in die analytische Statistik ein.

Tabelle 1: Patientenkollektiv nach Diagnosen aufgelistet

\begin{tabular}{|l|c|}
\hline Diagnose & Anzahl untersuchter Patienten (n) \\
\hline PD & 15 \\
\hline PDD & 23 \\
\hline AD & 47 \\
\hline DLB & 4 \\
\hline Auswertung gesamt & 89 \\
\hline $\begin{array}{l}\text { dementielles Syn- } \\
\text { drom }\end{array}$ & 13 \\
\hline gesamt & 102 \\
\hline
\end{tabular}




\subsubsection{Alters- und Geschlechtsverteilung}

Die Altersverteilung zeigte über alle Diagnosegruppen einen Mittelwert (M) von 68,25 Jahren bei einer Standardabweichung (SD) von 10,95 Jahren. Die Aufschlüsselung des Alters nach Krankheitsgruppen ergab für PD einen Mittelwert von 65,25 Jahren $( \pm 9,22 \mathrm{SD})$, für PDD einen solchen von 68,36 Jahren $( \pm 12,48 \mathrm{SD})$ und für $\mathrm{AD}$ einen Mittelwert von 68,54 Jahren $( \pm 10,73)$. Bei der Aufteilung nach dem Geschlecht zeigte sich für PD und PDD ein deutlich erhöhter Männeranteil (75\% und 100\%), für AD hingegen ein erhöhter Frauenanteil (60\%). Für die vier untersuchten Patienten mit DLB bestand ein mittleres Alter von 75,5 Jahren $( \pm 5,26 \mathrm{SD})$, wobei drei Patienten männlich und eine Patientin weiblich waren. Gemittelt über alle Diagnosegruppen bestand ein Männeranteil von 58,5\% und ein entsprechender Frauenanteil von $41,5 \%$.

\section{Abbildung 5: Geschlechtsverteilung}

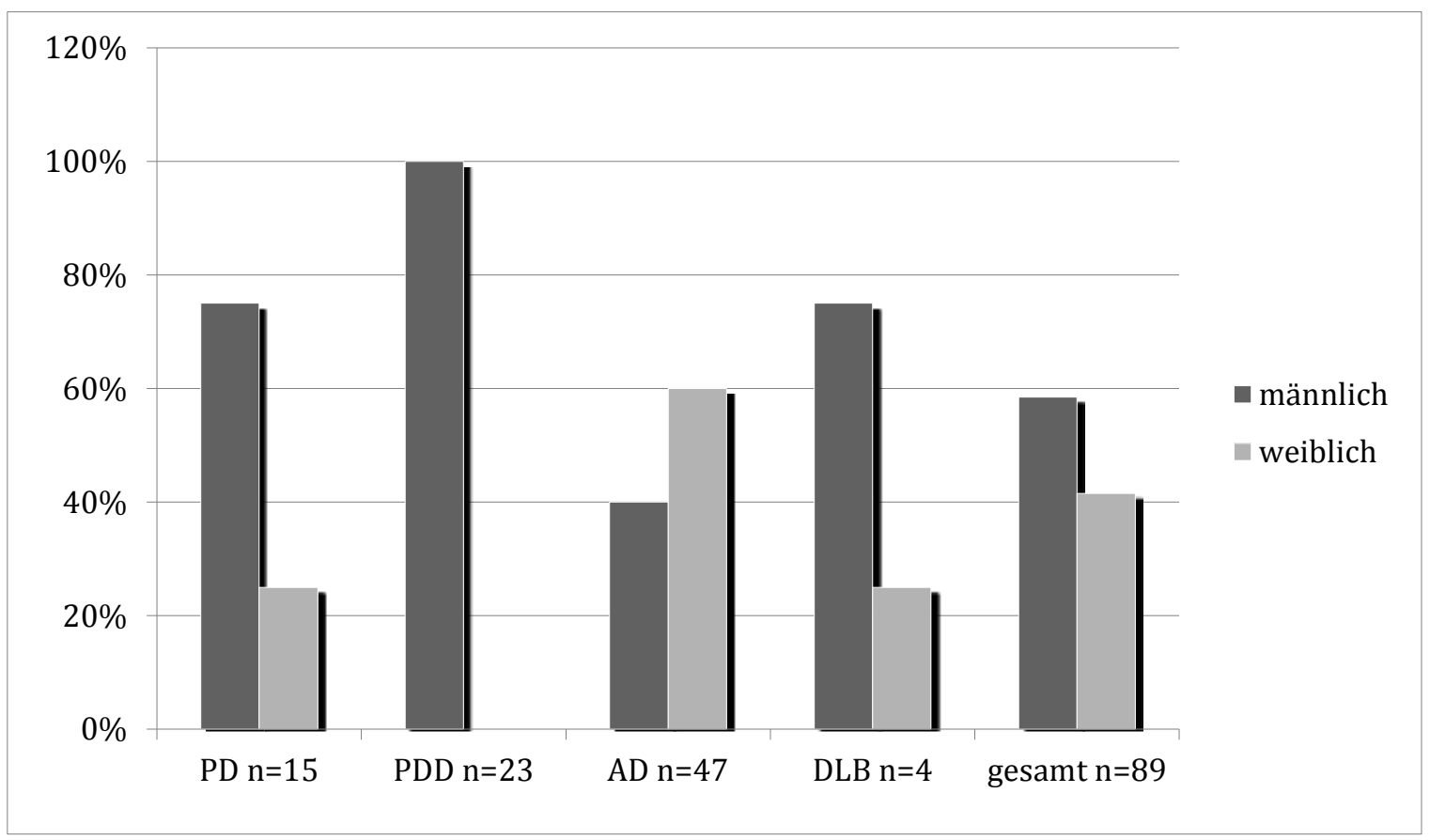

\subsubsection{Ausbildung}

Für all diejenigen Patienten, bei denen eine CERAD-Testbatterie angewendet werden konnte, wurden neben Alter und Geschlecht auch die Ausbildungsjahre, das heißt Jahre in Schul- und Berufsbildung vermerkt. 
Tabelle 2: Ausbildungzeit in Jahren

\begin{tabular}{|l|l|c|c|c|c|c|}
\hline \multicolumn{2}{|c|}{} & \multicolumn{6}{|c|}{ Diagnose } \\
\cline { 3 - 7 } \multicolumn{2}{|c|}{} & AD & PD & PDD & DLB & gesamt \\
\hline $\begin{array}{l}\text { Ausbildung } \\
\text { (nur ganze } \\
\text { Jahre) }\end{array}$ & Anzahl & 35 & 4 & 14 & 4 & 57 \\
\cline { 2 - 7 } & Mittelwert & 12 & 15 & 13 & 11 & 13 \\
\cline { 2 - 7 } & Standardabweichung & 3 & 2 & 3 & 3 & 3 \\
\hline
\end{tabular}

\subsubsection{Neuropsychologische Testung}

Für 57 Patienten lag die komplette CERAD-Testbatterie zur Auswertung vor, für weitere 17 ein Mini-Mental-Status-Test (MMSE). Die verbliebenen 15 Patienten ohne neuropsychologische Testung wurden aufgrund der vorliegenden Liquorwerte mit in die Auswertung übernommen.

Tabelle 3: Neuropsychologische Testungen nach Diagnosen

\begin{tabular}{|l|c|c|c|c|c|}
\hline & AD & PD & PDD & DLB & gesamt \\
\hline CERAD & $\mathrm{n}=35$ & $\mathrm{n}=4$ & $\mathrm{n}=14$ & $\mathrm{n}=4$ & $\mathrm{n}=57$ \\
\hline nur MMSE & $\mathrm{n}=0$ & $\mathrm{n}=9$ & $\mathrm{n}=8$ & $\mathrm{n}=0$ & $\mathrm{n}=15$ \\
\hline keine Testung & $\mathrm{n}=12$ & $\mathrm{n}=2$ & $\mathrm{n}=1$ & $\mathrm{n}=0$ \\
\hline gesamt & $\mathrm{n}=47$ & $\mathrm{n}=15$ & $\mathrm{n}=23$ & $\mathrm{n}=4$ & $\mathrm{n}=89$ \\
\hline
\end{tabular}

Die im Rahmen der neuropsychologischen Testung gewonnenen Rohdaten aus der CERADplus-Testbatterie wurden direkt im Anschluss an die Datenerhebung am Patienten mit Hilfe des CERADplus 1.0 Auswertungsprogrammes in sogenannte ZWerte umgewandelt. Diese geben die Leistungen des Probanden im Vergleich zu einer gesunden Vergleichsperson gleichen Alters, Geschlechts und Bildungsstands an. So bedeutet ein Z-Wert von Null, dass die untersuchte Person identische kogniti- 
ve Leistungen im Vergleich zum gesunden Vergleichskollektiv aufweist. Ein Z-Wert von -1 besagt, dass der Skalenwert eine Standardabweichung unter dem Mittelwert der Normstichprobe liegt. Je negativer der Z-Wert ist, desto geringer ist der prozentuale Anteil der Personen aus der Normstichprobe, die sich noch unterhalb dieses Wertes befinden. So liegen bei einem Z-Wert von -1 noch 16\% der Personen der Normstichprobe darunter, bei -2 nur noch $2 \%$ und bei -3 praktisch keine mehr. Die Normstichprobe der CERADplus-Testbatterie wurde für den deutschsprachigen Raum an 1100 gesunden Probanden an der Memoryclinic Basel validiert.

Die in dieser Studie beobachteten Z-Werte variierten ohne Berücksichtigung von Diagnose und Testbereich zwischen -8,8 und +3. Im Folgenden wurden Mittelwerte und Standardabweichungen für jeden Z-Wert der elf CERAD-Haupttests (und die Subtests der Testbereiche Wortliste Abrufen, Figuren Abrufen sowie den errechneten Wert Trailmaking B/A) getrennt nach Diagnosen berechnet und in der Reihenfolge ihrer Anwendung tabellarisch aufgearbeitet. Die Testergebnisse der Patienten mit DLB sind nicht aufgeführt, wurden allerdings zum Vergleich der Ausfallprofile in die Netzdiagramme (Abbildung 6 und 7) übernommen.

Tabelle 4: Leistungen (Z-Werte) in der CERADplus-Testbatterie inkl. der MMSE Einzeltestung nach Diagnosen

\begin{tabular}{|l|l|c|c|c|c|}
\hline \multirow{2}{*}{\multicolumn{2}{|c|}{}} & \multicolumn{4}{c|}{ Diagnose } \\
\cline { 3 - 6 } & & AD & PD & PDD & gesamt \\
\hline \multirow{3}{*}{$\begin{array}{l}\text { 1.Semantische Flüssig- } \\
\text { keit }\end{array}$} & gültige N & 35,00 & 4,00 & 14,00 & 53,00 \\
\cline { 2 - 6 } & Mittelwert & $-2,19$ & $-0,15$ & $-1,62$ & $-1,88$ \\
\cline { 2 - 6 } & Standardabweichung & 1,01 & 0,52 & 1,27 & 1,18 \\
\hline \multirow{3}{*}{ 2.Boston Naming Test } & gültige N & 34,00 & 4,00 & 14,00 & 52,00 \\
\cline { 2 - 6 } & Mittelwert & $-1,35$ & 0,45 & $-1,43$ & $-1,23$ \\
\cline { 2 - 6 } & Standardabweichung & 1,42 & 0,58 & 1,81 & 1,55 \\
\hline \multirow{3}{*}{ 3.MmS } & gültige N & 35,00 & 13,00 & 22,00 & 70,00 \\
\cline { 2 - 6 } & Mittelwert & $-4,28$ & $-0,65$ & $-3,57$ & $-3,38$ \\
\cline { 2 - 6 } & Standardabweichung & 2,29 & 0,90 & 2,45 & 2,53 \\
\hline \multirow{3}{*}{ 4.Wortliste Lernen } & gültige N & 35,00 & 4,00 & 14,00 & 53,00 \\
\cline { 2 - 6 } & Mittelwert & $-3,22$ & 0,15 & $-2,32$ & $-2,73$ \\
\cline { 2 - 6 } & Standardabweichung & 2,12 & 0,53 & 2,24 & 2,25 \\
\hline \multirow{3}{*}{ 5.Figuren Abzeichnen } & gültige N & 35,00 & 4,00 & 13,00 & 52,00 \\
\cline { 2 - 6 } & Mittelwert & $-2,16$ & 0,23 & $-1,95$ & $-1,93$ \\
\cline { 2 - 6 } & Standardabweichung & 2,16 & 0,90 & 2,62 & 2,27 \\
\hline \multirow{3}{*}{ 6.Wortliste Abrufen } & gültige N & 35,00 & 4,00 & 13,00 & 52,00 \\
\cline { 2 - 6 } & Mittelwert & $-2,34$ & $-0,48$ & $-1,24$ & $-1,92$ \\
\cline { 2 - 6 } & Standardabweichung & 1,39 & 0,29 & 1,51 & 1,49 \\
\hline
\end{tabular}




\begin{tabular}{|c|c|c|c|c|c|}
\hline & & \multicolumn{4}{|c|}{ Diagnose } \\
\hline & & $A D$ & PD & PDD & gesamt \\
\hline \multirow{3}{*}{6.1 Introsionen } & gültige N & 35,00 & 4,00 & 14,00 & 53,00 \\
\hline & Mittelwert & $-0,86$ & $-0,55$ & $-0,90$ & $-0,85$ \\
\hline & Standardabweichung & 1,36 & 0,89 & 1,22 & 1,28 \\
\hline \multirow{3}{*}{6.2 Savings } & gültige N & 34,00 & 4,00 & 13,00 & 51,00 \\
\hline & \begin{tabular}{|l} 
Mittelwert \\
\end{tabular} & $-1,92$ & $-0,48$ & $-1,04$ & $-1,58$ \\
\hline & Standardabweichung & 1,81 & 0,45 & 2,81 & 2,08 \\
\hline \multirow{3}{*}{$\begin{array}{l}\text { 7. Wortliste Wiederer- } \\
\text { kennen (Diskriminabili- } \\
\text { tät) }\end{array}$} & gültige $\mathrm{N}$ & 34,00 & 4,00 & 13,00 & 51,00 \\
\hline & Mittelwert & $-2,45$ & $-0,73$ & $-1,02$ & $-1,95$ \\
\hline & Standardabweichung & 1,35 & 1,07 & 1,46 & 1,51 \\
\hline \multirow{3}{*}{ 8. Figuren Abrufen } & gültige N & 35,00 & 4,00 & 13,00 & 52,00 \\
\hline & Mittelwert & $-2,62$ & 0,18 & $-1,75$ & $-2,19$ \\
\hline & Standardabweichung & 1,49 & 1,37 & 2,40 & 1,89 \\
\hline \multirow{3}{*}{ 8.1 Savings } & gültige $\mathrm{N}$ & 33,00 & 4,00 & 12,00 & 49,00 \\
\hline & Mittelwert & $-1,98$ & 0,00 & $-0,79$ & $-1,52$ \\
\hline & Standardabweichung & 1,26 & 0,88 & 1,62 & 1,47 \\
\hline \multirow{3}{*}{$\begin{array}{l}\text { 9. Phonematische Flüs- } \\
\text { sigkeit }\end{array}$} & gültige N & 31,00 & 4,00 & 13,00 & 48,00 \\
\hline & Mittelwert & $-1,55$ & 1,13 & $-0,95$ & $-1,16$ \\
\hline & Standardabweichung & 1,25 & 0,61 & 1,41 & 1,44 \\
\hline \multirow{3}{*}{ 10. Trailmaking A } & gültige $\mathrm{N}$ & 32,00 & 4,00 & 13,00 & 49,00 \\
\hline & Mittelwert & $-2,18$ & $-0,25$ & $-2,08$ & $-1,99$ \\
\hline & Standardabweichung & 1,62 & 0,37 & 1,20 & 1,53 \\
\hline \multirow{3}{*}{ 11. Trailmaking B } & gültige $\mathrm{N}$ & 30,00 & 4,00 & 12,00 & 46,00 \\
\hline & Mittelwert & $-2,01$ & $-0,53$ & $-2,18$ & $-1,92$ \\
\hline & Standardabweichung & 0,91 & 0,49 & 0,93 & 0,98 \\
\hline \multirow{3}{*}{ 11.1 Trailmaking B/A } & gültige $\mathrm{N}$ & 29,00 & 4,00 & 12,00 & 45,00 \\
\hline & \begin{tabular}{|l} 
Mittelwert \\
\end{tabular} & 0,13 & $-0,38$ & $-0,40$ & $-0,05$ \\
\hline & Standardabweichung & 1,38 & 0,25 & 1,34 & 1,32 \\
\hline
\end{tabular}

Zur Veranschaulichung der kognitiven Ausfallprofile erfolgte eine Darstellung der mittleren Z-Werte anhand eines Netzdiagramms. Dabei ist erkennbar, dass sich die Leistungsprofile der drei mit dementieller Entwicklung einhergehenden Krankheitsbilder von der Form her in vielen Bereichen ähneln und vor allem durch das Ausmaß der kognitiven Beeinträchtigungen unterscheiden. Das Leistungsprofil der Patienten mit PD setzt sich erwartungsgemäß deutlich ab und entspricht für den Großteil der Testbereiche mit Z-Werten um Null jenem der Normstichprobe.

Deutlichste Leistungsunterscheide zwischen AD und PDD bestehen in den Testbereichen Wortliste Lernen, Wortliste Abrufen, Wortliste Savings, Wortliste Diskriminabilität, Figuren Abrufen und Figuren Savings. Des Weiteren fällt auf, dass sich die ZWerte für PDD in den Testbereichen Wortliste Intrusionen, Wortliste Savings und 
Wortliste Diskriminabilität kaum von denen bei PD unterscheiden. Für die im zweiten Netzdiagramm angegebenen Tests gelten ähnliche Bedingungen, wobei eine Unterscheidung zwischen PDD und AD anhand der beinahe kongruenten Leistungsprofile nur schwer möglich erscheint. Die Testleistungen der untersuchten DLB-Patienten sind zum Vergleich ebenfalls angegeben und bestechen durch besonders unterdurchschnittliche Ergebnisse im Bereich Wortliste Lernen. Ansonsten zeigt sich ein Profil, dessen Verlauf ein Mischbild aus denjenigen von AD und PDD darstellt.

Der Versuch einer Einordnung der Demenzen zu einem typischen Ausfallprofil, das heißt Detektion eines primären Speicherdefizits (kortikale Demenz) oder Abrufdefizits (subkortikale Demenz) könnte anhand der Leistungsunterschiede in den Tests Wortliste Abrufen und Wortliste Wiedererkennen (Dikriminabilität) möglich sein. So zeigen sich für Morbus Alzheimer ähnlich schlechte Leistungen in beiden Testbereichen (ZWerte -2,34 zu -2,45), für Demenz bei Morbus Parkinson (Z-Werte -1,24 zu -1,02) und DLB (Z-Werte -1,95 zu -1,00) hingegen bessere Leistungen im Testteil Diskriminabilität. Signifikante Gruppen- und Paarvergleiche werden in Kapitel 3.2 näher erläutert.

Abbildung 6: Kognitive Ausfallprofile 1

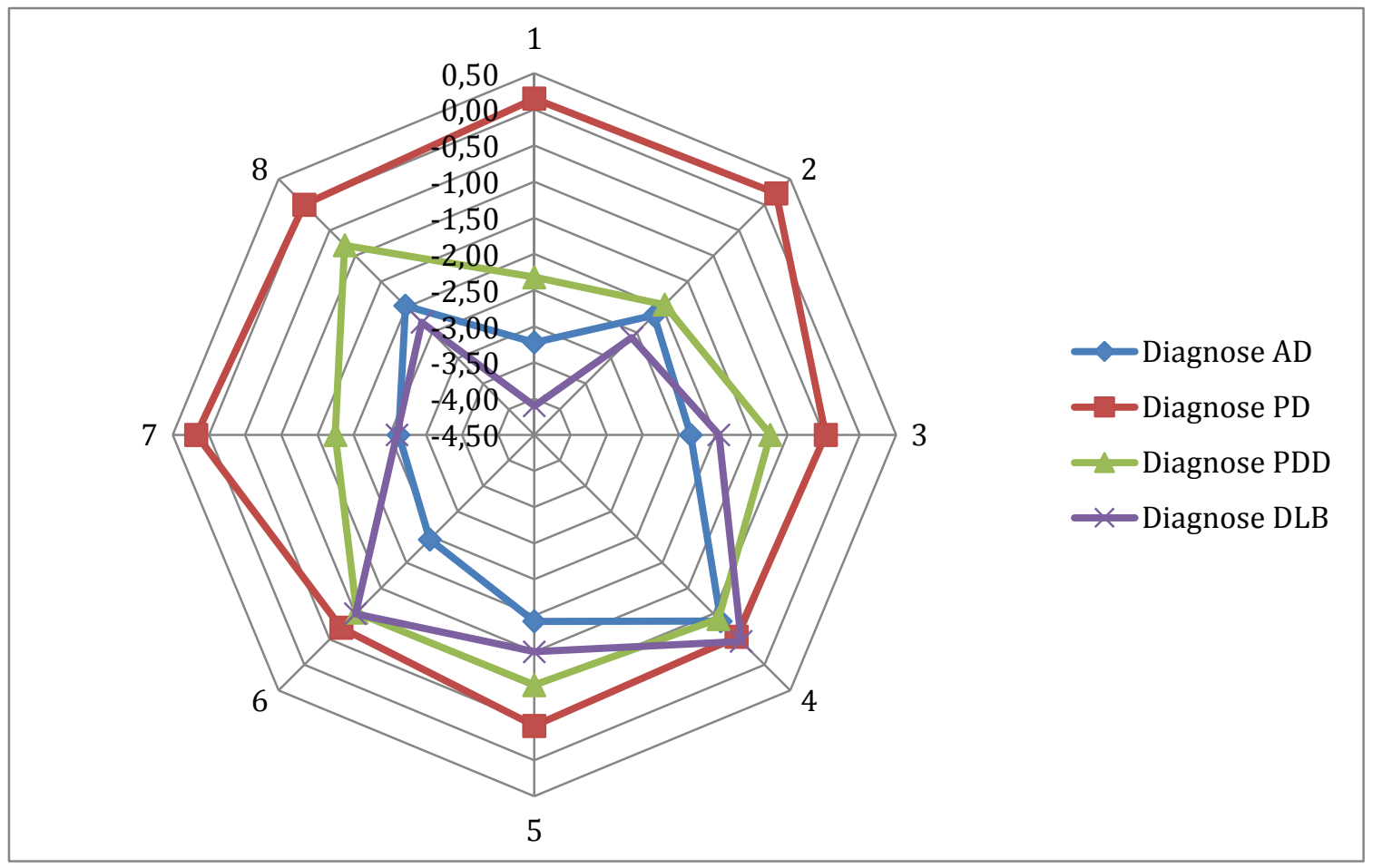

1: Wortliste Lernen, 2: Figuren Abzeichnen, 3: Wortliste Abrufen, 4: Wortliste Intrusionen, 5: Wortliste Savings, 6: Wortliste Diskriminabilität, 7: Figuren Abrufen, 8: Figuren Savings 
Abbildung 7: Kognitive Ausfallprofile 2

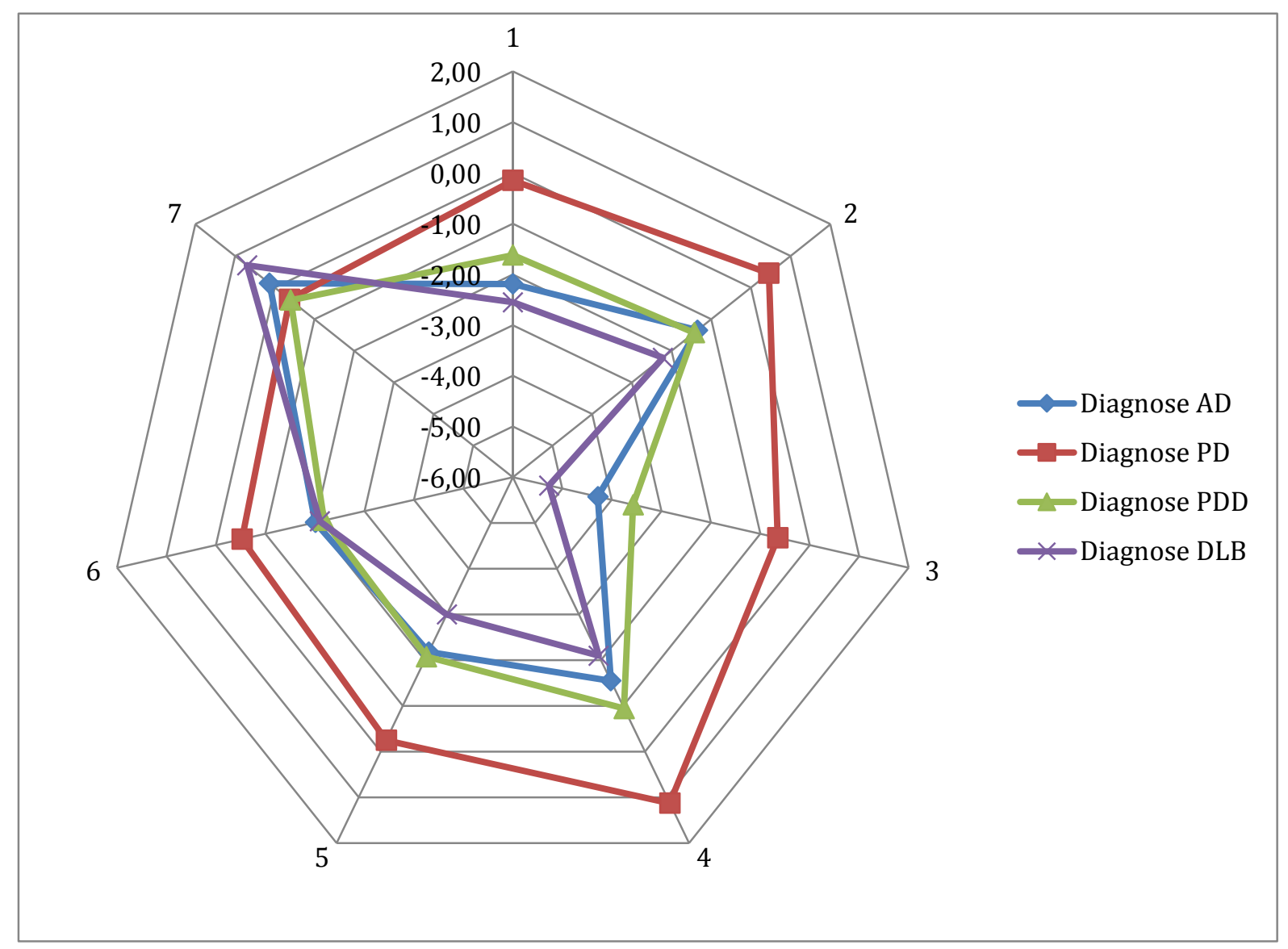

1: Semantische Flüssigkeit, 2: Boston Naming Test, 3: Mini-mental-status-examination, 4: Phonematische Flüssigkeit, 5: Trailmaking A, 6: Trailmaking B, 7: Trailmaking B/A

\subsubsection{Liquormarker}

Die durchschnittlichen Konzentrationen im Liquor für Homocystein, Apolipoprotein E, TGF-B1, VDBP, Tau-Protein, p-Tau und Abeta1-42 wurden getrennt nach Diagnosen berechnet. Alle Werte sind als Mittelwert $( \pm$ SD) sowie Median mit $25 \mathrm{er}$ und $75 \mathrm{er}$ Perzentil aufgeführt.

Tabelle 5: Konzentration der Liquormarker nach Diagnosen

\begin{tabular}{|l|l|c|c|c|c|}
\hline \multicolumn{2}{|c|}{} & \multicolumn{4}{c|}{ Diagnose } \\
\cline { 3 - 6 } \multicolumn{2}{|c|}{} & AD & PD & PDD & gesamt \\
\hline \multirow{4}{*}{$\begin{array}{l}\text { Homocystein } \\
(\mu \mathrm{mol} / L)\end{array}$} & gültige N & 41,00 & 13,00 & 18,00 & 72,00 \\
\cline { 2 - 6 } & Mittelwert & 9,34 & 11,22 & 11,68 & 10,26 \\
\cline { 2 - 6 } & Standardabweichung & 3,67 & 2,04 & 1,25 & 3,14 \\
\cline { 2 - 6 } & Perzentil 25 & 6,80 & 9,80 & 10,30 & 9,15 \\
\cline { 2 - 6 } & Median & 10,30 & 12,00 & 11,75 & 10,85 \\
\cline { 2 - 6 } & Perzentil 75 & 11,40 & 12,40 & 12,70 & 12,35 \\
\hline
\end{tabular}




\begin{tabular}{|c|c|c|c|c|c|}
\hline & & \multicolumn{4}{|c|}{ Diagnose } \\
\hline & & $A D$ & PD & PDD & gesamt \\
\hline \multirow{6}{*}{ Apo E ( $\mu g / m l)$} & gültige N & 43,00 & 13,00 & 20,00 & 76,00 \\
\hline & Mittelwert & 2,42 & 3,93 & 3,47 & 2,95 \\
\hline & Standardabweichung & 0,97 & 0,69 & 0,86 & 1,09 \\
\hline & Perzentil 25 & 1,78 & 4,00 & 2,87 & 2,16 \\
\hline & Median & 2,35 & 4,14 & 3,50 & 2,74 \\
\hline & \begin{tabular}{|l|} 
Perzentil 75 \\
\end{tabular} & 2,81 & 4,31 & 4,14 & 3,97 \\
\hline \multirow{6}{*}{ TGF-beta $1(p g / m l)$} & gültige N & 41,00 & 12,00 & 20,00 & 73,00 \\
\hline & Mittelwert & 213,03 & 192,33 & 151,46 & 192,76 \\
\hline & Standardabweichung & 412,84 & 165,04 & 68,74 & 317,50 \\
\hline & Perzentil 25 & 93,50 & 112,80 & 104,30 & 101,20 \\
\hline & Median & 130,20 & 124,95 & 126,45 & 128,60 \\
\hline & Perzentil 75 & 180,50 & 182,95 & 196,50 & 181,90 \\
\hline \multirow{6}{*}{$\operatorname{VDBP}(\mu g / m l)$} & gültige $\mathrm{N}$ & 45,00 & 13,00 & 20,00 & 78,00 \\
\hline & Mittelwert & 1,62 & 1,78 & 1,42 & 1,60 \\
\hline & Standardabweichung & 1,34 & 1,37 & 1,00 & 1,26 \\
\hline & Perzentil 25 & 0,62 & 1,08 & 0,55 & 0,75 \\
\hline & Median & 1,37 & 1,17 & 1,33 & 1,33 \\
\hline & Perzentil 75 & 2,08 & 1,92 & 1,84 & 1,92 \\
\hline \multirow{6}{*}{ Tau (pg/ml) } & gültige $\mathrm{N}$ & 39,00 & 10,00 & 18,00 & 67,00 \\
\hline & Mittelwert & 451,79 & 249,90 & 215,28 & 358,12 \\
\hline & Standardabweichung & 268,92 & 152,13 & 114,47 & 246,36 \\
\hline & \begin{tabular}{|l|} 
Perzentil 25 \\
\end{tabular} & 230,00 & 121,00 & 125,00 & 180,00 \\
\hline & Median & 364,00 & 191,00 & 178,50 & 271,00 \\
\hline & Perzentil 75 & 670,00 & 382,00 & 231,00 & 464,00 \\
\hline \multirow{6}{*}{ P-Tau $(p g / m l)$} & gültige $\mathrm{N}$ & 37,00 & 11,00 & 18,00 & 66,00 \\
\hline & \begin{tabular}{|l} 
Mittelwert \\
\end{tabular} & 81,84 & 53,73 & 50,89 & 68,71 \\
\hline & Standardabweichung & 33,12 & 29,03 & 24,06 & 33,36 \\
\hline & Perzentil 25 & 62,00 & 29,00 & 39,00 & 44,00 \\
\hline & Median & 73,00 & 48,00 & 44,50 & 64,00 \\
\hline & Perzentil 75 & 95,00 & 73,00 & 55,00 & 83,00 \\
\hline \multirow{6}{*}{$A B 1-42(p g / m l)$} & \begin{tabular}{|l|} 
gültige $\mathrm{N}$ \\
\end{tabular} & 39,00 & 12,00 & 19,00 & 70,00 \\
\hline & \begin{tabular}{|l|} 
Mittelwert \\
\end{tabular} & 494,74 & 691,00 & 718,58 & 589,14 \\
\hline & Standardabweichung & 279,93 & 376,53 & 207,58 & 297,41 \\
\hline & Perzentil 25 & 318,00 & 402,50 & 600,00 & 365,00 \\
\hline & Median & 434,00 & 641,00 & 655,00 & 504,00 \\
\hline & Perzentil 75 & 555,00 & 802,50 & 906,00 & 672,00 \\
\hline
\end{tabular}

Für die Patienten mit der Diagnose DLB lagen lediglich Liquorkonzentrationen für Tau-Protein, Phospho-Tau und Amyloid-beta1-42 vor. Sie sind aufgrund der geringen Fallzahl nur zum Vergleich in die unten angegebene Abbildung eingearbeitet worden, in welcher die differierenden Konzentrationen aller drei Liquormarker anschaulich dargestellt sind. Die bereits hier ersichtlichen Gruppen- und Paarunterschiede, die 
aller Voraussicht nach vor allem eine Abgrenzung von AD zu PD, PDD und DLB möglich machen werden, werden in Kapitel 3.2 näher beschrieben und auf eine mögliche statistische Signifikanz geprüft.

Abbildung 8: Liquorkonzentrationen von Tau, P-Tau und AB im Vergleich

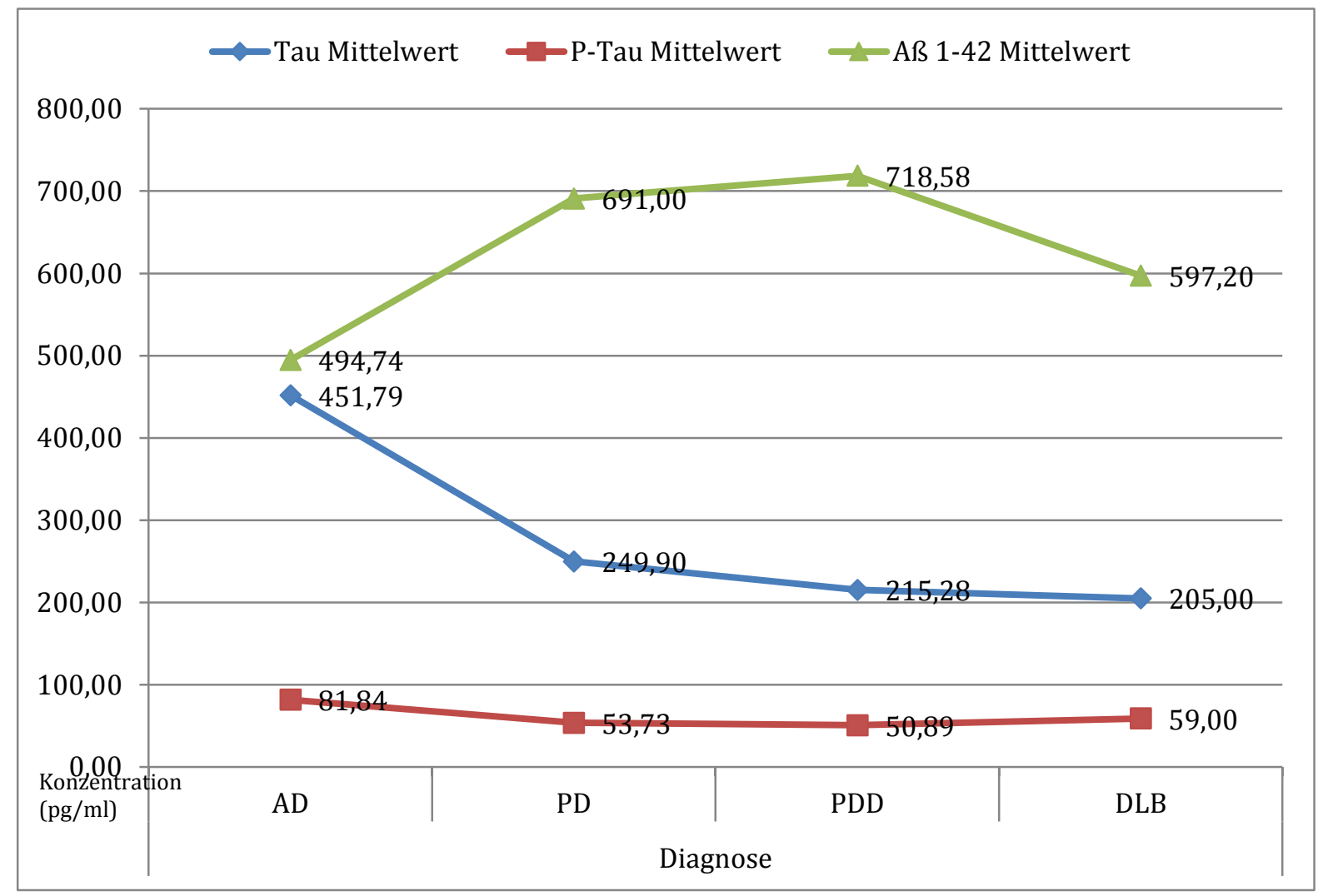

\subsubsection{Genetische Marker}

Zusätzlich zu den Liquormarkern wurden die genetischen Marker Apo E-Genotyp und Codon-129 des Prionprotein-Gens bei allen Patienten bestimmt, bei denen nach neuropsychologischer Testung die Erlaubnis zur Blutentnahme und zur anschließenden genetischen Analyse gegeben war. Hierbei zeigte sich für den ApoE-Genotyp in allen drei Krankheitsgruppen ein Überwiegen der Allelkombination E3/E3 (12 von 16 Patienten), das mit neurodegenerativen Erkrankungen in Verbindung gebrachte Allel E4 trat in Form einer E3/E4-Heterozygotie insgesamt nur bei 3 Patienten auf, wovon zwei an PDD und einer ein AD erkrankt waren. 


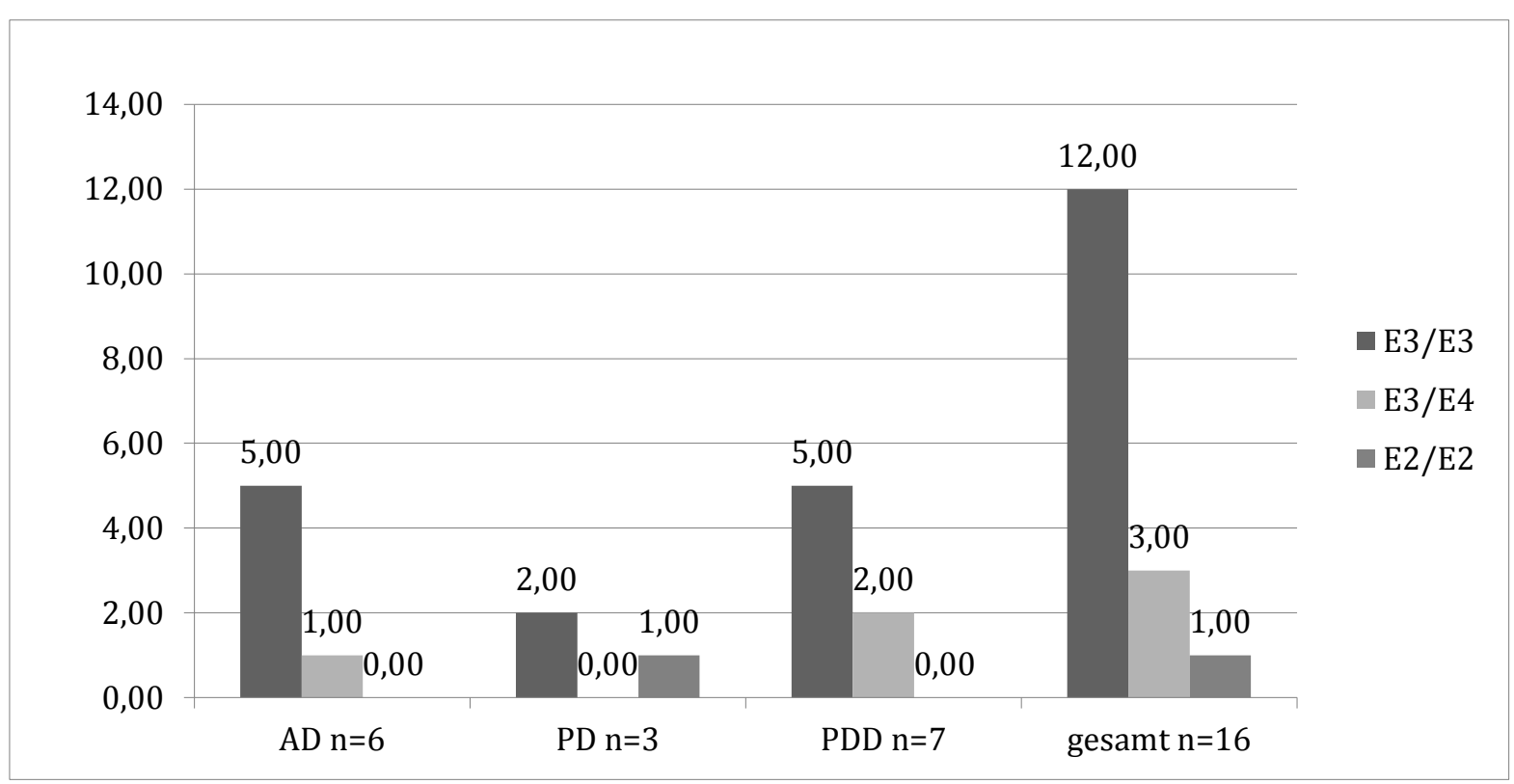

Bei Betrachtung der Allelkombinationen für das Prionprotein-Gen konnte ein Überwiegen des Methionin-Allels als Homo- (M/M) oder Heterozygotie $(M / V)$ in allen drei neurodegenerativen Erkrankungen beobachtet werden. Im Vergleich zur Allelverteilung in der Normalbevölkerung ( $37 \% \mathrm{MM}, 51 \% \mathrm{MV}, 12 \% \mathrm{VV}$ ) fällt vor allem für PDD eine Häufung einer Methionin-Homozygotie auf.

\section{Abbildung 10: Absolute Verteilung der Allelkombination für Codon 129 nach Diagnosen}

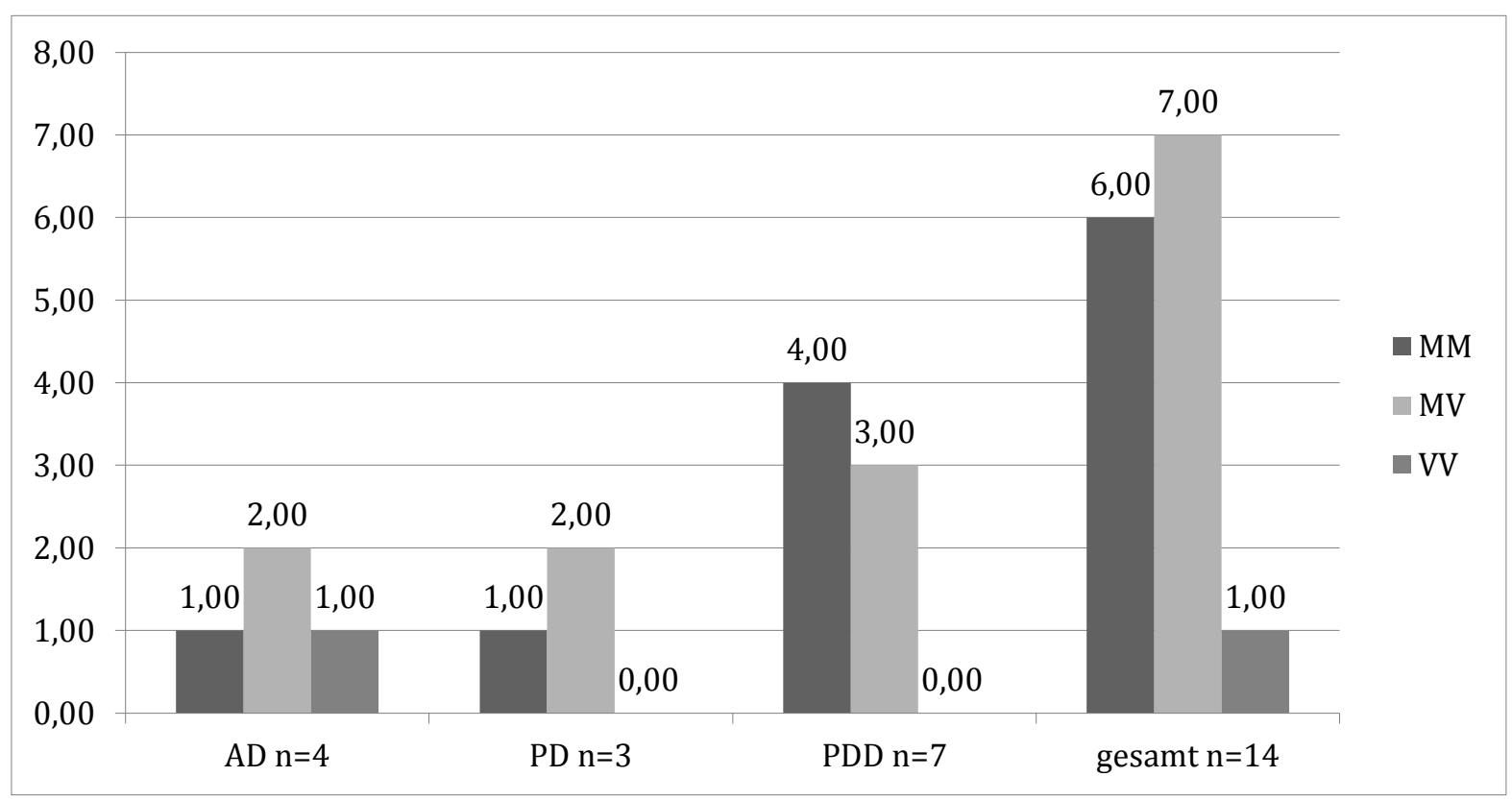




\subsection{Analytische Statistik}

\subsubsection{Gruppenvergleiche}

\subsubsection{Alter}

Bezüglich des Alters bestanden im Globaltest zwischen den Patientengruppen keine signifikanten Unterschiede ( $p=0,85$, ANOVA).

\subsubsection{Ausbildung}

Auch in Bezug auf die Ausbildung, das heißt Dauer der Jahre in Schul- und erster Berufsausbildung, konnten keine signifikanten Unterschiede festgestellt werden ( $p=0,11, A N O V A)$, obwohl in der graphischen Darstellung eine Tendenz zu weniger Ausbildungsjahren bei Krankheiten mit Demenz, also AD und PDD, ersichtlich ist.

\section{Abbildung 11: Mittelwert und 95\%-Konfidenzintervall Ausbildung}

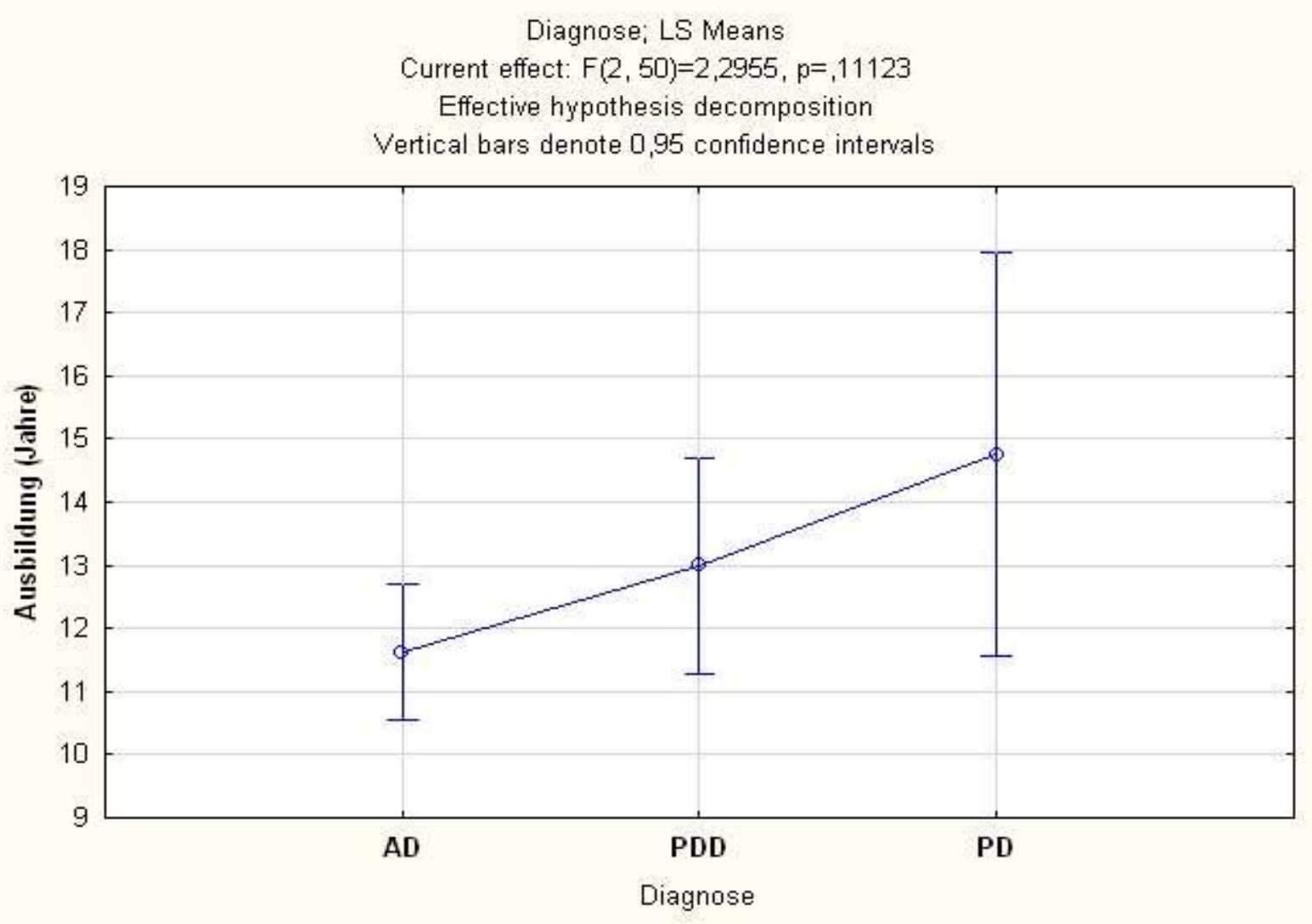




\subsubsection{Neuropsychologische Testung}

Für neun der insgesamt 15 Testbereiche (inklusive Subtests) der CERADTestbatterie konnten signifikante Unterschiede im Gruppenvergleich detektiert werden.

Im Bereich Semantische Flüssigkeit (Nennen von möglichst vielen Tieren innerhalb einer Minute) zeigte sich in der Varianzanalyse ein signifikanter Unterschied der kognitiven Leistungen ( $p=0,0018$, ANOVA) mit deutlich besserem Abschneiden der PDPatienten im Gegensatz zu PDD und AD. Im Paarvergleich konnte jene Signifikanz sowohl für $A D$ vs. PD ( $p=0,00058$, t-Test) und PDD vs. PD ( $p=0,00043$, t-Test) bestätigt werden. Zwischen AD und PDD ( $p=0,15$, $t$-Test) bestanden bei dezent besseren Leistungen der PDD-Patienten keine signifikanten Unterschiede.

\section{Abbildung 12: Mittelwert und 95\%-Konfidenzintervall Semantische Flüssigkeit}

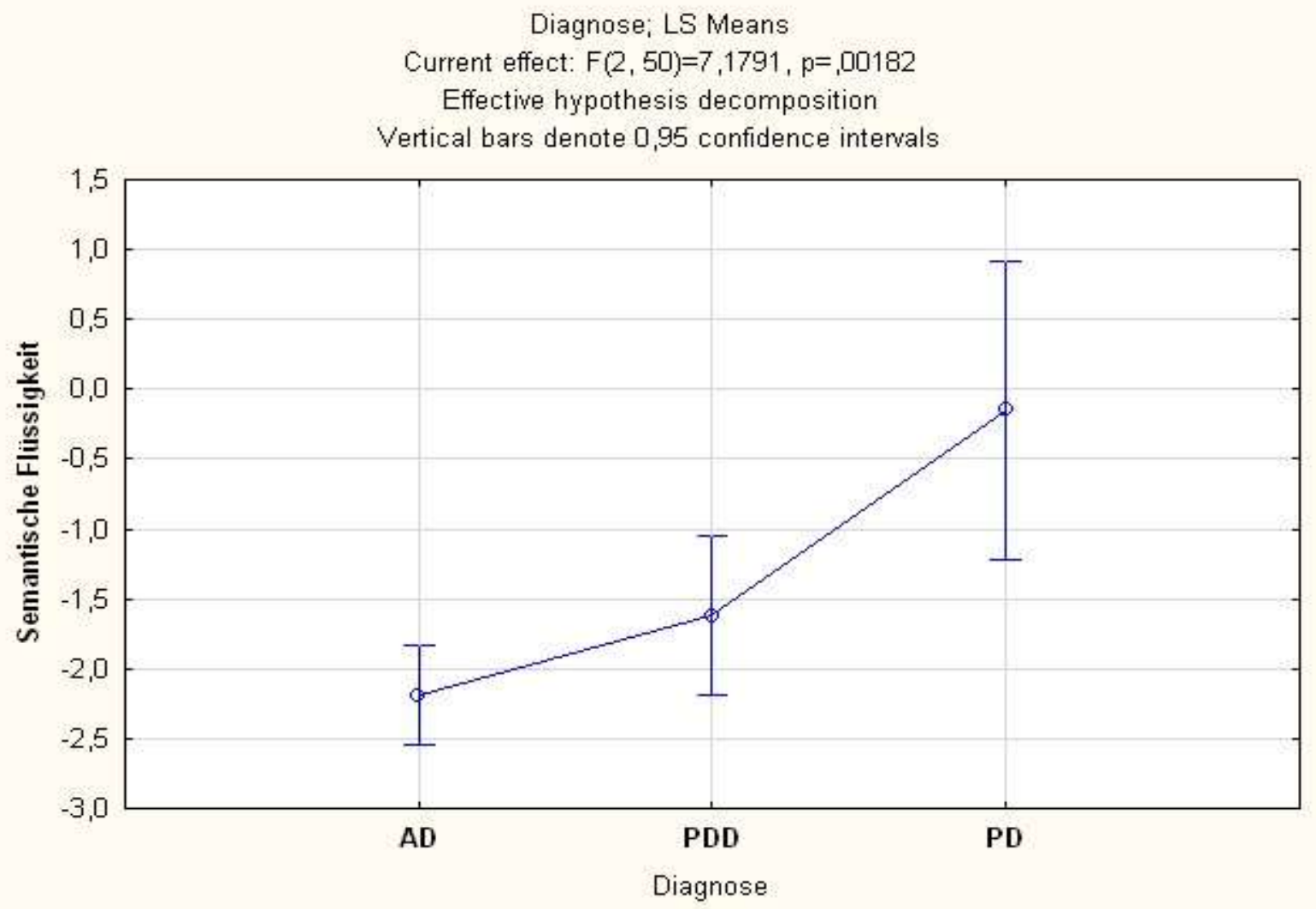

Für den Test Phonematische Flüssigkeit sollten die Patienten innerhalb einer Minute möglichst viele Begriffe nennen, die mit einem zuvor vorgegebenen Buchstaben begannen. Hier konnte eine signifikant bessere und über der Normstichprobe liegende Leistung der Patienten mit PD gegenüber jenen mit PDD ( $p=0,0011$, $t$-Test) und $A D$ 
( $p=0,0002$, t-Test) gefunden werden. Die Unterschiede zwischen PD und AD waren analog zu jenen im Testteil Semantische Flüssigkeit nicht signifikant $(p=0,1938$, $t$ Test).

\section{Abbildung 13: Mittelwert und 95\%-Konfidenzintervall Phonematische Flüssigkeit}

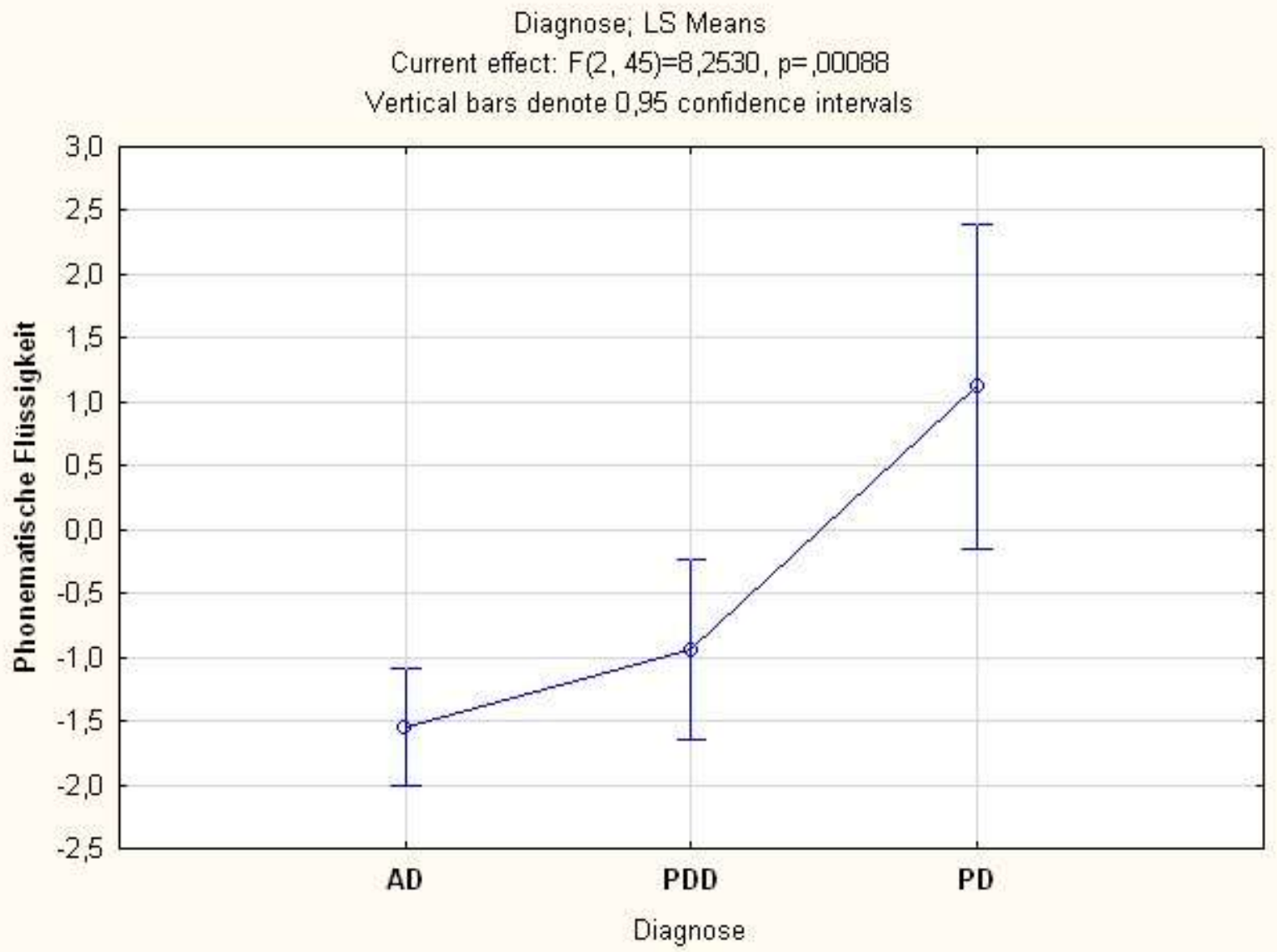

Für den Gruppen- und Paarvergleich des in der Klinik bewährten und zur Beurteilung einer Demenz sehr häufig genutzten MMSE-Test stand für Patienten mit PD und PDD eine größere Fallzahl von $n=13$ (PD) bzw. $n=22$ (PDD) zur Verfügung. Hier konnte sowohl im Gruppenvergleich ( $p=0,00001$, ANOVA) als auch im Paarvergleich zwischen AD und PD ( $p=0,00058$, t-Test) sowie PDD und PD ( $p=0,0043$, t-Test) ein Unterschied mit Signifikanz nachgewiesen werden. Bei Betrachtung der Leistungen von $A D$ und PDD zeigte sich ein tendenziell besseres Abschneiden der PDDPatienten ohne statistische Signifikanz. Bezüglich der Testergebnisse der per Definition nicht kognitiv eingeschränkten Gruppe mit reinem Parkinson (PD) bestand bei einem mittleren Z-Wert von -0,64 eine schlechtere Leistung gegenüber der gesunden Normstichprobe. 


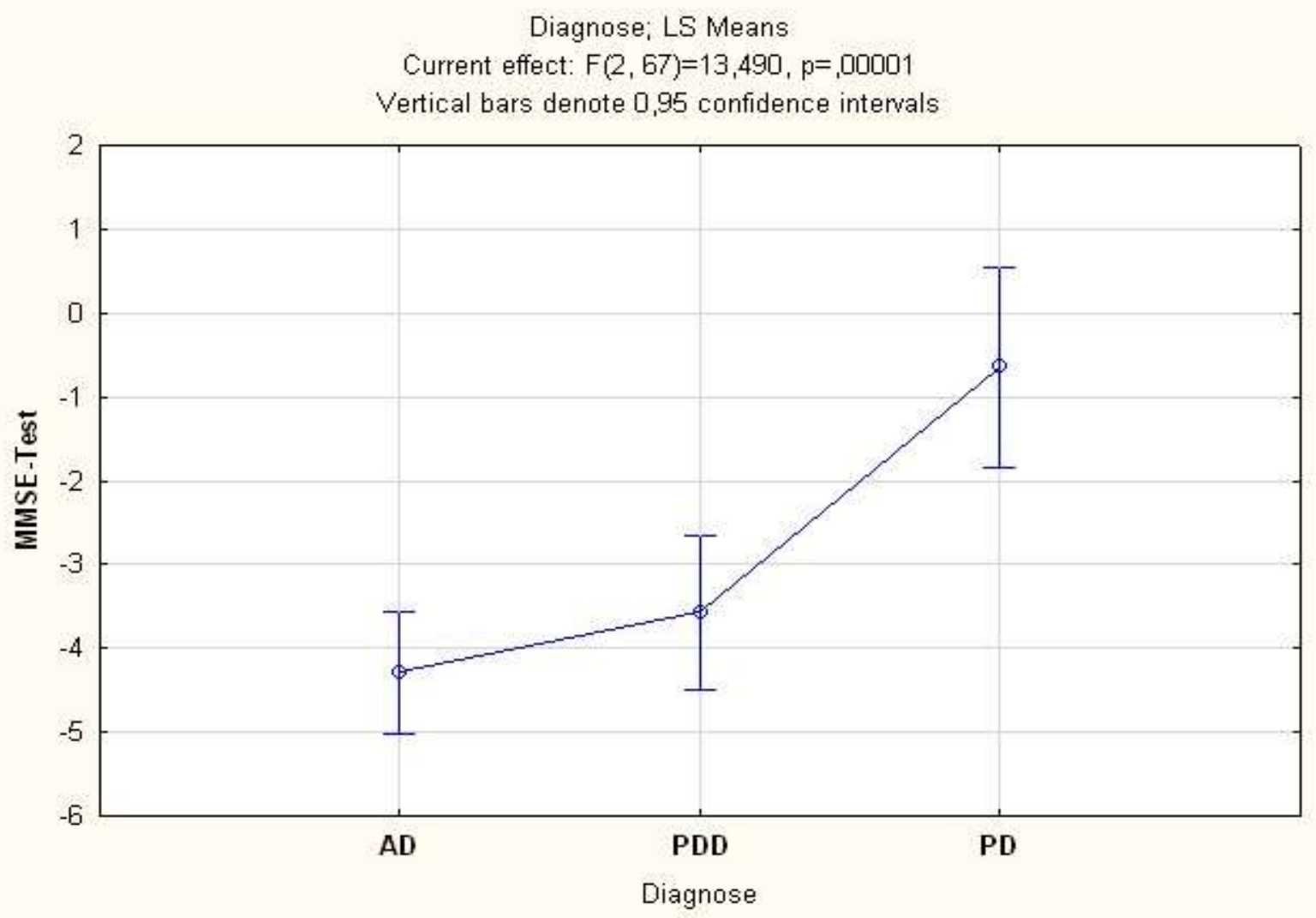

Der Test Wortliste Lernen, in dem 10 vorgegebene Wörter in drei Durchgängen zunächst erlernt und sofort erinnert werden müssen, prüft die Fähigkeit, neue, nicht assoziierte verbale Information zu erlernen. Auch hier zeigten sich erneut signifikante Unterschiede zwischen dementiellen und nicht dementiellen Erkrankungen ( $p=0,0000$ für $A D$ vs. $P D, p=0,0016$ für $P D D$ vs. $P D$ ). Ein signifikanter Unterschied im Paarvergleich zwischen AD und PDD konnte allerdings nicht detektiert werden.

In einem Folgetest mussten zuvor erlernte Wörter nach zeitlicher Latenz erneut erinnert werden (Wortliste Abrufen) um das verbale episodische Gedächtnis und dessen Speicherfähigkeit zu prüfen. Dabei fälschlicherweise als gelernt wiedergegebene Wörter wurden als Intrusionen bezeichnet und ebenfalls in Z-Werte konvertiert. Der Begriff Savings gibt das Verhältnis aus gelernten Wörtern im ersten Durchgang zu im verzögerten Abruf erinnerten Wörtern an.

Für den Teilbereich Wortliste Abrufen bestand ein signifikanter Unterschied sowohl im Gruppen- ( $p=0,0075$, ANOVA) als auch im Paarvergleich. Dabei zeigte sich ein erwartungsgemäß signifikant besseres Abschneiden der PD-Patienten im Vergleich zu jenen mit der Diagnose Morbus Alzheimer ( $p=0,0000$, t-Test). Des Weiteren konnten deutliche, jedoch nach der Bonferroni-Methode nicht signifikante Unterschiede 
zwischen PD und PDD ( $p=0,1057$, $t$-Test $)$ sowie AD und PDD ( $p=0,0334$, $t$-Test) gefunden werden.

Bei der Beurteilung der Testabschnitte Intrusionen sowie Savings konnte im Gruppenvergleich kein ausreichender Unterschied festgestellt werden ( $P$-Werte in Tabelle 6). Auf eine graphische Darstellung wurde daher verzichtet.

\section{Abbildung 15: Mittelwert und 95\%-Konfidenzintervall Wortliste Lernen und Wortliste Abrufen}
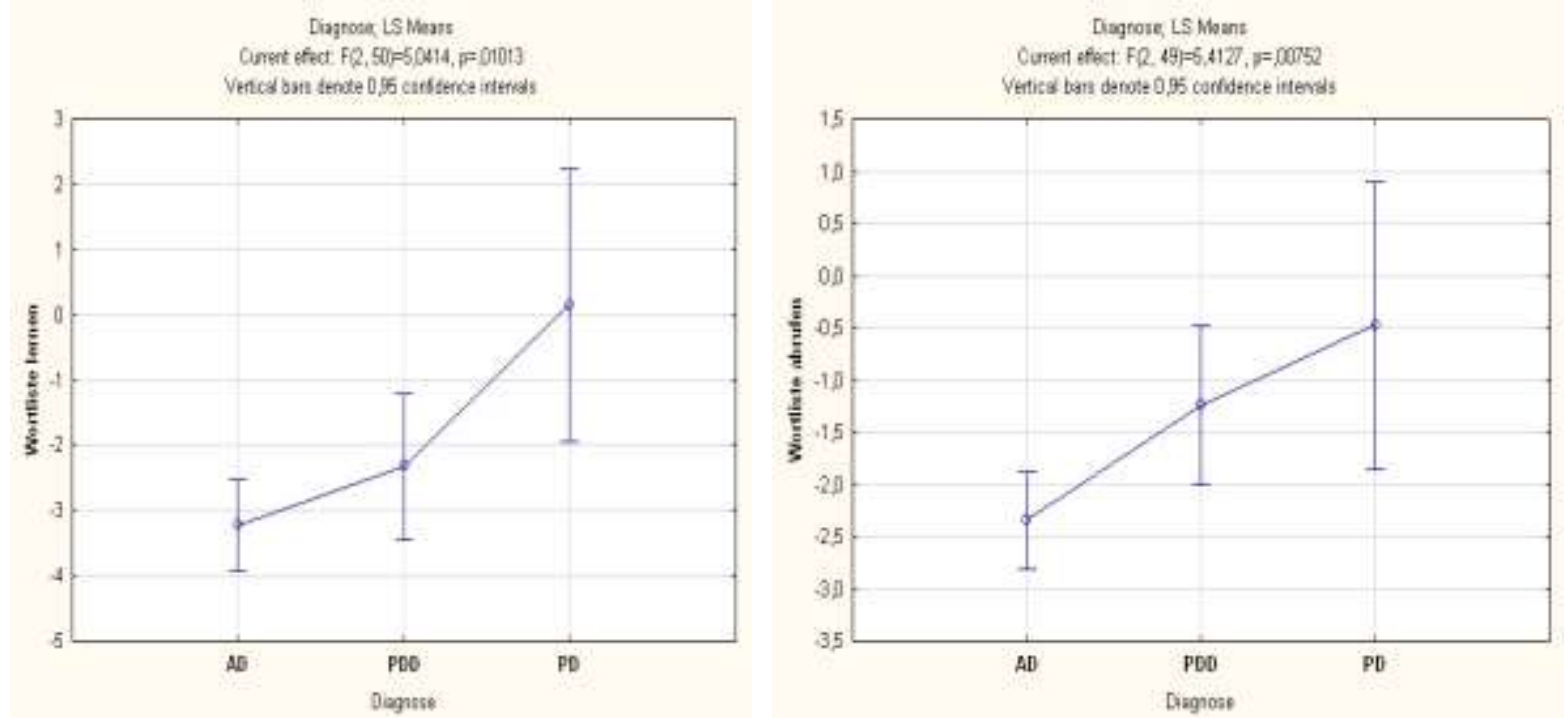

Im Zusatztest Wortliste Wiedererkennen (Diskriminabilität) bekamen die Probanden die zuvor erlernten Wörter mit zehn weiteren Wörtern gemischt vorgelegt und wurden gebeten, zwischen neuen und alten Begriffen zu unterscheiden. Diese Aufgabe ermöglicht eine Einschätzung darüber, ob ein Proband von erleichterten Abrufbedingungen im Sinne des Wiedererkennens profitiert und somit lediglich eine Abrufschwäche und kein primäres Speicherdefizit aufweist.

In der Auswertung zeigte sich hier erstmals ein signifikanter Unterschied zwischen den beiden dementiellen Erkrankungen, das heißt ein deutlich besseres Abschneiden der Patienten mit Parkinson-Demenz-Komplex im Gegensatz zu jenen mit Morbus Alzheimer ( $p=0,0061$, $t$-Test). Auffallend war dabei auch ein nur marginaler Leistungsunterschied zwischen PDD und PD. 
Abbildung 16: Mittelwert und 95\%-Konfidenzintervall Diskriminabilität

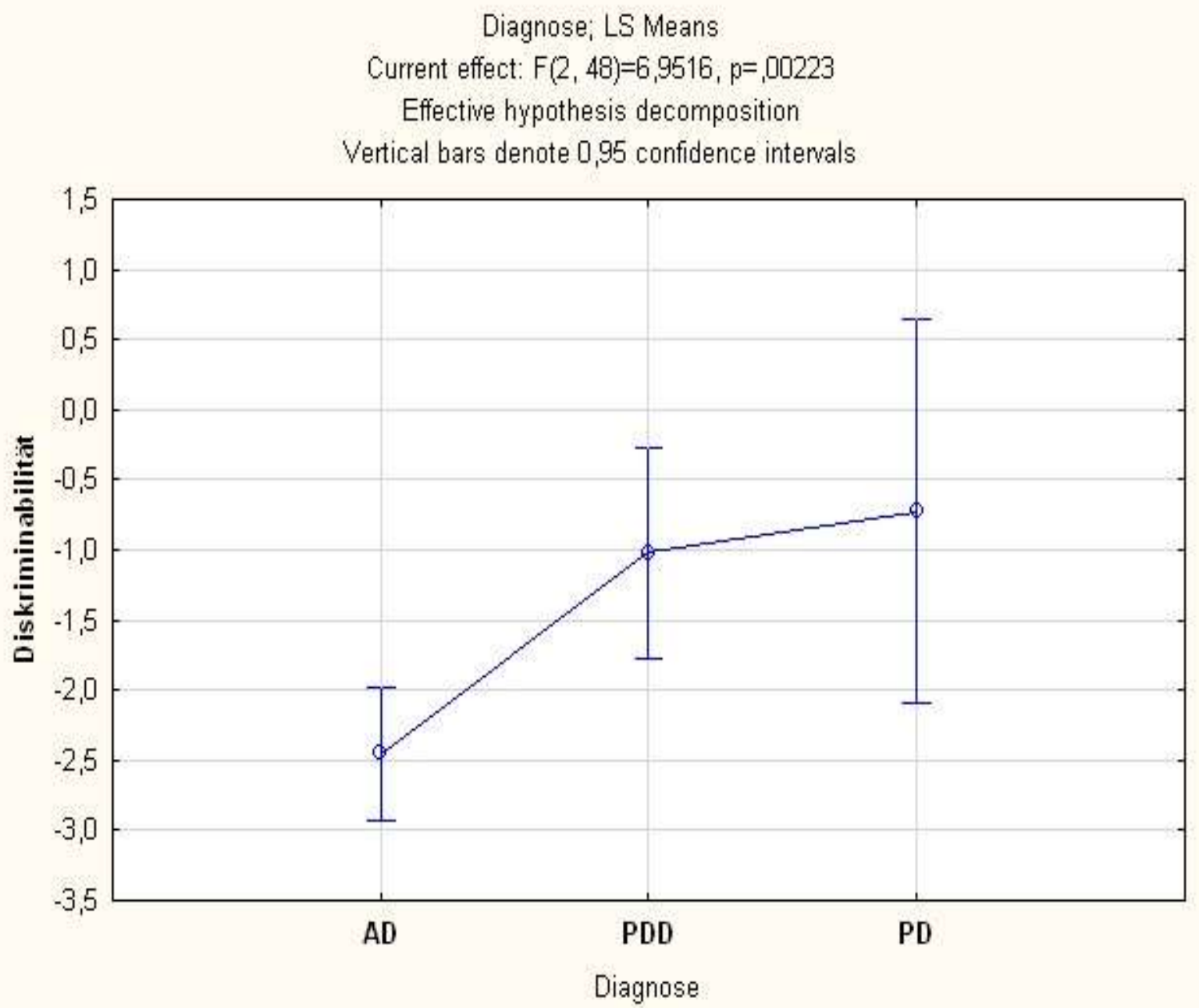

Der Testabschnitt Figuren, in dem konkordant zum Bereich Wortliste zunächst ein Abzeichnen vorgelegter Figuren und im Anschluss ein zeitlich verzögerter Abruf mit erneutem Zeichnen gefordert wird, prüft zum einen die visuokonstruktiven Fähigkeiten, zum anderen aber auch das nonverbale Gedächtnis.

Im untersuchten Patientenkollektiv konnte für das verzögerte Abrufen $(p=0,0095$, ANOVA) und Savings ( $p=0,0037$, ANOVA) ein signifikanter Unterschied im Gruppenvergleich ermittelt werden, der sich nach Anwendung des t-Tests und der BonferroniMethode zum Paarvergleich jedoch nicht mehr nachweisen ließ. Der Initialtest Figuren Abzeichnen ließ bereits in der Varianzanalyse keine Signifikanz erkennen $(p=0,1379)$. Trotzdem veranschaulichen unten angegebene Graphen die erwartete Abweichung der Demenzerkrankungen AD und PDD von der Normstichprobe ( $\varnothing Z$ Wert=0) sowie die altersentsprechenden Leistungen der Parkinsonpatienten. 
Abbildung 17: Mittelwerte und 95\%-Konfidenzintervalle für Figuren Abzeichnen, Figuren Abrufen und Figuren Savings
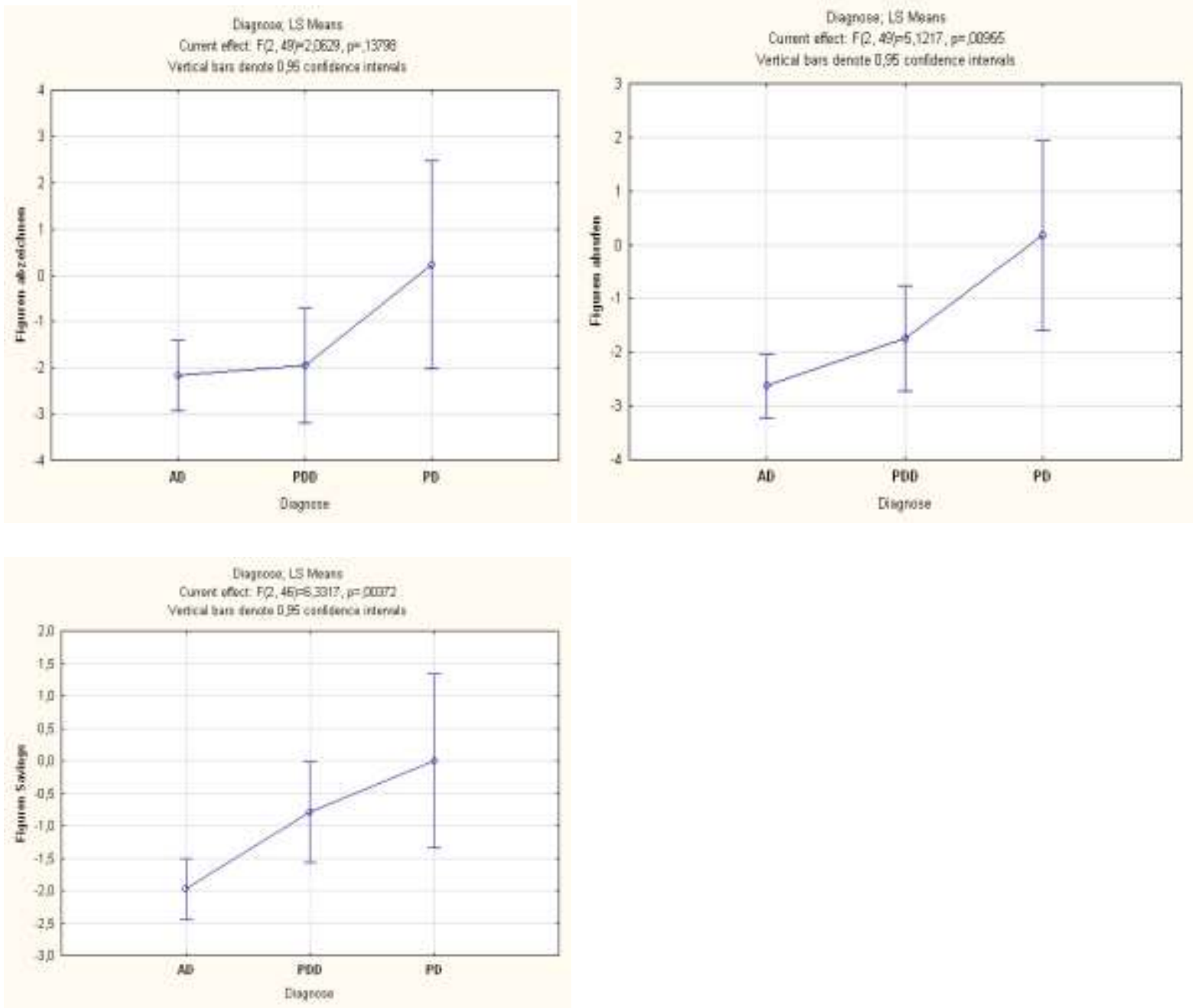

Der im Rahmen der CERAD-Testbatterie als Plus-Test bezeichnete Trailmaking-test gliedert sich in zwei Abschnitte, wobei Teil A in erster Linie Auskunft über die psychomotorische Geschwindigkeit der Testperson gibt und Teil B zusätzlich die exekutiven Funktionen fordert. Durch anschließendes Bilden eines Quotienten aus den Leistungen von Testteil B/A soll ein alleiniges Beurteilen der exekutiven Funktion unabhängig einer psychomotorischen Verlangsamung möglich sein.

Bei Betrachtung der Ergebnisse dieser Tests zeigte sich eine deutliche psychomotorische Verlangsamung (Trailmaking $\mathrm{A}$ ) für die untersuchten Patienten mit $\mathrm{AD}$ und PDD, wobei die Unterschiede im Gruppenvergleich allerdings nicht signifikant waren ( $p=0,0542$, ANOVA). Für den Testteil B konnte im Gruppen- ( $p=0,0072$, ANOVA) und Paarvergleich ein signifikanter Unterschied der Testergebnisse zwischen AD und PD $(p=0,0020)$ sowie PD und PDD ( $p=0,0008)$ gefunden werden. Dabei fiel für die Patienten mit PD und PDD ein stärkerer Abfall der Leistungen gegenüber jenen in Testteil $\mathrm{A}$ auf. Entsprechend ergab sich für diese Patientengruppen in der Berechnung 
des Quotienten aus Testteil B/A, welcher die reinen exekutiven Funktionen wiedergeben soll, ein schlechteres Abschneiden gegenüber den Patienten mit $A D$, deren Leistungen gemäß des Auswertungsprogrammes sogar über denen der Normstichprobe gelegen haben sollen.

Abbildung 18: Mittelwerte und 95\%-Konfidenzintervalle Trailmaking-Test A, B und B/A
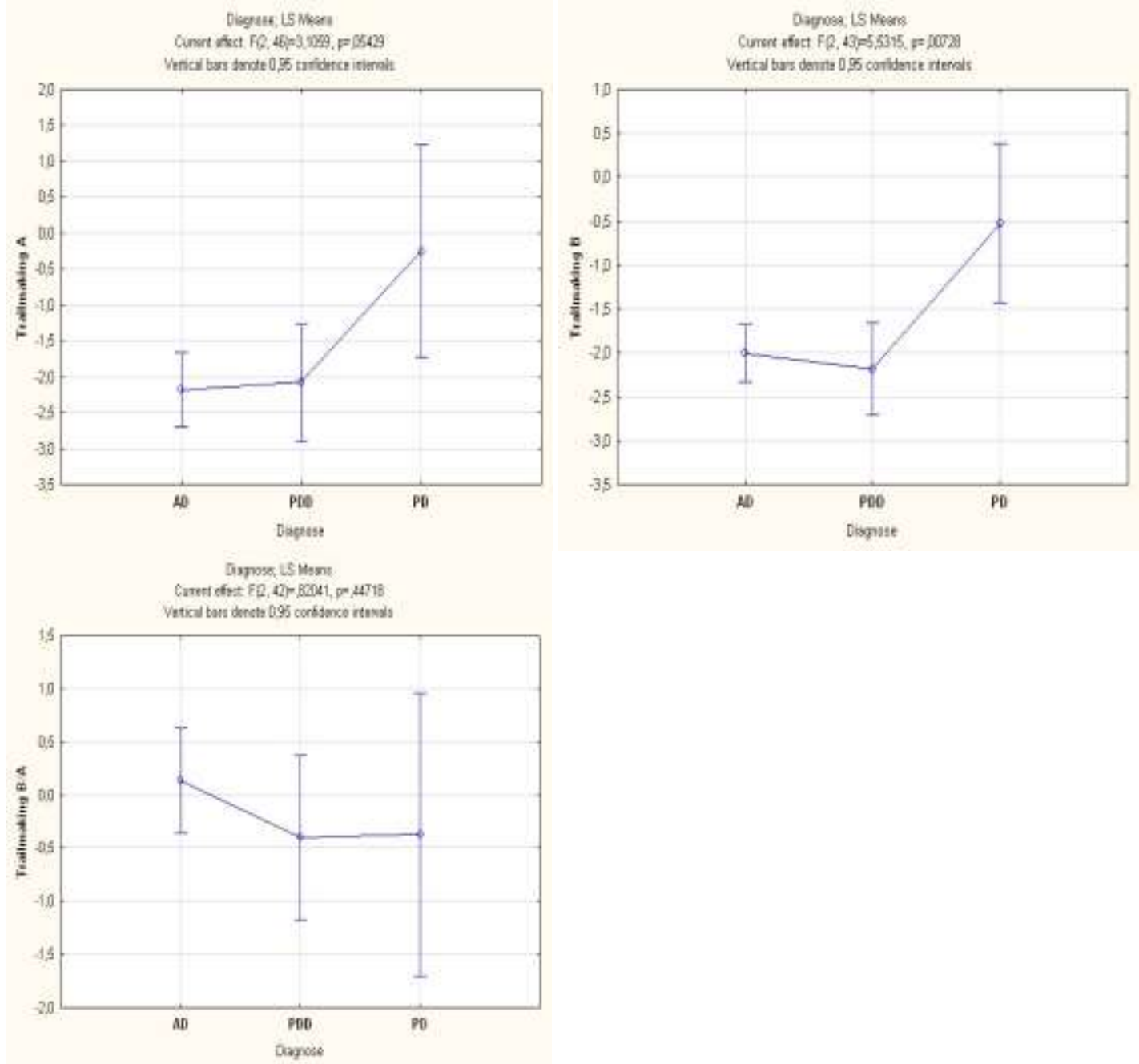

Zur Erleichterung der Übersicht sind in folgender Tabelle jene Subtests aufgeführt, bei denen aufgrund der fehlenden Signifikanz in der ANOVA-Varianzanalyse kein weiterer t-Test zum Vergleich der jeweiligen Diagnosen untereinander durchgeführt wurde. Waren trotz fehlender oder bei beinahe erreichter Signifikanz interessante Unterschiede festzustellen, sind diese trotzdem in der oben erfolgten Erläuterung der Gruppenvergleiche beschrieben worden. 
Tabelle 6: Subtests ohne Signifikanz im Gruppenvergleich

\begin{tabular}{|l|c|}
\hline Subtest & p (ANOVA) \\
\hline Boston Naming Test & 0,075 \\
\hline Figuren Abzeichnen & 0,137 \\
\hline Worliste Abrufen & \\
- Intrusionen & 0,890 \\
- Savings & 0,235 \\
\hline Trailmaking Test & \\
- A & 0,054 \\
- B/A & 0,447 \\
\hline
\end{tabular}

\subsubsection{Liquorparameter}

Fünf der sieben untersuchten Liquorparameter zeigten signifikante Unterschiede im Gruppenvergleich.

Die drei in der Demenzdiagnostik vor allem für Morbus Alzheimer etablierten Liquorparameter Tau-Protein, Phospho-Tau und Amyloid-beta 1-42 ließen im Paarvergleich jeweils eine deutliche und größtenteils signifikante Unterscheidung zwischen AD und den beiden anderen betrachteten Erkrankungen zu. Ein signifikanter Unterschied in der Liquorkonzentration zwischen PD und PDD konnte für keinen der drei Marker festgestellt werden.

Bezüglich des Tau-Proteins bestand für die AD-Gruppe ein Mittelwert von 451,79 $\mathrm{pg} / \mathrm{ml}$, der zum einen leicht über dem für gesunde Menschen akzeptierten Grenzwert von $450 \mathrm{pg} / \mathrm{ml}$ lag (Reiber et al. 2005), zum anderen einen signifikanten Unterschied $z u$ jenen von PDD $(215,27 \mathrm{pg} / \mathrm{ml}) \quad(p=0,0000, t-T e s t)$ und PD $(249,90 \mathrm{pg} / \mathrm{ml})$ $(p=0,0043$, t-Test) zeigte. Die Werte für PDD und PD unterschieden sich bei niedrigerem Tau-Protein für PDD nur dezent. 
Abbildung 19: Mittelwert und 95\%-Konfidenzintervall Tau-Protein

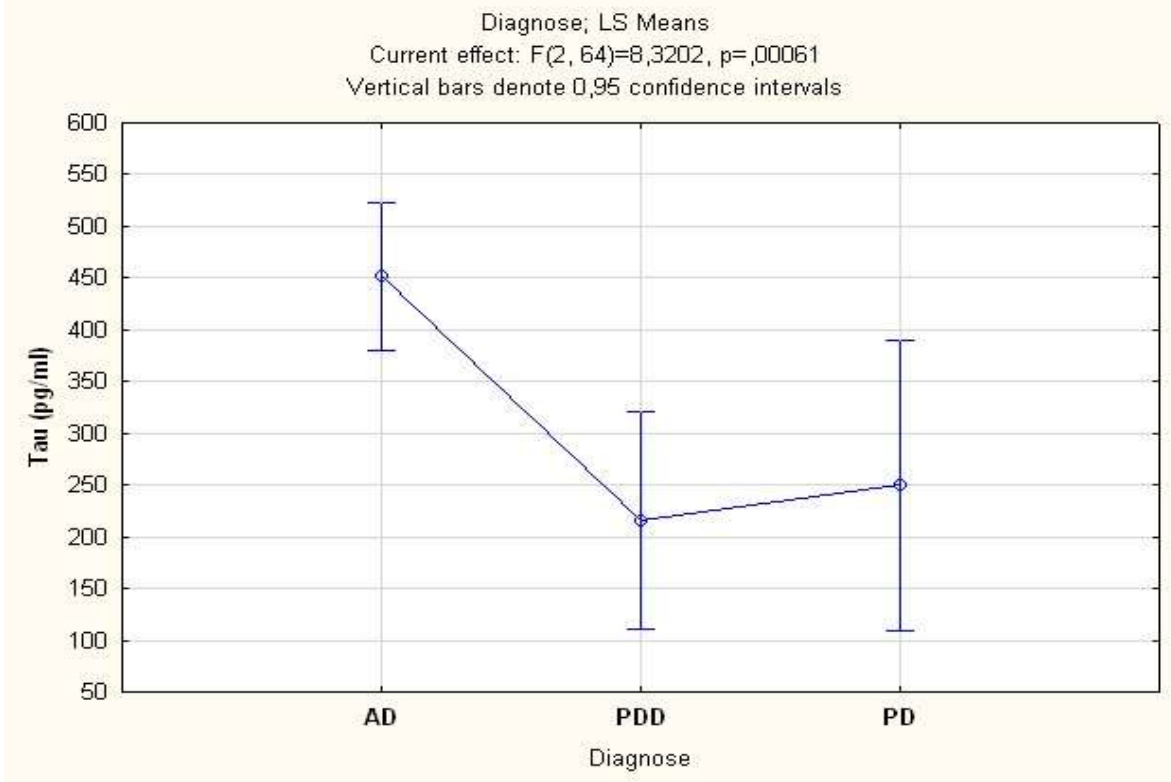

Im Normallfall, das heißt für gesunde, kognitiv nicht eingeschränkte Menschen, sollte das hyperphosphorylierte Tau-Protein (pTau) unter $60 \mathrm{pg} / \mathrm{ml}$ liegen (Reiber et al. 2005). Der Mittelwert der getesteten Patienten mit AD war mit $81,83 \mathrm{pg} / \mathrm{ml}$ daher deutlich erhöht. Die durchschnittlichen Werte für PDD und PD lagen im oberen Normbereich. Im Paarvergleich zeigte sich ein signifikanter Konzentrationsunterschied zwischen AD und PDD ( $p=0,0002$, $t-$ Test $)$ sowie AD und PD ( $p=0,0136$, tTest).

\section{Abbildung 20: Mittelwert und 95\%-Konfidenzintervall Phospho-Tau}

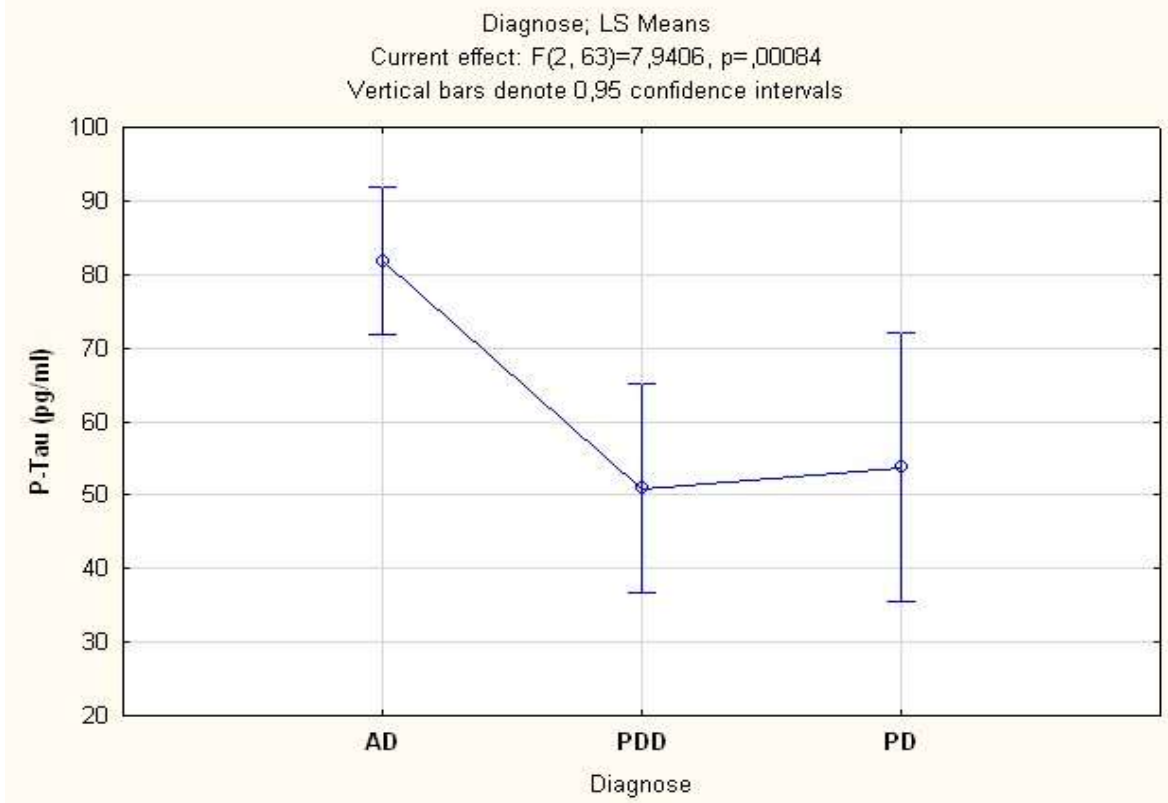


Auch für Amyloid-beta 1-42 konnte im Paarvergleich eine signifikante Erniedrigung des Wertes bei Alzheimerpatienten im Vergleich zu jenen mit Demenz bei Morbus Parkinson ( $p=0,0013$, $t$-Test) detektiert werden. Zwar war die Konzentration des Parameters auch für $P D$ deutlich höher als bei $A D$, der Unterschied zeigte sich allerdings als nicht signifikant. Die gemessenen Mittelwerte lagen allerdings für alle drei Erkrankungen, wenngleich für Morbus Alzheimer grenzwertig, im Normbereich von größer $450 \mathrm{pg} / \mathrm{ml}$.

Abbildung 21: Mittelwert und 95\%-Konfidenzintervall Amyloid-beta 1-42

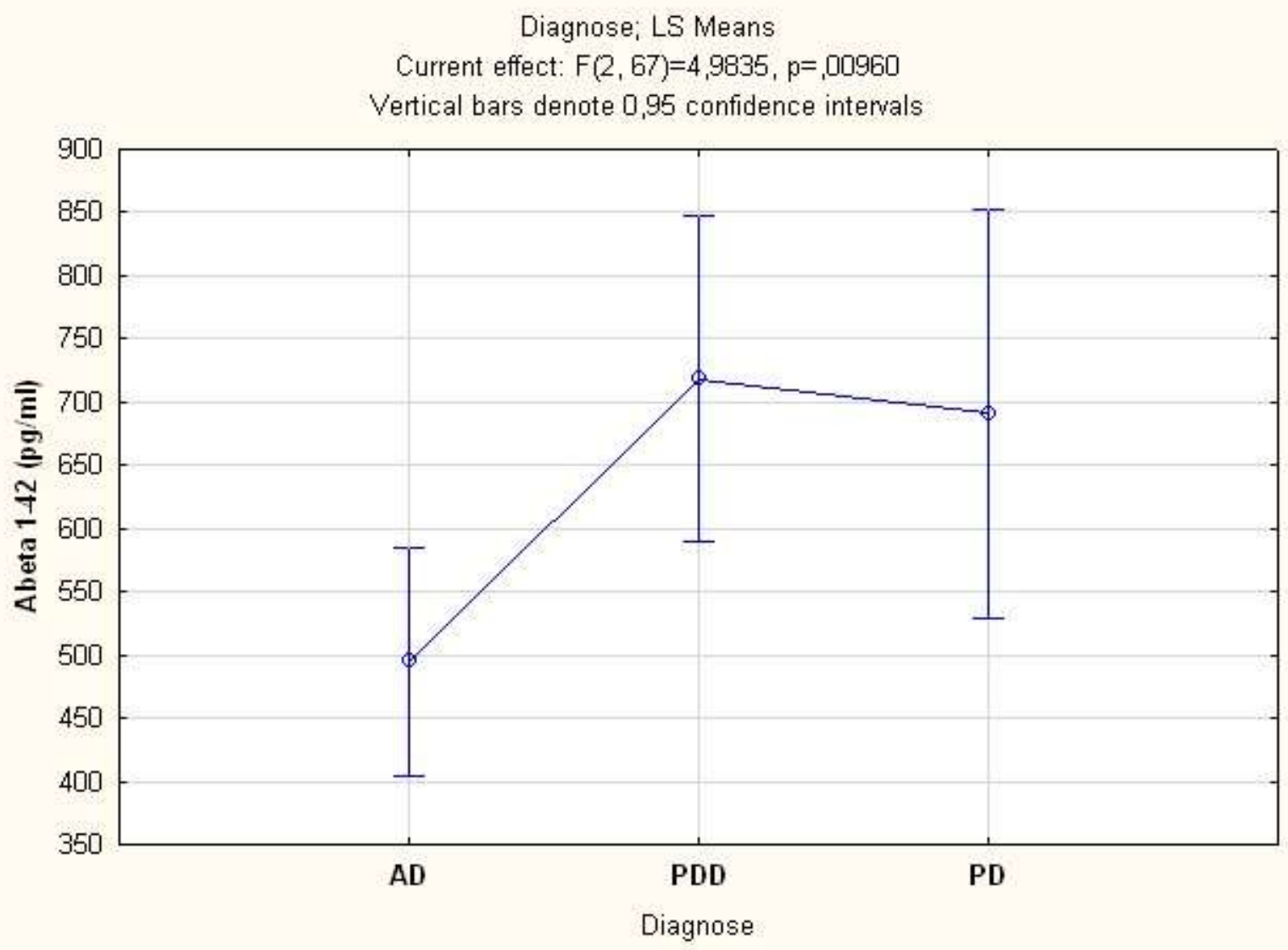

Bei Betrachtung der verbliebenen vier Parameter, deren routinemäßige Anwendung in der Demenzdiagnostik weiterer Validierung bedarf, zeigten sich lediglich für die Liquorkonzentrationen von ApoE und Homocystein signifikante Gruppenunterschiede.

So fiel auf, dass sich die Konzentration von Apolipoprotein $\mathrm{E}$ im Liquor von Patienten mit Morbus Alzheimer signifikant $z u$ jener von PDD ( $p=0,0000$, $t-T e s t)$ und PD $(p=0,0000, t-T e s t)$ unterscheidet und mit einer mittleren Konzentration von 2,415 $\mu \mathrm{g} / \mathrm{ml}$ zudem weit und signifikant unter dem einer in einer repräsentativen Studie an- 
gegebenen Normwert einer gesunden Kontrollgruppe $(n=95)$ von $3,9 \mu \mathrm{g} / \mathrm{ml}$ liegt (Zhang et al 2008). Im Vergleich mit dem Normwert wiesen die Patienten mit PD eine äquivalente und solche mit PDD eine nicht signifikant erniedrigte Apo-ELiquorkonzentration auf.

\section{Abbildung 22: Mittelwert und 95\%-Konfidenzintervall Apolipoprotein E}

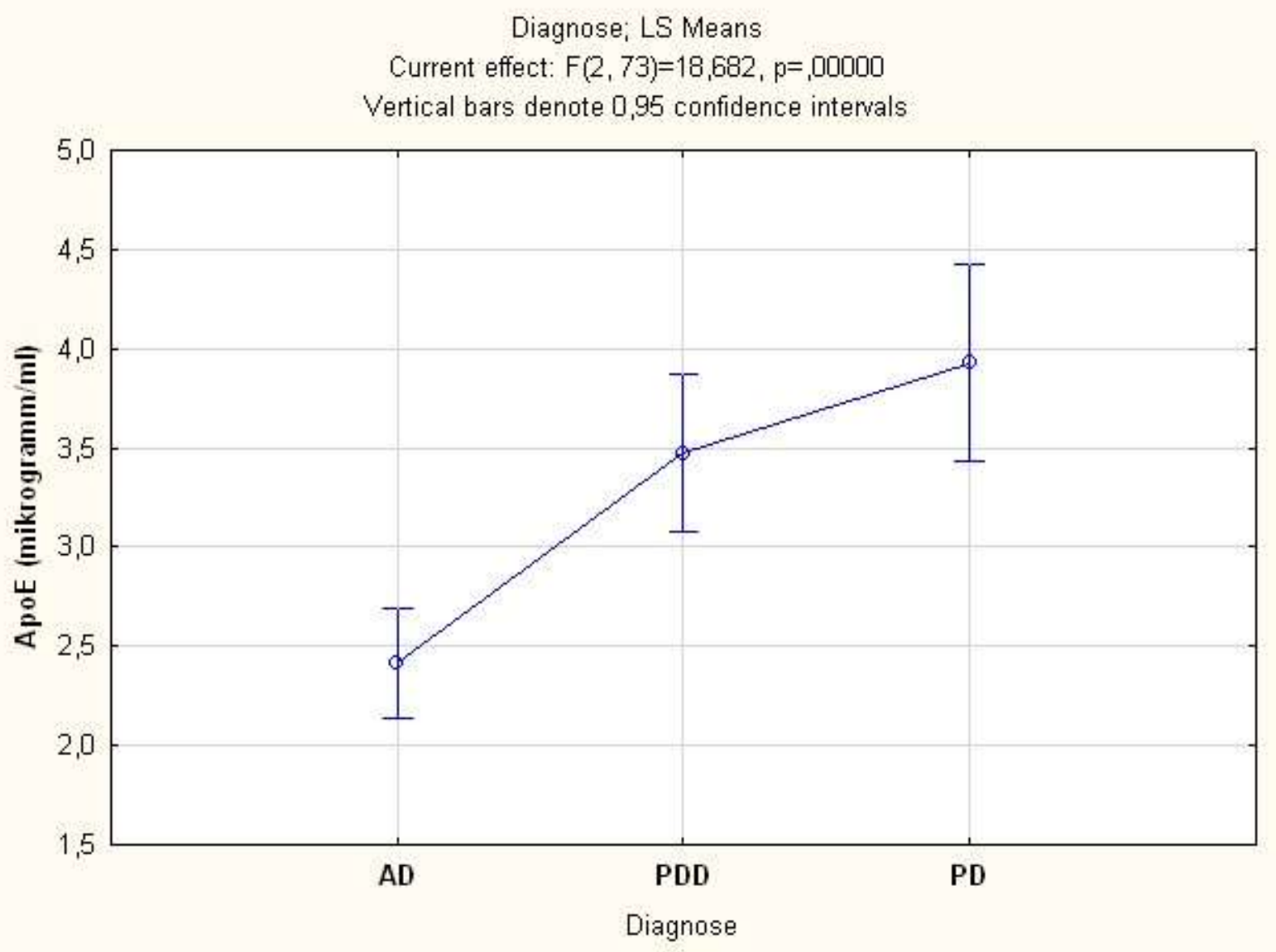

Innerhalb der Patienten mit PDD zeigte sich ein nicht signifikanter Unterschied zwischen jenen mit leichteren (Z-Wert -1 bis -4) und stärkeren (Z-Wert -4 bis -9) kognitiven Defiziten. Letztere wiesen im Mittel einen niedrigeren Apo-E-Spiegel im Liquor auf.

Tabelle 7: Apo-E-Spiegel bei PDD in Bezug auf Z-Werte

\begin{tabular}{|l|c|c|}
\hline PDD & Z-Wert -1 bis -4 (Mittel -1,93) & Z-Wert -4 bis -9 (Mittel -3,26) \\
\hline $\begin{array}{l}\text { Apo-E-Spiegel CSF } \\
\text { (Median/Mittel/Min/Max) }\end{array}$ & $3,51 / 3,53 / 2,14 / 4,72$ & $3,43 / 3,26 / 1,99 / 4,99$ \\
\hline
\end{tabular}


Im Gruppenvergleich für Homozystein zeigte sich eine zum Apo-E gleichsinnige Signifikanz im Gruppenvergleich, das heißt eine deutliche Erniedrigung der Liquorkonzentration für AD in Bezug auf PDD ( $p=0,0000$, t-Test) und PD ( $p=0,0253$, t-Test). Ein Vergleich mit Normwerten aus anderen Studien ist aufgrund unterschiedlicher, jeweils experimentell angewendeter ELISAs nicht sinnvoll.

Für TGF-beta 1 und VDBP konnte keine Signifikanz im Gruppenvergleich ermittelt werden. Allerdings lässt der Vergleich mit gängigen Normwerten die Annahme einer Bedeutung für neurodegenerative Erkrankungen zu. So konnte für alle drei Erkrankungen eine deutliche Erhöhnung des VDBP-Liquorspiegels im Vergleich zu Normwerten (Norm $<0,6 \mu \mathrm{g} / \mathrm{ml}$ (Zhang et al. 2008)) anderer Studien festgestellt werden. Hinweise für eine Erhöhung des VDBP-Spiegels bei neurodegenerativen Erkrankungen im Vergleich zur Normalpopulation sind also gegeben. Die Liquorkonzentration von TGF-beta1 war im Vergleich zu den Werten einer Studie von Rota et al. (2006) deutlich (max. 62fach) erniedrigt, zeigte allerdings eine ähnliche Verteilung zwischen den drei Krankheitsgruppen mit erhöhten Werten für AD (Mittelwert 213 pg/ml) im Vergleich zu PDD (Mittelwert 151 pg/ml) und PD (Mittelwert 192 pg/ml).

\section{Abbildung 23: Mittelwert und 95\%-Konfidenzintervall VDBP und TGF-beta1}
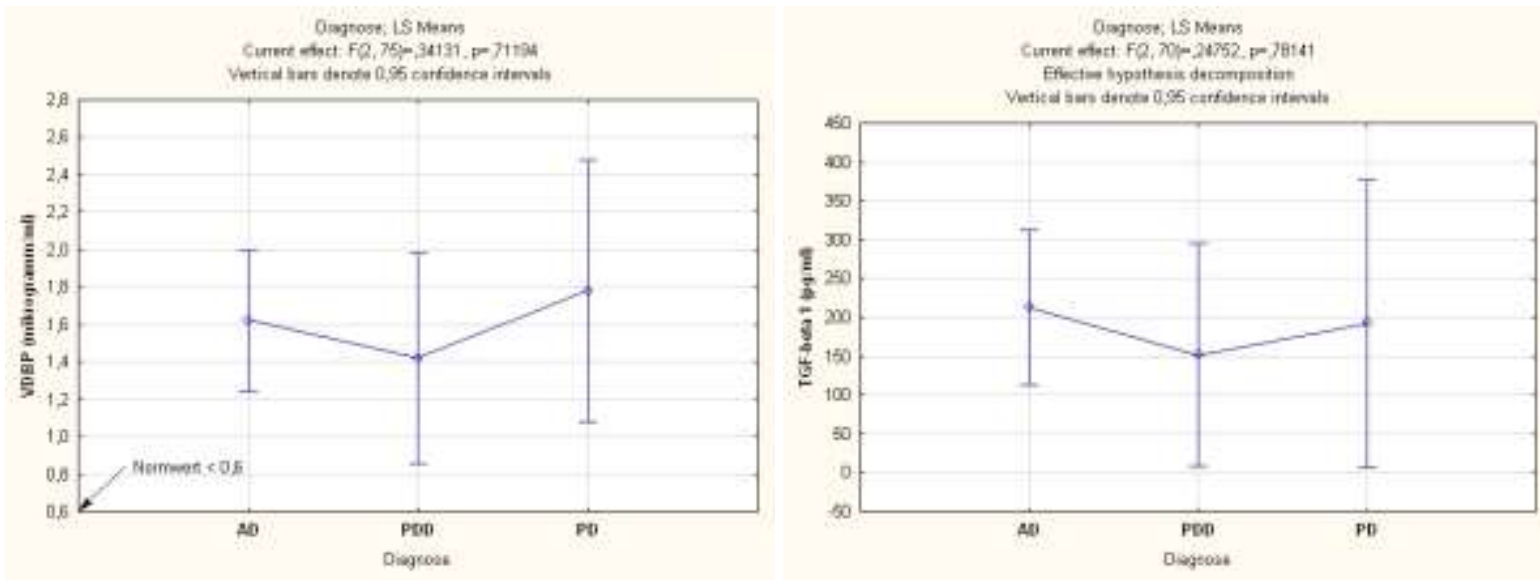

\subsubsection{Follow-up-Untersuchungen}

Für insgesamt acht Patienten konnten die Ergebnisse aus einer erneuten neuropsychologischen Testung nach neun Monaten ausgewertet werden. Zur Detektion einer eventuellen Fluktuation oder progredienten Verschlechterung der kognitiven Leistungen wurden die jeweiligen Mittelwertdifferenzen der CERAD-Subtests für Erst- und Zweituntersuchung betrachtet und nach Diagnosen getrennt tabellarisch aufgearbeitet. Dabei zeigte sich gemittelt über alle Testbereiche sowohl für AD als auch PDD 
eine dezente Verschlechterung der Testleistungen (Diff-gesamt=-0,027 bzw. Diffgesamt= -0,131) ohne jegliche Signifikanz. Auffallend für PDD war mit Z-WertDifferenzen zwischen minus 0,7 und plus 0,6 jedoch eine größere Schwankungsbreite bei den kognitiven Fähigkeiten zwischen Erst- und Zweituntersuchung. Bei PDD zeigte sich der stärkste Leistungsabfall in den Bereichen Boston Naming Test $(-0,7)$, MMSE $(-0,7)$ und Figuren Abrufen (-0,7). Für AD hingegen in den Tests semantische Flüssigkeit $(-0,6)$ und Diskriminabilität $(-0,5)$. Bezüglich des einzeln aufgeführten Patienten mit DLB fiel eine noch deutlichere Fluktuation mit extrem mangelhaften Leistungen in der Erstuntersuchung und deutlicher Besserung des kognitiven Ausfallprofiles beim Follow-up nach neun Monaten auf.

Tabelle 8: Mittelwertdifferenzen zwischen Erst- und Follow-up-Untersuchung

\begin{tabular}{|c|c|c|c|c|c|c|c|c|c|}
\hline \multirow{2}{*}{ Subtest } & \multicolumn{3}{|c|}{$A D n=4$} & \multicolumn{3}{|c|}{ PDD $n=3$} & \multicolumn{3}{|c|}{ DLB $n=1$} \\
\hline & M1 & M2 & Diff & M1 & M2 & Diff & M1 & M2 & Diff \\
\hline Semantische Flüssigkeit & $-3,2$ & $-3,8$ & $-0,6$ & $-0,8$ & $-0,9$ & $-0,1$ & $-1,8$ & $-0,8$ & +1 \\
\hline Boston Naming Test & $-2,2$ & $-2,1$ & $+0,1$ & -1 & $-1,7$ & $-0,7$ & $-2,9$ & $-1,8$ & $+1,1$ \\
\hline MMSE & $-5,3$ & $-5,7$ & $-0,4$ & $-1,5$ & $-2,2$ & $-0,7$ & $-3,9$ & $-4,7$ & $-0,8$ \\
\hline Wortliste Lernen richtig & $-4,2$ & $-4,4$ & $-0,2$ & $-0,8$ & $-0,6$ & $+0,2$ & n.m. & $-0,8$ & ++ \\
\hline Figuren Abzeichnen & $-2,8$ & $-2,5$ & $+0,3$ & $-0,8$ & $-0,8$ & 0 & n.m. & $-1,8$ & ++ \\
\hline Wortliste Abrufen richtig & -3 & -3 & 0 & 0,03 & $-0,3$ & +0.33 & $-0,2$ & $-0,1$ & $+0,1$ \\
\hline Wortliste Abrufen Introsionen & $-1,7$ & $-0,6$ & $+1,1$ & $-0,6$ & $-0,2$ & $+0,4$ & n.m. & $-0,7$ & ++ \\
\hline $\begin{array}{l}\text { Wortliste Wiedererkennen } \\
\text { Savings }\end{array}$ & $-2,3$ & $-2,2$ & $+0,1$ & 1,3 & 0,7 & $-0,3$ & n.m & 1 & ++ \\
\hline $\begin{array}{l}\text { Wortliste Wiedererkennen } \\
\text { Diskriminabilität }\end{array}$ & $-1,5$ & -2 & $-0,5$ & $-0,9$ & $-1,3$ & $-0,4$ & n.m. & 0,9 & ++ \\
\hline Figuren Abrufen richtig & $-2,9$ & $-2,9$ & 0 & $-0,1$ & $-0,8$ & $-0,7$ & n.m. & $-2,3$ & + \\
\hline Figuren Savings & $-2,8$ & $-2,8$ & 0 & 0,2 & $-0,2$ & $-0,4$ & n.m. & $-1,9$ & + \\
\hline Phonematische Flüssigkeit & $-1,7$ & $-1,8$ & $-0,1$ & $-2,1$ & $-1,5$ & $+0,6$ & $-0,5$ & $-0,4$ & $+0,1$ \\
\hline
\end{tabular}




\begin{tabular}{|l|c|c|c|c|c|c|c|c|c|}
\hline & \multicolumn{3}{|c|}{ AD n=4 } & \multicolumn{3}{c|}{ PDD n=3 } & \multicolumn{3}{c|}{ DLB n=1 } \\
\cline { 2 - 10 } Subtest & M1 & M2 & Diff & M1 & M2 & Diff & M1 & M2 & Diff \\
\hline Trailmaking A & $-2,5$ & $-2,4$ & $+\mathbf{0 , 1}$ & $-1,4$ & $-1,2$ & $\mathbf{+ 0 , 2}$ & $-2,9$ & $-1,9$ & $+\mathbf{1}$ \\
\hline Trailmaking B & $-1,8$ & $-1,8$ & $\mathbf{0}$ & $-2,5$ & $-2,7$ & $-\mathbf{0 , 2}$ & $-2,4$ & $-2,4$ & $\mathbf{0}$ \\
\hline Trailmaking B/A (Exekutive) & 0,7 & 0,4 & $-\mathbf{0 , 3}$ & $-1,5$ & $-1,7$ & $-\mathbf{0 , 2}$ & 0,3 & -1 & $-\mathbf{1 , 3}$ \\
\hline gesamt & & & $-\mathbf{0 , 0 2 7}$ & & & $\mathbf{- 0 , 1 3 1}$ & & & ++ \\
\hline
\end{tabular}

M1: Mittlerer Z-Wert Erstuntersuchung M2: Mittlerer Z-Wert Follow-up Diff: Differenz aus M1 und M2 n.m: Z-WertBestimmung aufgrund mangelhafter Testleistungen nicht möglich ++: Verbesserte Testleistungen, fehlende Differenz

\subsubsection{Korrelationen}

\subsubsection{Alter}

Für das Patientenalter und die Leistungen in der neuropsychologischen Testung fanden sich bei Anwendung eines alterskorrigierten Z-Wertes erwartungsgemäß keinerlei signifikante Korrelationen.

\subsubsection{Ausbildung}

In Bezug auf die Ausbildung ( $\mathrm{n}$ gesamt $=57$ ), das heißt Jahre in Schul- und Berufsbildung, und Leistungen in der neuropsychologischen Testbatterie ließ sich trotz Bildungskorrektur des Z-Wertes eine positive Korrelation in drei Testbereichen nachweisen. Eine längere Ausbildungsdauer war statistisch gesehen mit besseren Leistungen in den Testbereichen Figuren Abzeichnen, Phonematische Flüssigkeit und Trailmaking-Test A korreliert.

Tabelle 9: Korrelation Ausbildung vs. neuropsychologische Testung

\begin{tabular}{|l|c|c|c|}
\hline $\begin{array}{l}\text { Korrelation } \\
\text { nach Pearson }\end{array}$ & Figuren Abzeichnen & $\begin{array}{c}\text { Phonematische } \\
\text { Flüssigkeit }\end{array}$ & Trailmaking A \\
\hline Ausbildung & & & \\
$\mathrm{r}$ & 0,35 & 0,35 & 0,38 \\
$\mathrm{p}$ & 0,01 & 0,01 & 0,00 \\
$\mathrm{r}^{2}$ & 0,12 & 0,12 & 0,15 \\
\hline
\end{tabular}




\subsubsection{Liquormarker und Neuropsychologische Testbatterie}

Für die Konzentration der Liquormarker und die Z-Werte der neuropsychologischen Testbatterie konnten Zusammenhänge für Apolipoprotein E ( $n=44)$, Tau-Protein $(n=43)$ und Phospho-Tau $(n=41)$ gefunden werden.

Betrachtet für alle untersuchten Erkrankungen (AD, PD, PDD) zeigte die Konzentration von ApoE für 8 Testbereiche des CERAD eine positive Korrelation nach Pearson, das heißt Defizite in der neuropsychologischen Testung (negativer Z-Wert) spiegelten sich in niedrigerer Konzentration von ApoE im Liquor cerebrospinalis wieder. Im Folgenden sind Korrelationskoeffizienten, Signifikanz sowie das Bestimmtheitsmaß für die zutreffenden Subtests tabellarisch aufgezeigt. Des Weiteren ist in Abbildung 24 exemplarisch ein verwendeter Scatterplot für die Korrelation von Apolipoprotein E mit den Z-Werten des Testteils Figuren Abrufen angegeben.

Tabelle 10: Korrelation ApoE vs. neuropsychologische Testung (Diagnosen gesamt)

\begin{tabular}{|l|c|c|c|c|c|c|c|c|}
\hline $\begin{array}{l}\text { Korrelation } \\
\text { nach } \\
\text { Pearson }\end{array}$ & $\begin{array}{c}\text { Semanti- } \\
\text { sche } \\
\text { Flüssigkeit }\end{array}$ & MMSE & $\begin{array}{c}\text { Figuren } \\
\text { Abzeich- } \\
\text { nen }\end{array}$ & $\begin{array}{c}\text { Wortliste } \\
\text { Diskrimi- } \\
\text { nabilität }\end{array}$ & $\begin{array}{c}\text { Figuren } \\
\text { Abrufen }\end{array}$ & $\begin{array}{c}\text { Figuren } \\
\text { Savings }\end{array}$ & $\begin{array}{c}\text { Trailma- } \\
\text { king A }\end{array}$ & $\begin{array}{c}\text { Trailma- } \\
\text { king B }\end{array}$ \\
\hline $\begin{array}{l}\text { ApoE } \\
(\mu \mathrm{g} / \mathrm{ml})\end{array}$ & & & & & & & & \\
$\mathrm{r}$ & 0,416 & 0,387 & 0,393 & 0,376 & 0,458 & 0,405 & 0,351 & 0,360 \\
$\mathrm{p}$ & 0,005 & 0,002 & 0,009 & 0,014 & 0,002 & 0,008 & 0,022 & 0,024 \\
$\mathrm{r}^{2}$ & 0,173 & 0,150 & 0,154 & 0,141 & 0,210 & 0,164 & 0,123 & 0,129 \\
\hline
\end{tabular}


Scatterplot Apo E vs. Figuren abrufen

ApoE $=3,228+0,2558^{*} \times$

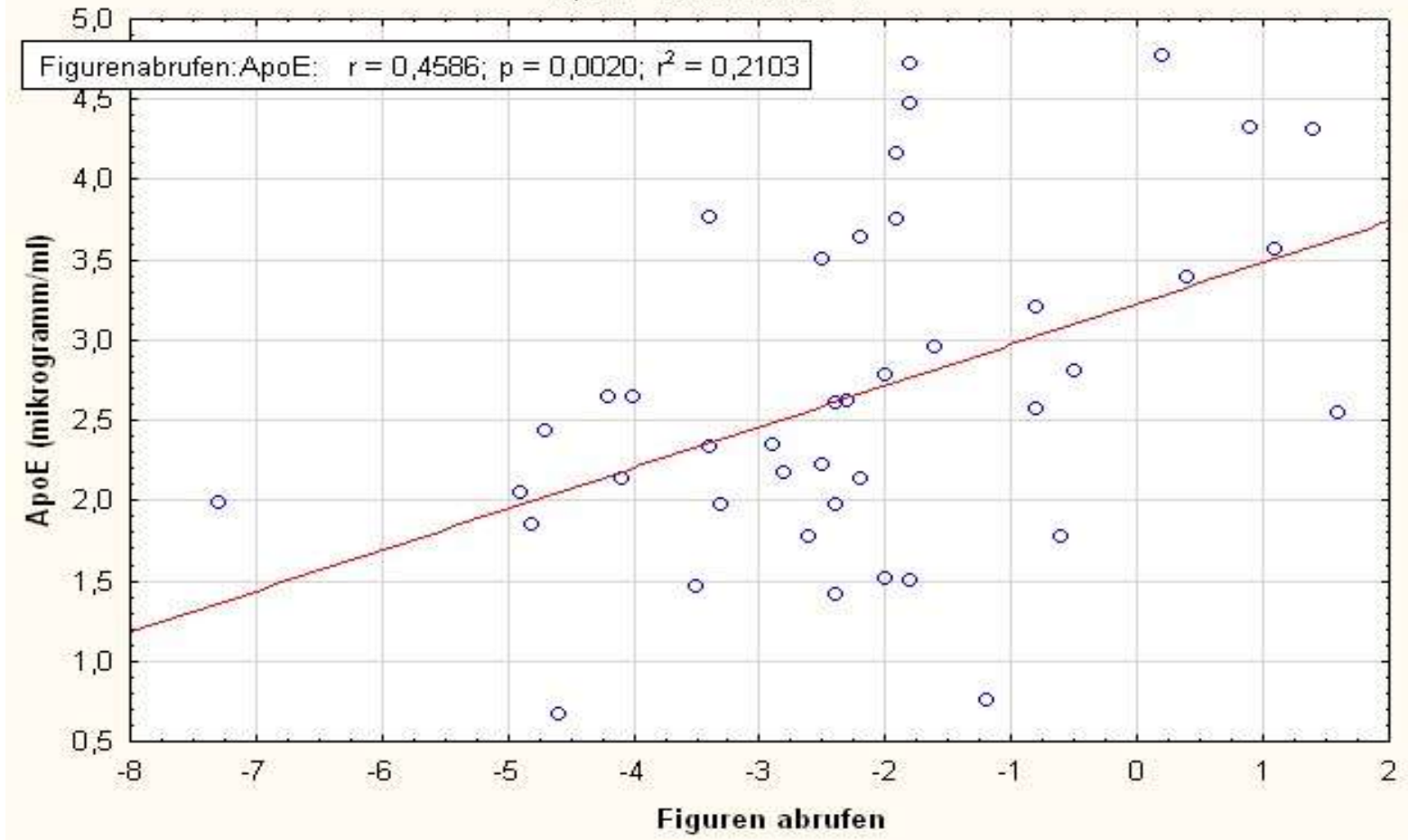

Bei Aufschlüsselung der Korrelation zwischen ApoE-Spiegel und neuropsychologischer Testung nach untersuchten Erkrankungen ließ sich für Morbus Alzheimer ( $n=30$ ) lediglich für den Trailmaking-Test B eine statistische Signifikanz nachweisen. Für PDD $(n=10)$ zeigte sich jene für die Testbereiche Figuren Abrufen und Trailmaking-Test $\mathrm{A}$, hier jedoch mit einer bedeutenden mittleren bis hohen Korrelation. Die jeweiligen Scatterplots finden sich in Abbildung 25 und 26.

Tabelle 11: Korrelation Apo E vs. neuropsychologische Testung (AD)

\begin{tabular}{|l|c|c|c|c|c|c|c|c|}
\hline $\begin{array}{l}\text { Korrelation } \\
\text { nach } \\
\text { Pearson }\end{array}$ & $\begin{array}{c}\text { Semanti- } \\
\text { sche } \\
\text { Flüssigkeit }\end{array}$ & MMSE & $\begin{array}{c}\text { Figuren } \\
\text { Abzeich- } \\
\text { nen }\end{array}$ & $\begin{array}{c}\text { Wortliste } \\
\text { Diskrimi- } \\
\text { nabilität }\end{array}$ & $\begin{array}{c}\text { Figuren } \\
\text { Abrufen }\end{array}$ & $\begin{array}{c}\text { Figuren } \\
\text { Savings }\end{array}$ & $\begin{array}{c}\text { Trailma- } \\
\text { king A }\end{array}$ & $\begin{array}{c}\text { Trailma- } \\
\text { king B }\end{array}$ \\
\hline $\begin{array}{l}\text { ApoE } \\
(\mu \mathrm{g} / \mathrm{ml})\end{array}$ & 0,323 & 0,207 & 0,323 & 0,187 & 0,280 & 0,124 & 0,269 & $\mathbf{0 , 4 2 9}$ \\
$\mathrm{r}$ & 0,076 & 0,262 & 0,076 & 0,328 & 0,125 & 0,520 & 0,150 & $\mathbf{0 , 0 2 2}$ \\
$\mathrm{p}$ & 0,104 & 0,043 & 0,104 & 0,035 & 0,078 & 0,015 & 0,072 & $\mathbf{0 , 1 8 4}$ \\
$\mathrm{r}^{2}$ & 0 & & & & & & \\
\hline
\end{tabular}


Tabelle 12: Korrelation Apo E vs. neuropsychologische Testung (PDD)

\begin{tabular}{|l|c|c|c|c|c|c|c|c|}
\hline $\begin{array}{l}\text { Korrelation } \\
\text { nach }\end{array}$ & $\begin{array}{c}\text { Semanti- } \\
\text { sche } \\
\text { Flüssigkeit }\end{array}$ & MMSE & $\begin{array}{c}\text { Figuren } \\
\text { Abzeich- } \\
\text { nen }\end{array}$ & $\begin{array}{c}\text { Wortliste } \\
\text { Diskrimi- } \\
\text { nabiliät }\end{array}$ & $\begin{array}{c}\text { Figuren } \\
\text { Abrufen }\end{array}$ & $\begin{array}{c}\text { Figuren } \\
\text { Savings }\end{array}$ & $\begin{array}{c}\text { Trailma- } \\
\text { king A }\end{array}$ & $\begin{array}{c}\text { Trailma- } \\
k i n g ~ B\end{array}$ \\
\hline $\begin{array}{l}\text { ApoE } \\
(\mu \mathrm{g} / \mathrm{ml})\end{array}$ & & & & & & & & \\
$r$ & 0,394 & 0,236 & 0,486 & 0,529 & $\mathbf{0 , 6 2 7}$ & 0,544 & $\mathbf{0 , 7 5 5}$ & 0,595 \\
$\mathrm{p}$ & 0,229 & 0,329 & 0,153 & 0,115 & $\mathbf{0 , 0 5 2}$ & 0,103 & $\mathbf{0 , 0 1 1}$ & 0,090 \\
$\mathrm{r}^{2}$ & 0,115 & 0,055 & 0,236 & 0,279 & $\mathbf{0 , 3 9 3}$ & 0,296 & $\mathbf{0 , 5 7 0}$ & 0,355 \\
\hline
\end{tabular}

Abbildung 25: Scatterplot ApoE vs. Figuren Abrufen (PDD)

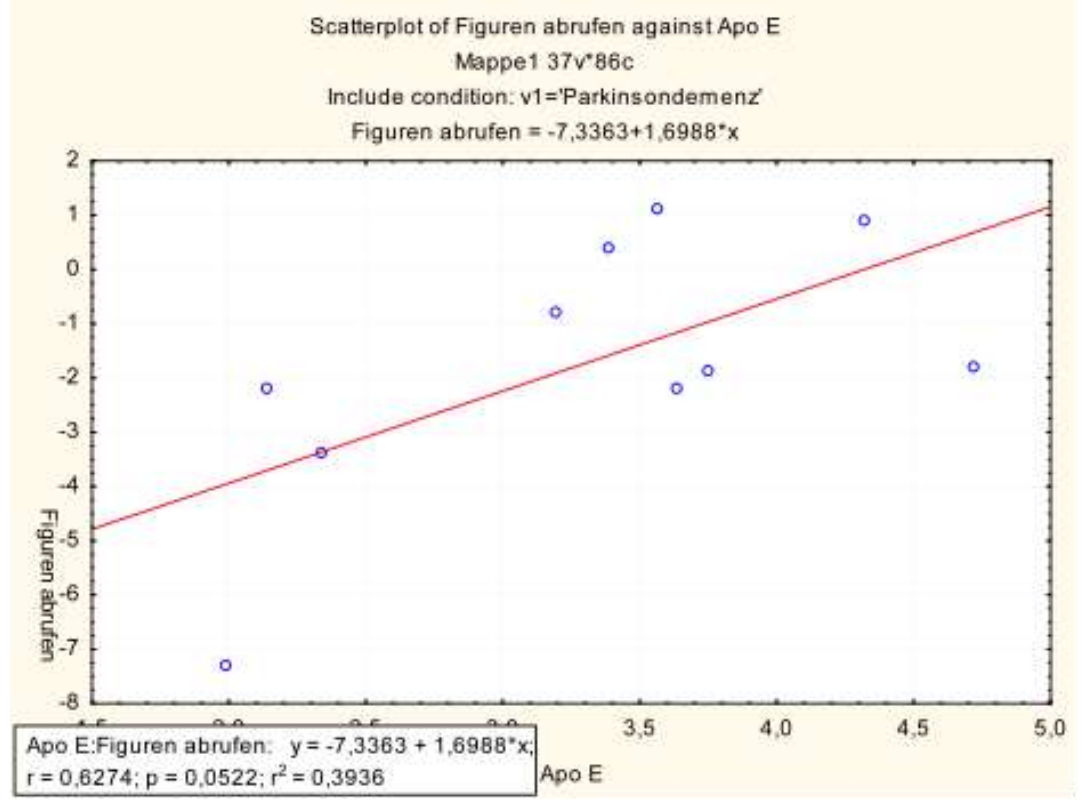

Abbildung 26: Scatterplot ApoE vs. Trailmaking A (PDD)

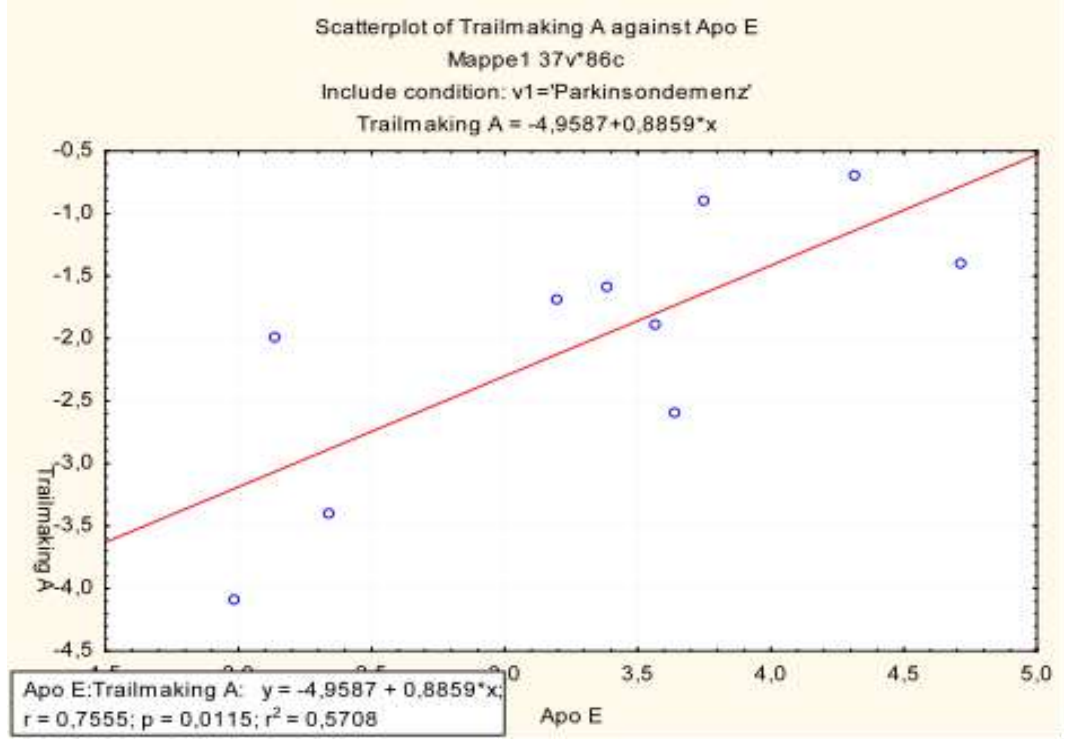

Außerdem bestand, gemittelt über alle Diagnosen, eine negative Korrelation zwi- 
schen Tau-Protein-Konzentrationen im Liquor und Z-Werten in 6 Subtests, das heißt Patienten mit höherem Tau-Protein-Spiegel wiesen statistisch schlechtere kognitive Leistungen in unten tabellarisch angegebenen Testbereichen auf.

Tabelle 13: Tau-Protein vs. neuropsychologische Testung (Diagnosen gesamt)

\begin{tabular}{|l|c|c|c|c|c|c|}
\hline $\begin{array}{l}\text { Korrelation nach } \\
\text { Pearson }\end{array}$ & MMSE & $\begin{array}{c}\text { Wortliste } \\
\text { Lernen }\end{array}$ & $\begin{array}{c}\text { Figuren Ab- } \\
\text { zeichnen }\end{array}$ & $\begin{array}{c}\text { Wortliste } \\
\text { Abrufen }\end{array}$ & $\begin{array}{c}\text { Wortliste } \\
\text { Diskriminabili- } \\
\text { tät }\end{array}$ & $\begin{array}{c}\text { Phonemati- } \\
\text { sche Flüssig- } \\
\text { keit }\end{array}$ \\
\hline Tau-Protein (pg/ml) & & & & & & $-0,369$ \\
$p$ & $-0,300$ & $-0,365$ & $-0,314$ & $-0,456$ & $-0,565$ & 0,019 \\
$r^{2}$ & 0,022 & 0,014 & 0,039 & 0,002 & 0,000 & 0,163 \\
\hline
\end{tabular}

Die Aufteilung nach Diagnosen zeigte, dass die gesehene Korrelation lediglich für jene Patienten mit Morbus Alzheimer $(n=31)$ als signifikant anzusehen ist. Die höchste Korrelation zeigte sich hierbei zwischen erhöhtem Tau-Protein-Spiegel und mangelhaften Leistungen im Subtest Wortliste Diskriminabilität (Scatterplot in Abbildung 27).

Tabelle 14: Tau-Protein vs. neuropsychologische Testung (AD, $n=31)$

\begin{tabular}{|l|c|c|c|c|c|c|}
\hline $\begin{array}{l}\text { Korrelation } \\
\text { nach Pearson }\end{array}$ & MMSE & $\begin{array}{c}\text { Wortliste Ler- } \\
\text { nen }\end{array}$ & $\begin{array}{c}\text { Figuren Ab- } \\
\text { zeichnen }\end{array}$ & $\begin{array}{c}\text { Wortliste Abru- } \\
\text { fen }\end{array}$ & $\begin{array}{c}\text { Wortliste Dis- } \\
\text { kriminabilität }\end{array}$ & $\begin{array}{c}\text { Phonematische } \\
\text { Flüssigkeit }\end{array}$ \\
\hline $\begin{array}{l}\text { Tau-Protein } \\
(\mathrm{pg} / \mathrm{ml})\end{array}$ & & & & & & \\
$\mathrm{r}$ & $-0,270$ & $-0,403$ & $-0,383$ & $-0,429$ & $-0,550$ & $-0,438$ \\
$\mathrm{p}$ & 0,133 & $\mathbf{0 , 0 2 1}$ & $\mathbf{0 , 0 3 0}$ & $\mathbf{0 , 0 1 4}$ & $\mathbf{0 , 0 0 1}$ & $\mathbf{0 , 0 1 7}$ \\
$\mathrm{r}^{2}$ & 0,073 & $\mathbf{0 , 1 6 3}$ & $\mathbf{0 , 1 4 6}$ & $\mathbf{0 , 1 8 4}$ & $\mathbf{0 , 3 0 2}$ & $\mathbf{0 , 1 9 1}$ \\
\hline
\end{tabular}


Tabelle 15: Tau-Protein vs. neuropsychologische Testung (PDD, $n=10$ )

\begin{tabular}{|l|c|c|c|c|c|c|}
\hline $\begin{array}{l}\text { Korrelation nach } \\
\text { Pearson }\end{array}$ & MMSE & $\begin{array}{c}\text { Wortliste } \\
\text { Lernen }\end{array}$ & $\begin{array}{c}\text { Figuren Ab- } \\
\text { zeichnen }\end{array}$ & $\begin{array}{c}\text { Wortliste } \\
\text { Abrufen }\end{array}$ & $\begin{array}{c}\text { Wortliste } \\
\text { Diskriminabili- } \\
\text { tät }\end{array}$ & $\begin{array}{c}\text { Phonemati- } \\
\text { sche Flüssig- } \\
\text { keit }\end{array}$ \\
\hline Tau-Protein $(\mathrm{pg} / \mathrm{ml})$ & & $-0,142$ & 0,300 & $-0,234$ & $-0,237$ & 0,310 \\
$\mathrm{r}$ & $-0,061$ & 0,693 & 0,431 & 0,543 & 0,538 & 0,416 \\
$\mathrm{r}^{2}$ & 0,814 & 0,020 & 0,090 & 0,055 & 0,056 & 0,096 \\
\hline
\end{tabular}

Abbildung 27: Scatterplot Tau vs. Wortliste Diskriminabilität (AD)

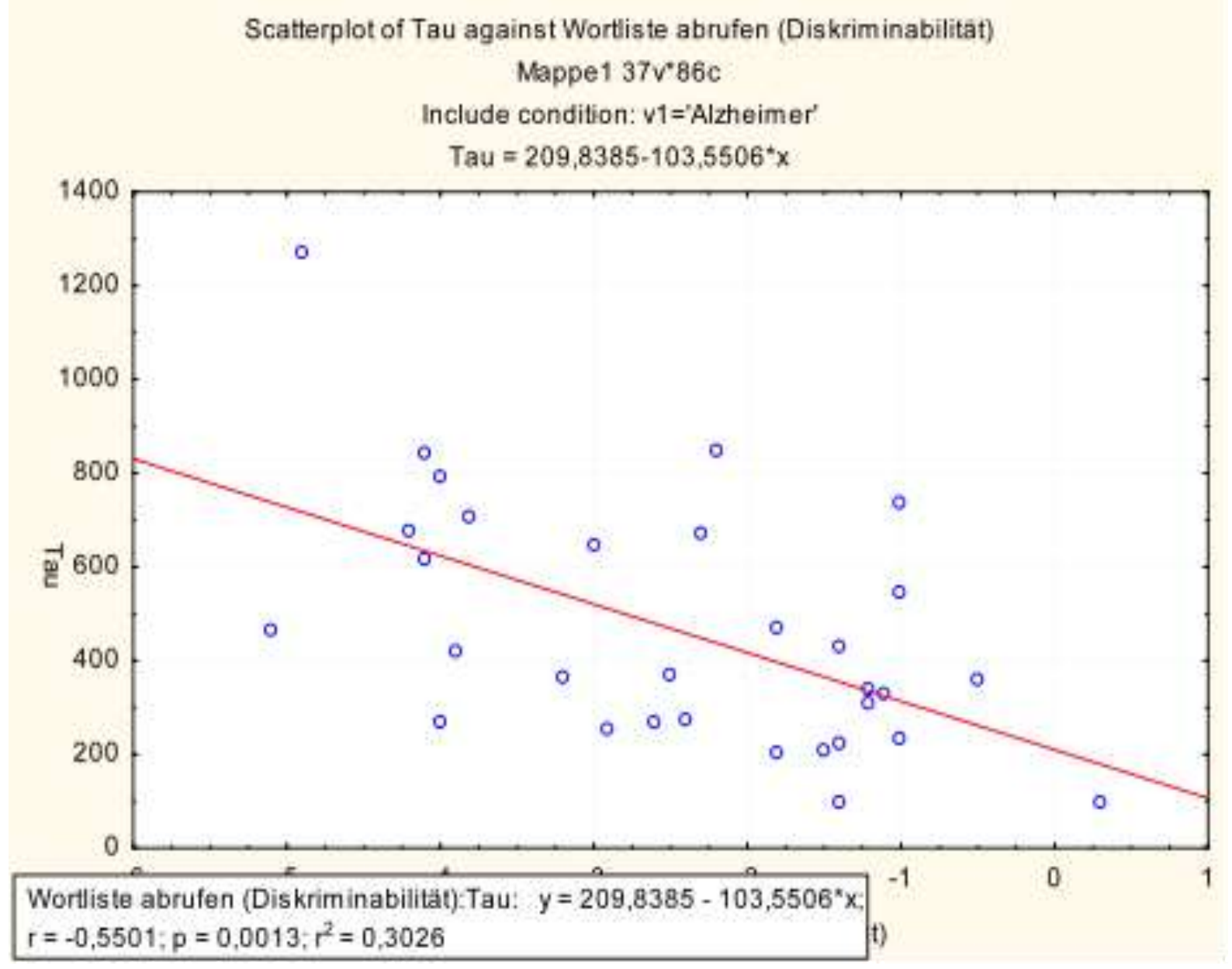

Bei Betrachtung eines möglichen Zusammenhangs zwischen der Konzentration von Phospho-Tau und den CERAD-Testleistungen der Probanden ließ sich ebenfalls eine negative Korrelation nachweisen. Erhöhte Liquorspiegel von Phospho-Tau gingen mit statistisch schlechteren Leistungen in den Testbereichen Wortliste Abrufen ( $r=-$ $\left.0,360 / p=0,020 / r^{2}=0,129\right)$, Wortliste Savings $\left(r=-0,350 / p=0,026 / r^{2}=0,122\right)$ und Wortlis- 
te Diskriminabilität $\left(r=-0,454 / p=0,003 / r^{2}=0,206\right)$ einher.

Die Aufteilung nach Diagnosen zeigte, dass diese, konkordant zu jenen Ergebnissen von Tau-Protein, lediglich für Patienten mit Morbus Alzheimer $(n=30)$ gelten. Ein statistischer Zusammenhang zwischen Phospho-Tau und Testleistungen der Patienten mit PDD $(n=9)$ zeigte sich indes nicht.

Tabelle 16: Phospho-Tau vs. neuropsychologische Testung ( $A D, n=30)$

\begin{tabular}{|l|c|c|c|}
\hline $\begin{array}{l}\text { Korrelation nach } \\
\text { Pearson }\end{array}$ & $\begin{array}{c}\text { Wortliste Abru- } \\
\text { fen }\end{array}$ & $\begin{array}{c}\text { Wortliste } \\
\text { Savings }\end{array}$ & $\begin{array}{c}\text { Wortliste Dis- } \\
\text { kriminabilität }\end{array}$ \\
\hline P-Tau (pg/ml) & & & $\mathbf{- 0 , 5 1 1}$ \\
r & $-0,345$ & $\mathbf{0 , 0 0 4}$ & $\mathbf{0 , 4 9 2}$ \\
$p$ & 0,061 & $\mathbf{0 , 2 6 0 6}$ & $\mathbf{0 , 2 4 2}$ \\
$r^{2}$ & 0,119 & & \\
\hline
\end{tabular}

Tabelle 17: Phospho-Tau vs. neuropsychologische Testung (PDD, $n=9$ )

\begin{tabular}{|l|c|c|c|}
\hline $\begin{array}{l}\text { Korrelation nach } \\
\text { Pearson }\end{array}$ & $\begin{array}{c}\text { Wortliste Abru- } \\
\text { fen }\end{array}$ & $\begin{array}{c}\text { Wortliste } \\
\text { Savings }\end{array}$ & $\begin{array}{c}\text { Wortliste Dis- } \\
\text { kriminabilität }\end{array}$ \\
\hline P-Tau (pg/ml) & & 0,120 & 0,157 \\
$r$ & 0,013 & 0,757 & 0,686 \\
$p$ & 0,977 & 0,014 & 0,024 \\
\hline$r^{2}$ & 0,000 & & \\
\hline
\end{tabular}


Abbildung 28: Scatterplot P-Tau vs. Wortliste Diskriminabilität (AD)

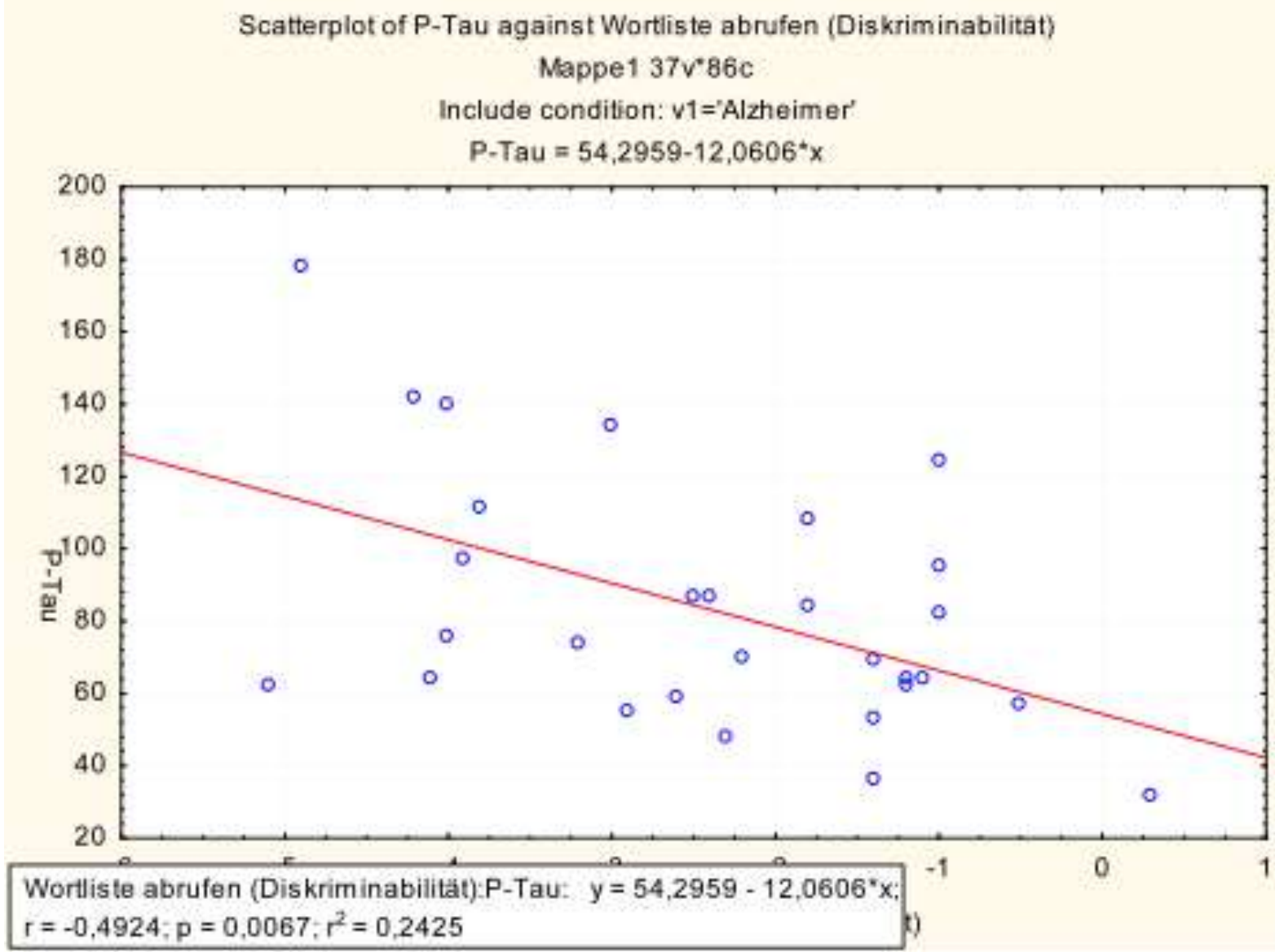

\subsubsection{Einfluss des Apo-E-Genotyps}

Für keine der Erkrankungen zeigte sich ein signifikanter Einfluss des Apo-EGenotyps auf die Leistungen in der neuropsychologischen Testung oder auf die Konzentration der übrigen Liquorparameter.

\subsubsection{Einfluss des Codon-129-Polymorphismus}

Für PDD-Patienten $(n=7)$ korrelierte eine M/V-Heterozygotie mit einem signifikant besseren Abschneiden in den Testbereichen Semantische Flüssigkeit und Wortliste Introsionen.

Generell zeigte sich sowohl für AD und PDD eine tendenziell bessere neuropsychologische Testleistung bei Vorliegen der M/V-Heterozygotie, die jedoch ohne statistische Signifikanz blieb. 
Abbildung 29: Scatterplot Codon-129 vs. Semantische Flüssigkeit (PDD)

Scatterplot of Semantische Fluss sigkeit against Codon 129

Mappe1 $37 v^{*} 86 \mathrm{c}$

Include condition: $v 1=' P$ arkinsondemenz'

Semantische Fluss sigkeit $=-173,7+1,7^{*} \mathrm{x}$

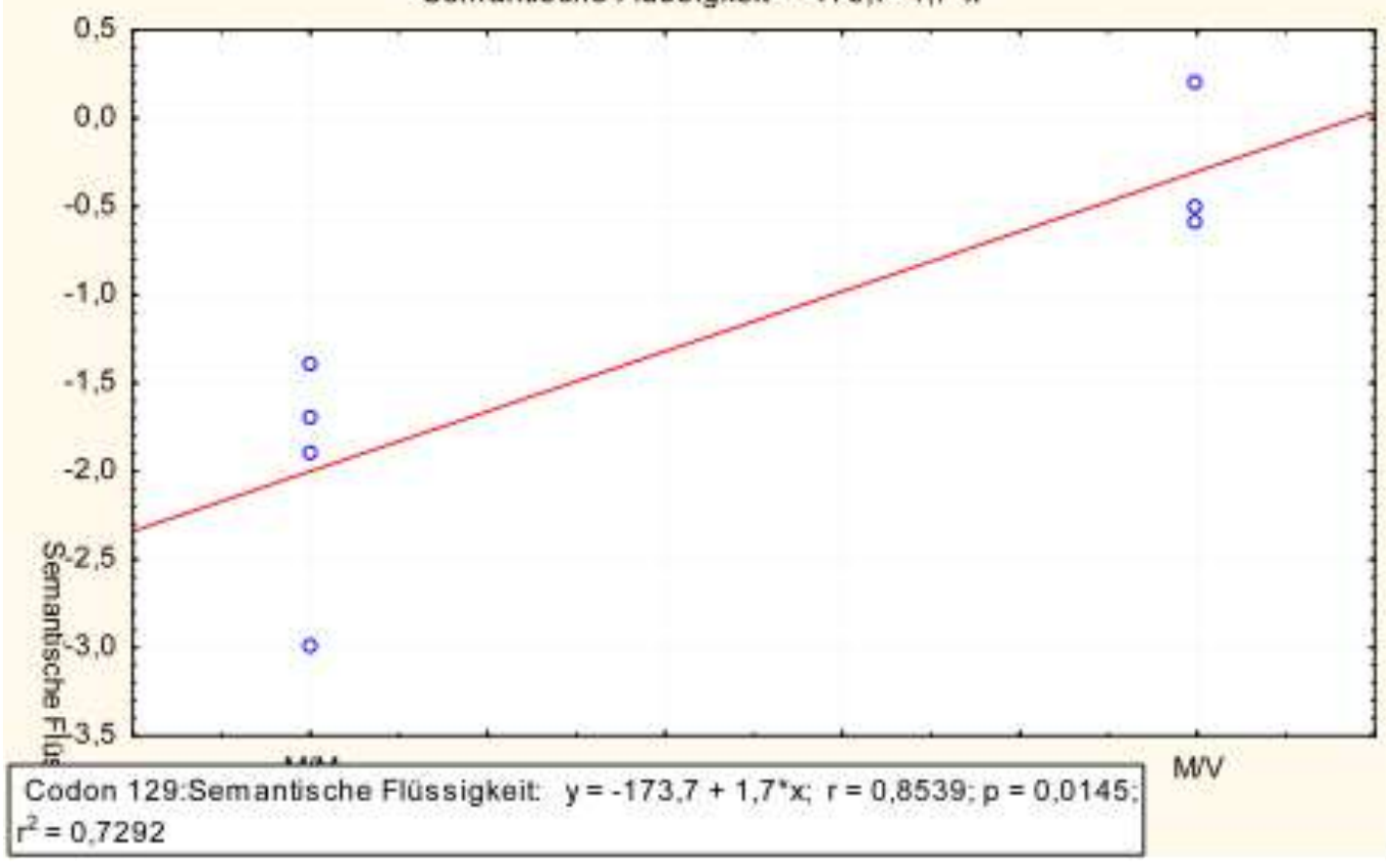

Abbildung 30: Scatterplot Codon-129 vs. Wortliste Introsionen (PDD)

Scatterplot of Wortlis te abrufen(introsionen) against Codon 129

Mappe1 $37 v^{*} 86 \mathrm{c}$

Include condition: $v 1=' P$ arkinsondemenz'

Wortliste abrufen (introsionen $)=-162,1833+1,5917^{*} \mathrm{x}$

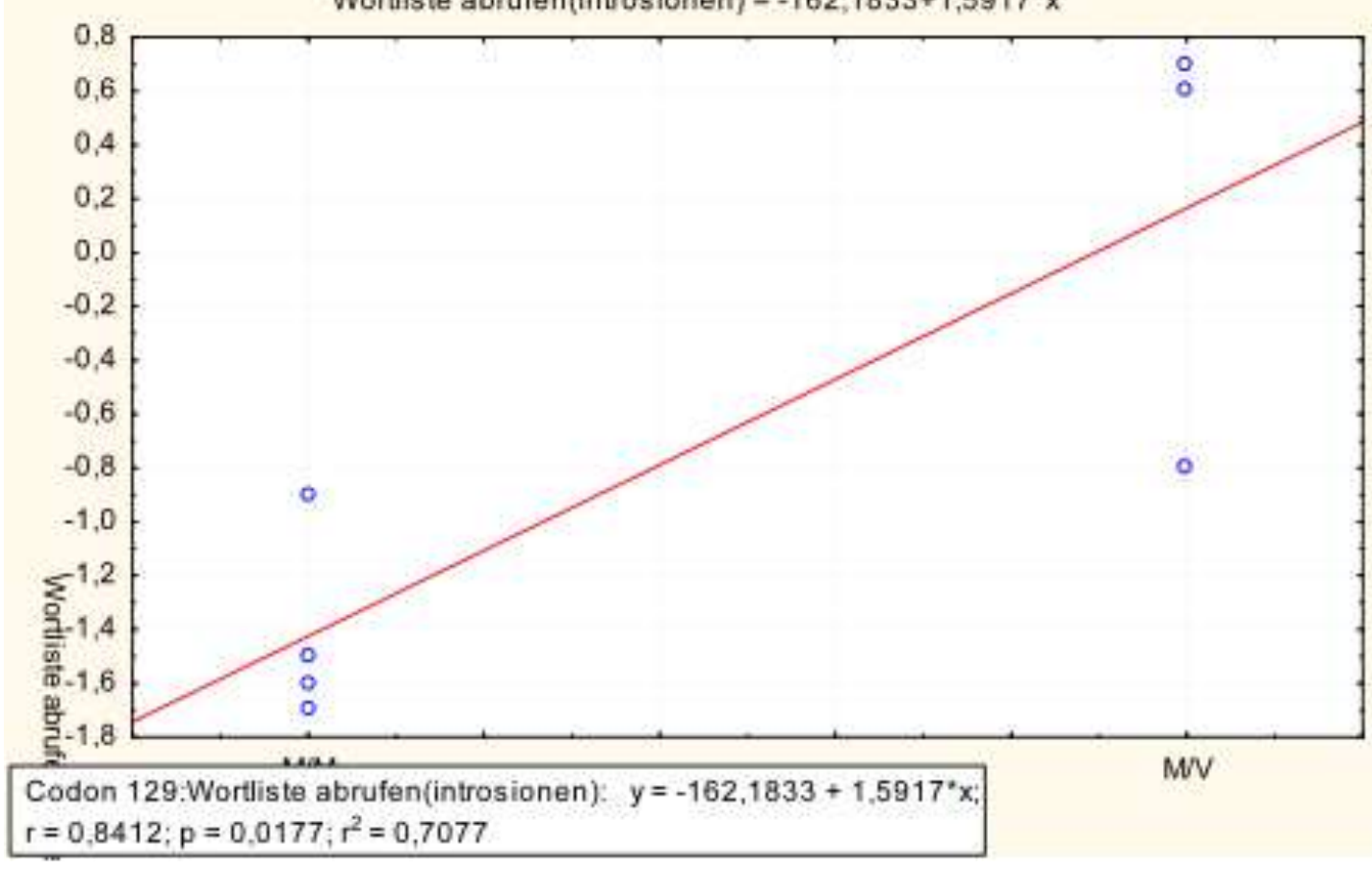


Bei Überprüfung eines möglichen Zusammenhanges zwischen dem Codon-129Polymorphismus und der Konzentration der übrigen untersuchten Liquorparameter, konnte dieser für Homocystein (PDD, $n=6)$ und VDBP ( $A D, n=3$ ) gesehen werden. Eine Methionin-Homozygotie ging statistisch gesehen mit höheren Homocystein(PDD) und VDBP-Spiegeln (AD) einher.

\section{Abbildung 31: Scatterplot Codon-129 vs. Homocystein (PDD)}

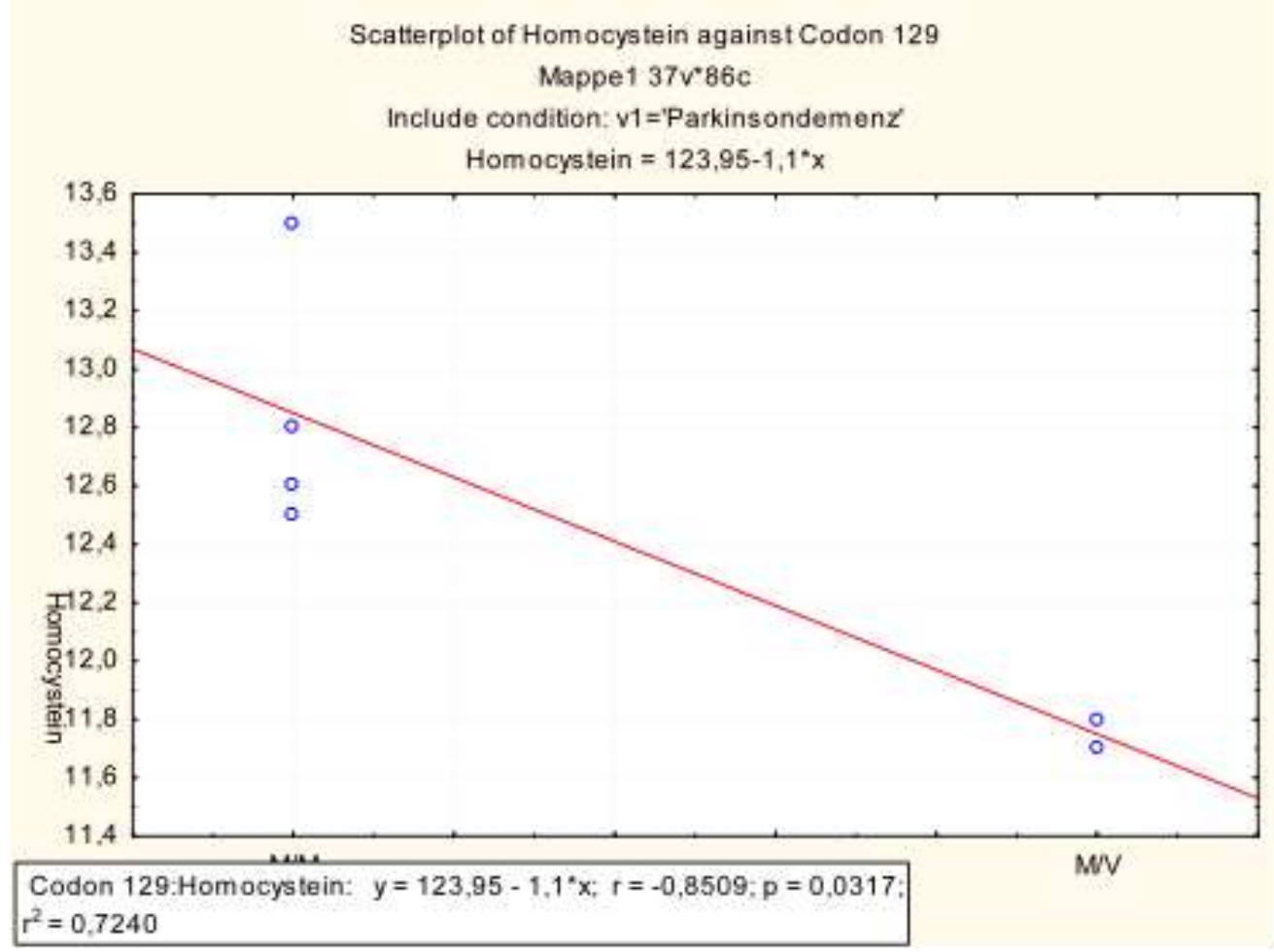

Abbildung 32: Scatterplot Codon-129 vs. VDBP (AD)

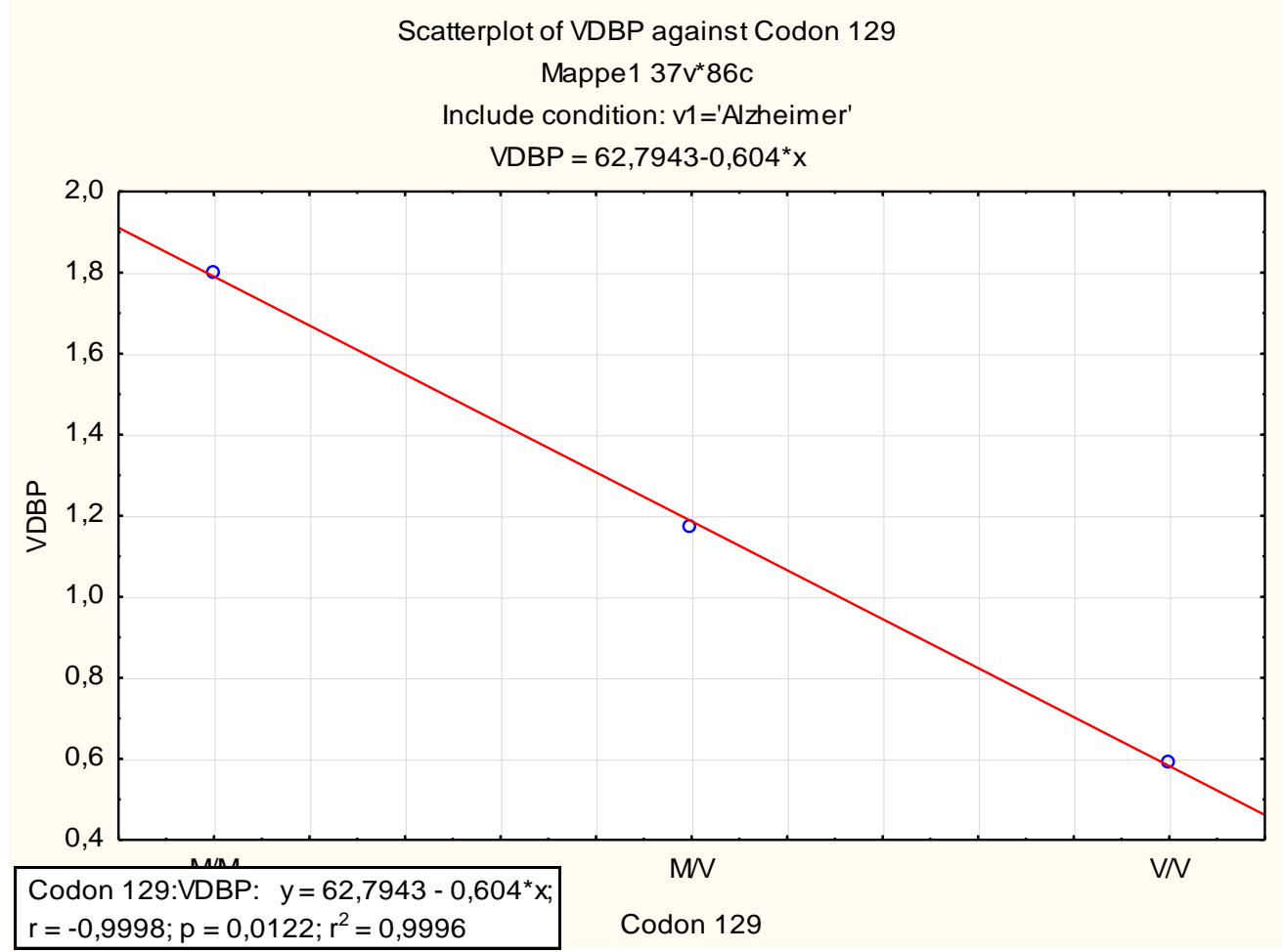




\section{DISKUSSION}

Etwa 32\% Prozent der an Morbus Parkinson erkrankten Patienten entwickeln im Verlauf dieser bis heute unheilbaren Erkrankung eine Demenz (Aarsland et al. 2005 b). In dieser Studie erfolgte zur Evaluation der für diese Erkrankung typischen kognitiven Ausfälle eine ausführliche neuropsychologische Testung. Des Weiteren wurden Liquormarker bestimmt, die bei Demenzerkrankungen verändert sein können. Zur besseren Beurteilbarkeit und Vergleichbarkeit der Ergebnisse für PDD-Patienten wurden Patienten mit der Diagnose Morbus Parkinson und Morbus Alzheimer einbezogen.

Im Folgenden erfolgt zunächst die kritische Auseinandersetzung mit Material und Methodik. Im Anschluss werden in dieser Studie erhobene Ergebnisse mit aktuellen wissenschaftlichen Erkenntnissen verglichen. Dabei wird versucht, Liquormarker zu finden, die mit der Entwicklung einer Demenz bei Morbus Parkinson in Verbindung stehen könnten.

\subsection{Material und Methodik}

\subsubsection{Patientenkollektiv}

Die Bedingungen zur Teilnahme an der Studie waren durch Festlegung von Ein- und Ausschlusskriterien genau definiert. Die Einordnung der Patienten zu den jeweiligen Diagnosen sollte in Form einer Dreiteilung anhand geltender Richtlinien von Hughes et al. (1992), McKhann et al. (1984) und McKeith et al. (1996/1999) in „wahrscheinlich“, "möglich“ und "sicher" erfolgen. Methodenkritisch muss allerdings angemerkt werden, dass die Diagnosen im klinischen Alltag und in Absprache mit den behandelnden Ärzten oftmals in Zusammenschau aller Befunde dichotom gestellt wurden, das heißt primär eine Zweiteilung in „Vorhanden“ und „nicht vorhanden“ getroffen wurde.

\subsubsection{Neuropsychologische Testung}

Die genutzte CERAD-Testbatterie ist ein in der neuropsychologischen Diagnostik 
mittlerweile weit verbreitetes und für den deutschen Sprachraum validiertes Testinstrument zur Beurteilung kognitiver Ausfallprofile. Die verlässliche Trennung zwischen gesunden Kontrollprobanden, leichter kognitiver Beeinträchtigung und manifester Demenz konnte in mehreren Studien bestätigt werden (Barth et al. 2005, Diehl et al. 2005). Die im Rahmen der neuropsychologischen Testung gewonnenen Erkenntnisse über die kognitiven Leistungen der Patienten wurden an die behandelnden Ärzte weitergegeben und waren somit Teil der Diagnosefindung.

Bezüglich der Anzahl der erfolgreich durchgeführten und somit in die Auswertung eingehenden neuropsychologischen Testungen bestand innerhalb der Diagnosegruppen eine Heterogenität. Die größte Gruppenstärke gab es für die Patienten mit der Diagnose Morbus Alzheimer ( $n=29-35$ je nach Subtest), gefolgt von PDD ( $n=12-$ 22) und PD $(n=4)$. Ursächlich hierfür ist die zusätzliche Nutzung von CERADErgebnissen für Patienten mit Morbus Alzheimer, die aus unserer parrallel laufenden Studie "Charakterisierung von Prädiktoren (Klinik, Bildgebung, Liquor- und Serumparameter) rapid progressiver Verläufe des Morbus Alzheimer als Differentialdiagnose zur Creutzfeldt-Jakob-Krankheit“ stammen. Die Aussagekraft der kognitiven Testprofile für PD ist aufgrund der geringen Fallzahl daher als geringer einzuschätzen.

Die bei Planung des Studiendesigns vorgesehenen Follow-up-Untersuchungen nach neun Monaten konnten lediglich für acht Patienten durchgeführt werden. Gewonnene Ergebnisse der Ersttestung und parallel bestimmte Markerkonzentrationen sind daher im Sinne einer Längsschnittstudie als Momentaufnahme zu sehen.

\subsubsection{Bestimmung der Liquorparameter}

Die Untersuchung der Proteine Tau-, Phospho-Tau und Amyloid-beta1-42 im Liquor hat mittlerweile Einzug in die Differentialdiagnostik von Demenzerkrankungen, insbesondere des Morbus Alzheimer, gefunden. Die im Rahmen dieser Studie bestimmten Konzentration von Tau-Protein, Phospho-Tau und Amyloid-beta 1-42 wurden anhand validierter ELISA-Testkits bestimmt und können somit als vergleichbar mit Konzentrationen aus der gängigen Literatur bezeichnet werden. Die übrigen Parameter wurden aufgrund von Hinweisen aus vorherigen Studien mittels kommerziell erhältlicher Testkits und in Rücksprache mit beteiligten Firmen bestimmt. Die Vergleichbarkeit der erhobenen experimentellen Liquorparameter mit ebenfalls experimentellen Konzentrationen aus anderen Studien kann nur unter Vorbehalt erfolgen. 
Bezüglich der Anzahl der Liquoruntersuchungen besteht für jede der drei untersuchten Krankheiten eine ausreichende Fallzahl, um valide Hinweise für Konzentrationsänderungen aufzuzeigen und diese in Folgestudien weiter zu evaluieren.

\subsection{Ergebnisse}

\subsubsection{Alters- und Geschlechtsverteilung}

Bei einem mittleren Alter von 68,25 Jahren bestanden zwischen den beobachteten Diagnosen keine signifikanten Unterschiede, wobei die kognitiv gesunden Probanden der PD-Gruppe mit einem Mittelwert von 65,25 Jahren unerheblich jünger waren. Die in dieser Studie beobachtete Altersstruktur ist im Vergleich zu anderen Studien relativ jung, in denen sich die Prävalenzrate der Demenz von 1,2\% ab dem 65. Lebensjahr etwa alle fünf Altersjahre verdoppelt und bei den über 90 -Jährigen über $30 \%$ beträgt (Bickel 2010). Eine Ursache für das recht junge Patientenkollektiv kann zum einen in der Einbeziehung der jüngeren PD-Patienten gesehen werden, zum anderen aber auch in dem recht häufigen Vorkommen besonders junger Demenzpatienten in hochspezialisierten Demenzambulanzen wie jener der Universitätsmedizin Göttingen liegen. Der Vorteil des verhältnismäßig jungen Alters der Patienten liegt sicherlich in der somit besseren Anwendbarkeit der Ergebnisse aus neuropsychologischen Testungen und Liquorbestimmungen für Patienten mit erstem Verdacht auf eine Demenz. Schließlich ist besonders die Früherkennung kognitiver Defizite und prädiktiver Liquormarker ein Ziel der gegenwärtigen Demenzforschung.

Gemittelt über alle Diagnosen bestand eine Geschlechtsverteilung von 58,5 \% männlichen und $41,5 \%$ weiblichen Patienten, die im Vergleich mit der Literatur deutlich zugunsten des männlichen Geschlechts verschoben scheint. Zwar befallen Demenzerkrankungen im Allgemeinen Männer und Frauen gleich häufig, durch die deutlich längere Lebenserwartung von Frauen treten diese gemäß Literatur mit bis zu $70 \%$ der Fälle allerdings deutlich häufiger in Erscheinung (Bickel 2010). Ursache für das in dieser Studie verschobene Geschlechterverhältnis ist am ehesten das deutlich häufigere Auftreten von Morbus Parkinson und somit auch PDD beim männlichen Geschlecht (Miller et al. 2010, Dluzen und McDermott 2000). 


\subsubsection{Ausbildung}

Die mittlere Ausbildungsdauer unterschied sich innerhalb der drei Diagnosen nicht signifikant, tendenziell war allerdings eine längere Ausbildung der nicht kognitiv eingeschränkten PD-Patienten zu beobachten. Jene Beobachtung legt den Verdacht nahe, dass nicht nur Normalleistungen in neuropsychologischen Tests mit der Dauer der Ausbildung korrelieren (Bickel 2010), sondern ein höherer Bildungsstatus womöglich präventiv im Hinblick auf die Ausbildung einer Demenz zu sein scheint (Launer et al. 1999, Mortimer et al. 2003). Auch Glatt konnte eine Assoziation von Ausbildung und der Wahrscheinlichkeit der Entwicklung einer Demenz bei Morbus Parkinson nachweisen (Glatt et al. 1996). Diese Annahme müsste aufgrund der geringen Fallzahl an untersuchten kognitiv gesunden Patienten allerdings in Folgestudien geprüft werden.

\subsubsection{Neuropsychologische Testung}

Für insgesamt 15 Testbereiche der angewendeten neuropsychologischen Testbatterie konnten signifikante Unterschiede im Gruppenvergleich gefunden werden. Des Weiteren grenzten sich die kognitiven Ausfallprofile der Demenzerkrankungen in den meisten der untersuchten Bereiche deutlich von denen der Normstichprobe ab. Im Folgenden werden Testleistungen der verschiedenen Erkrankungen in kognitive Bereiche zusammengefasst, erläutert und mit Ergebnissen der Literatur verglichen. AuBerdem erfolgt der Versuch der Unterscheidung von AD und PDD anhand ihrer typischen Ausfallprofile.

\subsubsection{Verbales und nonverbales Gedächtnis}

Die Gedächtnisstörung gilt im Allgemeinen als zentrales Symptom der Demenz. Trotzdem bestehen diesbezüglich bedeutende Unterschiede zwischen den verschiedenen Erkrankungen. So ist eine Störung des verbalen und nonverbalen Gedächtnisses oft Hauptsymptom primär kortikaler Störungen, deren Hauptvertreter die Demenz vom Alzheimertyp darstellt und im Rahmen der subkortikalen Demenzen, deren klassischer Vertreter die vaskuläre Demenz (Roman et al. 2002) ist, oftmals eher zu vernachlässigen. Eine solche primäre Gedächtnisstörung entsteht durch direkte 
Schädigung der an der Speicherung von Gedächtnisinhalten beteiligten Neurone. Sind nicht die eigentlichen Neurone, sondern lediglich subkortikale Verschaltungen defekt, resultiert aufgrund von eingeschränkter Konzentration und reduzierter Exekutive zwar ebenfalls eine Störung des verbalen Gedächtnisses, diese lässt sich jedoch durch vereinfachte Abrufbedingungen (Wortliste Wiedererkennen) als sekundäre Gedächtnisstörung mit erhaltenen kortikalen Neuronen entlarven (Schmidtke und Hüll 2007).

Die neuropsychologischen Testprofile der in dieser Studie untersuchten ADPatienten spiegeln die beschriebenen Defizite des verbalen Gedächtnisses mit primärer Encodierstörung im Sinne einer kortikalen Demenz wider. So bestehen in den Bereichen Wortliste Lernen und Abrufen mit gemittelten Z-Werten von -3,22 und 2,34 über alle Testbereiche besonders mangelhafte Leistungen. Des Weiteren profitieren die Patienten nicht von erleichterten Abrufbedingungen im Testteil Wortliste Wiedererkennen (Z-Wert -2,45).

Die untersuchten PDD-Patienten weisen mit Z-Werten von -2,32 (Wortliste Lernen) und -1,24 (Wortliste Abrufen) eine (nicht signifikant) bessere Leistung als die ADPatienten auf. Auch in anderen Studien konnte dieses bessere Abschneiden von PDD-Patienten vor allem im Bereich des verbalen episodischen Gedächtnisses gezeigt werden (Tröster 2008). Von Bedeutung ist außerdem das signifikant bessere Abschneiden der PDD-Patienten im Testteil Wortliste Wiedererkennen (Z-Wert -1,02) und der somit deutliche Hinweis auf einen bedeutenden subkortikalen Anteil an der Demenz. Diese Ergebnisse decken sich mit jenen von Janvin et al., die für PDD ein zu 56\% subkortikal geprägtes Ausfallprofil angeben (Janvin et al. 2006).

Das nonverbale Gedächtnis wird im Rahmen der CERAD-Testbatterie durch Abrufen von zuvor gezeichneten geometrischen Figuren geprüft. Hier zeigte sich im Vergleich von AD und PDD ein zum Testteil Wortliste Abrufen konkordantes Leistungsverhältnis mit tendenziell besseren Leistungen der PDD-Patienten im Vergleich zu AD, wobei die Leistungen hier generell schlechter als im Bereich des verbalen Gedächtnisses waren. Beide beobachteten demenziellen Erkrankungen weisen also ein stärkeres Defizit im Bereich des nonverbalen, figuralen Gedächtnisses auf. Ein in der Literatur berichtetes im Verhältnis zu Morbus Alzheimer schlechteres Abschneiden der PDD-Patienten im Bereich des nonverbalen Gedächtnisses (Aarsland et al. 2003 b) zeigte sich allerdings nicht. 


\subsubsection{Visuell-räumliches Denken}

Das visuell-räumliche Denken ist in dieser Studie über das Abzeichnen von Figuren steigender Komplexität geprüft worden. Beeinträchtigungen in diesem Bereich gehen oft mit räumlichen Orientierungsstörungen und somit hoher Relevanz für das Alltagsleben der Patienten einher.

Für AD und PDD zeigten sich Z-Werte von -2,16 und -1,95 ohne statistisch signifikanten Unterschied. Zwar offenbart der Blick auf die graphische Darstellung des kognitiven Ausfallprofiles, dass PDD in diesem Subtest weniger Unterschiede zu AD als im Bereich Wortliste Lernen aufweist, von einem in anderen Studien angegebenen überproportional schlechten Abschneiden der PDD-Patienten im visuellräumlichen Denken (Tröster 2008) ist aber nicht zu sprechen.

Dabei sei allerdings anzumerken, dass dieser Testabschnitt der CERAD-Testbatterie im Rahmen eines Vergleiches verschiedener neuropsychologischer Testungen und deren Gültigkeit als insuffizient bezeichnet wurde. So seien die ersten drei Figuren zu leicht, der letzte dreidimensionale Würfel allerdings selbst für kognitiv gesunde ältere Menschen oftmals nur fehlerhaft abzuzeichnen (Schmidtke und Hüll 2007). Unsere Ergebnisse der vier nicht kognitiv eingeschränkten Parkinsonpatienten scheinen diese Annahme aufgrund der sogar leicht über der Normstichprobe liegenden Ergebnisse jedoch nicht zu untermauern. Ob Parkinsonpatienten ohne Demenz allerdings tatsächlich vollkommen normale Leistungen im visuell-räumlichen Denken zeigen, müsste aufgrund der geringen Stichprobengröße in Folgestudien erneut untersucht werden.

\subsubsection{Benennen}

Störungen des Benennens von Gegenständen sind zentrales und oftmals frühes Symptom kortikaler Gedächtnisstörungen wie dem Morbus Alzheimer. In vorangegangenen Studien am Boston Naming Test, der im Rahmen der CERAD-Testbatterie in einer Kurzform angewendet wird, zeigten sich entsprechend schlechtere Leistungen von AD-Patienten im Vergleich zu PDD (Tröster et al. 1996). Diese konnten wir in dieser Studie bei sogar dezent besseren Leistungen der AD-Patienten allerdings nicht bestätigen. Eine Ursache dieser mangelhaften Unterscheidung könnte in der angewendeten Kurzform des Tests mit lediglich 15 anstatt 60 (Originalversion) zu benennenden Gegenständen liegen. Wahrscheinlicher ist aber eine gemischt kortikal-subkortikal vorliegende Demenz der PDD-Patienten mit Leistungsstörungen im 
Bereich des Objektbenennens.

Der Boston Naming Test eignet sich somit zumindest in der hier angewendeten Kurzform nicht als Screeningtest bzw. Unterscheidungsmerkmal zwischen AD und PDD.

\subsubsection{Wortflüssigkeit}

Neben Defiziten im Benennen von Gegenständen ist ein überproportional schlechtes Abschneiden im Bereich der semantischen verbalen Flüssigkeit typisch für primär kortikale Demenzen. Auch die Ergebnisse unserer Testung untermauern diese Theorie mit deutlich negativeren mittleren Z-Werten für den Testteil semantische vs. phonematische Flüssigkeit für Morbus Alzheimer. Allerdings zeigt sich ein ähnliches Verhältnis mit im Allgemeinen geringfügig besseren Leistungen auch für PDDPatienten. Eine Unterscheidung der beiden Erkrankungen anhand des Verhältnisses zwischen semantischer und phonematischer Flüssigkeit scheint also kaum möglich zu sein.

\subsubsection{Exekutive}

Als Exekutive wird ein Spektrum kognitiver Fähigkeiten bezeichnet, dass mit zielgerichtetem, planvollem und flüssigem Denken verbunden wird. Dazu zählen beispielsweise Aufmerksamkeit, Konzentration und Denkgeschwindigkeit. Aufgrund der weitreichenden Folgen beeinflussen Defizite der Exekutive all jene Testbereiche, die Tempo, Planung und aktive Informationsverarbeitung erfordern (Schmidtke und Hüll 2007). Viele Studien berichten über besonders schlechte Leistungen von PDD- und DLB-Patienten im Bereich von Exekutive und Aufmerksamkeit (Tröster 2008, Collerton et al. 2003), andere bezweifeln wiederum die Messbarkeit der Exekutive in neuropsychologischen Testungen (Connor et al. 1998). Im Fall der angewendeten CERAD-Testbatterie wurde versucht, die Exekutive anhand des Trailmaking-Tests sowie im Speziellen durch Bildung des Quotienten aus Testteil B/A darzustellen. Hierbei zeigte sich für die untersuchten AD-Patienten mit einem mittleren Z-Wert von 0,13 eine Exekutivleistung nahe derjenigen der Normstichprobe. Für PDD und PD ergab sich hingegen jeweils eine um -0,4 Standardabweichungen verschobene Leistung. Hinweise für schlechteres Abschneiden der PDD-Patienten gegenüber AD bestehen somit, allerdings scheinen auch die nicht kognitiv eingeschränkten PDPatienten exekutive Funktionsstörungen aufzuweisen. Jene sind also nicht primär demenziell, sondern in Verbindung mit Morbus Parkinson im Allgemeinen zu sehen. 


\subsubsection{Liquorparameter}

Ziel dieser Studie war neben der Evaluation typischer kognitiver Ausfallprofile vor allem die Validierung neuer Liquorparameter, die eine Unterscheidung zwischen $A D$ und PDD sowie PD und PDD ermöglichen. In einem weiteren Schritt wurde versucht, eine Korrelation von kognitiven Defiziten mit Konzentrationen von Liquormarkern herzustellen, um eine Aussage über die Anwendbarkeit des Liquormarkers als Prädiktor für die Ausprägung oder zukünftige Entwicklung einer Demenz zu ermöglichen. Im Folgenden werden zunächst die Ergebnisse der in der Alzheimerdiagnostik etablierten Liquorparameter Tau-Protein, Phospho-Tau und Amyloid-beta 1-42 diskutiert und mit Literaturangaben verglichen.

Im Weiteren widmen wir uns der Diskussion um die Anwendbarkeit der in dieser Studie experimentell bestimmten Liquormarker Apolipoprotein E, VDBP, TGF-B1 und Homocystein. Von besonderer Bedeutung soll dabei sein, ob sich einer der Liquormarker zukünftig für die Diagnostik von PDD eignen könnte.

\subsubsection{Die etablierten Liquormarker Tau-Protein, Phospho-Tau und Abeta 1-42}

Wie bereits in der Einleitung dieser Arbeit erwähnt, sind die klassischen Demenzmarker Tau-Protein, Phospho-Tau und Amyloid-beta praktisch vor allem für die Diagnostik eines Morbus Alzheimer von Bedeutung und im Rahmen vieler Studien validiert. Die Gesamtkonzentration von Tau-Protein im Liquor ist dabei vor allem ein Zeichen neuronaler Schädigung und Degeneration und gemäß geltender Literatur für AD-Patienten im Schnitt 3,2 fach erhöht (Blennow et al. 2001). Zur Differentialdiagnostik zwischen Demenz und akutem Nervenzelluntergang, zum Beispiel im Rahmen eines Schlaganfalles, sollte zusätzlich allerdings immer Phospho-Tau bestimmt werden. Dieses steigt beim akuten Nervenzelluntergang nicht an und kann daher als demenzspezifisch angesehen werden (Hesse et al. 2001). Abeta 1-42 konnte als Hauptprotein der neurotoxischen Plaques bei Morbus Alzheimer identifiziert werden und ist aufgrund seiner Aggregation in erniedrigter Konzentration im Liquor nachweisbar (Masters et al. 1985).

Die beschriebene Kombination aus signifikant erhöhtem Tau-Protein und PhosphoTau sowie erniedrigtem Amyloid-beta 1-42 zeigte sich auch für die in unserer Studie untersuchten AD-Patienten, wobei aufgrund des fehlenden gesunden Vergleichskollektivs lediglich ein Vergleich zu Patienten mit PDD und PD möglich war. Hier ermög- 
licht die Abeta 1-42-Konzentration eine zuverlässige Unterscheidung zwischen $A D$ und PD bzw. PDD, eignet sich allerdings nicht zur Diagnosestellung des Morbus Alzheimers. Am deutlichsten erhöht zeigte sich Phospho-Tau mit einer Konzentration von $81,84 \mathrm{pg} / \mathrm{ml}$. Es eignet sich in dieser Studie somit am zuverlässigsten für die unabhängige Diagnose eines Morbus Alzheimers.

Die Anwendung der oben beschriebenen Demenzmarker für die Demenzdiagnostik bei Morbus Parkinson hat sich aufgrund mangelnder Forschungskenntnisse bzw. unterschiedlicher Ergebnisse bisheriger Studien noch nicht durchgesetzt. Für PD konnte in einer Vielzahl von Studien eine normale bzw. der gesunden Kontrollgruppe entsprechende Konzentration des Gesamt-Tau im Liquor gefunden werden (Blennow et al. 1995, Molina et al. 1997, Jansen et al. 1998, Kahle et al. 2000, Sjögren et al. 2000). Dabei schwankten die gemessenen Mittelwerte bei Nutzung des in unserer Studie ebenfalls verwendeten Innotest ${ }^{\circledR} \mathrm{hTau}$ zwischen 117 und $313 \mathrm{pg} / \mathrm{ml}$. Auch für PDD wird in den meisten Studien von einer unveränderten Tau-Konzentration berichtet (Jansen et al. 1998, Parnetti et al. 2008), allerdings gibt es auch Hinweise für eine signifikante, jedoch im Bereich der Normalwerte liegende Erhöhung von Tau-Protein bei PDD im Vergleich zu PD (Mollenhauer et al. 2006).

Die gemittelten Total-Tau-Werte unserer Studie lagen mit 249,90 pg/ml für PD und 215,28 pg/ml für PDD im Bereich der oben genannten Literaturergebnisse und somit ebenfalls weit unterhalb des pathologischen Grenzwertes von $450 \mathrm{pg} / \mathrm{ml}$. Des Weiteren entsprechen unsere Ergebnisse jenen von Jansen und Parnetti und zeigen im Gegensatz zu Mollenhauer et al. keinen signifikanten Unterschied zwischen PDD und PD. Da die Tau-Protein-Konzentration bei PDD im Vergleich zu PD sogar leicht erniedrigt ist, eignet sie sich bei fehlender Korrelation mit dem Ausmaß der kognitiven Einschränkung keinesfalls zur Diagnose eines demenziellen Prozesses bei Morbus Parkinson. Eine Bestimmung von Tau-Protein zur Differentialdiagnose AD vs. $P D$ und $A D$ vs. PDD ist aufgrund der von uns bestätigten signifikanten Konzentrationsunterschiede allerdings sinnvoll und sollte klinische Anwendung finden.

Der Bestimmung des an sich demenzspezifischeren Phospho-Tau für die Diagnose von PDD haben sich bisher nur wenige Forschungsgruppen gewidmet. In einer 2008 veröffentlichten Studie von Parnetti et al. wird von normalen Phospho-TauKonzentrationen bei PD $(37 \mathrm{pg} / \mathrm{ml})$ und PDD $(52 \mathrm{pg} / \mathrm{ml})$ mit dezenter, allerdings nicht signifikanter Erhöhung bei PDD berichtet (Parnetti et al. 2008). Ähnliche Werte finden sich auch in unserer Studie, wobei die Phospho-Tau-Konzentration bei PDD (50,89 
$\mathrm{pg} / \mathrm{ml})$ sogar leicht niedriger als bei PD $(53,73 \mathrm{pg} / \mathrm{ml})$ ist. Ursache für die normalen Werte bei PDD könnten in der berichteten relativen Spezifität von Phospho-Tau für $A D$ und dessen Anwesenheit neurofibrillärer Tangles und Plaques im Bereich des Hippocampus liegen (Hampel et al. 2004). Zusammenfassend sei hervorzuheben, dass sich auch Phospho-Tau nicht als Liquormarker einer Demenz bei Morbus Parkinson eignet, aufgrund signifikanter Konzentrationsunterscheide zu AD allerdings zu dessen Differentialdiagnose nützlich sein kann.

Bezüglich Abeta 1-42 und Morbus Parkinson wird in allen Studien von Normwerten, das heißt Konzentrationen von über $450 \mathrm{pg} / \mathrm{ml}$ für PD (Kanemaru et al. 2000, Sjögren et al. 2000, Holmberg et al. 2003, Verbeek et al. 2003, Mollenhauer et al. 2006) und PDD (Mollenhauer et al. 2006) berichtet. Mollenhauer et al. konstatieren in ihrer 2006 veröffentlichten Studie mit verhältnismäßig großer Gruppenstärke für PD ( $n=23)$ und PDD ( $n=73$ ) allerdings einen signifikanten Gruppenunterschied, also deutlich niedrigere Abeta 1-42-Konzentration für PDD (470 pg/ml) im Vergleich zu PD (559 $\mathrm{pg} / \mathrm{ml}$ ). Diesen können wir in unserer Studie bei fehlender Signifikanz im Paarvergleich und zudem leicht höheren Liquorkonzentrationen von Abeta für $\operatorname{PDD}(718,58$ pg/ml) im Vergleich zu PD (691,00 pg/ml) nicht bestätigen. Der deutliche Konzentrationsunterschied zwischen AD vs. PDD und AD vs. PD belegt allerdings die Anwendbarkeit des Parameters für die Diagnose Morbus Alzheimer.

Zusammenfassend sei festzustellen, dass sich AD und PD in Bezug auf die etablierten Demenzparameter Tau, Phospho-Tau und Abeta 1-42 vom Liquorprofil her tendenziell stärker ähneln als die beiden demenziellen Erkrankungen PDD und AD. Auch bei stärkeren kognitiven Ausfällen nähert sich das Liquorprofil eines Patienten mit PDD also keinesfalls jenem von AD an. Dieser Unterschied zwischen PDD und $A D$ unterstützt die Annahme einer unterschiedlichen Pathologie bzw. Genese der Erkrankungen und ermöglicht die zuverlässige Anwendung der Marker in der Differentialdiagnose AD vs. PDD. Eine alleinige Bestimmung von Tau-Protein, PhosphoTau und Abeta 1-42 bietet sich zur Diagnose oder als Prädiktor der Entwicklung einer Demenz bei Morbus Parkinson allerdings nicht an.

In folgend angegebener Tabelle findet sich eine Übersicht zu bisherigen Ergebnissen anderer Studien im Vergleich zu unseren Ergebnissen. 
Tabelle 18: Übersicht eigene Ergebnisse vs. Literatur

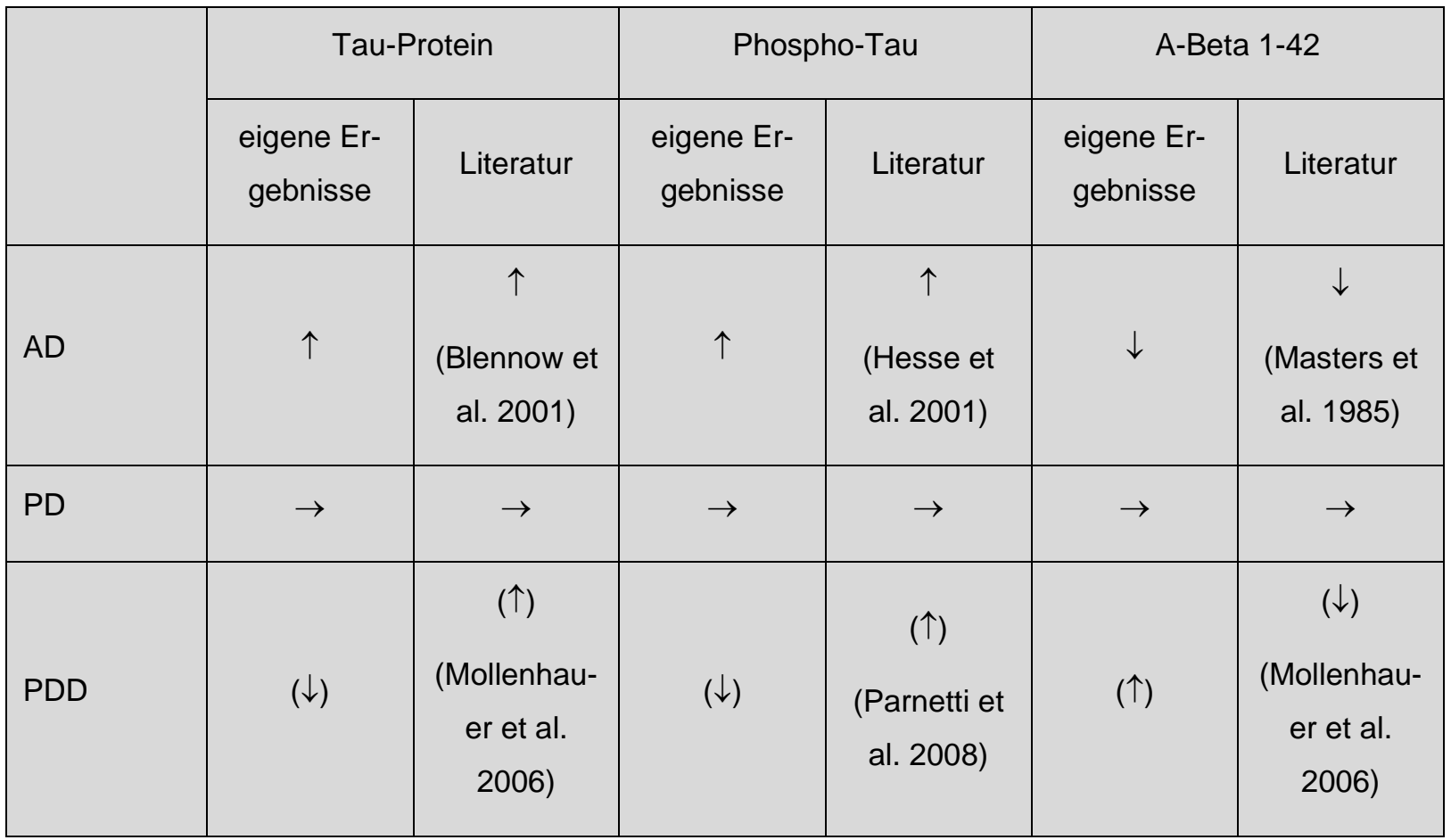

$\uparrow=$ signifikante Erhöhung im Vergleich zu Normwerten

$\downarrow=$ signifikante Erniedrigung im Vergleich zu Normwerten

$\rightarrow=$ normwertig

$(\uparrow)=$ normwertig, aber erhöht im Vergleich zu PD

$(\downarrow)=$ normwertig, aber erniedrigt im Vergleich zu PD

\subsubsection{Experimentelle Liquormarker: ApoE, Homocystein, TGFß-1, VDBP}

Die experimentelle Bestimmung der bisher nicht ausreichend validierten Liquormarker basierte auf Hinweisen für deren Beteiligung in Prozessen der Demenzentstehung.

Ursächlich für die Entscheidung zur quantitativen Messung der Apolipoprotein-EKonzentration im Liquor unserer Patienten waren verschiedenste Hinweise auf dessen Beteiligung in der Entwicklung von neurodegenerativen Erkrankungen. Zhang et al. konnten in einer 2008 veröffentlichten Studie eine signifikante Erniedrigung des ApoE-Spiegels im Liquor von AD- und PD-Patienten im Vergleich zu einer gesunden Kontrollgruppe $(3,9 \mu \mathrm{g} / \mathrm{ml})$ nachweisen. Die beiden neurodegenerativen Erkrankungen untereinander unterschieden sich mit 2,5 $\mu \mathrm{g} / \mathrm{ml}$ (AD) und 2,3 $\mu \mathrm{g} / \mathrm{ml}$ (PD) hingegen nicht (Zhang et al. 2008).

Die quantitative Bestimmung von ApoE im Liquor zeigte mit einer mittleren Konzentration von 2,42 $\mu \mathrm{g} / \mathrm{ml}$ eine signifikante Erniedrigung für die von uns untersuchten AD-Patienten, sowohl in Bezug auf PDD $(3,47 \mu \mathrm{g} / \mathrm{ml})$ und PD $(3,93 \mu \mathrm{g} / \mathrm{ml})$ als auch 
im Vergleich mit der gesunden Kontrollgruppe aus oben genannter Studie. Unsere Ergebnisse stützen also die Annahme einer deutlichen Erniedrigung des ApoESpiegels bei Patienten mit Morbus Alzheimer im Vergleich zu PDD und PD, die von Zhang et al. berichtete Erniedrigung der Konzentration bei Morbus Parkinson können wir zumindest im Vergleich zur von Zhang et al. untersuchten Kontrollgruppe nicht bestätigen. Interessant zur zukünftigen Unterscheidung zwischen PD und PDD wäre ein unterschiedlicher Liquorspiegel zwischen diesen beiden Erkrankungen gewesen, ein signifikanter Unterschied lässt sich bei geringfügig niedrigeren Liquorspiegeln für PDD allerdings nicht nachweisen. Die sichtbare Tendenz von erniedrigten Werten bei PDD sollte jedoch in Studien größerer Gruppenstärke erneut geprüft werden. Eine routinemäßige Bestimmung bei Morbus Parkinson und Verdacht auf Demenz ist aus unserer Sicht zum heutigen Zeitpunkt noch nicht sinnvoll.

Zwischen einer Hyperhomocysteinämie in Plasma und dem Auftreten neurodegenerativer Erkrankungen scheint eine positive Korrelation zu bestehen (Wald et al. 2011). Isobe et al. haben zudem eine gleichsinnige Konzentrationserhöhung im Liquor von Patienten mit AD und PD postuliert (Isobe et al. 2005). Die Konzentrationen in unserer Studie zeigten sich hingegen signifikant unterschiedlich zwischen $A D$ $(9,34 \mu \mathrm{mol} / \mathrm{L})$ vs. PDD $(11,68 \mu \mathrm{mol} / \mathrm{L})$ und $A D$ vs. PD $(11,22 \mu \mathrm{mol} / \mathrm{L})$. Eine Bestimmung von Homocystein im Liquor zur Unterscheidung zwischen AD vs. PD/PDD ist also naheliegend. Eine Unterscheidbarkeit zwischen PD und PDD ist anhand unserer Ergebnisse allerdings nicht möglich.

Bis heute ist die letztliche Ursache der Neurodegeneration bei AD, PD und PDD nicht vollends geklärt, jedoch gibt es immer wieder Erklärungsansätze auf dem Boden eines entzündlichen Prozesses des zentralen Nervensystems. TGF-beta 1 ist ein inflammatorisches Zytokin, welches möglicherweise eine Rolle in verschiedenen neurodegenerativen Erkrankungen spielen könnte. Entsprechend konnte sowohl für $A D$ als auch PD eine erhöhte Konzentration von TGF-B1 im Liquor nachgewiesen werden (Rota et al. 2006, Nagatsu et al. 2000). Das in unserer Studie ermittelte Konzentrationsverhältniss für TGF-B1 zwischen $A D, P D D$ und $P D$ findet sich auch in einer von Rota et al. durchgeführten Studie. So konnten auch wir keine signifikanten Unterschiede zwischen den drei beobachteten Erkrankungen feststellen, sehen allerdings einen Trend zu erhöhten Werten bei AD $(213 \mathrm{pg} / \mathrm{ml}$ vs. $151 \mathrm{pg} / \mathrm{ml}$ für PDD und $192 \mathrm{pg} / \mathrm{ml}$ für PD). Im Vergleich zwischen PDD und PD fältt uns im Gegensatz zu Rota et al. ein stärkerer, allerdings nicht signifikanter Konzentrationsunterschied auf (Rota et al.: $P D=16,8 \mathrm{ng} / \mathrm{ml}, \mathrm{PDD}=18,4 \mathrm{ng} / \mathrm{ml}$ ). Die tendenziell niedrigeren Werte für 
PDD sprechen eindeutig gegen einen Hinweis auf einen direkten Zusammenhang zwischen erhöhtem TGF-B1 im Liquor und Demenz bei Morbus Parkinson.

Das Vitamin-D-bindende Protein scheint bei nekrotischen Prozessen im menschlichen Körper frei zu werden und spielt des Weiteren eine Rolle als makrophagenaktivierender Faktor (Meier et al. 2006). Zhang et al. konnten eine Erhöhung dieses Glykoproteins im Liquor cerebrospinalis von Alzheimer- und Parkinsonpatienten nachweisen. Dabei zeigte sich für $A D$ und $P D$ eine gleichsinnige Konzentrationserhöhung $(A D=1,1 \mu \mathrm{g} / \mathrm{ml}, \mathrm{PD}=1,2 \mu \mathrm{g} / \mathrm{ml})$ mit signifikantem Unterschied zur Kontrollgruppe (0,6 $\mu \mathrm{g} / \mathrm{ml})$. Auch für das von uns untersuchte Patientenkollektiv imponierte eine signifikante Erhöhung des VDBP für AD $(1,62 \mu \mathrm{g} / \mathrm{ml})$ und PD $(1,78 \mu \mathrm{g} / \mathrm{ml})$, weshalb unsere Ergebnisse die Annahme einer Beteiligung des Glykoproteins an nekrotischen Prozessen stützen. Auch die bisher nicht untersuchte Patientengruppe PDD zeigt mit einer VDBP-Konzentration von 1,42 $\mu \mathrm{g} / \mathrm{ml}$ eine signifikante Erhöhung. Bei Betrachtung der Diagnosen untereinander ergibt sich auch unter Hinzunahme von PDD kein signifikanter Unterschied. Die Bestimmung des VDBP eignet sich also möglicherweise als Marker neurodegenerativer Erkrankungen, lässt aber ebenfalls keine Unterscheidung zwischen demenziellen und nicht demenziellen Erkrankungen sowie $A D$ und PDD zu.

\subsubsection{Genetische Parameter: ApoE-Genotyp, Codon 129-Polymorphismus}

Das Überwiegen des ApoE4-Allels konnte in einer Vielzahl von Studien als Risikofaktor für die Entstehung von Morbus Alzheimer gefunden werden (Corder et al. 1993, Bertram und Tanzi 2008, Bu 2009), scheint allerdings auch bei den neurodegenerativen Erkrankungen Morbus Parkinson und DLB überrepräsentiert zu sein (Martinez et al. 2005, Josephs et al. 2004). Bezüglich der ApoE-Allelfrequenz konnten unsere DNA-Analysen die gängige wissenschaftliche Meinung eines Überwiegens des ApoE4-Allels bei AD und PD/PDD nicht bestätigen. Unsere Ergebnisse decken sich mit einem ApoE4-Anteil von 18,75\% über alle drei Erkrankungen vielmehr mit jener der Normalpopulation, für die ein Anteil von ca. 15 Prozent angegeben wird (Bu 2009). Einen dezenten Hinweis für die Beteiligung des ApoE4-Allels an der Entwicklung von demenziellen Erkrankungen finden wir aber in der Tatsache, dass in unserem untersuchten Patientenkollektiv lediglich jene mit AD und PDD überhaupt ein ApoE4-Allel aufweisen. Bei den per Definition kognitiv gesunden Patienten mit Morbus Parkinson tritt dieses nicht auf. Methodenkritisch sollte allerdings angemerkt werden, dass die 
Ergebnisse unserer genetischen Analyse aufgrund der leider nur geringen Fallzahlen $(A D=6, P D D=7, P D=3$ ) lediglich als Hinweis für zukünftige Studien gesehen werden können.

Neben der bekannten Häufung einer Methionin-Homozygotie des Codon 129 des Prion-Protein-Genes bei der Creutzfeldt-Jakob-Erkrankung wurde diese auch als Risikofaktor für Morbus Alzheimer bezeichnet (Gacia et al. 2006). Für Morbus Parkinson konnte bisher kein signifikanter Unterschied im PRNP-Polymorphismus evaluiert werden. In unserer Studie fällt eine gegensätzliche Verteilung mit Häufung einer Methionin-Homozygotie bei Parkinson-Demenz-Komplex auf. Die Allelverteilung bei AD entspricht hingegen weitestgehend jener der Normalpopulation.

\subsubsection{Eignung von Liquormarkern als Prädiktor für die Demenzentwicklung}

Die Eignung der bestimmten Liquormarker als Prädiktor für die Entwicklung einer Demenz lässt sich im Rahmen dieser Querschnittsstudie mit nur einmaliger Liquorpunktion und neuropsychologischer Testung am ehesten anhand einer Korrelation zwischen Konzentration der Liquormarker und kognitiven Leistungen in der CERADTestbatterie abschätzen.

Für drei der untersuchten Liquorparameter konnten statistische Zusammenhänge zwischen Konzentration und Ausmaß der kognitiven Einschränkung gefunden werden.

So zeigte sich, dass eine Erhöhung des Tau-Proteins bei Patienten mit Morbus Alzheimer mit statistisch signifikant schlechteren Leistungen in den Testbereichen Wortliste Lernen, Figuren Abzeichnen, Wortliste Abrufen, Wortliste Diskriminabilität und Phonematische Flüssigkeit einhergeht. Die deutlichste Korrelation bestand dabei zwischen erhöhter Liquorkonzentration von Tau-Protein und schlechteren Leistungen in Fähigkeiten des verbalen Gedächtnisses (Wortliste Abrufen, Wortliste Diskriminabilität), das typischerweise vor allem bei kortikalen Demenzen wie Morbus Alzheimer eingeschränkt ist. Für PDD-Patienten ergab sich keine signifikante Korrelation, eine Anwendung von Tau-Protein als Verlaufsparameter der Demenzentwicklung bei PDD-Patienten bietet sich somit nicht an.

Ein ähnliches Verhältnis zeigte sich auch für Phospho-Tau, bei dem erhöhte Werte ein signifikant schlechteres Abschneiden in Testbereichen Wortliste Savings und Wortliste Diskriminabilität bei Patienten mit AD bedeuteten. Ein statistischer Zusam- 
menhang zwischen Phospho-Tau und Testleistungen der Patienten mit PDD zeigte sich auch hier nicht.

Zusammenhänge zwischen CERAD-Testbereichen und Liquormarkern für beide untersuchten Demenzerkrankungen zeigten sich lediglich für Apolipoprotein E. So konnten wir für PDD-Patienten eine mittlere bis hohe Korrelation zwischen erniedrigten ApoE-Liquorspiegeln und kognitiven Defiziten in den Testbereichen Figuren Abrufen und Trailmaking-Test A sehen. Da sowohl in unserer neuropsychologischen Testung als auch in anderen Studien eine hochgradige Einschränkung der PDDPatienten im Bereich des nonverbalen, figuralen Gedächtnisses gesehen wurde, könnte eine Bestimmung von ApoE als Prädiktor für Störungen des nonverbalen Gedächtnisses bei PDD daher sinnvoll sein.

Die untersuchten Patienten mit Morbus Alzheimer zeigten hingegen eine signifikante, allerdings geringe Korrelation zwischen erniedrigtem Apo-E-Spiegel und schlechterer Leistung im Subtest Trailmaking B, der neben der psychomotorischen Geschwindigkeit die Exekutive Funktion abbilden soll. Die betrachteten Patienten mit PDD zeigten indes zwar eine höhere Korrelation, die sich jedoch als nicht signifikant erwies.

Zur letztlichen sicheren Prüfung der Eignung der Marker als Prädiktoren für die Entwicklung oder das Fortschreiten einer Demenz empfehlen wir eine Reevaluation in Form einer Längsschnittstudie, in der eine Veränderung der Liquormarker in Bezug auf die zeitliche Entwicklung kognitiver Defizite beurteilt werden könnte. 


\section{ZUSAMMENFASSUNG}

Die Entwicklung einer Demenz hat weitreichende Folgen für das selbständige Leben sowie die Lebensqualität von betroffenen Patienten. Im Gegensatz zur häufigsten Demenz Morbus Alzheimer gibt es für Morbus Parkinson bisher keine zuverlässigen validierten Liquormarker, die die Entwicklung einer Demenz anzeigen oder diese zumindest sicher diagnostizieren können. Auch die neuropsychologische Einordnung von PDD anhand eines typischen kognitiven Ausfallprofiles ist bis heute nicht möglich.

Zur vertieften Darstellung der kognitiven Defizite bei Parkinsonerkrankungen wurden in dieser Studie Patienten mit Morbus Parkinson mit und ohne Demenz anhand der CERAD-Testbatterie neuropsychologisch untersucht. In einem weiteren Schritt erfolgte der Versuch der Evaluation bekannter sowie neuer Liquormarker, die in Verbindung mit der Ausprägung einer Demenz bei Morbus Parkinson stehen könnten. Als Vergleichsgruppe dienten Patienten mit der klinischen Diagnose eines Morbus Alzheimers, die ebenfalls der beschriebenen neuropsychologischen Testung und Liquoruntersuchung unterzogen wurden.

Die Ergebnisse der neuropsychologischen Testung zeigten sowohl für AD als auch PDD für alle Subtests ein eindeutiges Abweichen von der an der Uniklinik Basel validierten, kognitiv gesunden Normstichprobe. Des Weiteren ermöglichten die Ergebnisse in den meisten Testbereichen eine zuverlässige Trennung zwischen PDD und PD. Die Anwendung der an sich für Morbus Alzheimer entwickelten CERADTestbatterie im klinischen Alltag ist entsprechend auch für Demenz bei Morbus Parkinson sinnvoll.

Für einen Großteil der Subtests zeigten die von uns untersuchten AD-Patienten durchweg schlechtere kognitive Leistungen als jene mit PDD, wobei der Unterschied vor allem im Bereich des verbalen episodischen Gedächtnisses deutlich war. Lediglich im Bereich der Exekutive, die anhand des Trailmaking-Tests geprüft wurde, wiesen sowohl die PDD- als auch PD-Patienten schlechtere Leistungen auf. Die für Morbus Parkinson berichtete frontale bzw. exekutive Dysfunktion (Goldmann Gross et al. 2008) hat sich im Rahmen unserer Testung also bestätigt. Des Weiteren konnten wir signifikante Unterschiede im Bereich Wortliste Wiedererkennen (Diskriminabilität) darstellen. Dies ermöglicht zum einen die sichere Unterscheidung von AD und PDD anhand der CERAD-Testbatterie, zum anderen die Zuordnung zu primärer 
Speicherschwäche (AD) und Abrufdefizit (PDD) bzw. kortikal und subkortikal dominierter Demenz. Das im Rahmen neuropsychologischer Studien berichtete überproportional schlechte Abschneiden von Parkinsonpatienten im Bereich des visuellräumlichen Denkens können wir bei beinahe gleichen Z-Werten für $A D$ und PDD sowie der Normstichprobe entsprechenden Leistungen der PD-Patienten nicht bestätigen. Eine erhoffte Unterscheidung zwischen AD und PDD anhand des Verhältnisses der Leistungen zwischen semantischer und phonematischer Wortflüssigkeit war nicht möglich. Beide Erkrankungen zeigten schlechtere Leistungen im Bereich der semantischen Flüssigkeit und bieten somit Hinweise auf einen auch kortikal geprägten Demenzanteil. Zusammenfassend ist die Demenz bei Morbus Parkinson aufgrund eines Abrufdefizits im Bereich des verbalen Gedächtnisses, Störungen der Exekutive und Überwiegen von Einschränkungen im Bereich der semantischen Flüssigkeit als gemischt kortikal-subkortikal zu bezeichnen. Das kognitive Profil der Kontrollgruppe mit Morbus Alzheimer entspricht mit primärer Encodierstörung bzw. Speicherschwäche im Bereich des verbalen und nonverbalen Gedächtnisses am ehesten einer kortikalen Demenz.

Die Bestimmung der klassischen Demenzparameter Tau-Protein, Phospho-Tau und Amyloid-beta 1-42 offenbarte in unserer Studie eine zuverlässige und signifikante Trennung zwischen AD und PDD bzw. PD. Eine Anwendung zur differentialdiagnostischen Trennung zwischen AD und PDD ist daher empfehlenswert. Zudem zeigte sich für $A D$ eine signifikante Korrelation zwischen erhöhter Konzentration von TauProtein und Phospho-Tau mit schlechteren Leistungen im Bereich des verbalen Gedächtnisses. Beide Parameter scheinen sich somit als Verlaufsparameter kognitiver Defizite bei Morbus Alzheimer zu eignen. Die Konzentrationen von Tau-Protein, Phospho-Tau und Amyloid-beta 1-42 bei PDD und PD lagen für alle drei Parameter innerhalb des geltenden Normbereiches und sind entsprechend als nicht pathologisch einzustufen. In vorherigen Studien wurde von signifikant erhöhtem Tau-Protein sowie erniedrigtem Abeta1-42 bei PDD im Vergleich zu PD berichtet (Mollenhauer et al. 2006). Diese Annahme konnten wir nicht bestätigen, konstatieren entsprechend unter der Einschränkung unserer geringen Fallzahlen, dass sich die Bestimmung von Tau-Protein, Phospho-Tau und Amyloid-beta 1-42 nicht für eine Unterscheidung zwischen PDD und PD eignet.

Die Bestimmung sowie Auswertung der experimentellen Liquorparameter ApoE, Homocystein, VDBP und TGF-beta1 gestaltete sich aufgrund der dünnen Datenlage und fehlender für Liquor validierter ELISAs schwierig und ist als experimentell einzu- 
stufen.

Bezüglich der Konzentration des Apolipoproteins E im Liquor cerebrospinalis konnten wir für Morbus Alzheimer eine signifikante Erniedrigung im Vergleich zu PDD, PD und Normwerten aus einer anderen Studie nachweisen. Außerdem bestand eine Korrelation zwischen erniedrigter Liquorkonzentration und schlechteren Leistungen im Bereich der psychomotorischen Geschwindigkeit und Exekutive. Wir empfehlen daher die vertiefende Validierung von ApoE als weiteren Liquormarker für Morbus Alzheimer.

Die ApoE-Konzentration der PDD-Patienten war tendenziell niedriger als jene bei PD, ein signifikanter Unterschied bestand allerdings nicht. Es zeigte sich jedoch eine signifikante Korrelation von erniedrigtem Apo-E-Liquorspiegel und kognitiven Defiziten im Bereich des nonverbalen Gedächtnisses. Eine Anwendung des Markers zur Unterscheidung PDD vs. PD ist anhand unserer Daten demnach nicht sinnvoll, es scheint aber ein möglicher Zusammenhang zwischen Defiziten im Bereich des nonverbalen Gedächtnisses und erniedrigter Liquorkonzentration bei PDD zu bestehen.

Für die Konzentrationen von Homocystein zeigte sich ein signifikanter Konzentrationsunterschied in der Konstellation AD vs. PDD und AD vs. PD, es gibt daher Anlass zur möglichen Trennbarkeit von AD und PDD anhand dieses Biomarkers.

Unsere Ergebnisse für TGF-beta1 und das VDBP zeigten für alle drei Erkrankungen, dass eine Trennung zwischen AD, PDD und PD bei nur geringen Unterschieden nicht möglich ist.

Zusammenfassend ist festzuhalten, dass die Liquormarker Tau-Protein, PhosphoTau, Amyloid-beta 1-42, Apolipoprotein E und Homocystein für die Trennung zwischen AD und PDD geeignet zu sein scheinen. Des Weiteren haben wir Hinweise für eine erhöhte VDBP-Konzentration bei AD, PDD und PD gefunden. Eine sichere Unterscheidung zwischen PD und PDD scheint allerdings anhand von keinem der untersuchten Liquormarker sicher möglich zu sein. 


\section{ANHANG}

\section{1: Klassifikationkriterien PD, Hughes et al. 1992}

UK Parkinson's Disease Society Brain Bank clinical diagnostic criteria

\section{Diagnosis of Parkinsonian syndrome}

- Bradykinesia (slowness of initiation of voluntary movement with progressive reduction in speed and amplitude of repetitive actions)

- And at least one of the following:

O muscular rigidity

- 4-6 Hz rest tremor

O postural instability not caused by primary visual, vestibular, cerebellar, or proprioceptive dysfunction.

\section{Exclusion criteria for Parkinson's disease}

- History of repeated strokes with stepwise progression of parkinsonian features

- History of repeated head injury

- History of definite encephalitis

- Oculogyric crises

- Neuroleptic treatment at onset of symptoms

- More than one affected relative

- Sustained remission

- Strictly unilateral features after 3 years

- Supranuclear gaze palsy

- Cerebellar signs

- Early severe autonomic involvement

- Early severe dementia with disturbances of memory, language, and praxis

- Babinski sign

- Presence of cerebral tumour or communicating hydrocephalus on CT scan

- Negative response to large doses of levodopa (if malabsorption excluded)

- MPTP exposure

III. Supportive prospective positive criteria for Parkinson's disease (Three or more required for diagnosis of definite Parkinson's disease) 


\begin{tabular}{|l|}
\hline - Unilateral onset \\
- Rest tremor present \\
- Progressive disorder \\
- Persistent asymmetry affecting side of onset most \\
- Excellent response (70-100\%) to levodopa \\
- Severe levodopa-induced chorea \\
- Levodopa response for 5 years or more \\
- Clinical course of 10 years or more
\end{tabular}

\section{2: Klassifikationskriterien DLB, McKeith et al. 1996/1999}

\begin{tabular}{|l|l|}
\hline $\begin{array}{l}\text { I. The central feature required } \\
\text { for a diagnosis of DLB is: }\end{array}$ & $\begin{array}{l}\text { - a progressive cognitive decline of sufficient magnitude to interfere with } \\
\text { normal social or occupational function. Prominent or persistent memory } \\
\text { impairment may not necessarily occur in the early stages but is usually } \\
\text { evident with progression. Deficits on test of attention and of frontal- } \\
\text { subcortical skills and visuospatial ability may be especially prominent }\end{array}$ \\
\hline $\begin{array}{l}\text { II. Two of the } \\
\text { following core }\end{array}$ & $\begin{array}{l}\text { - fluctuation of cognition with pronounced variations in attention and } \\
\text { features are }\end{array}$ \\
$\begin{array}{l}\text { essential for a } \\
\text { diagnosis of }\end{array}$ & $\begin{array}{l}\text { - recurrent visual hallucinations that are typically well formed and de- } \\
\text { PROBABLE DLB }\end{array}$ \\
\hline $\begin{array}{l}\text { and one is essential } \\
\text { for POSSIBLE DLB }\end{array}$ & - spontaneous motor features of parkinsonism \\
\hline
\end{tabular}




\begin{tabular}{|c|c|}
\hline $\begin{array}{l}\text { III. Features supportive of the } \\
\text { diagnosis are: }\end{array}$ & $\begin{array}{l}\text { - repeated falls } \\
\text { - syncope } \\
\text { - transient loss of consciousness } \\
\text { - neuroleptic sensitivity } \\
\text { - systematised delusions } \\
\text { - hallucinations in other modalities } \\
\text { - REM sleep behavior disorder (McKeith et al. 1999) } \\
\text { - depression ( McKeith et al. 1999) }\end{array}$ \\
\hline $\begin{array}{l}\text { IV. A diagnosis of } \\
\text { DLB is less likely }\end{array}$ & $\begin{array}{l}\text { - stroke disease, evident as a focal neurological signs or on brain imaging } \\
\text { - evidence on physical examination and investigation of any physical ill- } \\
\text { ness }\end{array}$ \\
\hline
\end{tabular}

\section{3: Klassifikationskriterien AD, McKhann et al. 1984}

\begin{tabular}{|l|l|}
$\begin{array}{l}\text { I. The Criteria for the clinical } \\
\text { diagnosis of PROBABLE }\end{array}$ & $\begin{array}{l}\text { - dementia established by clinical examination and documented by } \\
\text { the Mini-Mental Test, Blessed Dementia Scale, or some similar } \\
\text { examination, and confirmed by neuropsychological tests; } \\
\text { - deficits in two or more areas of cognition; } \\
\text { - progressive worsening of memory and other cognitive functions; } \\
\text { - no disturbance of consciousness; } \\
\text { - onset between ages } 40 \text { and 90, most often after age 65; and } \\
\text { - absence of systemic disorders or other brain diseases that in and } \\
\text { of themselves could account for the progressive deficits in } \\
\text { memory and cognition. }\end{array}$
\end{tabular}


II. The Diagnosis of

PROBABLE Alzheimer`s

disease is supported by:
- progressive deterioration of specific cognitive functions such as language (aphasia), motor skills (apraxia), and perception (agnosia);

- impaired activities of daily living and altered patterns of behavior;

- family history of similar disorders, particularly if confirmed neuropathologically; and

- laboratory results of normal lumbar puncture as evaluated by standard techniques,

- normal pattern or nonspecific changes in EEG, such as increased slow-wave activity, and

- evidence of cerebral atrophy on CT with progression documented by serial observation.

- plateaus in the course of progression of the illness;

- associated symptoms of depression, insomnia, incontinence, delusions, illusions, hallucinations, catastrophic verbal, emotional, or physical outbursts, sexual disorders, and weight loss;

- other neurologic abnormalities in some patients, especially with more advanced disease and including motor signs such as increased muscle tone, myoclonus, or gait disorder;

- seizures in advanced disease; and

- CT normal for age.

- sudden, apoplectic onset;

- focal neurologic findings such as hemiparesis, sensory loss, visual field deficits, and incoordination early in the course of the illness; and - seizures or gait disturbances at onset or very early in the course of the illness. 


\begin{tabular}{|c|c|}
\hline $\begin{array}{l}\text { V. Clinical diagnosis of } \\
\text { POSSIBLE Alzheimer`s } \\
\text { disease: }\end{array}$ & $\begin{array}{l}\text { - may be made on the basis of dementia syndrome, in the absence of } \\
\text { other neurologic, psychiatric, or systemic disorders sufficient to cause } \\
\text { dementia, and in the presence of variations in the onset, in presentation, } \\
\text { or in the clinical course; } \\
\text { - may be made in the presence of a second systemic or brain } \\
\text { disorder sufficient to produce dementia, which is not considered } \\
\text { to be the cause of the dementia; and } \\
\text { - should be used in research studies when a single, gradually } \\
\text { progressive severe cognitive deficit is identified in the absence of other } \\
\text { identifiable cause. }\end{array}$ \\
\hline $\begin{array}{l}\text { VI. Criteria for diagnosis of } \\
\text { DEFINITE Alzheimer's } \\
\text { disease are: }\end{array}$ & $\begin{array}{l}\text { - the clinical criteria for probable Alzheimer`s disease and } \\
\text { histopathologic evidence obtained from a biopsy or autopsy. }\end{array}$ \\
\hline $\begin{array}{l}\text { VII. Classification of } \\
\text { Alzheimer`s disease for } \\
\text { research purposes should } \\
\text { specify features that may } \\
\text { differentiate subtypes of } \\
\text { disorder, such as: }\end{array}$ & $\begin{array}{l}\text { - familial occurrence; } \\
\text { - onset before age of 65; } \\
\text { - presence of trisomy-21; and } \\
\text { - coexistence of other relevant conditions such as Parkinson's } \\
\text { disease. }\end{array}$ \\
\hline
\end{tabular}




\section{4: UPDRS}

\section{Unified Rating Scale for Parkinsonism, UPDRS}

[Vereinheitlichtes Bewertungsschema fūr Morbus Parkinson]

Version 3.0 - Februar 1987

\section{ABSCHNITT 1: SCHWERE DER SYMPTOME UND ANZEICHEN FŨR MORBUS PARKINSON}

\section{DENKLEISTUNG, VERHALTEN UND STIMMUNGSLAGE}

(Diese Kategorien werden bewertet wie sie auftreten, d.h. ungeachtet der genauen Ätiologie).

1. Geistige Beeinträchtigung

$0=$ Keine

1 = Gering. Beständige Vergeßlichkeit mit teilweisem Wiederfinden der Erinnerung an Ereignisse, aber keine sonstigen Schwierigkeiten

2 = Mäßige Beeinträchtigung der Gedảchtnisleistung, wobei Desorientierung und mäßige Schwierigkeiten beim

Bewãltigen komplexer Probleme auftreten. Geringe aber erkennbare Beeintrăchtigung der Bewãltigung hãuslicher Aufgaben, gelegentliches Nachhelfen ist nötig.

3 = Starke Beeinträchtigung der Gedächtnisleistung mit zeitlicher und oft auch rãumlicher Desorientierung. Starke

Beeintrāchtigung bei der Bewältigung alltäglicher Probleme.

4 = Starke Beeintrảchtigung der Gedächtnisleistung, Orientierung nur noch auf die eigene Person beschränkt. Unfähig, Entscheidungen allein zu treffen oder Probleme zu lösen. Benōtigt bei der Körperpflege viel Hilfe. Kann überhaupt nicht allein gelassen werden.

2. Denkstōrung

(aufgrund von Demenz oder Medikamentenintoxikation)

$0=$ Keine.

1 = Lebhaftes Träumen.

2 = "Gutartige" Halluzinationen bei Erhalt der Einsicht.

3 = Gelegentliche bis hãufige Halluzinationen oder Wahnvorstellungen ohne Einsicht; diese kõnnen Alltagsaktivitảt beeintrãchtigen.

4 = Persistierende Halluzinationen, Wahnvorstellungen oder floride Psychose. Selbstpflege unmöglich.

3. Depression

$0=$ Nicht vorhanden.

1 = Lãnger als normal andauernde Perioden von Traurigkeit oder Schuldgefūhlen, nie Tage oder Wochen andauernd. 2 = Anhaltende Depression (eine Woche oder länger).

3 = Anhaltende Depression mit vegetativen Symptomen (Schlaflosigkeit, Appetitlosigkeit, Gewichtsverlust, Interesseverlust).

4 = Anhaltende Depression mit vegetativen Symptomen und Suizidgedanken oder -absicht.

4. Motivation/Antrieb

$0=$ Normal.

1 = Geringeres Durchsetzungsvermögen als normal. Passiver als sonst.

2 = Antriebsverlust oder Interesselosigkeit in Bezug auf freiwillige (nicht routinemãßige) Tätigkeiten.

$3=$ Antriebsverlust oder Interesselosigkeit in Bezug auf alltãgliche (routinemäßige) Tätigkeiten.

4 = Zurückgezogen. Völliger Motivationsverlust.

\section{ALLTAGSAKTIVITĀTEN}

(Diese anamnestischen Daten sollten für die besten wie auch die schlechtesten Perioden des Patienten gesammelt werden, d.h. für "an"- wie für "off" Phasen)

5. Sprache

$0=$ Normal.

1 = Leicht beeinträchtigt. Patient kann problemlos verstanden werden.

2 = MäBig beeinträchtigt. Wird manchmal gebeten, Gesagtes zu wiederholen

3 = Stark beeintrãchtigt. Wird hãufig gebeten, Gesagtes zu wiederholen.

4 = Meistens unverständlich.

6. Speichelfluß

$0=$ Normal.

1 = Geringer aber erkennbarer Speichelüberfluß im Mund. Möglicherweise nächtliche Sialorrhö.

2 = Mäßiger Speichelüberfluß. Mōglicherweise minimale Sialorrhö.

3 = Starker Speichelüberfluß mit gelegentlicher Sialorrhõ.

4 = Starke Sialorrhö. Benõtigt ständig Taschentuch.

7. Schlucken

$0=$ Normal.

1 = Selten Schwierigkeiten beim Schlucken. 
2 = Gelegentliche Schwierigkeiten beim Schlucken.

3 = Braucht weiche Nahrung.

4 = Muß über transnasale Magensonde oder Gastrostomie ernährt werden.

8. Handschrift

$0=$ Normal.

$1=$ Etwas langsam oder klein.

2 = Mäßig langsam oder klein. Alle Wörter lesbar.

3 = Stark beeintrãchtigt. Nicht alle Wörter lesbar.

4 = Der Großteil der Wörter nicht lesbar.

9. Benutzung von Besteck

$0=$ Normal.

$1=$ Etwas langsam und unbeholfen, aber keine Hilfe nötig.

2 = Kann die meisten Nahrungsmittel schneiden, wenn auch unbeholfen und langsam. Ein gewisses Maß an Hilfe nötig.

$3=$ Jemand muß die Nahrung für den Patienten schneiden. Er kann aber noch selbst langsam essen.

$4=$ Muß gefüttert werden.

10. An- und Auskleiden

$0=$ Normal.

1 = Etwas langsam, aber keine Hilfe nōtig.

2 = Gelegentlich Hilfe nötig beim Zuknöpfen und Arme in die Ärmel führen.

$3=$ Erhebliche Hilfe nötig. Kann aber einiges allein.

$4=$ Hilf los.

11. Körperpflege

$0=$ Normal

1 = Etwas langsam, aber keine Hilfe nötig.

2 = Braucht zum Duschen oder Baden Hilfe, oder ist sehr langsam bei Körperpflege.

3 = Braucht Hilfe beim Waschen, Zähneputzen, Kämmen und bei der Toilettenbenutzung.

4 = Ballonkatheter ("Foley catheter") oder andere mechanische Hilfen nötig.

12. Lageänderung im Bett und Zurechtlegen der Decken

$0=$ Normal

1 = Etwas langsam und unbeholfen, aber keine Hilfe nötig.

2 = Kann sich allein umdrehen und Decken zurechtlegen, aber mit großen Schwierigkeiten.

3 = Kann Umdrehen oder Zurechtlegen der Decken veranlassen, aber nicht allein ausführen.

$4=$ Hilflos.

13. Fallneigung unabhảngig von ("freezing")

$0=$ Keine.

$1=$ Fällt selten

2 = Fällt gelegentlich, weniger als einmal pro Tag.

$3=$ Fällt durchschnittlich einmal pro Tag.

4 = Fällt mehr als einmal pro Tag.

14. Bewegungsblockade ("freezing") beim Gehen

$0=$ Keine.

1 = Selten Bewegungsblockaden beim Gehen. Möglicherweise Starthemmung.

2 = Gelegentlich Bewegungsblockaden beim Gehen.

3 = Hảufig Bewegungsblockaden. Gelegentliches Fallen bedingt durch Bewegungsblockaden.

4 = Hảufiges Fallen bedingt durch Bewegungsblockaden.

15. Gehen

$0=$ Normal. Geringe Schwierigkeiten. Möglicherweise Fehlen des Mitschwingens der Arme oder Tendenz, ein Bein nachzuziehen.

2 = Mäßige Schwierigkeiten, aber nur geringe oder keine Hilfe nötig.

3 = Schwere Störung des Gehens. Unterstützung nötig.

4 = Kann überhaupt nicht gehen, auch nicht mit Unterstützung.

16. Tremor

$0=$ Nicht vorhanden

$1=$ Wenig ausgeprãgt und selten.

$2=$ MäBig. Bereitet dem Patienten Beschwerden.

3 = Schwer. Beeinträchtigt viele Tátigkeiten.

4 = Stark ausgeprägt. Beeinträchtigt die meisten Tätigkeiten.

17. Sensorische Beschwerden mit Parkinsonismus zusammenhãngend

$0=$ Keine. 
1 = Gelegentliche Gefühllosigkeit, Kribbeln oder leichter Schmerz.

2 = Hảufige Gefühllosigkeit, Kribbeln oder Schmerz. Nicht quảlend.

3 = Hảufige Schmerzempfindung.

4 = Quảlender Schmerz.

\section{UNTERSUCHUNG DER MOTORIK}

(zu einem bestimmten Zeitpunkt)

18. Sprache

$0=$ Normal.

1 = Leichtes Nachlassen in Ausdruck, Artikulation und/oder Lautstärke. Monoton, verwaschen aber verständlich. MãBig beeintrāchtigt.

3 = Deutliche Beeintrãchtigung. Schwer verständlich.

4 = Unverstảndlich.

19. Mimik

$0=$ Normal.

1 = Geringfügige Hypomimie. Könnte ein normales "Pokergesicht" sein.

2 = Leichte aber erkennbar abnormale Verminderung der Mimik.

3 = Mảßige Hypomimie. Lippen zeitweise geöffnet.

4 = Maskenhafter oder starrer Gesichtsausdruck mit schwerer Beeinträchtigung oder völligem Verlust der Mimik. Lippen einen halben Zentimeter oder weiter geöffnet.

\section{Ruhetremor}

$0=$ Nicht vorhanden.

$1=$ Wenig ausgeprägt und selten.

2 = Mit geringem Ausschlag und anhaltend. Oder mit mäßigem Ausschlag aber mit Unterbrechungen.

$3=$ Mit mãßigem Ausschlag und fast ständig vorhanden.

4 = Mit starkem Ausschlag und fast ständig vorhanden.

21. Bewegungs- oder Haltungstremor der Hände

0 Nicht vorhanden.

1 Leicht, bei Bewegung.

2 Mit mäßigem Ausschlag, bei Bewegung.

3 Mit mäßigem Ausschlag, sowohl beim Halten als auch bei Bewegung.

4 Mit starkem Ausschlag, beeinträchtigt den Patienten beim Essen.

22. Rigor (Beurteilung auf Grund passiver Bewegung der Hauptgelenke, wobei der Patient eine sitzende Haltung einnimmt. Zahnradphãnomen nicht beachten.)

$0=$ Nicht vorhanden.

1 = Gering oder nur feststellbar, wenn durch spiegelbildliche oder andere Bewegungen ausgelöst.

2 = Schwach bis mäßig.

3 = Deutlich, aber volle Bewegungsbreite wird leicht erreicht.

4 = Stark. Bewegungsbreite wird nur unter Schwierigkeiten erreicht.

23. Fingertippen (Der Patient tippt in schneller Folge mehrfach den Zeigefinger auf den Daumen. Zwischen den Berührungen sollen die Finger so weit wie möglich auseinander genommen werden. Jede Hand einzeln.)

$0=$ Normal.

$1=$ Gering verlangsamt und/oder Verringerung des Abstandes.

2 = MäBig beeinträchtigt. Deutliche und frühe Ermüdung. Möglicherweise gelegentliche kurze Unterbrechungen in der Bewegung.

3 = Stark beeintrãchtigt. Hãufiges Zõgern beim Beginn der Bewegung oder kurze Unterbrechungen mitten in der Bewegung.

4 = Kann die Aufgabe kaum erfüllen.

24. Handbewegungen (Der Patient öffnet und schließt die Hảnde in schneller Folge, wobei das Öffnen so weit wie möglich sein soll. Jede Hand einzeln.)

$0=$ Normal.

$1=$ Gering verlangsamt und/oder Verringerung des Abstandes.

2 = Mäßig beeinträchtigt. Deutliche und frühe Ermüdung. Möglicherweise gelegentliche kurze Unterbrechungen in der Bewegung.

3 = Stark beeintrãchtigt. Hãufiges Zõgern beim Beginn der Bewegung oder kurze Unterbrechungen mitten in der Bewegung.

4 = Kann die Aufgabe kaum erfüllen.

25. Rasche alternierende Handbewegungen (Pronations-Supinations-Bewegungen der Hände, vertikal oder horizontal, Bewegung so weit wie möglich. Beide Hände gleichzeitig.)

$0=$ Normal.

$1=$ Gering verlangsamt und/oder Verringerung des Abstandes. 
2 = Mäßig beeinträchtigt. Deutliche und frühe Ermüdung. Möglicherweise gelegentliche kurze Unterbrechungen in der Bewegung.

3 = Stark beeintrãchtigt. Hãufiges Zõgern beim Beginn der Bewegung oder kurze Unterbrechungen mitten in der Bewegung.

4 = Kann die Aufgabe kaum erfüllen.

26. Beinbeweglichkeit (Der Patient tritt in schneller Folge mit der Ferse auf den Boden und hebt dabei das ganze Bein etwa acht Zentimeter an.)

$0=$ Normal.

$1=$ Gering verlangsamt und/oder Verringerung des Abstandes.

2 = Mäßig beeinträchtigt. Deutliche und frühe Ermüdung. Möglicherweise gelegentliche kurze Unterbrechungen in der Bewegung.

3 = Stark beeintrãchtigt. Hãufiges Zõgern beim Beginn der Bewegung oder kurze Unterbrechungen mitten in der Bewegung.

4 = Kann die Aufgabe kaum erfüllen.

27. Aufstehen von einem Stuhl (Der Patient versucht, von einem Holz- oder Metallstuhl mit gerader Lehne aufzustehen, seine Arme sind dabei vor der Brust verschränkt.)

$0=$ Normal.

1 = Langsam oder benötigt mehr als einen Versuch.

$2=$ Drūckt sich an den Armlehnen hoch.

3 = Neigt zum Zurûckfallen. Braucht möglicherweise mehrere Versuche, kann aber ohne Hilfe aufstehen.

4 = Kann ohne Hilfe nicht aufstehen.

28. Haltung

$0=$ Normal.

1 = Nicht ganz aufrecht. Leicht gebückte Haltung, kõnnte bei älterer Person normal sein.

2 = MäBig gebückte Haltung. Deutlich abnormal. Möglicherweise leicht zu einer Seite geneigt.

3 = Stark gebückte Haltung mit Kyphose. Möglicherweise mäßig zu einer Seite geneigt.

4 = Starke Beugung bei extrem abnormaler Haltung.

29. Gang

$0=$ Normal

1 = Geht langsam. Möglicherweise schlurfend mit kleinen Schritten. Keine Festination oder Propulsion.

2 = Geht mit Schwierigkeiten, braucht aber nur wenig oder keine Unterstũtzung. Möglicherweise gewisses Maß an

Festination, kleinen Schritten oder Propulsion.

3 = Starke Störung des Gangs. Braucht Unterstützung.

4 = Kann nicht allein gehen, auch nicht mit Unterstützung.

30. Haltungsstabilität (Reaktion auf plötzliche Rûckwärtsbewegung durch Ziehen an den Schultern. Der Patient steht dabei aufrecht mit leicht geöffneten Beinen und hat die Augen geöffnet. Er ist auf das Ziehen vorbereitet.)

$0=$ Normal.

1 = Retropulsion, fảngt sich aber ohne Hilfe.

2 = Keine Haltungsreaktion. Würde fallen, wenn man ihn nicht hielte.

$3=$ Sehr instabil. Neigt zu spontanem Verlust des Gleichgewichts.

$4=$ Kann nicht ohne Hilfe stehen.

31. Bradykinesie und Hypokinesie des Körpers (Kombination von Langsamkeit, Zögern, vermindertem Mitschwingen der Arme, geringer Bewegungsamplitude und allgemeiner Bewegungsarmut)

$0=$ Keine .

1 = Minimale Langsamkeit, wodurch die Bewegung absichtlich erscheint. Kõnnte für einige Personen normal sein.

Mōglicherweise eingeschränkte Bewegungsamplitude.

$1: 2=$ Geringes Maß an Langsamkeit und Bewegungsarmut, das

deutlich abnormal ist. Alternativ ein gewisses $\mathrm{Maß}$ an Einschrãnkung der Bewegungsamplitude.

3 = MäBige Langsamkeit. Mangelnde oder geringe Bewegungsamplitude.

4 = Ausgeprägte Langsamkeit. Mangelnde oder geringe Bewegungsamplitude.

ABSCHNITT 2: KOMPLIKATIONEN EINER DOPAMINERGEN THERAPIE FÜR MORBUS PARKINSON

(Dieser Abschnitt sollte den Status des Patienten in der Woche vor der Untersuchung aufzeigen.)

\section{A. DYSKINESIEN}

32. Dauer: In welchem Ausmaß treten während des Wachzustands an einem Tag Dyskinesien auf? (vom Patienten bzw. von Angehörigen angegeben)

$0=$ Keine.

$1=1-25 \%$ des Tages

$2=26-50 \%$ des Tages

$3=51-75 \%$ des Tages

$4=76-100 \%$ des Tages 
33. Behinderung: Wie stark behindern die Dyskinesien?

(vom Patienten bzw. von Angehörigen angegeben; kann durch die Untersuchung in der Praxis ergãnzt werden)

0 Keine Behinderung

$1=$ Geringe Behinderung

2 = MäBige Behinderung

$3=$ Starke Behinderung

4 = Vollstảndige Behinderung

34. Schmerzhafte Dyskinesien: Wie schmerzhaft sind die Dyskinesien?

$0=$ Keine schmerzhaften Dyskinesien

1 = Leicht

2 = MäBig

$3=$ Sehr

4 = Stark ausgeprägt

35. Inzidenz frühmorgendlicher Dystonie

(vom Patienten bzw. von Angehörigen angegeben)

$0=$ Nein

$1=\mathrm{Ja}$

\section{B. KLINISCHE SCHWANKUNGEN}

36. In welchem Ausmaß treten beim Patienten durchschnittlich während des Wachzustands an einem Tag "off'-Phasen auf?

$0=$ Keine.

$1=1-25 \%$ des Tages

$2=26-50 \%$ des Tages

$3=51-75 \%$ des Tages

$4=76-100 \%$ des Tages

37. Sind "off"-Phasen in Bezug auf die Zeitspanne nach einer Medikamentenverabreichung vorhersehbar?

$0=$ Nein

$1=\mathrm{Ja}$

38. Sind "off'-Phasen in Bezug auf die Zeitspanne nach einer Medikamentenverabreichung nicht vorhersehbar?

$0=$ Nein

$1=\mathrm{Ja}$

39. Treten "off"-Phasen plötzlich auf, z.B. innerhalb einiger .Sekunden?

$0=$ Nein

$1=\mathrm{Ja}$

\section{ANDERE KOMPLIKATIONEN}

40. Treten beim Patienten Anorexie, Nausea oder Erbrechen auf?

$0=$ Nein

$1=\mathrm{Ja}$

41. Hat der Patient Schlafstörungen, z.B. Schlaflosigkeit oder Hypersomnaolenz?

$0=$ Nein

$1=\mathrm{Ja}$

42. Zeigt der Patient orthostatische Blutdruckschwankungen?

$0=$ Nein

$1=\mathrm{Ja}$ 


\section{5: CERAD Testbatterie}

ID-Nr.:

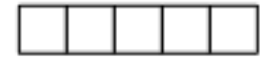

Initialen Testperson:

Untersuchungsdatum:
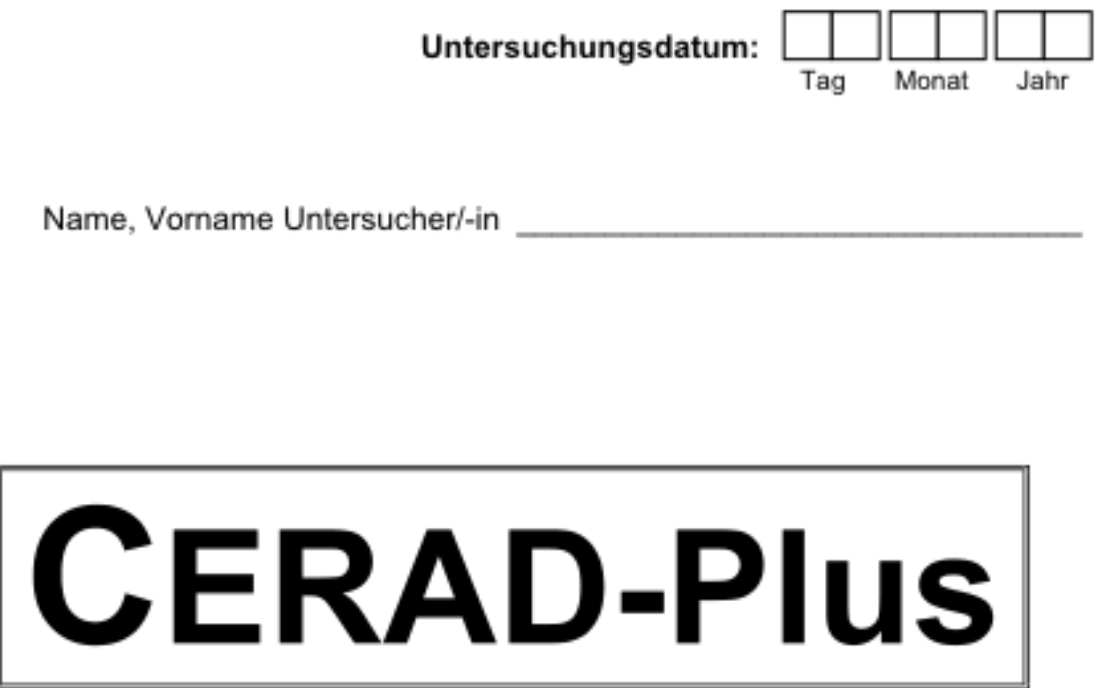

The Consortium to Establish a Registry for Alzheimer's Disease

\section{Neuropsychologische Testbatterie}

mit zusätzlichen Tests (Plus):

- Trail Making Test A, B

- Phonematische Flüssigkeit (S-Wörter) 


\title{
Anwendungs- und Bewertungs-Manual
}

\author{
für die
}

\section{Neuropsychologische Testbatterie CERAD-Plus}

\begin{abstract}
Allgemeine Instruktionen
Alle CERAD-Aufgaben mūssen in ihrer entsprechenden Reihenfolge durchgeführt werden. Ferner muss die gesamte CERAD-Batterie immer vor allen anderen neuropsychologischen Tests, welche an den jeweiligen klinischen Zentren verwendet werden, durchgeführt werden. Die Versuchsleiter, welche die Untersuchung mit der Testbatterie durchführen, sollen die TP dazu ermutigen die Aufgaben zu beenden, ohne aber die Testsituation noch mehr zu belasten. Sie sollen neutrale Aufforderungen zur Unterstützung der TP anbieten, wenn eine TP eine Aufgabe nicht erfüllen kann. Ein Feedback für die TP sollte positiv sein, darf aber keine Information über die Richtigkeit der Antwort enthalten.

Angemessene Sātze, welche verwendet werden können, sind: "Das ist gut!" oder "Sie machen das ausgezeichnet!". Ausserdem müssen die Bewertungsblātter ausserhalb des Sichtfeldes der TP plaziert werden.
\end{abstract}

CERAD Plus - Neuropsychologische Testbatterle 
ID-Nr.

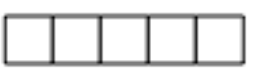

Untersuchungsdatum:

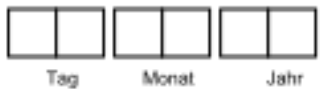

Seite 3

\section{Zusammenfassung der Tests}

\begin{tabular}{|c|c|c|c|c|}
\hline Durchgeführte Tests & \multicolumn{4}{|c|}{ Nicht durchgeführte Tests } \\
\hline Score $=>0$ & $\begin{array}{l}\text { Konperikhe } \\
\text { Behindenrng } \\
\text { Wekthe?) }\end{array}$ & $\begin{array}{c}\text { Nicht } \\
\text { kocperativ }\end{array}$ & $\begin{array}{c}\text { Kognisiv } \\
\text { beeintrachtigt }\end{array}$ & $\begin{array}{l}\text { Ansere } \\
\text { Grinde } \\
\text { (Weiche?) }\end{array}$ \\
\hline
\end{tabular}

$\begin{array}{lllllll}\text { 1. Verbale Flüssigkeit } & 0 & 1 & 2 & 3 & 4 & 5 \\ \text { 2. Boston Naming Test } & 0 & 1 & 2 & 3 & 4 & 5 \\ \text { 3. Mini-Mental Status } & 0 & 1 & 2 & 3 & 4 & 5 \\ \begin{array}{l}\text { 4. Wortliste Lernen } \\ \text { 5. Figuren Abzeichnen }\end{array} & 0 & 1 & 2 & 3 & 4 & 5 \\ \text { 6. Wortliste Abrufen } & 0 & 1 & 2 & 3 & 4 & 5 \\ \begin{array}{l}\text { 7. Wortliste Wiedererkennen } \\ \text { 8. Figuren Abrufen }\end{array} & 0 & 1 & 2 & 3 & 4 & 5 \\ \begin{array}{l}\text { 9. Trail Making Test A } \\ \text { 10. Trail Making Test B }\end{array} & 0 & 1 & 2 & 3 & 4 & 5 \\ \text { 11. Phonematische Flüssigkeit } & 0 & 1 & 2 & 3 & 4 & 5 \\ \text { (S-Wörter) } & 1 & 2 & 3 & 4 & 5\end{array}$

Kommentar:

CERAD-Plus - Neuropsychologische Testbatterie 


\section{Verbale Flüssigkeit: Kategorie 'Tiere'}

Dieser Test misst einerseits Störungen in der verbalen Produktion, andererseits ist es ein Test zur Untersuchung des semantischen Gedächtnis und der Sprache.

\section{Instruktion:}

"Ich werde lhnen eine Kategorie nennen und möchte, dass Sie so schnell Sie können alle Dinge aufzählen, die in diese Kategorie gehören. Wenn ich zum Beispiel 'Kleidungsstücke' sage, kōnnen Sie 'Hemd', 'Krawatte' oder 'Hut', usw. aufzählen. Können Sie mir weitere Kleidungsstücke nennen?"

Warten Sie bis die TP zwei Wörter genannt hat. Gelingt es ihr, dann sagen Sie, dass die Antworten korrekt sind und fahren sie mit dem eigentlichen Test (Kategorie 'Tiere') fort.

Nennt die TP ein falsches Wort oder gibt eine unpassende Antwort, korrigieren sie die Antwort und wiederholen sie die Instruktion. Misslingt es der TP abermals zu antworten, wiederholen sie die Instruktion ein zweites Mal. Wenn es eindeutig wird, dass die TP die Instruktion immer noch nicht versteht, beenden sie diese Aufgabe und klären sie ab, weshalb dies so ist.

Wenn sie überzeugt sind, dass die TP die Aufgabe versteht und zwei Wörter genannt hat, die Kleidungsstücke bezeichnen, sagen Sie:

"Gut! Ich möchte Sie nun bitten, mir alle Dinge aufzuzählen, die zu einer anderen Kategorie gehören nämlich zur Kategorie 'Tiere'. Sie haben eine Minute Zeit. Sind Sie bereit? Bitte beginnen Sie!"

Die Bearbeitungszeit dieses Tests ist auf 60 Sekunden beschränkt. Hōrt die TP vor Ablauf dieser Zeit auf, ermutigen Sie sie weitere Wörter zu finden. Nennt er/sie länger als 15 Sekunden keine Tiere, wiederholen Sie die Instruktion ("Zählen Sie mir alle Tiere auf, die Ihnen in den Sinn kommen"). Auch wenn die Instruktion während der Untersuchung wiederholt werden muss, wird kein Zeitzuschlag gewährt!

\section{Bewertung:}

Im Verlaufsprotokoll werden die Antworten entsprechend den vier 15-Sekunden-Intervallen notiert. Der Punktwert der TP ist die Summe der korrekten Tiernennungen aus jedem 15 SekundenIntervall. Korrekt als 'Tier' bewertet wird alles, was lebendig ist und weder Pflanze noch Mineral darstellt. Jeder Vertreter des Tierreiches, real oder fiktiv, jede männliche, weibliche und kindliche Tierbezeichnung, jede Tierart oder -rasse innerhalb einer Spezies wird als richtig bewertet. Ausnahmen bilden Repetitionen und Eigennamen.

Beispiele für die Bewertung

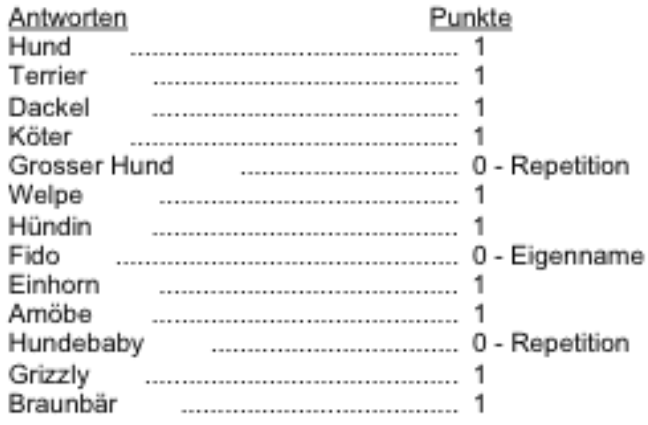


ID-Nr

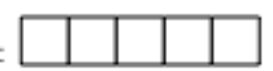

Untersuchungsdatum:

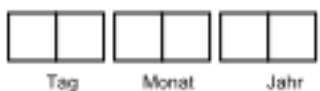

Seite 5

1. Verbale Flüssigkeit: Kategorie 'Tiere'

Zeitintervalle:

TIERE
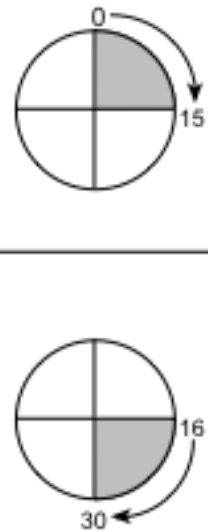

\begin{tabular}{|l|}
\hline \\
\hline
\end{tabular}

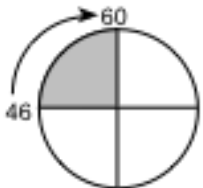

Bewertung:

Richtige

0 - 15 Sekunden

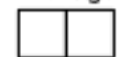

$16-30$ Sekunden

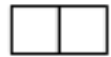

31 - 45 Sekunden

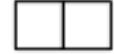

46 - 60 Sekunden

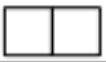

Total

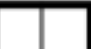




\section{15 Items des Boston Naming Test}

Kaplan E, Goodglass H, Weintraub S, Segal O. (1978). Boston Naming Test. Lea \& Febiger, Philadelphia.

Dieser Test untersucht die sprachliche Fähigkeit der TP Objekte, welche als Strichzeichnungen vorliegen, zu benennen. Diese Kurzform enthält 15 Items, welche dem Boston Naming Test (Kaplan et al., 1978) entnommen sind. Die Auswahl enthält 5 häufige, 5 mittelhäufige und 5 weniger häufige Items. Jeder TP werden alle 15 Items (siehe Testheft) angeboten. Die richtigen Bezeichnungen der abgebildeten Objekte befinden sich auf dem Antwortblatt.

\section{Instruktion:}

"Nun werde ich lhnen einige Bilder zeigen. Bitte sagen Sie mir, wie diese

Dinge heissen."

Fragen Sie bei jedem Bild:

"Wie ist der Name dieses Gegenstandes?" oder "Wie heisst das?"

Notieren Sie fortlaufend alle Antworten wörtlich. Ist die Antwort falsch, notieren Sie die Antwort der TP und fahren Sie mit dem nächsten Item fort.

Gewähren Sie pro Bild eine maximale Antwortzeit von 10 Sekunden. Ist die TP nicht in der Lage, das Bild in dieser Zeit zu benennen, ermuntern Sie die TP und gehen Sie zum nächsten Item über. Macht die TP einen Fehler und korrigiert sich selbst spontan, wird die Antwort als richtig gewertet.

\section{Bewertung:}

Die Summe aller korrekten Benennungen der häufigen, mittelhäufigen und weniger häufigen Items ergibt den Gesamtwert.

Es dürfen keine semantischen oder phonematischen Hilfen angeboten werden. Eine unspezifische Hilfe darf nur dann angeboten werden, wenn die Antwort zu allgemein ist. Zum Beispiel, wenn die TP für das Item 'Kanu' die Antwort 'Boot' gibt, fragen Sie dann: "Gibt es einen anderen Namen dafür?", aber fragen Sie nicht "Ist dies nicht eine spezielle Art von Boot?"' Müssen Sie eine Hilfe nach einer zu allgemeinen Antwort (z.B. 'Boot') anbieten, wird nur die korrigierte Antwort (z.B. 'Kanu') bewertet. Regionale Varianten von Ausdrücken und Synonyme, falls verifiziert, werden als richtig bewertet.

Beispiele für die Bewertung:

$\begin{array}{ll}\text { Item } & \text { Beispiele für korrekte Antworten } \\ \text { Blume } & \text { Rose, Distel } \\ \text { Haus } & \text { Schulhaus, Spital } \\ \text { Maske } & \text { Larve, Halbmaske } \\ \text { Harmonika } & \text { Mundharmonika, Schnurengeige, Maulorgel } \\ \text { Kamel } & \text { Dromedar }\end{array}$

CERAD-Plus - Neuropsychologische Testbatterie 


\section{15 Items des Boston Naming Test}

Kaplan E, Goodglass H, Weintraub S, Segal O. (1978). Boston Naming Test. Lea \& Febiger, Philadelphia.

Dieser Test untersucht die sprachliche Fähigkeit der TP Objekte, welche als Strichzeichnungen vorliegen, zu benennen. Diese Kurzform enthält 15 Items, welche dem Boston Naming Test (Kaplan et al., 1978) entnommen sind. Die Auswahl enthält 5 häufige, 5 mittelhäufige und 5 weniger häufige Items. Jeder TP werden alle 15 Items (siehe Testheft) angeboten. Die richtigen Bezeichnungen der abgebildeten Objekte befinden sich auf dem Antwortblatt.

\section{Instruktion:}

"Nun werde ich lhnen einige Bilder zeigen. Bitte sagen Sie mir, wie diese

Dinge heissen."

Fragen Sie bei jedem Bild:

"Wie ist der Name dieses Gegenstandes?" oder "Wie heisst das?"

Notieren Sie fortlaufend alle Antworten wörtlich. Ist die Antwort falsch, notieren Sie die Antwort der TP und fahren Sie mit dem nächsten Item fort.

Gewähren Sie pro Bild eine maximale Antwortzeit von 10 Sekunden. Ist die TP nicht in der Lage, das Bild in dieser Zeit zu benennen, ermuntern Sie die TP und gehen Sie zum nächsten Item über. Macht die TP einen Fehler und korrigiert sich selbst spontan, wird die Antwort als richtig gewertet.

\section{Bewertung:}

Die Summe aller korrekten Benennungen der häufigen, mittelhäufigen und weniger häufigen Items ergibt den Gesamtwert.

Es dürfen keine semantischen oder phonematischen Hilfen angeboten werden. Eine unspezifische Hilfe darf nur dann angeboten werden, wenn die Antwort zu allgemein ist. Zum Beispiel, wenn die TP für das Item 'Kanu' die Antwort 'Boot' gibt, fragen Sie dann: "Gibt es einen anderen Namen dafür?", aber fragen Sie nicht: "Ist dies nicht eine spezielle Art von Boot?" Müssen Sie eine Hilfe nach einer zu allgemeinen Antwort (z.B. 'Boot') anbieten, wird nur die korrigierte Antwort (z.B. 'Kanu') bewertet. Regionale Varianten von Ausdrücken und Synonyme, falls verifiziert, werden als richtig bewertet.

Beispiele für die Bewertung:

$\begin{array}{ll}\text { Item } & \text { Beispiele für korrekte Antworten } \\ \text { Blume } & \text { Rose, Distel } \\ \text { Haus } & \text { Schulhaus, Spital } \\ \text { Maske } & \text { Larve, Halbmaske } \\ \text { Harmonika } & \text { Mundharmonika, Schnurengeige, Maulorgel } \\ \text { Kamel } & \text { Dromedar }\end{array}$

CERAD-Plus - Neuropsychologische Testbatterie 
ID-Nr.

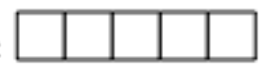

Untersuchungsdatum:

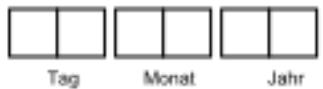

Seite 7

\section{Boston Naming Test}

"Nun werde ich Ihnen einige Bilder zeigen. Bitte sagen Sie mir, wie diese Dinge heissen."

(Notieren Sie alle Antworten wörtlich. Die maximale Bilddarbietungsdauer beträgt 10 Sekunden.)

Bild

[HÄUFIG]

Baum

Bett

Pfeife

Blume

Haus

[MITTEL]

Kanu

Zahnbürste

Vulkan

Maske

Kamel

[SELTEN]

Mundharmonika

Zange

Hängematte

Trichter

Dominosteine
Richtige Antworten

[HÄUFIG]

[MITTEL]

[SELTEN]

Total
Antwort

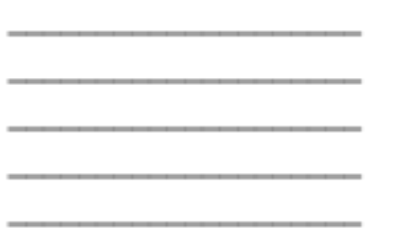

$\begin{array}{ll}0 & 1 \\ 0 & 1 \\ 0 & 1 \\ 0 & 1 \\ 0 & 1\end{array}$

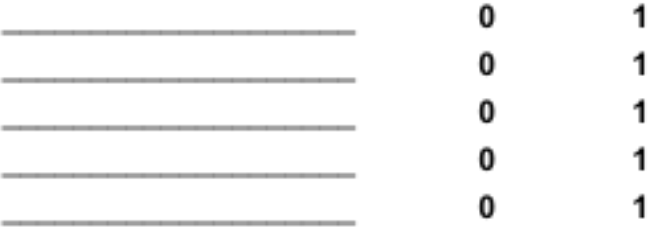

falsch richtig

\section{1}

1

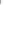

1

1

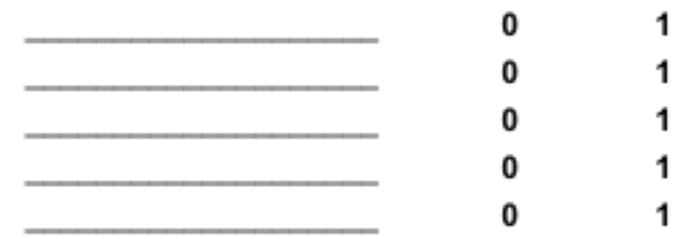


Seite 8

\section{Mini-Mental Status}

Folstein MF, Folstein SE, McHugh PR. 'Mini Mental State"- A practical method for grading the cognitive state of patients for the clinician. Joumal of Psychiatric Research 1975;12:189-198.

Stellen Sie die Fragen genau so, wie sie aufgeschrieben sind. Die drei Beiblätter können lose von den Untersuchungsbeilagen sein, vergewissern Sie sich aber, dass die CERAD ID-Nr. und das Datum auf jedem Blatt vermerkt sind.

\section{Vorbemerkungen:}

ad Fragen: 5) Welchen Monat haben wir? Sowohl der Monatsname (z.B. 'Juli') als auch die entsprechende Zahl (z.B. der 'siebte' Monat) werden richtig gewertet.

7) Kanton?

Gemeint ist der Kanton in welchem der Test durchgeführt wird. Fragen Sie nicht nach dem Heimatkanton!

10) ........ Adresse?

Fragen Sie nach dem "Namen oder der Adresse". Sowohl Name, als auch Adresse werden richtig gewertet.

12) Bewertung des rückwărts buchstabierten Wortes "PREIS" - korrekte Sequenz = 5 Punkte.

- je 1 Fehler für jede Auslassung, Buchstabentranspositionen (Verwechseln benachbarter Buchstaben), Einfügungen (Einfügen eines neuen Buchstaben) oder Fehlplazierungen (Fehlplazierung der

Buchstaben P, R, E, I, S um mehr als nur einen ihm angestammten Platz).

Beispiele: (Punktzahlen in Klammern)

Richtig = S I E R P (5)

\begin{tabular}{|c|c|c|c|c|}
\hline & Auslassung & Transposition & Einschub & Fehlplazierung \\
\hline Auslassung & SIRP (4) & & & \\
\hline Transposition & $S R \mid P(3)$ & SIREP (4) & & \\
\hline Einschub & SIIRP (3) & IEPPRS (3) & SIEERP (4) & \\
\hline Fehlplazierung & I R P $\underline{\underline{S}}$ (3) & I EPRS (3) & I ERRP $\underline{S}$ (3) & I E R P $\underline{\underline{S}}$ (4) \\
\hline
\end{tabular}

CERAD-Plus - Neuropsychologische Testbatterie 


\section{Mini-Mental Status}

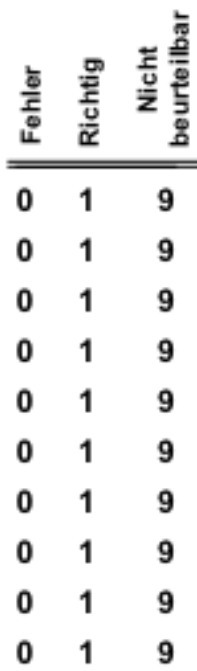

"Nun möchte ich Ihnen einige Fragen stellen, um Ihr Gedächtnis und Ihre Konzentration zu prüfen. Einige Fragen mögen einfach, andere schwieriger sein."

1) "Welches Jahr haben wir?"

2) "Welche Jahreszeit?"

3) "Den wievielten des Monates?"

4) "Welcher Wochentag ist heute?"

5) "Welcher Monat?"

6) "In welchem Land sind wir?"

7) "In welchem Kanton?"

8) "In welcher Ortschaft?"

9) "Auf welchem Stockwerk?"

10) "An welchem Ort (Name oder Adresse) befinden wir uns hier?"

11) "Ich werde Ihnen nun drei Wörter nennen. Nachdem ich Ihnen diese gesagt habe, möchte ich Sie bitten, sie zu wiederholen. Versuchen Sie sich diese Wōrter zu merken; in einigen Minuten werde ich Sie bitten, sich wieder an diese Wörter zu erinnern."

$\begin{array}{lll}0 & 1 & 9 \\ 0 & 1 & 9 \\ 0 & 1 & 9\end{array}$

"Zitrone" Bitte wiederholen Sie die Wörter!

"Schlüssel" (Die erste Wiederholung ergibt die Punktzahl [1 Punkt ersten Versuch nachgesprochen, wiederholen Sie die drei Begriffe bis zu $3 \mathrm{Mal}$, bis alle Wörter gelernt sind.)

12) "Nun werde ich Ihnen ein Wort nennen und bitte Sie dieses vorwärts und rūckwärts zu buchstabieren. Das Wort ist "PREIS" Können Sie es vorwärts buchstabieren?

Bitte buchstabieren Sie es jetzt rūckwärts!"

(Wiederholen Sie das Wort wenn nōtig und helfen Sie, wenn nōtig, beim Vorwärtsbuchstabieren.)

Bewertung: Anzahl richtige Buchstaben in der korrekten Reihenfolge:

$$
\bar{S} \bar{I} \overline{\mathrm{E}} \overline{\mathrm{P}}
$$

( 0 bis $5 ; 9=$ nicht durchführbar). 
ID-Nr:

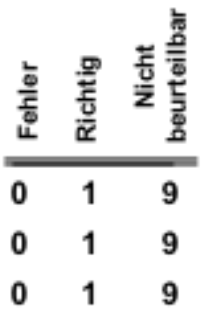

$\begin{array}{lll}0 & 1 & 9\end{array}$

$\begin{array}{lll}0 & 1 & 9\end{array}$

$0 \quad 1 \quad 9$

$\begin{array}{lll}0 & 1 & 9\end{array}$

$\begin{array}{lll}0 & 1 & 9\end{array}$

$\begin{array}{lll}0 & 1 & 9\end{array}$

$0 \quad 1 \quad 9$

$\begin{array}{lll}0 & 1 & 9\end{array}$

$\begin{array}{lll}0 & 1 & 9\end{array}$

(Summe aller Punkte der 22 Fragen, ausgeschlossen sind Scores von '9'.)

"Welches sind die drei Wörter, die Sie sich merken sollten?"

13) "Zitrone"

14) "Schlüssel"

15) "Ball"

16) (Zeigen Sie der TP ihre Armbanduhr)

"Was ist das?"

17) (Zeigen Sie der TP einen Bleistift)

"Was ist das?"

18) "Sprechen Sie mir nach:

(Der Satz lautet:) 'BITTE KEINE WENN UND ABER'."

Es ist nur ein Versuch erlaubt!

19) "Lesen Sie bitte was auf diesem Blatt steht und führen Sie es aus!"

(Auf dem Blatt steht:) "SCHLIESSEN SIE IHRE AUGEN" Richtig ist, wenn die TP die Augen schliesst!

20) "Ich werde Ihnen ein Blatt Papier geben. Wenn ich es Ihnen gebe, nehmen Sie es bitte mit der rechten Hand,
Rechte Hand

Falten

Auf Schoss falten Sie es mit beiden Händen und legen es dann auf Ihren Schoss!"

Lesen Sie zuerst die vollständige Instruktion und reichen Sie erst dann der TP das Blatt mit beiden Händen. Wiederholen Sie weder die Instruktion, noch leiten Sie die TP an.
21) "Schreiben Sie bitte irgendeinen vollstăndigen Satz auf dieses Blatt Papier!"

22) "Hier ist eine Figur. Bitte zeichnen Sie diese Figur auf dem gleichen Blatt Papier ab!"

Richtig ist, wenn die zwei sich überlappenden Fünfecke ein Viereck bilden und alle Ecken der Fünfecke vorhanden sind. 


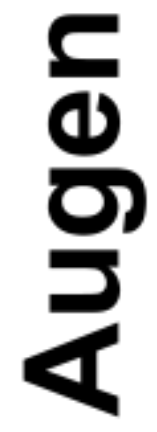

를

오

$\boldsymbol{\infty}$

들

()

()

()

(1)

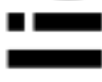

政

0

の 


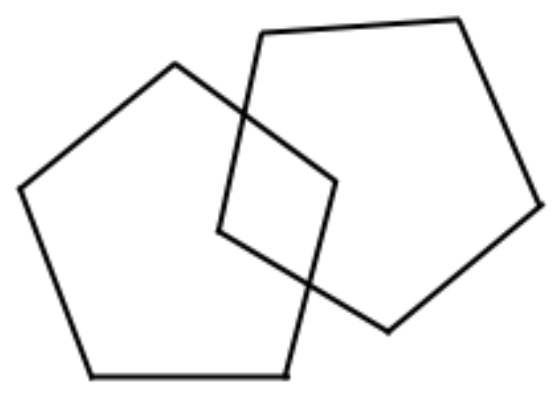




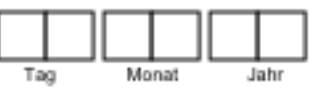

\section{Wortliste Lernen}

Dieser Wortlisten Lerntest mit zehn alläglichen Begriffen dient dazu, die Fähigkeit der TP zu untersuchen, neu gelernte Information zu erinnern. Um sicher zu stellen, dass die TP mit den Wörtern vertraut ist und diese auch mōglichst gut aufnimmt, wird sie gebeten, die Wörter einzeln aus dem Testheft vorzulesen. Die zehn Wörter werden in gleichmässiger Geschwindigkeit nacheinander präsentiert. Unmittelbar nach der Präsentation der Wörter bitten Sie die TP, so viele wie möglich zu erinnern. Die Reihenfolge spielt dabei keine Rolle.

Denjenigen TPen, die aufgrund einer Sehbehinderung oder minimaler Bildung die Wörter nicht lesen können, werden die Wörter vom Testleiter vorgelesen und die TPen müssen die Wörter laut wiederholen. Allerdings ist festzuhalten, dass diese Vorgehensweise nicht dem laut lesen lassen entspricht, kommt der Originalaufgabe aber am nächsten. Auf diese Weise ist es möglich auch sehbehinderte und wenig gebildete TPen zu untersuchen, welche sonst nicht getestet werden könnten).

Es gibt drei Durchgänge, in jedem werden die Wörter in einer anderen Reihenfolge präsentiert.

Die Instruktion für den ersten Durchgang lautet:

"Ich werde Ihnen zehn Wörter zeigen. Lesen Sie bitte jedes Wort laut vor, wenn ich es Ihnen zeige. Danach werde ich Sie bitten, alle diese zehn Wörter aus dem Gedächtnis abzurufen."

Zeigen Sie der TP die Wörter des ersten Durchganges im Abstand von zwei Sekunden. Sollte die TP ein Wort nicht lesen können, lesen Sie es ihr/ihm vor und vermerken Sie es auf dem Antwortblatt für das entsprechende Wort in der Spalte "Kann nicht lesen". Nachdem das letzte Wort gelesen wurde, soll die TP versuchen, möglichst viele dieser Wörter zu erinnern. Die TP hat maximal 90 Sekunden Zeit. Verfahren Sie dann in gleicher Weise mit dem zweiten und dritten Durchgang dieser Wörter; ändern Sie lhre Instruktion ein wenig, um die TP zu ermutigen.

Der Punktwert der TP ergibt sich aus der Summe der richtig erinnerten Wörter pro Durchgang. Vermerken Sie auch bei jedem Durchgang die Anzahl Wörter, welche die TP "erinnert", die aber nicht in der Liste enthalten sind (Intrusionen). 
ID-Nr.
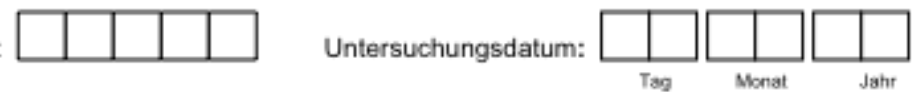

\section{Wortliste Lernen}

Instruktion:

"Ich werde Ihnen zehn Wörter zeigen. Lesen Sie bitte jedes Wort laut vor, wenn ich es Ihnen zeige. Danach werde ich Sie bitten, diese zehn Wörter aus dem Gedächtnis abzurufen."

Expositionszeit: je 1 Wort im Abstand von 2 Sekunden

Erinnerungszeit: Maximum 90 Sekunden pro Durchgang

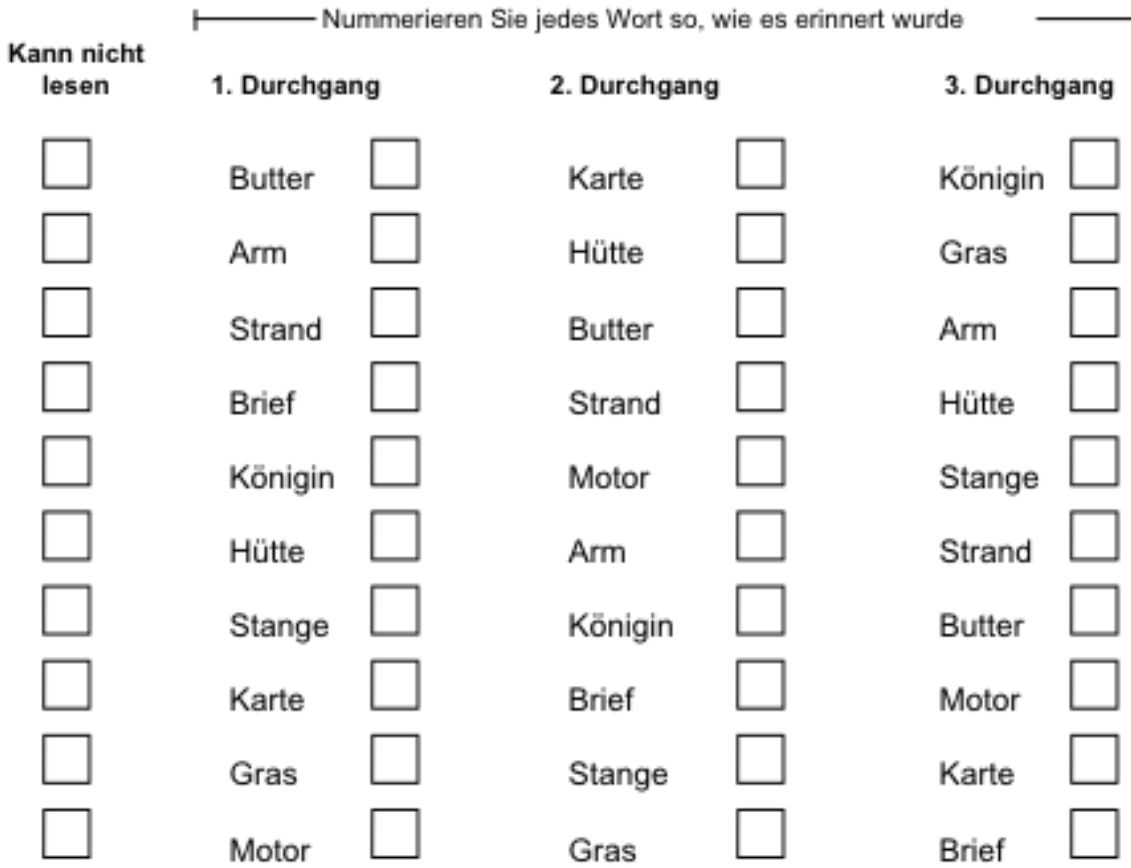

Intrusionen:

Total:

\ 1 < Kann nicht lesen

Richtige $=>$
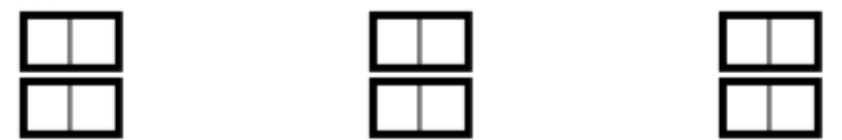


\section{Figuren Abzeichnen}

Rosen WG, Mohs RC, Davis KL. A new rating scale for Alzheimer's disease. American Joumal of Psychiatry 1984;11:1356-64.

Diese vier einfachen geometrischen Figuren von Rosen (1984) werden benutzt, um die konstruktive Praxis zu untersuchen, welche bei der Demenz beeinträchtigt ist. Die vier Figuren nehmen in ihrer Komplexität zu, so dass sowohl Patienten mit milderen als auch schwereren Beeinträchtigungen beurteilt werden können.

Instruktionen:

Zeigen Sie der TP das Blatt mit dem Kreis (Figur 1) und sagen Sie, indem Sie auf die untere leere Hälfte des Blattes zeigen:

"Hier ist ein Kreis. Bitte zeichnen Sie ihn hier direkt darunter ab!"

Die meisten TP können einen geschlossenen Kreis zeichnen.

Zeigen Sie der TP das Blatt mit dem Rhombus (Figur 2) und sagen Sie:

"Hier haben wir die Zeichnung eines Rhombus. Zeichnen Sie sie ebenfalls so gut es geht darunter ab."

Hat die TP diese Figur abgezeichnet, zeigen Sie ihr das Blatt mit den sich überschneidenden Rechtecken (Figur 3):

"Gut! Und nun zeichnen Sie bitte auch diese dritte Figur!"

Nach der Figur der sich ūberschneidenden Rechtecke zeigen Sie der TP das Blatt mit dem Wūrfel (Figur 4):

"Nun kommt die schwierigste Figur, die Sie zeichnen sollen. Lassen Sie sich Zeit!"

Lassen Sie der TP für jede zu kopierende Figur maximal 2 Minuten Zeit. Wiederholen Sie die Instruktion einmal, wenn die TP die Aufgabe nicht beim ersten Mal versteht. Es ist den TPen erlaubt, Fehler zu korrigieren, weshalb für diese Aufgabe ein Bleistift verwendet werden muss. Wenn die TP mehrere Male beginnt, ist dies erlaubt, ermutigen Sie sie/ihn aber nicht dazu. Bewertet wird der letzte Versuch oder diejenige Figur, welche von der TP als diejenige mit der Vorlage am besten übereinstimmend, angegeben wird.

\section{Bewertung (spezielle Details)}

Figur 1 (='Kreis') und 2 (='Rhombus'): zwischen den Linien einer Figur werden Lücken won 3 mm akzeptert. Figur 3 (='Rechtecke')
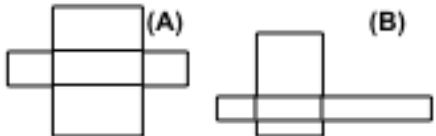

(A)
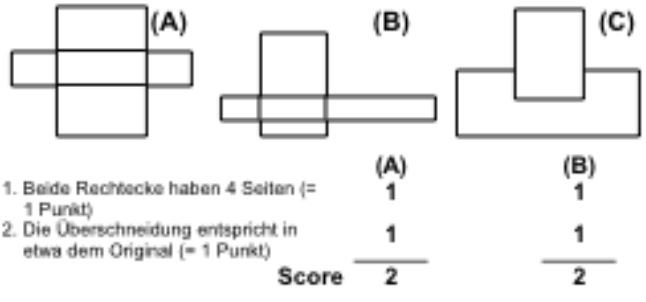

(B)

1

$\frac{1}{2}$
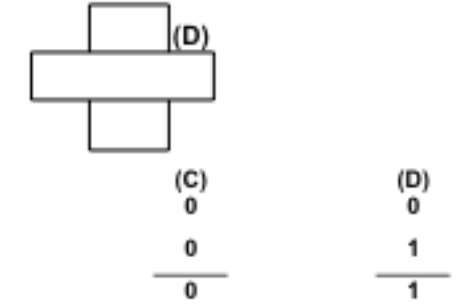

Figur 4 (= 'Wirfel'):

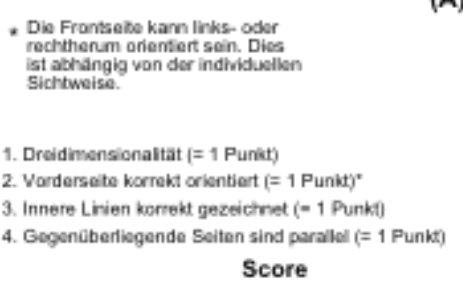

(A)

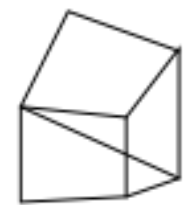

(A)

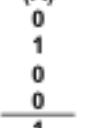

(B)

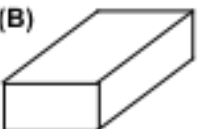

(B)

$\begin{array}{r}1 \\ 1 \\ 0 \\ 1 \\ \hline\end{array}$

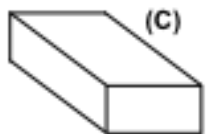

(C)

CERAD-Plus - Neuropsychologische Testbatterie 

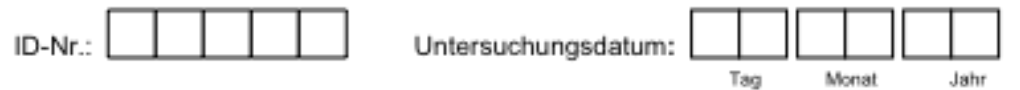

\section{Figuren Abzeichnen}

\section{Falsch Richtig}

\section{Figur 1: 'Kreis'}

a) geschlossener Kreis (Lücken $\leq 3$ Millimeter)

b) annăhernd kreisförmig

0

\section{Figur 2: 'Rhombus'}
a) vier Seiten vorhanden
$0 \quad 1$
b) geschlossene Linien (Lücken $\leq 3$ Millimeter)
0
1
c) Seiten alle etwa gleich lang
0
1

\section{Figur 3: 'Rechtecke'}

a) beide Figuren haben vier Seiten

0

1

b) überschneidende Rechtecke sehen dem

Original ähnlich

0

\section{Figur 4: 'Würfel'}

a) Figur ist dreidimensiona

b) Frontseite korrekt orientiert (egal ob links- oder rechtsorientiert)

c) innere Linien sind korrekt gezeichnet

0

1

0

1

d) die gegenüberliegenden Seiten sind parallel (innerhalb $10^{\circ}$ )

Total richtig:

Figur 1 ('Kreis')

Figur 2 ('Rhombus')

Figur 3 ('Rechtecke')

Figur 4 ('Würfel') 


$$
\text { o }
$$


$\diamond$ 


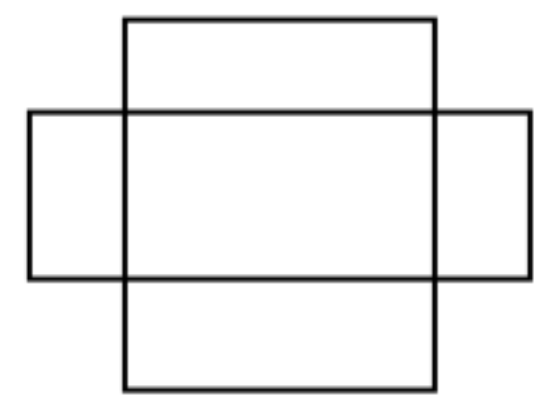




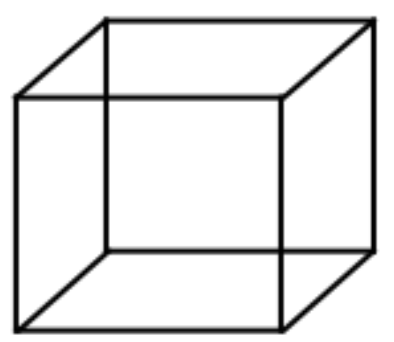




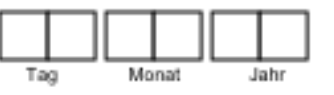

\section{Wortliste Abrufen}

Das Ziel dieser Aufgabe ist es festzustellen, wie gut sich die TP noch an die Wörter von Aufgabe 4 erinnern kann.

\section{Die Instruktion für diese Erinnerungsaufgabe lautet:}

"Vor wenigen Minuten habe ich Sie gebeten, eine Liste von 10 Wörtern zu lernen, die

Sie eins nach dem anderen von verschiedenen Kärtchen vorgelesen haben. Jetzt

möchte ich Sie bitten, sich an diese Wörter zu erinnern und möglichst viele dieser 10

Wörter aufzuzählen!"

Die TP hat für diese Aufgabe 90 Sekunden Zeit. Die erinnerten Wörter werden auf dem Antwortbogen entsprechend der durch die TP reproduzierten Reihenfolge numeriert.

\section{Bewertung:}

Die Summe der richtig erinnerten Wörter ergibt den Punktwert.

Notieren und bewerten Sie ebenfalls Wörter, welche durch die TP aufgezählt werden, die aber nicht auf dieser Liste figurierten (= Intrusionen!). 
ID-Nr.
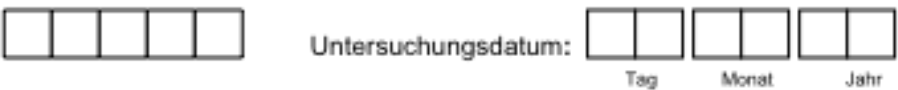

\section{Wortliste Abrufen}

\section{Instruktion:}

"Vor wenigen Minuten habe ich Sie gebeten, eine Liste von 10 Wörtern zu lernen, die Sie eins nach dem anderen von verschiedenen Kärtchen vorgelesen haben. Jetzt möchte ich Sie bitten, sich an diese Wörter zu erinnern und möglichst viele dieser 10 Wörter aufzuzählen!"

Zeitlimite: 90 Sekunden

$$
\begin{aligned}
& \text { Nummerieren Sie die Wörter } \\
& \text { entsprechend der Nennung } \\
& \text { durch die TP }
\end{aligned}
$$

Butter

Arm

Strand

Brief

Königin

Hütte

Stange

Karte

Gras

Motor

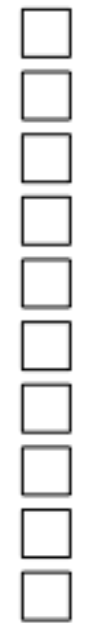

Intrusionen:

Total:

\section{Richtige:}

Intrusionen:
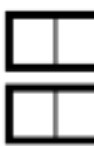


\section{Wortliste Wiedererkennen}

Die Instruktion für diesen Erkennungstest lautet:

"Als nächstes werde ich Ihnen eine Reihe von auf Kärtchen geschriebenen Wörtern zeigen. Einige davon sind Wörter, die Sie auf der früheren Liste schon gesehen haben und einige sind Wörter, die ich lhnen noch nicht gezeigt habe. Ich möchte Sie bitten, mir diejenigen Wörter zu nennen, die Sie auf der früheren Liste bereits gesehen haben, und welche dieser Wörter neu sind." (Zeigen Sie nun die erste Karte mit dem ersten Wort ['Kirche']). "Ist das eines der Wörter, das sie vorher schon gesehen haben?"

Wiederholen Sie bei jedem Wort diese letzte Frage oder sagen Sie:

"Und wie ist es mit diesem Wort?"

Notieren Sie sich die Antworten der TP auf dem Antwortblatt.

\section{Bewertung:}

Die Bewertung für diesen Test berücksichtigt die richtig erkannten Wörter, die zuvor auch gesehen wurden (richtige 'Ja'-Antworten [= 'hit']) und die Anzahl der korrekt zurūckgewiesenen neuen Wörter (richtige 'Nein'-Antworten [= 'correct rejection']).

Fordern Sie die TP dazu auf, die Frage mit 'Ja' oder 'Nein' zu beantworten, weil "Ich weiss es nicht"-Antworten nicht bewertbar sind. 
ID-Nr:

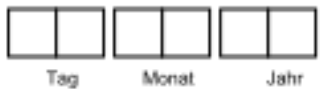

\section{Wortliste Wiedererkennen}

"Als nächstes werde ich lhnen eine Reihe von auf Kärtchen geschriebenen Wörtern zeigen. Einige davon sind Wörter, die Sie auf der früheren Liste bereits gesehen haben und einige sind Wörter, die ich lhnen noch nicht gezeigt habe. Ich möchte Sie bitten, mit 'JA' zu antworten, wenn das Wort, welches ich Ihnen zeige, eines ist, das Sie früher schon gesehen haben."

Nur 'JA'- oder 'NEIN'-Antworten sind zulässig!

Richtige

'JA'-Antworten
Richtige

'NEIN'-Antworten

Kirche

1

Kaffee

Butter *

Dollar

Arm *

Strand *

Fünf

Brief *

Hotel

Berg

Königin

Hütte *

Pantoffel

Stange *

Dorf

Band

Karte *

Heer

Gras *

Motor *

$\begin{array}{ll}1 & 1 \\ 1 & 1 \\ 1 & 1 \\ 1 & 1 \\ & 1 \\ 1 & 1 \\ 1 & 1 \\ 1 & 1 \\ 1 & 1 \\ 1 & 1\end{array}$

Total richtige

'JA':

Total richtige

"NEIN":

* Originalwörter aus Aufgabe 4 (Wortliste Lernen) 


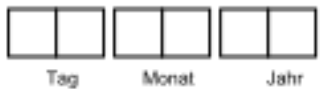

\section{Figuren Abrufen}

"Vor einiger Zeit habe ich Ihnen auf separaten Blättern einige Zeichnungen gezeigt. Sie mussten sie sich ansehen und dann auf dem gleichen Blatt Papier abzeichnen. Erinnern Sie sich noch an diese Figuren? Ich möchte Sie nun bitten, diese Figuren aus dem Gedächtnis auf dieses Blatt Papier zu zeichnen."

\section{1. "Kreis"}

a) geschlossener Kreis

b) zirkuläre Form

\section{Erinnert}

Erinnert mit Cue ${ }^{\star}$

Nein Ja

Nein Ja

\section{2. "Rhombus"}

a) vier Seiten vorhanden

b) alle Winkel geschlossen

c) alle Seiten etwa gleich lang

$\begin{array}{ll}0 & 1 \\ 0 & 1\end{array}$

$\begin{array}{ll}0 & 1 \\ 0 & 1\end{array}$

\section{3. "Rechtecke"}

a) beide Figuren haben vier Seiten

b) Überschneidung entspricht in etwa dem Original

$\begin{array}{llll}0 & 1 & 0 & 1 \\ 0 & 1 & 0 & 1 \\ 0 & 1 & 0 & 1\end{array}$

\section{4. "Würfel"}

a) Figur ist dreidimensional

b) Frontseite korrekt orientiert

c) innere Linien sind korrekt gezeichnet

0

0

1

01

) die gegenüberliegenden

Seiten sind parallel

(innerhalb $10^{\circ}$ )

$\begin{array}{llll}0 & 1 & 0 & 1 \\ 0 & 1 & 0 & 1 \\ 0 & 1 & 0 & 1 \\ 0 & 1 & 0 & 1\end{array}$

* Wird eine der obigen Figuren ausgelassen, geben Sie der TP neutrale Gedächtnisstützen, wie z.B.:

"Erinnern Sie sich noch an andere Figuren?"

Zeichnet die TP die 5-Eck-Figuren aus dem MMS, bewerten Sie sie nach untenstehender Formel. Werden die 5-Eck-Figuren aus dem MMS nicht gezeichnet, fragen Sie die TP:

"Waren da noch andere Zeichnungen?"

\section{5. "Fünfecke"}
a) zwei fünfseitige Figuren
b) sich überschneidend
01
c) der sich überschneidende Teil ist eine Figur mit vier Seiten
0

$\begin{array}{lll}1 & 0 & 1 \\ 1 & 0 & 1 \\ 1 & & 0\end{array}$

$\begin{array}{llll}0 & 1 & 0 & 1\end{array}$

Total Richtig:

Item 1

Item 4
Item 2

Item 5 
Seite 34

\section{Trail Making Test $A$ und $B$}

(Aufmerksamkeit, exekutive Funktionen)

Zahlen (Test A) oder Zahlen und Buchstaben (Test B) sollen in aufsteigender Reihenfolge so schnell wie möglich verbunden werden. Die benötigte Zeit wird gestoppt.

\section{Öbungsblatt A}

„Auf diesem Blatt hat es verschiedene Nummern. Beginnen Sie bei der Zahl 1 und zeichnen Sie einen Strich von 1 nach 2 , von 2 nach 3, von 3 nach 4 usw., bis Sie am Ende sind."

Wāhrend der Erklärung Schritte zeigen, von 1 - Ende

„Zeichnen Sie die Linien so schnell wie möglich und entfernen Sie den Bleistift nicht vom Papier!"

Wenn Übungsblatt A verstanden wurde, zur Testung übergehen.

Falls die TP im Übungsbeispiel einen Fehler macht, wird sie sofort darauf aufmerksam gemacht! 
Trail Making Test A:

Übungsbeispiel

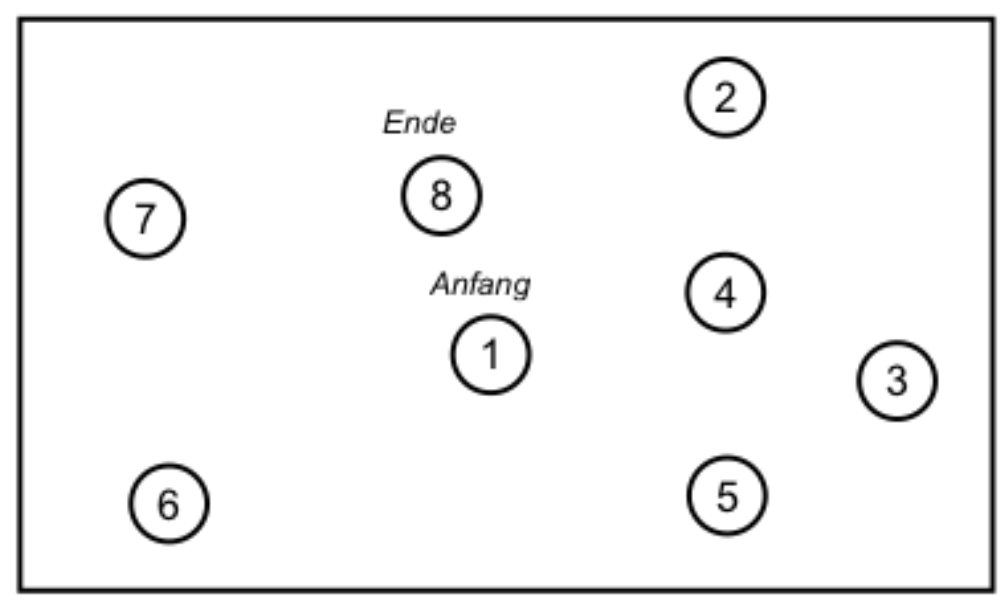

Zeit Test A Sek.

Fehler Test A 


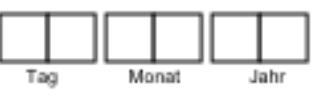

\section{Trail Making Test A}

„Bitte verbinden sie alle Zahlen von 1 bis 25 in aufsteigender Reihenfolge.

Zeichnen Sie die Linien so schnell wie möglich ein und entfernen Sie den Bleistift nicht vom Papier!"

Erst jetzt das Blatt geben.

„Hier ist ihr Anfang. Los!"

Parallel zum „Los!" Stoppuhr drücken.

Wenn die TP einen Fehler macht, sofort darauf aufmerksam machen und Fehler korrigieren lassen, d.h. zum letzten richtigen Kreis zurückkehren und von dort aus weiterfahren. Zeit weiter laufen lassen.

Bewertung: Zeit (in Sek.); Fehler werden vor allem indirekt, durch die zusätzlich aufgewendete Zeit bewertet. Die Striche der TP sollen die Kreise mindestens berühren (darauf hinweisen, zählt aber nicht als Fehler).

Abbruch Test A nach 3 Min. 
(15)

(17)

(21)

(20)

(19)

(16)

(18)

(5)

(4) 22

(13)

(6)

(7)

(1)

(24)

(14)

(8) (10) 2

(9)

(12)

(11) 25

(3)

(23) 


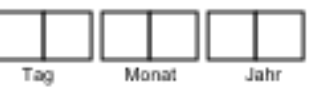

\section{Übungsblatt B}

„Zeichnen Sie bitte eine Linie von 1 nach A, von A nach 2, von 2 nach B, von B nach 3, von 3 nach C usw., Zahlen in aufsteigender Reihenfolge, Buchstaben nach dem Alphabet."

Wāhrend der Erklärung jeden Schritt von 1 - A bis Ende zeigen.

„Zeichnen Sie die Linien so schnell wie möglich ein, ohne den Bleistift vom Blatt zu nehmen."

Wenn Übungsblatt B verstanden wurde zur Testung übergehen. 
Trail Making Test B

Übungsbeispiel

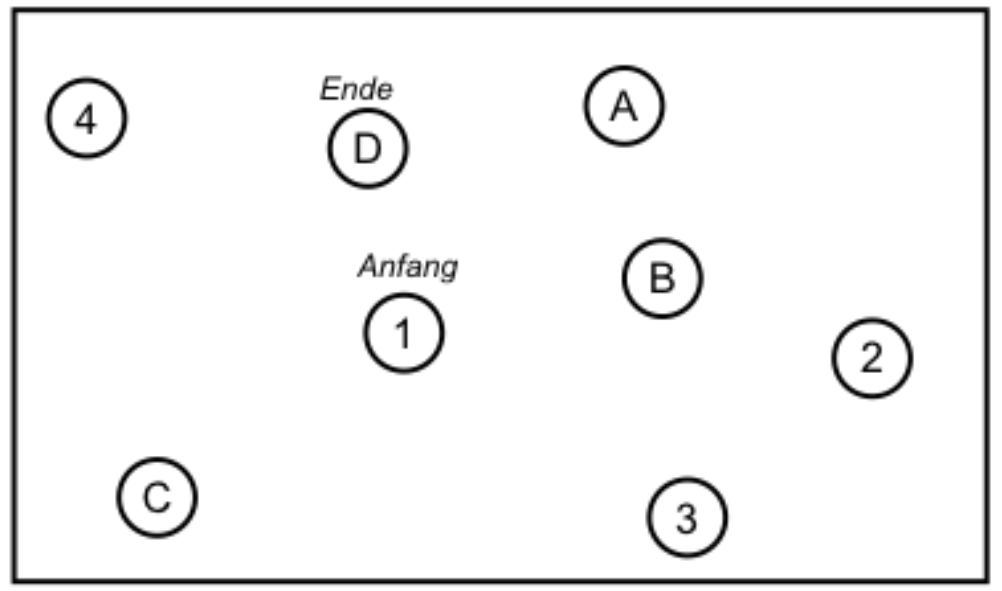

Zeit Test B Sek.

Fehler Test B 


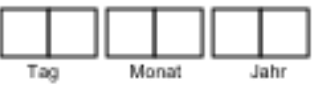

\section{Trail Making Test B}

„Erinnern Sie sich daran, dass Sie zuerst eine Zahl, dann einen Buchstaben, dann wieder eine Zahl, dann wieder einen Buchstaben, usw. verbinden müssen. Halten Sie die Reihenfolge ein und lassen Sie keine Kreise aus. Zeichnen Sie die Linien so schnell wie möglich ein, ohne den Bleistift vom Blatt zu nehmen."

Unbedingt darauf hinweisen, dass die Buchstabenreihenfolge .... i j $k$ lautet. Erst jetzt Blatt geben.

\section{„Hier ist ihr Anfang. Los!"}

Parallel zum „Los!" Stoppuhr drücken.

Wenn die TP einen Fehler macht, sofort darauf aufmerksam machen und Fehler korrigieren lassen, d.h. zum letzten richtigen Kreis zurückkehren und von dort aus weiterfahren. Zeit weiter laufen lassen.

Bewertung: Zeit (in Sek.); Fehler werden vor allem indirekt, durch die zusātzlich aufgewendete Zeit bewertet. Die Striche der TP sollen die Kreise mindestens berühren (darauf hinweisen, zählt aber nicht als Fehler).

Abbruch Test B nach 5 Min. 
(13) (3) (1) (1) (1)

(3)

(7)

$\oplus$

(5)

(12)

()

(c)

(A) (1)

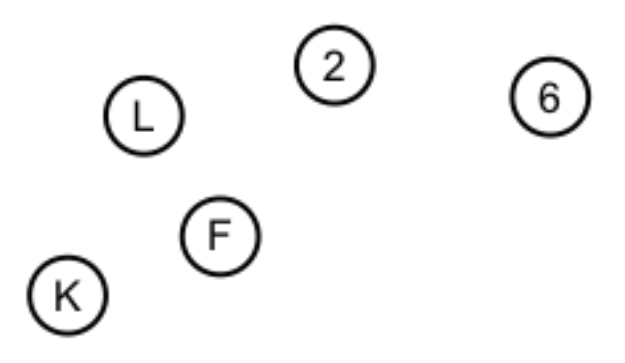

(ㄷ)

(11) 


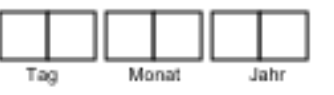

\title{
11. Phonematische Flüssigkeit: S-Wörter
}

\begin{abstract}
„Jetzt bitte ich Sie, so viele Wörter wie nur möglich aufzuzählen, die mit einem bestimmten Buchstaben beginnen. Es dürfen Wörter aller Wortarten sein (Hauptwörter, Verben usw.). Nicht erlaubt sind 1.) Namen von Personen, 2.) geographische Namen, 3.) Nummern, 4.) das selbe Wort in verschiedenen Formen oder mit verschiedenen Endungen wie zum Beispiel bitten, bat, bittend. Zudem sind Stammergänzungen untersagt, z.B. Biene, Bienenstich, Bienenhonig. Ich möchte Sie nun bitten, so viele Wörter wie möglich aufzuzählen, die mit dem Buchstaben S beginnen. Sie haben eine Minute Zeit. Sind Sie bereit? Los!"
\end{abstract}

Parallel zum „Los!" Stoppuhr drücken.

Die Bearbeitungszeit dieses Tests ist auf 60 Sekunden beschränkt. Hört die TP vor Ablauf dieser Zeit auf, ermutigen Sie sie weitere Wörter zu finden. Nennt er/sie länger als 15 Sekunden keine Wörter, wiederholen Sie die Instruktion ("Zählen Sie mir Wörter auf, die mit dem Buchstaben S beginnen". Auch wenn die Instruktion während der Untersuchung wiederholt werden muss, wird kein Zeitzuschlag gewährt! 


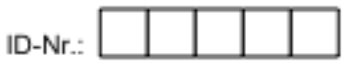

Untersuchungsdatum:

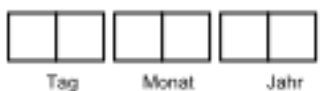

Seite 43

Phonematische Flüssigkeit: S-Wörter

Zeitintervalle:

S-Wörter
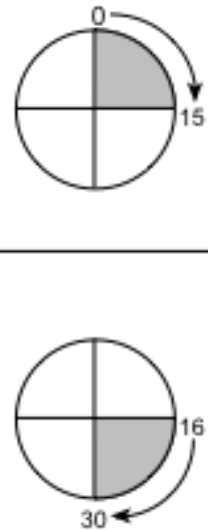

\begin{tabular}{|l|l|}
\hline \\
\hline
\end{tabular}

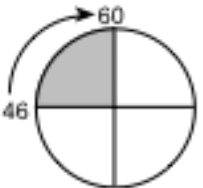

Bewertung:

Richtige

0 - 15 Sekunden

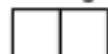

$16-30$ Sekunden

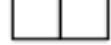

31 - 45 Sekunden

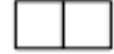

$46-60$ Sekunden

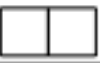

Total

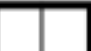




\section{LITERATURVERZEICHNIS}

Aarsland D, Ballard C, Larsen JP, McKeith I (2001): A comparative study of psychiatric symptoms in dementia with Lewy bodies and Parkinson's disease with and without dementia. Int J Geriatr Psychiatry $\underline{16}$, 528-536

Aarsland D, Andersen K, Larsen JP, Lolk A, Kragh-Sørensen P (2003 a): Prevalence and characteristics of dementia in Parkinson disease: an 8-year prospective study. Arch Neurol. 60, 387-392

Aarsland D, Litvan I, Salmon D, Galasko D, Wentzel-Larsen T, Larsen JP (2003 b): Performance on the dementia rating scale in Parkinson's disease with dementia and dementia with Lewy bodies: comparison with progressive supranuclear palsy and Alzheimer's disease. J Neurol Neurosurg Psychiatry $\underline{74}$, 1215-1220

Aarsland D, Ballard CG, Halliday G (2004): Are Parkinon's diesease an dementia with Lewy bodies the same entity? J Geriatr Psychiatry Neurol 17, 137-145

Aarsland D, Perry R, Larsen JP, McKeith IG, O'Brien JT, Perry EK, Burn D, Ballard CG (2005 a): Neuroleptic sensitivity in Parkinson's disease and parkinsonian dementias. J Clin Psychiatry 66, 633-637

Aarsland D, Zaccai J, Brayne C (2005 b): A systematic review of prevalence studies of dementia in Parkinson's disease. Mov. Disord. 20, 1255-1263

Aarsland D, Ballard C, Walker Z, Bostrom F, Alves G, Kossakowski K, Leroi I, PozoRodriguez F, Minthon L, Londos E (2009): Memantine in patients with parkinsono's disease dementia or dementia with Lewy bodies: a double-blind, placebo-controlled, multicentre trial. Lancet Neurol $\underline{8}$, 613-618

Aebi C: Validierung der neuropsychologischen Testbatterie CERAD - eine Multicenterstudie. Med. Dissertation. Institut für Psychologie, Universität Basel, Schweiz 2002

Alperovitch A, Zerr I, Pocchiari M, Mitrova E, de Pedro Cuesta J, Hegyi I, Collins S, Kretzschmar H, van Duijn C, Will RG (1999): Codon 129 prion protein genotype and sporadic Creutzfeldt-Jakob disease. Lancet $\underline{353}, 1673$-1674

Alzheimer A (1907): Über eine eigenartige Erkrankung der Hirnrinde. Allg Z Psychiat Psych-Gerichtl Med 64, 146-148

Arsenbaum-Hanke S, Auff E, Brücke T, Dal-Bianco P, Fischer P, Gerschlager W, Grossmann J, Hochschorner G, Jellinger KA, Katzenschlager R: Konsensus-

Statement Parkinson-Demenz; in: CliniCum, das Magazin für Führungskräfte im Krankenhaus, Sonderausgabe April 2005; P.b.b. Verlagspostamt, Wien 2005, 5-6

Athey RJ, Porter RW, Walker RW (2005): Cognitive assessment of a representive community population with Parkinson's disease (PD) using the Cambridge Cognitive Assessment-Revised (CAMCOG-R). Age Ageing 34, 268-273

Ballard CG (2004): Definition and diagnosis of dementia with Lewy bodies. Dement Geriatr Cogn Disord 17, 15-24

Ballard C, Kahn Z, Corbett A (2011): Treatment of dementia with lewy bodies and Parkinson's disease dementia. Drugs Aging 28, 769-777

Barth S, Schonknecht P, Pantel J, Schroder J (2005): Mild cognitive impairmanet and Alzheimer's disease: an investigation of the CERAD-NP test battery. Fortschr Neurol Psychiatr $\underline{73}$, 568-576

Betram L, Tanzi RE (2008): Thirty years of Alzheimer's disease genetics: the implica- 
tions of systematic meta-analyses. Nat Rev Neurosci $\underline{9}, 768-778$

Bickel H (2000): Demenzsyndrom und Alzheimerkrankheit: Eine Schätzung des Krankenstandes und der jährlichen Neurerkrankungen in Deutschland. Das Gesundheitswesen $\underline{62}, 211-218$

Bickel H: Epidemiologie und Gesundheitsökonomie. In: Wallesch C-W und Förstl H, Georg Thieme Verlag, Stuttgart 2005, 1-15

Bickel H: Die Epidemiologie der Demenz; in: Das Wichtigste 08/10, Deutsche Alzheimer Gesellschaft, Berlin 2010, 1-5

Biggins CA, Boyd JL, Harrop FM, Madeley P, Mindham RH, Randall JI, Spokes EG (1992): A controlled, longitudinal study on dementia in Parkinson's disease. J Neurol Neurosurg Psychiatry $\underline{55}, 566-571$

Blacker D, Haines JL, Rodes L, Terwedow H, Go RC, Harrell LE, Perry RT, Bassett SS, Chase G, Meyers D, (1997): ApoE-4 and age at onset of Alzheimer's disease: the NIMH genetics initiative. Neurology $\underline{48}, 139-147$

Blennow K (2004): CSF biomarkers for mild cognitive impairment. J intern Med 256, 224-234

Blennow K, Wallin A, Agren H, Spenger C, Siegfried J, Vanmechelen E (1995): Tau protein in cerebrospinal fluid: a biochemical marker for axonal degeneration in Alzheimer disease? Mol Chem Neuropathol 26, 231-245

Blennow K, Vanmechelen E, Hampel H (2001): CSF total atu, Aß42 and phosphorylated tau protein as biomarkers for Alzheimer's disease. Mol Neurobiol 24, 87-87

Boeve BF, Silber MH, Ferman TJ, Kokmen E, Smith GE, Ivnik RJ, Parisi JE, Olson EJ, Petersen RC (1998): REM sleep behaviour disorder and degenerative dementia; an association likely reflecting Lewy body disease. Neurology $\underline{51}, 363-370$

Bu G (2009): Apoliporotein E and ist receptors in Alzheimer's disease: pathways, pathogenesis and therapy. Nat Rev Neurosci 10, 333-344

Buée L, Bussiere T, Buée-Scherrer V, Delacourte A, Hof PR (2000): Tau protein isoforms, phosphorylation an role in neurodegerative disorders. Brain $\underline{33}$, 95-130

Buhl L, Bojsen-Møller M (1988): Frequency of Alzheimer's disease in a postmortem study of psychiatric patients. Dan Med Bull $\underline{35}$, 288-290

Burn DJ, McKeith IG (2003): Current treatment of dementia with Lewy bodies and dementia associated with Parkinson's disease. Mov Disord 18, 72-79

Burn DJ, Rowan EN, Minett T, Sanders J, Myint P, Richardson J, Thomas A, Newby J, Reid J, O'Brien JT, McKeith IG (2003): Extrapyramidal features in Parkinson's disease with and without dementia with Lewy bodies: A cross-sectional comparative study. Mov Disord 18, 884-889.

Collerton D, Burn D, McKeith I, O’Brien J (2003): Systematic review and meta analysis show that dementia with Lewy bodies is a visual-perceptual and attentionalexecutive dementia. Dement Geriatr Cogn Disord 16, 229-237

Connor DJ, Salmon DP, Sandy TJ, Galasko D, Hansen LA, Thal LJ (1998): Cognitive profiles of autopsy-confirmed Lewy body variant vs pure Alzheimer disease. Arch Neurol 55, 994-1000

Corder EH, Saunders AM, Strittmatter WJ, Schmechel DE, Gaskell PC, Small GW, Roses AD, Haines JL, Pericak-Vance MA (1993): Gene dose of apoliporotein E type 4 allele and the risk of Alzheimer's disease in late onset families. Science 261, 921- 
De Lau LM, Schipper CM, Hofman A, Koudstaal PJ, Breteler MM (2005): Prognosis of Parkinson disease: risk of dementia and mortalitiy: the Rotterdam Study. Arch Neurol. 62, 1265-1269

Diehl J, Monsch AU, Aebi C, Wagenpfeil S, Krapp S, Grimmer T, Seeley W, Forstl H, Kurz A (2005): Frontotemporal dementia, semantic demetia, and Alzheimer's disease: the contribution of standard neuropsychological tests to differential diagnosis. J Geriatr Psychiatry Neurol 18, 39-44

Dluzen DE, McDermott JL (2000): Gender differences in neurotoxity of the nigrostriatal dopaminergic system: implications for Parkinson's disease. J Gend Specif Med $\underline{3}$, 36-42

Duda (2004): Pathology and neurotransmitter abnormalities of dementia with Lewy bodies. Dement Geriatr Cogn Disord 17, 3-14

Ewers M, Buerger K, Tepel SJ, Scheltens P, Schröder J, Zinkowski RP, Bouwman FH, Schönknecht P, Schoonenboom NSM, Andreasen N (2007): Multicenter assesment of CSF-phosphorylated tau for the prediction of conversion of $\mathrm{MCl}$. Neurology $\underline{69}, 2205-2212$

Farlow MR, Cummings JL, Olin JT, Meng X (2010): Effects of oral rivastigmine on cognitive domains in mild-to-moderate Alzheimer's disease. Am J Alzheimers Dis Other Demen 25, 347-352

Gacia M, Safranow K, Styczynska M, Jakubowska K, Peplonska B, ChodakowskaZebrowska M, Przekop I, Slowik A, Golanska E, Hulas-Bigoszewska K (2006): Prion protein gene M129 allele is a risk factor for Alzheimer's disease. J Neural Trans $\underline{113}$, 1747-1751

Gerlach M, Reichmann H, Riederer P: Die Parkinson-Krankheit. Grundlagen, Klinik, Therapie. 3. Auflage; Springer, Wien 2003

Giasson BI, Lee VMY, Trojanowski JQ: Parkinsons's disease, Dementia with Lewy Bodies, multiple system atrophy and the spectrum of diseases with alphy-synuclein inclisions. In: The neuropathology of dementia, Cambridge Universitiy Press, Cambridge 2004, 353-375

Glatt SL, Hubble JP, Lyons K, Paolo A, Tröster AI, Hassanein RE, Koller WC (1996): Risk factors for dementia in Parkinson's disease: effect of education. Neuroepidemiology $\underline{15}$, 20-25

Goate A, Chartier-Harlin MC, Mullan M, Brown J, Crawford F, Fidani L, Giuffra L, Haynes A, Irving N, James L (1991): Segregation of a missense mutation in the amyloid precursor protein gene with familial Alzheimer's disease. Nature $\underline{349}$, 704-706

Goetz CG, Poewe W, Rascol O, Sampaio C, Fahn S, Lang AE, Martinez-Martin P, Tilley B, Van Hilten B (2003): The Unified Parkinson's Disease Rating Scale (UPDRS): Status and Recommendations. Mov Disord 7 , 738-750

Goldmann Gross R, Siderowf A, Hurtig HI (2008): Cognitive impairment in Parkinson's diesease and Dementia with Lewy Bodies: A spectrum of disease. Neurosignals $\underline{16}, 24-34$

Gossrau G, Herting B, Möckel S, Kempe A, Koch R, Reichmann H, Lampe JB (2006): Analysis of the polymorphic prion protein gene codon 129 in idiopathic Parkinson's disease. J Neural Transm 113, 331-337

Grimmer T, Drzezga A, Stimmer H (2005): Bildgebende Verfahren in der Diagnostik. 
Alzheimer Info $\underline{1}$, 10-11

Grundke-lqbal I, Iqbal K, Tunj YC, Quinlan M, Wisniewski HM, Binder LI (1986): Abnormal phosphorylation of the microtubule-associated protein tau in Alzheimer cytoskelletal pathology. Proc Natl Acad Sci $\underline{83}$, 4913-4917

Hamilton RL (2000): Lewy bodies in Alzheimer's disease: a neuropathological review of 145 cases using alphasynuclein immunohistochemistry. Brain Pathol 10, 378-384

Hampel H, Mitchell A, Blennow K, Frank RA, Brettschneider S, Weller L, Moller HJ (2004): Core biological marker candidates of Alzheimer's disease-perspectives for diagnosis, prediction of outcome and reflection of biological activity. J Neural Transm 111, 247-272

Hansen L, Salmon D, Galasko D, Masliah E, Katzman R, DeTeresa R, Thal L, Pay MM, Hofstetter R, Klauber M (1990): The Lewy body variant of Alzheimer's disease: a clinical and pathological entity. Neurology $\underline{40}, 1-8$

Hardy J, Allsop D (1991): Amyloid deposition as the central event in the aetiology of Alzheimer's disease. Trends Pharmacol Sci 12, 383-388

Hardy J, Higgins GA (1992): Alzheimer's disease. The amyloid cascade hypothesis. Science 256, 184-185

Hatters DM, Peters-Libeu CA, Weisgraber KH (2006): Apolipoprotein E structure: insights into function. Trends Biochem $\underline{31}$, 445-454

Heinemann U, Gloeckner F, Varges D, Meissner B, Krasnianski A, Zerr I (2007): Differenzialdiagnose rasch progredienter Demenzen. Z Gerontopsychol Psychiatr $\underline{20}$, 17-26

Hesse C, Rosengren L, Anfreasen N, Davidsson P, Vanderstichele H, Vanmechelen $\mathrm{E}$, Blennow K (2001): Transient increase in total tau but not phospho-tau in human cerebrospinal fluid after acute stroke. Neurosci lett 297, 187-190

Hobson P, Gallacher J, Meara J (2005): Cross-sectional survey of Parkinson's disease and parkinsonism in a rural area of the United Kingdom. Mov Disord. 20, 995998

Hoehn MM, Yahr MD (1967): Parkinsonism. Onset, progression and mortality. Neurology $\underline{17}, 427-442$

Holmberg B, Johnels B, Blennow K, Rosengren (2003): Cerebrospinal fluid Abeta42 is rduced iin multiple system atrophy but normal in Parkinson's disease and progressive supranuclear palsy. Mov Disord 18, 186-190

Hughes AJ, Daniel SE, Kilford L, Lees AJ (1992): Accuracy of clinical diagnosis of idiopathic Parkinson's diesease: a clinico-pathological study of 100 cases. J Neurol Neurosurg Psychiatry $\underline{55}$, 181-184

Hutchinson M, Raff U (1999): Parkinson's disease: a novel MRI method for determining structural changes in the substantia nigra. J Neurol Neurosurg Psychiatry $\underline{67}$, 815-818

Isobe C, Murata T, Sato C, Terayama Y (2005): Increase of total homocysteine concentration in cerebrospinal fluid in patients with Alzheimers disease and Parkinson's disease. Life Sci $\underline{77}$, 1836-1843

Jansen SE, Vermes I, de Vos RA (1998): Cerebrospinal-fluid tau protein and aspartate aminotransferase in Parkinson's disease. Lancet $\underline{351}$, 1105-1106

Janvin CC, Larsen JP, Salmon DP, Galasko D, Hugdahl K, Aarsland D (2006): Cog- 
nitive profiles of individual patients with Parkiinson's disease and dementia: comparison with dementia with lewy bodies and Alzheimer's disease. Mov Disord 21, 337342

Josephs KA, Tsuboi Y, Cookson N, Watt H, Dickson DW (2004): Apoliporotein E epsilon 4 is a determinant for Alzheimer-type pathologic features in tauopathies, synucleinopathies, and frontotemporal degeneration. Arch Neurol 61, 1579-1584

Kahle PJ, Jakowec M, Teipel SJ, Hampel H, Petzinger GM, Di Monte DA, Silverberg GD, Möller HJ, Yesavage JA, Tinklenberg JR (2000): Combined assessment of tau and neuronal thread protein in Alzheimer's disease CSF. Neurology 11, 1498-1504

Kanemaru K, Kameda N, Yamanouchi H (2000): Decreased CSF amyloid beta42 and normal tau levels in dementia with Lewy bodies. Neurology $\underline{54}$, 1875-1876

Kosaka K (1990): Diffuse Lewy body disease in Japan. J Neurol 237, 197-204

Kraepelin E: Das senile und präsenile Irresein; in: Psychiatrie: Ein Lehrbuch für Studierende und Ärzte; Verlag von Johann Ambrosius Barth, Leipzig 1910, 533-632

Launer LJ, Andersen K, Dewey ME, Letenneur L, Ott A, Amaducci LA, Brayne C, Copeland JR, Dartigues JF, Kragh-Sorenesen P (1999): Rates and risk factors for dementia and Alzheimer's disease: results from EURODEM pooled analyses. EURODEM Incidence Research Group an Work Groups. European Studies of Dementia. Neurology. $\underline{52}, 78-84$

Lee HG, Perry G, Moreira PI, Garrett MR, Liu Q, Zhu X, Takeda A, Nanomura A, Smith MA (2005): Tau phosphorylation in Alzheimer's disease: pathogen or protector? Trends Mol Med 11, 164-169

Lewczuk P, Esselmann H, Otto M, Maler JM, Henkel AW, Henkel MK, Eikenberg O, Antz C, Krause WR, Reulbach U (2004): Neurochemical diagnosis of Alzheimer's dementia by CSF Abeta42, Abeta42/Abeta40 ratio and total tau. Neurobiol Aging $\underline{25}$, 273-281

Lewy FH (1913): Zur pathologischen Anatomie der Paralysis Agitans. Deutsche Zeitschrift für Nervenheilunde $\underline{50}, 50-55$

Lippa CF, Duda JE, Grossmann M, Hurtig HI, Aarsland D, Boeve BF, Brooks DJ, Dickson DW, Dubois B, Emre M (2007): DLB and PDD boundary issues. Diagnosis, treatment, molecular pathology, and biomarkers. Neurology $\underline{68}, 812-819$

Macdonald A, Cooper B (2007): Long-term care and demntia services: an impending crisis. Age Ageing 36, 16-22

Marder K, Tang MX, Cote L, Stern Y, Mayeux R (1995): The frequency and associated risk factors for dementia in patients with Parkinson's disease. Arch Neurol. $\underline{52}$, 695-701

Martinez M, Brice A, Vaughan JR, Zimprich A, Breteler MM, Meco G, Filla A, Farrer MJ, Bétard C, Singleton A (2005): Apoliporotein E4 is probably responsible for the chromosome 19 linkage peak for Parkinson's disease. Am J Med Genet B Neuropsychiatr Genet 136B, 72-74

Masters CL, Simms G, Weinman NA, Multhaup G, Mc Donald BL, Beyreuther K (1885): Amyloid plaquw core Protein in Alzheimer's disease and Down-Syndrome. Proc Natl Acad Sci 82, 4245 -4249

Mayeux R, Chen J, Mirabello E, Marder K, Bell K, Dooneief G, Stern Y (1990): An estimate of the incidence of dementia in idiopathic Parkinson's disease. Neurology $\underline{40}, 1513-1517$ 
McKeith IG, Galasko D, Kosaka K, Perry EK, Dickson DW , Hansen LA, Salmon DP, Lowe J, Mirra SS, Byrne EJ (1996): Consensus guidelines fort he clinical an pathologic diagnosis of dementia with Lewy bodies: Report of the consortium on DLB international workshop. Neurology $\underline{47}, 1113-1123$

McKeith IG, Perry EK, Perry RH (1999): Report of the second dementia with Lewy body international workshop. Neurology $\underline{53}, 902-905$

McKeith IG, Mintzer J, Aarsland D, Burn D, Chiu H, Cohen-Mansfield J, Dickson D, Dubois B, Duda JE, Feldman H (2004): Dementia with Lewy bodies. Lancet Neurol $\underline{3}$, 19-27

McKeith IG, Dickson DW, Lowe J, Emre M, O'Brien JT,Feldman H (2005): Diagnosis and management of dementia with Lewy bodies: third report of the DLB Consortium. Neurology $\underline{65}, 1863-1872$

McKhann G, Drachman D, Folstein M, Katzman R, Price D, Stadlan EM (1984): Clinical diagnosis of Alzheimer's disease: Report of the NINCDS-ADRDA Work Group under the auspices of Department of Health and Human Services Task Force on Alzheimer's disease. Neurology 34, 939-944

Meier U, Gressner O, Lammert F, Gressner AM (2006): Gc-globulin: roles in response to unjury. Clin Chem $\underline{52}, 1247-1253$

Miech RA, Breitner JC, Zandi PP, Khachaturian AS, Anthony JC, Mayer L (2002): Incidence of AD may decline in the early 90 s for men, later for women: The Cache County study. Neurology $\underline{58}, 209-218$

Miller IN, Cronin-Golomb A (2010): Gender differences in Parkinson's disease: clinical characteristics and cognition. Mov Disord 25, 2695-2703

Molina J, Benito-Léon J, Jiménez-Jiménez F, Orti-Pareja M, Berbel A, TallónBarranco $A$, de Bustos $F$, Hernànz $A$ (1997): Tau protein concentrations in cerebrospiinal fluid of non-demented Parkinson's disease patients. Neurosci Lett 238, 139141

Mollenhauer B, Cepek L, Bibl M, Wiltfang J, Schulz-Schaeffer WJ, Ciesielczyk B, Neumann M, Steinacker P, Kretzschmar HA, Poser S (2005): Tau Protein, AB 42 and S-100B Protein in Cerebrospinal Fluid of Patients with Dementia with Lewy Bodies. Dement Geriatr Cogn Disord 129, 164-170

Mollenhauer B, Trenkwalder C, von Ahsen N, Bibl M, Steinacker P, Brechlin P, Schindehuette J, Poser S, Wiltfang J, Otto M (2006): Beta-amyloid 1-42 and tauprotein in cerebrospinal fluid of patients with Parkinson's disease dementia. Dement Geriatr Cogn Disord 22, 200-208

Mortimer JA, Snowdon DA, Markesbery WR (2003): Head circumference, education and risk for dementia: findings from the Nun Study. J Clin Exp Neuropsychol 25, 671679

Nagatsu T, Mogi M, Ichinose H, Togari A (2000): Changes in cytokines and neurotrophins in Parkinson's disease. J Neural Transm Suppl 60, 277-290

Parkinson J (1817): An essay on the shaking palsy. 1817. J Neuropsychiatry Clin Neurosci 14, 223-236.

Parnetti L, Tiraboschi P, Lanari A, Peducci M, Padiglioni C, DÁmore C, Pierguidi L, Tambasco N, Rossi A, Calabresi P (2008): Cerebrospinal Fluid Biomarkers in Parkinson's Disease with Dementia and Dementia with Lewy Bodies. Biol Psychiatry $\underline{64}$, 850-855 
Perry RH, Irving D, Blessesd G, Fairbairn A, Perry EK (1990): Senile dementia of Lewy body type. A clinical and neuropathologically distinct form of Lewy body dementia in the elderly. J Neurol Sci. $\underline{95}, 119-139$

Pirker W, Brücke T (2004): SPECT in der Diagnostik von Parkinson-Syndromen. J Neurol Neurosurg Psychiatry $\underline{5}, 9-20$

Pitas RE, Boyles JK, Lee SH, Foss D, Mahley RW (1987): Actrocytes synthesize apolipoprotein $\mathrm{E}$ and metabolize apolipoprotein $\mathrm{E}$-containing lipoproteins. Biochim Biophys Acta 917, 148-161

Polymeropoulos MH, Lavedan C, Leroy E, Ide SE, Dehejia A, Dutra A, Pike B, Root $H$, Rubenstein J, Boyer R (1997): Mutation in the alpha-synuclein gene identified in families with Parkinson's disease. Science 276, 2045-2047

Procter AW, Palmer AM, Francis PT, Lowe SL, Neary D, Murphy E, Doshi R, Bowen DM (1988): Evidence of glutaminergic denervation and possible abnormal metabolism in Alzheimer's disease. J Neurochem 무, 790-802

Qiu Z, Crutcher KA, Hyman BT, Rebeck GW (2003): ApoE isoforms affect neuronal $\mathrm{N}$-methyl-D-aspartate calcium responses and toxity via receptor-mediated processes. Neuroscience 122, 291-303

Reiber H: Liquordiagnostik. In: Labor und Diagnose, 6. Auflage; hrsg. Thomas L; TH Books Verlagsgesellschaft, Frankfurt 2005.

Reid WG, Hely MA, Morris JG, Broe GA, Adena M, Sullivan DJ, Williamson PM (1996): A longitudinal of Parkinson's disease: clinical and neuropsychological correlates of dementia. J Clin Neurosci. $\underline{3}, 327-333$

Riordan KC, Hoffman Snyder CR, Wellik KE, Caselli RJ, Wingerchuk DM, Demaerschalk BM (2011): Effectiveness of adding memantine to an Alzheimer dementia treatment regimen which already includes stable donepezil therapy: a critical appraised topic. Neurologist 17, 121-123

Roman GC, Erkinjutti T, Wallin A, Pantoni L, Chui HC (2002): Subcortical ischaemic vascular dementia. Lancet Neurol $\underline{7}, 426-436$

Rota E, Bellone G, Bergamasco B, Emanuelli G, Ferrero P (2006): Increased intrathecal TGF-B1, but not IL-12, IFN- $\gamma$ and IL-10 levels in Alzheimer's disease patients. Neurol Sci 27, 33-39

Satzger W, Hampel H, Padberg F, Bürger K, Nolde T, Ingrassia G, Engel RR (2001): Zur Anwendung der CERAD-Testbatterie als neuropsych. Defizitscreening. Nervenarzt $\underline{72}, 196-203$

Saunders AM, Strittmater WJ, Schmechel D, George-Hyslop PH, Pericak-Vance MA, Joo SH, Rosi BL, Gusella JF, Crapper-MacLachlan DR, Alberts MJ (1993): Association of apolipoprotein E allele (e4) with late onset familial and sporadic Alzheimer's disease. Neurology. $\underline{43}, 1467-1472$

Schmidtke K, Hüll M (2007): Neuropsychologische Untersuchung von Patienten bei Demenzverdacht. Nervenheilkunde 26 651-658

Serot JM, Barbé F, Arning E, Bottiglieri T, Franck P, Montagne P, Nicolas JP (2005): Homocysteine and methylmalonic acid concentrations in cerebrospinal fluid: relation with age and Alzheimer's disease. J Neurol Neurosurg Psychiatry $\underline{76}$, 1585-1587

Shibao C, Garland EM, Gamboa A, Vnencak-Jones CL, Van Woeltz M, Haines JL, Yu C, Biaggioni I (2008): PRNP M129V homozygositiy in multiple system atrophy vs. Parkinson's disease. Clin Auton Res $\underline{18}$, 13-19 
Shimokawa M, Yanagisawa K, Nishiye H, Miyatake T (1993): Identification of amyloid precursor protein in synaptic plasma membrane. Biochem Biophys Res Commun 196, 240-244

Shulman (2000): Clock-drawing: is it the ideal cognitive screening test? Int J Geriatr Psychiatry 15, 548-561

Sisodia SS, Koo EH, Beyreuther K, Unterbeck A, Price DL (1990): Evidence that beta-amyloid protein in Alzheimer's disease is not derived by normal processing. Science $248,492-495$

Sjögren M, Minthon L, Davidsson P, Granérus A-K, Clarberg A, Vanderstichele $H$, Vanmechelen E, Wallin A, Blennow K (2000): CSF levels of tau, beta-amyloid (1-42) and GAP-43 in frontotemporal dementia, other types of dementia and normal aging. $J$ Neural Transm 107, 563-579

Smach MA, Jacob N, Golmard JL, Charfeddine B, Lammouchi T, Ben Othman L, Dridi H, Bennamou S, Limen K (2011): Folate and homocysteine in the cerebrospinal fluid of patients with Alzheimer's disease or dementia: a case control study. Eur Neurol $\underline{65}, 270-278$

Terry RD, Gonatas NK, Weiss M (1964): Ultrastructural studies in Alzheimer's presenile dementia. Am J Pathol 44, 269-297

Tröster Al (2008): Neuropsychological characteristics of Dementia with Lewy Bodies and Parkinson's disease with Dementia: Differentation. Early Detection, and Implications for „Mild Cognitive Impairment“ and Biomarkers. Neuropsychol Rev $\underline{18}$, 103-119

Tröster AI, Fields JA, Paola AM, Pahwa R, Koller WC (1996): Visual confrontation naming in Alzheimer's disease and Parkinson's disease with dementia. Neurology $\underline{46}, 292-293$

Varges D, Jung K, Gawinecka J, Heinemann U, Schmitz M, von Ahsen N, Krasnianski A, Armstrong VW, Zerr I (2001): Amyloid-B 1-42 levels are modified by apolipoprotein E4 in Creutzfeldt-Jakob disease in a somilar manner as in Alzheimer's disease. J Alzheimers Dis $\underline{23}, 717-726$

Verbeek MM, De Jon D, Kremer HP (2003): Brain-specific proteins in cerebrospinal fluid fort he diagnosis of neurodegenerative diseases. Ann Clin Biochem $\underline{40}, 25-40$

Vermesch P, Delacourte A, Javoy-Agid F, Hauw JJ, Agid Y (1993): Dementia in Parkinson's disease: biochemical evidence for cortical involvement using the immunodetection of abnormal proteins. Ann Neurol $\underline{33}, 445-450$

Wald DS, Kasturiratne A, Simmonds M (2011): Serum homocysteine and dementia: meta-analysis of eight cohort studies including 8669 paticipants. Alzheimers Dement 7, $412-417$

Zaccai J, McCracken C, Brayne C (2005): A systematic review of prevalence and incidence studies of dementia with Lewy bodies. Age Ageing 34, 561-566

Zhang J, Sokal I, Peskind ER, Quinn JF, Jancovic J, Kenney C, Chung KA, Millard SP, Nutt JG, Montine TJ (2008): CSF Multianalyte Profile Distinguishes Alzheimer and Parkinson Diseases. Am J Clin Pathol 129, 526-529 